$$
\begin{gathered}
\text { REPUBLICA ARGENTINA } \\
\text { UNIVERSIDAD NACIONAL DE LA PLATA }
\end{gathered}
$$

FACULTAD DE CIENCIAS JURÍDICAS Y SOCIALES INSTITUTO DE RELACIONES INTERNACIONALES

CHARLES PENNAFORTE

MOVIMIENTOS ANTISISTÉMICOS EN EL SISTEMA-MUNDO CONTEMPORÁNEO: EL CASO VENEZOLANO

TESIS DE DOCTORADO

LA PLATA, 2013 


\author{
REPUBLICA ARGENTINA \\ UNIVERSIDAD NACIONAL DE LA PLATA
}

FACULTAD DE CIENCIAS JURÍDICAS Y SOCIALES

INSTITUTO DE RELACIONES INTERNACIONALES

MOVIMIENTOS ANTISISTÉMICOS EN EL SISTEMA-MUNDO CONTEMPORÁNEO: EL CASO VENEZOLANO

Tesista: Charles Pennaforte

Director de Tesis: Roberto Miranda

(Universidad Nacional de Rosario) 
REPUBLICA ARGENTINA

UNIVERSIDAD NACIONAL DE LA PLATA

FACULTAD DE CIENCIAS JURÍDICAS Y SOCIALES INSTITUTO DE RELACIONES INTERNACIONALES

\section{MOVIMIENTOS ANTISISTÉMICOS EN EL SISTEMA-MUNDO CONTEMPORÁNEO: EL CASO VENEZOLANO}

Miembros de la Banca Evaluadora:

Aprobado:

$$
\text { Angél Tello }
$$

Universidad Nacional de La Plata

Aprobado:

$$
\text { Francisco Itarrupe }
$$

Universidad Central de Venezuela

Aprobado:

Gilberto Aranda Bustamante

Universidad de Chile 
Al amigo Édson José de Souza (In Memorian) Al maestro Milton Santos (In Memorian) A los latinoamericanos que cayeron en los movimientos de construcción antisistémicos A las víctimas de la dictadura militar en Argentina 


\section{AGRADECIMIENTOS}

A los colegas y profesores de la Universidad Nacional de La Plata, que proporcionan un ambiente agradable para el intercambio de ideas $y$ perspectivas sobre la realidad de América Latina.

A mi director de tesis el Prof. Dr. Roberto Miranda por su ayuda y atención constante durante el transcurso de nuestro trabajo.

Al Prof. Dr. Alejandro Simonoff por su ayuda constante.

Al amigo Prof. Ricardo Luigi por el importante intercambio de ideas, críticas y sugerencias durante la preparación del trabajo.

Al Prof. Ronaldo Limoeiro y Rodrigo Limoeiro por su apoyo durante mi doctorado.

Al amigo Prof. Dr. Angelo Segrillo del Departamento de Historia de la Universidad de São Paulo (USP) por la lectura crítica y sugerencias.

Al Prof. Claudio Alberto Briceño Monzón por diálogos esclarecedores sobre temas de la política venezolana durante mi estancia en La Plata.

También quiero agradecer a la Secretaria Municipal de Educação de Duque de Caxias (Brasil/Río de Janeiro) por el apoyo a la preparación de esta tesis a través de licencias por estudios.

A Profesora Sonia Pegoral principalmente por el apoyo durante la preparación de esta tesis.

A Fabiana de Oliveira por su atención y ayuda en el proceso de revisión de la tesis.

Al amigo Prof. Dr. José Alexandre da Silva por su participación en el proceso de revisión de la tesis. 


\section{MAPAS}

Mapa $01 \quad$ Produto Interno Bruto 2008 - UNASUR 157

$\begin{array}{lll}\text { Mapa } 02 & \text { Venezuela - Físico } & 191\end{array}$

Mapa $03 \quad$ Venezuela - Político 192

\section{FIGURAS}

$\begin{array}{lll}\text { Figura } 01 \quad K o n d r a t i e f f ~ W a v e s & 38\end{array}$

Figura 02 Séculos Longos e Ciclos Sistêmicos de Acumulação 39

$\begin{array}{lll}\text { Figura } 03 & \text { Wallersteins's Hegemonic Cycles } & 57\end{array}$

\section{GRÁFICOS}

$\begin{array}{lll}\text { Gráfico } 01 \quad \text { United Sates Interest Rate } & 61\end{array}$

Gráfico $02 \quad$ Preços do óleo Cru - preços em Dólar 201090

Gráfico $03 \quad$ Produção de Óleo Cru - Milhares de barris/dia 91

Gráfico $04 \quad$ Venezuelan Crude Oil Exports by Destination, 2010 


\section{CUADRO}

Cuadro 01 Incidência da Pobreza e da indigência na América latina 1980-2002

Cuadro 02 Participação dos Estratos Sociais na Distribuição de Renda Total, América Latina 1990-2005

Cuadro 03 Evolução de Alguns Indicadores Econômicos na América latina 1990-99 e 2000-03

Cuadro 04 América Latina: Indicadores Econômicos

Cuadro 05 Alguns Indicadores macroeconômicos (1979-1999)

Cuadro 06 Lares em Situação de Pobreza (1980-1997)

Cuadro 07 Força de Trabalho (1983-1888)

Cuadro 08 Gasto Social do Governo da Venezuela como percentual do PIB, 1998/2006

Cuadro 09 Índices de pobreza da Venezuela, 1997/2007

Cuadro 10 Evolução de indicadores sociais da Venezuela, 1950/2007

Cuadro 11 Datos económicos Países membros - Alianza Bolivariana para as Américas - Tratado de Comércio de los Pueblos

Cuadro 12 Evolución de la Integración Sudamericana

Cuadro 13 Indicadores Econômicos - Venezuela, 2010

193

Cuadro 14 Balança comercial e reservas internacionais da Venezuela, 1998/2008

Cuadro 15 Evolução da condição de pobreza da população venezuelana, 1998/2007 ( 2 - semestre)

Cuadro 16 Distribuição de renda entre as classes sociais e coeficiente de Gini da Venezuela 1998/2007

Cuadro 17 Tasa de desocupación, marzo 1999-2010

Cuadro 18 Venezuela. Tendencia de largo plazo del índice de Desarrollo Humano, 1980-2007

Cuadro 19 Venezuela. Evolución del índice de Desarrollo Humano, 1980-2007

Cuadro 20 Tasa de mortalidad general, 1998-2007 200

Cuadro 21 Tasa de mortalidad general, 1990-2008 200 
Cuadro 22 Esperanza de vida al nacer, 1989-2009

Cuadro 23 Economia chinesa, 1951-2007 


\section{SIGLAS}

Acción Democrática (AC)

Alianza Bolivariana para las Américas - Tratado de Comercio de los Pueblos (ALBA-TCP)

Área de Libre Comercio de las Américas (ALCA)

Banco Interamericano de Desarrollo (BID)

Banco Nacional de Desarrollo Económico y Social (BNDES)

Corporación Andina de Fomento (CAF)

Comunidad de los Estados Latinoamericanos y Caribeños (CELAC)

Comisión Económica para América Latina y el Caribe (CEPAL)

Comité de Organización Politica Electoral Independiente (COPEI)

Federación de Cámaras y Asociaciones de Comercio y Producción de Venezuela (FEDECÁMARAS)

Fondo Común Chino-Venezolano (FCCV)

Fondo Financiero para el Desarrollo de la Bacía del Plata (FONPLATA)

Frente Farabundo Martí de Liberación Nacional (FFMLN)

Foro Social Mundial (FMS)

Fondo Monetario Internacional (FMI)

Iniciativa para la Integración de la Infraestructura Regional Surdamericana (IIRSA)

Movimiento Al Socialismo (MAS)

Partido Socialista Unido de Venezuela (PSUV)

Petróleos de Venezuela S.A. (PDVSA)

Unión de las Naciones Suramericanas (UNASUL) 


\section{RESUMEN}

Este estudio tiene como objetivo analizar los acontecimientos en Venezuela desde la llegada de Hugo Chávez Frías al poder en 1998 y la posición adoptada por el país dentro de una perspectiva antisistémica en los escenarios regional e internacional. El enfoque utilizado en el análisis de la posición antisistémica venezolana se basa en la propuesta defendida por Immanuel Wallerstein, llamada de "Análisis de Sistemas-Mundo" y de los Movimientos Antisistémicos, en la obra de Giovanni Arrighi sobre ciclos sistémicos de acumulación, y el alcance teórico desarrollado por el pensador italiano Antonio Gramsci sobre la revolución pasiva y la función piamontesa. Para entender el proceso que ocurre en Venezuela, debe ser evaluado históricamente la bancarrota del modelo político basado en el llamado Puntofijo, cuyo colapso se produjo con la victoria de Hugo Chávez, a finales de 1990. La administración del actual presidente venezolano ha logrado importantes avances en la mejora de los indicadores sociales y económicos en los estratos más pobres del país. En el ámbito internacional, Chávez ha adoptado un discurso antimperialista y anti-EE.UU para marcar su posición como una alternativa a la globalización neoliberal. Su actuación se desarrolla dentro del espectro antisistémico que implica promover la reducción de la hegemonía de los EE.UU y busca la construcción de un mundo multipolar y de una América Latina con una menor influencia política e ideológica de Washington.

Palabras clave: Revolución Bolivariana, Práctica antisistémica, Desafío a los EE.UU., Función Piamontesa, Hegemonía. 


\begin{abstract}
The present study aims to analyze the events in Venezuela from the arrival of Hugo Chávez Frías to power in 1998 and the position taken by the country within an antisystemic perspective in regional and international scenarios. The approach used in the analysis of antisystemic positions of Venezuela is based on the proposal advocated by Immanuel Wallerstein called World-Systems Analysis and Antisystemics Movements, on the work of Giovanni Arrighi on Systemic Cycles of Accumulation, and the theoretical scope developed by the Italian thinker Antonio Gramsci on Passive Revolution and Piedmontese Function. To understand the process that occurs in Venezuela will be necessary to evaluate the historical failure of the model political party based on called Puntofijo whose collapse occurred with the victory of Hugo Chávez in late 1990. The administration of the Venezuelan leader has managed major advances in improving the social economic and social indicators of the poorest in the country. On the international scene, Chávez has adopted an anti-imperialist and anti-US Speech to mark his position as an alternative to neoliberal globalization. His performance is developed within the spectrum antisystemic to seek to promote the reduction of U.S. hegemony and seeks to build a multipolar world and Latin America with a less ideological and political influence in Washington.
\end{abstract}

Keywords: Bolivarian Revolution, Antisystemic Practice, Challenge to the U.S., Piedmontese Function, Hegemony. 
(...)And making sense of defending what is happening in Venezuela is perhaps one of the most important tasks for progressives around the world today, since Venezuela is at the forefront in the effort to find a real progressive alternative to capitalism, to representative democracy, and to U.S. imperialism.

Greg Wilpert

(...) [The] Capitalism is based on the constant absorption of economic loss by political entities, while economic gain is distributed to "private" hands.

Immanuel Wallerstein

Duas coisas ameaçam o mundo: a ordem e a desordem.

Paul Valéry

The people understand that the process is not of one person but everyone, and we have seen that there are not one or two people who are talking, but the people. The people who will not stay quiet.

Iraida Morocoima 


\section{SUMARIO}

INTRODUCCIÓN

1 - FUNDAMENTACIÓN TEÓRICO-METODOLÓGICA 22

1.1 - Estado, Hegemonía y Revolución Pasiva. 24

1.2 - El Análisis de Sistemas-Mundo 32

1.3 - Los Ciclos Sistémicos de Acumulación 37

2 - EL DECLIVE DE AMÉRICA DEL NORTE. 44

2.1 - La Economía-Mundo Capitalista 45

2.2 - La Crisis del Sistema Fordista de Producción 47

2.3 - El Post-Fordismo 49

2.3.1 - Asia como un Adversario Competitivo 52

2.4 - La Pérdida de la Hegemonía 55

3 - MOVIMIENTOS ANTISISTÉMICOS EN EL SISTEMA-MUNDO 64

3.1 - Movimientos Antisistémicos como una Alternativa en el Sistema-Mundo Moderno 65

3.2 - Las Condiciones Históricas para el Surgimiento de Hugo Chávez: el Fracaso del Neoliberalismo 69

3.3 - La Década Neoliberal 69

3.4 - La llegada de Hugo Chávez al poder 77

3.5 - Hugo Chávez en el poder y el "Socialismo Bolivariano". 85 
4.1 - Los EE.UU. y la América Latina: la Política Exterior de Washington ..... 99

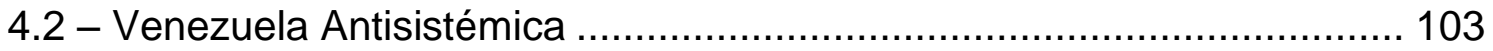

4.3 - La Política Exterior de Chávez: una Visión General ............................... 107

4.4 - La Actuación de Venezuela en el ALBA-TCP ..................................... 121

4.5 - La Actuación de Venezuela en el Escenario Internacional ................... 134

5 - DILEMAS Y CONTRADICCIONES DE LA ACTUACIÓN ANTISISTÉMICA

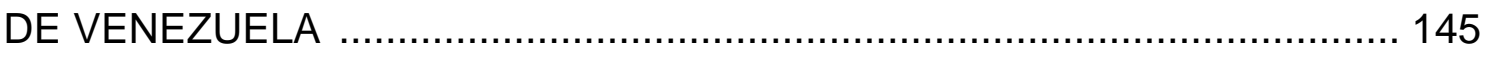

5.1 - Venezuela y la Integración Regional ..............................................147

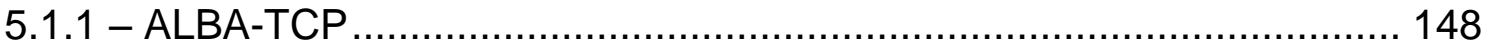

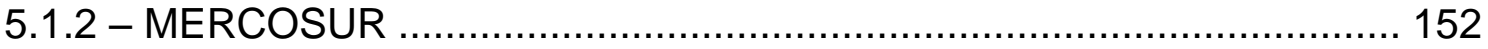

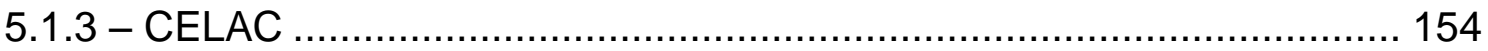

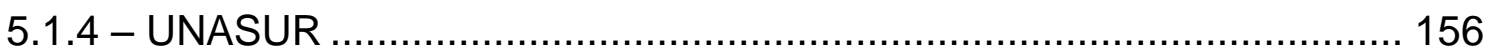

5.2 - Desafíos ante la Actuación Antisistémica .............................................. 158

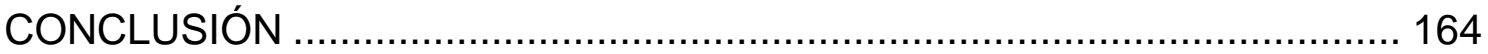

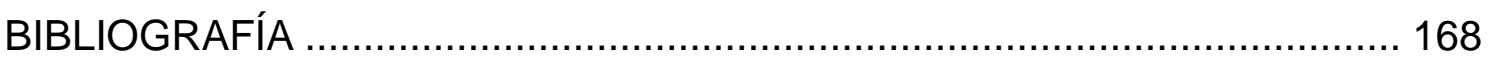

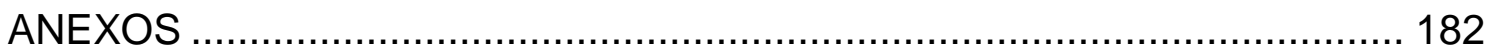


INTRODUCCIÓN 
El siglo XX marcó cambios importantes en América Latina. La superación del neoliberalismo que ha causado grandes impactos sociales y económicos negativos fue uno de los principales triunfos de las fuerzas políticas progresistas del continente. Sin embargo, por desgracia, el agotamiento del modelo neoliberal registró un aumento de la pobreza y de la miseria de millones de latinoamericanos. Como ejemplo de este proceso de superación del modelo neoliberal, la Venezuela bolivariana es sin duda el mejor ejemplo.

La elección del Teniente Coronel Hugo Chávez Frías en 1998, que había intentado un golpe de Estado contra el entonces presidente Carlos Andrés Pérez, en 1992, marcó un giro a la izquierda en América Latina, que tuvo su inicio en el comienzo del siglo XXI. Desde Venezuela y la quiebra del modelo neoliberal en el país, las fuerzas políticas progresistas latinoamericanas lograron obtener capital político y ganaron importantes victorias.

El proceso dirigido por el líder venezolano ha ganado importancia en el contexto, marcado por una lógica de la lucha contra la influencia política, ideológica y económica de EE.UU.. Nuestro trabajo consiste en identificar la postura antisistémica del liderazgo de Hugo Chávez desde su inserción en la región de América Latina y internacional y busca analizar críticamente el proceso en fase de desarrollo.

Por lo tanto, nos propusimos responder en nuestro trabajo a la pregunta principal siguiente: el gobierno de Hugo Chávez tiene como objetivo poner a Venezuela como un player internacional y el retador de la hegemonía estadunidense? Desde esta perspectiva, buscamos: (a) identificar el papel antisistémico de la Venezuela en América Latina, (b) investigar sobre todo el conjunto de las políticas oficiales del gobierno venezolano dirigidas a la inserción del país en el comercio y en la comunidad internacional, (c) determinar las políticas de la hegemonía de Estados Unidos en el siglo XX en América Latina y (d) analizar la construcción de "políticas de influencia" para América Latina.

La comprensión de este proceso de transformación política y económica en la América Latina está poniendo en marcha nuestra propuesta para analizar 
la dinámica venezolana y su influencia no sólo en América Latina sino también a las operaciones internacionales del país, a partir de diálogos con el profesor Ricardo Luigi, en el ámbito del Centro de Estudos em Geopolítica e Relações Internacionais (CENEGRI) de Rio de Janeiro.

En el CENEGRI a través del Grupo de Estudio sobre Reorganización Territorial (GERT), fue creado en el año 2005 una línea de investigación titulado "Movimientos Antisistémicos en América Latina", que tiene como objetivo evaluar críticamente los cambios que se producen en lo que llamamos "post-neoliberalismo"1.

Como base teórica para el estudio de los cambios que ocurren en el continente, adoptamos el "Análisis de Sistemas-Mundo" (ASM) de Immanuel Wallerstein y Giovanni Arrighi, así como los planteamientos de Antonio Gramsci.

La ASM se ha convertido en una importante herramienta analítica para comprender lo que está sucediendo dentro del sistema capitalista desde el final de la Segunda Guerra Mundial. La perspectiva macro-sociológica (Sociología Comparada Histórica y Economía Política de los sistemas-mundo), aunque criticado por poseer un amplio espectro de cobertura, para nosotros ha sido de gran importancia.

La tradición marxista de la comprensión del todo se pone en evidencia en la lógica capitalista ASM para trabajar la lógica capitalista como un sistema histórico que subyace en el proceso de la civilización. Además, como propone Wallerstein ${ }^{2}$ :

O capitalismo é, em primeiro lugar e principalmente, um sistema social histórico.

\footnotetext{
${ }^{1}$ En septiembre de 1994 tuvo lugar en Río de Janeiro el Seminario Internacional sobre "PostNeoliberalismo - Las políticas sociales y el Estado democrático" en la Universidad del Estado de Río de Janeiro (UERJ), con la presencia de numerosos intelectuales, entre ellos: Atilio Borón, Göran Therborn Pablo Gentili, Perry Anderson y Pierre Salama. En septiembre de 1999, se produjo una segunda parte del "Seminario Internacional de Post-neoliberalismo", ahora con el tema "¿Qué Estado para la democracia?". Estuvieron presentes en el evento Michael Löwy, Robin Blackburn, Atilio Borón, Göran Therborn, Gentile Pablo, entre otros.

${ }^{2}$ Capitalismo histórico e civilização capitalista. Rio de Janeiro, Contraponto, 2001, p.13.
} 
(...) Algo distingue o sistema social que estamos chamando de capitalismo histórico: nele o capital passou a ser usado (investido) de maneira especial, tendo como objetivo, ou intensão primordial, a auto-expansão. (....)

Por lo tanto, en nuestra opinión, es fundamental que la comprensión de los fenómenos contemporáneos en la economía, en la política y en las relaciones internacionales, sean analizados sobre la base de la comprensión del capitalismo como sistema social y histórico. Es decir, que abarque no sólo los aspectos económicos para entender el momentum actual, como la dinámica interna de cada país y de las relaciones entre los Estados.

En este punto, creemos que la ASM arroja luz importante para entender el debilitamiento general de EE.UU., tanto ideológico como económico. Este proceso explicaría, en nuestra opinión, la aparición de movimientos antisistémicos en el sistema interestatal, en el que la Venezuela sería un ejemplo.

La crisis de 2008 demostró el problema estructural de la actual crisis capitalista: la ausencia de un control mínimo sobre los flujos de capital, a pesar de las numerosas crisis sistémicas en el tiempo derivados de este factor. Cabe mencionar que este tema ya se trató por Immanuel Wallerstein y Giovanni Arrighi desde hace, por lo menos, una década.

El uso de categorías gramscianas de Ciencia Política, por otro lado, como herramienta de análisis, nos permitió entender de un modo más dinámico lo que ocurre en Venezuela, en el nivel doméstico y en la escena internacional.

Nos gustaría aclarar que no hemos hecho una transposición lineal de ámbito teórico de Gramsci, Wallerstein y Arrighi. Como en un proceso dialéctico, identificamos similitudes y aspectos compatibles de los métodos utilizados por los autores para crear una lectura diferente del tema propuesto.

Por lo tanto, trabajamos con la perspectiva de la disminución económica e ideológica de EE.UU. (Wallerstein/Arrighi), de la revolución pasiva y de la 
"Función Piamontesa" (Gramsci) como conceptos clave de nuestra tesis, que serán a priori expuestos en el capítulo 1.

Después del marco teórico-metodológico para la comprensión del tema propuesto, comenzamos con el análisis de la decadencia y la crisis de la hegemonía de EE.UU., en el Capítulo 2: LA DECADENCIA DE ESTADOS UNIDOS. Los dos aspectos (el "Eagle Landing") son defendidos por Wallerstein y Arrighi, a pesar de haber sido identificados como "sin datos económicos concretos" en la década de 1990, hoy parecen perfectamente plausibles ${ }^{3}$.

Nuestro objetivo en este capítulo va a ser situar el proceso de decadencia de EE.UU. a partir de hechos importantes sobre la dinámica capitalista, como la crisis fordista de la década de 1970; la aparición del postfordismo como una respuesta a esta crisis; el surgimiento de Asia como un competidor sistémico importante desde la década de 1980, los factores que causaron la pérdida de la hegemonía de los EE.UU., y por último, la crisis económica de 2008, que tuvo su epicentro en Wall Street y continúa con sus efectos hasta los días de hoy. El debilitamiento económico e ideológico facilitará el surgimiento de países "desafiadores" del status quo tradicional predicado por Washington.

En el capítulo 3, MOVIMIENTOS ANTISISTÉMICOS EN EL SISTEMAMUNDO, trazamos una retrospectiva histórica del surgimiento de movimientos antisistémicos a partir del enfoque adoptado por I. Wallerstein. Empezamos con la aparición del término "antisistémico" para clasificar los movimientos políticos y sociales en Europa y su idiosincrasia que se origina en el siglo XIX y alcanzó el período de lucha del mundo bipolar. Con el derrumbe de la bipolaridad a principios de 1990, estos movimientos han cambiado de orden constitutiva desde el año 1999 dentro de la dinámica de la globalización.

La comprensión de Venezuela como un país que cabe dentro de un movimiento antisistémico interestatal es el resultado del rompimiento con el

\footnotetext{
${ }^{3}$ Zbigniew Brzezinski, ex asesor de seguridad nacional del presidente de los EE.UU. Jimmy Carter, en su libro Strategic Vision: America and the Crisis of Global Power, analiza el declive económico y geopolítico.
} 
modelo neoliberal. La búsqueda de nuevas alternativas a este modelo es lo que permite la llegada de Hugo Chávez al poder en el siglo XX.

En este capítulo también tratamos de identificar los orígenes teóricos y metas del "Socialismo del Siglo XXI" de Hugo Chávez con su creación, el papel de liderazgo de Venezuela en la construcción de este nuevo modelo para América Latina, más allá del nivel de adhesión de la población y otros países a sus propuestas.

Siguiendo, configuramos a Venezuela como parte del movimiento antisistémico, analizando el desempeño de Hugo Chávez como un "referente internacional" (o su intento) que pretende poner en entredicho las posiciones adoptadas por los EE.UU.

Otro aspecto clave para el desarrollo de nuestro trabajo fue la preocupación de enmarcar una dimensión analítica de los acontecimientos en Venezuela desde 1998 y que tiene como contexto la misma dinámica capitalista y el debilitamiento de la hegemonía de EE.UU.

En el Capítulo 4, LA ACTUACIÓN ANTISISTÉMICA DE VENEZUELA, se demuestra cómo el gobierno de Hugo Chávez inició su actividad en los ámbitos regional e internacional en una posición que clasificamos como antisistémica. Antes, se realizó un trabajo retrospectivo del papel de los EE.UU. para la política latinoamericana desde una perspectiva crítica. También tenemos en cuenta la creación del ALBA-TCP y el acercamiento de países como Bolivia y Ecuador, por ejemplo, de la órbita de influencia de Venezuela. Finalmente se discute críticamente la política exterior venezolana desde 1998 por Hugo Chávez, teniendo en cuenta el análisis de los expertos ubicados en ambos espectros políticos.

En el último capítulo, DILEMAS Y CONTRADICCIONES DE LA ACTUACIÓN ANTISISTÉMICA DE VENEZUELA, se analizan los desafíos que enfrenta Venezuela para poner en práctica su proyecto ideológico y económico en América Latina. A pesar de toda la retórica anti-imperialista del gobierno de Venezuela, las relaciones económicas con los EE.UU. todavía persisten y son de gran importancia para la patria de Simón Bolívar. 
El proyecto puesto en práctica por Hugo Chávez encuentra una serie de contradicciones y dificultades inherentes al papel de Venezuela en el actual sistema-mundo. Se analiza en qué medida es posible a este país sostener una posición antisistémica mientras esté inserido en el actual sistema-mundo capitalista. Sostener una posición antisistémica dentro de la economía-mundo capitalista requiere de una gran capacidad, al menos económicamente.

Se discute también cómo Venezuela se inserta en el sistema internacional y como el país busca actuar como un jugador a la cabeza, al menos en América Latina, de los países con similares posiciones antiimperialistas. Creemos que nuestro trabajo será de gran aporte para futuros estudios sobre el tema desde un enfoque diferente y crítico.

En los adjuntos, ponemos inúmeras tablas que muestran los avances sociales logrados desde 1998. Estos indicadores ayudan a entender la buena aceptación de Hugo Chávez entre los sectores más pobres de la población. 
1 - FUNDAMENTACIÓN TEÓRICO-METODOLÓGICA 
Sigo creyendo que el análisis de los sistemas-mundo, es en primer lugar una protesta en contra de las formas en las cuales la ciencia social se presenta actualmente, e incluyendo aquí el ámbito de su modo de teorizar.

Immanuel Wallerstein ${ }^{5}$

Nuestro estudio tiene como objetivo ampliar el enfoque analítico sobre el fenómeno de Hugo Chávez y, al mismo tiempo, analizar su influencia sobre Venezuela en el escenario en latinoamericano e internacional a partir de la perspectiva antisistémica. Para ello vamos a utilizar el marco teórico elaborado por Antonio Gramsci, Immanuel Wallerstein y Giovanni Arrighi.

La realidad capitalista va a ser evaluada desde la perspectiva del Sistema-Mundo (economía-mundo) como la comprensión actual de la dinámica global propuesta por I. Wallerstein. En lo que respecta específicamente a la economía capitalista, se utiliza la base teórica propuesta por Arrighi sobre la base de Ciclos Sistémicos de Acumulación. Gramsci utiliza el concepto de Hegemonía y Revolución Pasiva.

La crisis de hegemonía de EE.UU. será de gran importancia para la comprensión de nuestro trabajo, porque vamos a tratar de hacer un enlace entre esta crisis $y$ el surgimiento de nuevos grupos antihegemónicos/antisistémicos en América Latina explicando la dirección tomada por Venezuela en la confrontación ideológica y política contra Washington durante el gobierno de Chávez.

\footnotetext{
5 The itinerary of world-systems analysis or how to resist becoming a theory. Apud Immanuel Wallerstein y la Perspectiva Crítica del "Análisis de los Sistema-Mundo". Carlos Antonio A. Rojas. Textos de Economia. Florianópolis, v. 10, no 2, p. 14, jul/dez, 2007.
} 


\section{1 - Estado, Hegemonía Y Revolución Pasiva}

La comprensión del desarrollo capitalista debe hacerse a través de un análisis del papel del Estado como condición sine qua non para el desarrollo del capitalismo y la consecuente reproducción del capital. Por lo tanto, el Estado y la hegemonía en la perspectiva gramsciana son indisociables. Arrighi $^{6}$, por ejemplo, señala que en las relaciones internacionales:

(...) "O conceito de "hegemonia mundial" (...) se refere ao poder que um Estado tem de exercer funções governamentais sobre um sistema de Estados soberanos". (...)

Arrighi e Silver ${ }^{7}$ profundizan los aspectos de la hegemonía que demuestran la complejidad de su construcción. Tal proceso implica varios aspectos que, de acuerdo con los autores:

"Hegemony is thus something more and different than dominations pure and simple; it is the additional power that accrues to a dominate group by virtue of its capacity to lead society in a direction that not only serves the dominant group's interests, but is also perceived by subordinate groups as serving a more general interest, it is the inverse of the notion of 'power deflation' used by Talcott Parsons to designates situations in which governmental control cannot be exercised except through the widespread use or threat of force. If subordinate groups have confidence in their

\footnotetext{
6 "As três hegemonias do capitalismo Histórico". In: Gall, Stephen. Gramsci, Materialismo e relações internacionais. Rio de Janeiro, Editora UFRJ, 2007, p. 227. Las Reflexiones de Gramsci fueron preparados para la realidad italiana. Sin embargo, importantes trabajos fueron preparados buscando implementar estos análisis para el sistema internacional. Además de Arrighi tenemos Robert W. Cox (2007), Mark Rupert (2007).

${ }^{7}$ Chaos and Governance and the Modern World System. Minneapolis, University of Minnesota Press, pp. 26-27, 1999.
} 
rulers systems of domination can be governed without resorting to force. But if that confidence wanes, they cannot. By analogy, Gramsci's notion of hegemony may be said to consist of the 'power inflation' that ensues from the capacity of dominant groups to present with credibility their rule as serving not just their interests, but those of subordinate groups as well. When such credibility is lacking, we shall speak of 'dominance without hegemony'".

“(...) when we speak of leadership in an international context, the term is used to designate two quite different phenomena. On the on hand, the term is used to designate the fact that by virtue of its achievements, a dominate state becomes the 'model' for others states to emulate and thereby draws them onto its path of development". (...)

La supremacía de EE.UU. en el sistema internacional debe ser visto a través de la lógica de transformación de sus intereses (capitalistas) como "valores universales". Por lo tanto, es algo más elaborado que "la dominación pura y simple", como habla Arrighi ${ }^{8}$. Un destacado experto en la obra de Gramsci, Luciano Gruppi ${ }^{9}$, dirige su análisis a un mismo punto de la comprensión del concepto de hegemonía:

(...) "o conceito de hegemonia é apresentado por Gramsci em toda a sua amplitude, isto é, como algo que opera não apenas sobre a estrutura econômica e sobre a organização política da sociedade, mas também sobre o modo de pensar, sobre as orientações ideológicas e inclusive sobre o modo de conhecer".

\footnotetext{
8 "As três hegemonias do capitalismo Histórico". In: Gill, Stephen. Gramsci, Materialismo e relações internacionais. Op. cit., p. 228.

9 "O conceito de hegemonia em Gramsci". Rio de Janeiro, Edições Graal, 6ª ed., 2000, p. 3.
} 
Junto a esto, el papel del bloque histórico es crucial para mantener la cohesión del poder, tanto en moneda nacional como internacional ${ }^{10}$. La supremacía y la aceptación de una nación como "hegemónica" se asocia con su capacidad de influir "positivamente" a otras naciones en el concierto internacional. Según Arrighi ${ }^{11}$, con las reflexiones de Antonio Gramsci:

"O conceito de 'hegemonia mundial' aqui adotado, no entanto, refere-se especificamente à capacidade de um Estado exercer funções de liderança e governo sobre um sistema de nações soberanas. Em princípio, esse poder pode implicar apenas a gestão corriqueira desse sistema, tal como instituído num dado momento. Historicamente, entretanto, o governo de um sistema de Estados soberanos sempre implicou algum tipo de ação transformadora, que alterou fundamentalmente 0 modo de funcionamento do sistema".

Los EE.UU. tienen esta característica, aspecto que facilita la puesta en práctica de sus intereses y deseos, colocándolos como un "interés colectivo". Cox ${ }^{12}$ discutiendo la creación de este "interés colectivo" y la relación entre bloque histórico y hegemonía muestra que

"Um bloco histórico não pode existir sem uma classe social hegemônica. Em um país ou em uma formação social em que a classe hegemônica é a classe dominante, o Estado (no conceito

\footnotetext{
10 "No movimento rumo à hegemonia e à criação de um bloco histórico, Gramsci distinguia três níveis de consciência: o econômico-corporativo, no qual determinado grupo tem conhecimento de seus interesses específicos; a solidariedade ou consciência de classe que se estende a toda uma classe social, mas continua num nível puramente econômico; e o hegemônico, que harmoniza os interesses da classe dirigente com os das classes subordinadas e incorpora esses outros interesses numa ideologia expressa em termos universais" (Gramsci, 1971, p. 180-195). Apud Robert Cox. "Gramsci, hegemonia e relações internacionais: um ensaio sobre o método". In: Gill, Stephen. Gramsci, Materialismo e relações internacionais. Rio de Janeiro, Editora UFRJ, 2007, p. 112.

${ }^{11}$ O Longo Século XX. Rio de Janeiro, Editora Contraponto/Unesp, 1996, p. 27.

${ }^{12}$ Cox, Op. cit., p. 111.
} 
ampliado de Gramsci) mantém a coesão e a identidade no interior do bloco por meio da propagação de uma classe comum". (...)

La "solución" para crear alternativas reales al capitalismo a nivel nacional, en otras palavras, el control del Estado como una forma de combatir la lógica capitalista, no debe entenderse como un simple "asalto al poder," en una perspectiva "blanquista"13. Tomar el control del Estado dentro de la dinámica capitalista y lo utilizar como un paso en el proceso de superar el modelo asume características muy importantes. Acerca de dilemas para la construcción de los Estados bajo un liderazgo no burgués, Cox señala claramente este tipo de problemas y dificultades ${ }^{14}$ :

(...) Construir as bases de um Estado e de uma sociedade civil alternativos sob liderança da classe operária significa criar instituições e recursos intelectuais alternativos dentro de uma existente e construir pontes entre os operários e as outras classes subordinadas. Significa ativamente uma contra hegemonia no interior de uma hegemonia estabelecida, e, ao mesmo tempo, aumentar a resistência contra as pressões e as tentações de recair na busca de ganhos incrementais para grupos subalternos no seio das estruturas da hegemonia burguesa. Essa é a linha que separa a guerra de posição, como estratégia revolucionária de longo prazo, e a democracia social, como política para obter ganhos dentro da ordem estabelecida.

Otro concepto de la utilización de la teoría gramsciana en nuestro trabajo es el de la revolución pasiva. Para Gramsci, la revolución pasiva fue el resultado de la falta de participación popular en el proceso de transformación

\footnotetext{
${ }^{13}$ Doctrina política básica de revolucionario francés Louis-Auguste Blanqui (1805-1881). El revolucionario abogó por una élite relativamente pequeña, centralizada y jerárquica, para llevar a cabo una insurgencia para reemplazar el poder del Estado capitalista por su propia dictadura revolucionaria.

${ }^{14}$ Cox, Op. Cit., p. 107.
} 
social. Gramsci explica este proceso a partir de dos principios importantes de la ciencia política ${ }^{15}$ :

“(... 1) nenhuma formação social desaparece enquanto as forças produtivas que nela se desenvolveram ainda encontrarem lugar para um novo movimento progressista; 2) a sociedade não se põe tarefas para cuja solução ainda não tenham germinado as condições necessárias, etc. Naturalmente, estes princípios devem ser, primeiro, desdobrados criticamente em toda a sua dimensão e depurados de todo resíduo de mecanicismo e fatalismo. Assim, devem ser referidos à descrição dos três momentos fundamentais em que se pode distinguir uma "situação" ou um equilíbrio de forças, com o máximo de valorização do segundo momento, ou equilíbrio das forças políticas e especialmente do terceiro momento, ou equilíbrio político militar". (...)

En realidad, en donde los movimientos sociales no han tenido la fuerza para lograr la superación del orden existente a través de las luchas de amplio espectro como, por ejemplo, las revoluciones, y tuvo que ser tutelados por los líderes carismáticos ${ }^{16}$, encontramos un ejemplo de revolución pasiva ${ }^{17}$.

En nuestro análisis, Hugo Chávez actúa como un "líder carismático" desde el momento en que supo catalizar el descontento de gran parte de la población pobre del país que había sufrido los efectos del neoliberalismo en la década de 1990. Hasta entonces, el movimiento social venezolano no había podido cumplir sus deseos a través del viejo sistema político ("partidocracia").

\footnotetext{
${ }^{15}$ Cadernos do Cárcere. Rio de Janeiro, Civilização Brasileiro, 2002, pp.321-322.

${ }^{16}$ Max Weber para las Ciencias Sociales ha desarrollado el tipo ideal de "dominación carismática", una forma especial de dominación que se legitima a partir de una "devoção afetiva à pessoa do senhor e a seus dotes sobrenaturais (carisma) e, particularmente: a faculdades mágicas, revelações ou heroísmo, poder intelectual ou de oratória". Os três tipos puros de dominação legítima. In : COHN, G. (org.). Weber : Sociologia. $7^{\mathfrak{a}}$ ed. São Paulo, Ática. pp. 134-135.

${ }^{17}$ (...) "O impasse resultante com as classes sociais tradicionalmente dominantes criou as condições do que Gramsci chamou de "revolução passiva": a introdução de mudanças que não envolveram nenhuma sublevação de forças populares". Cox, Op. cit., p. 108.
} 
Por lo tanto, creemos que Venezuela se encontraba en una situación de revolución pasiva y que se desarrolló para la construcción de una nueva configuración del Estado y de la sociedad venezolanos.

Después que Hugo Chávez llegó al poder, ha estado buscando trabajar en la construcción de un bloque histórico basado en la participación popular de amplio espectro, a través de un largo proceso de transformación social.

Según Gramsci, el tutelaje de los movimientos sociales por los líderes provocaría el surgimiento del cesarismo: líderes con gran fuerza o el transformismo mediante la formación de alianzas políticas de amplio espectro. Por lo tanto ${ }^{18}$,

"De acordo com a análise gramsciana, um exemplo típico de revolução passiva é o cesarismo: um homem forte intervém para resolver o impasse entre forças sociais equivalentes e opostas. Gramsci admitia a existência tanto de formas progressistas quanto reacionárias de cesarismo: progressistas, quando o governo forte preside um processo mais ordenado de criação de um novo estado; reacionárias, quando estabiliza 0 poder existente. Napoleão I foi um caso de cesarismo progressista, mas Napoleão III - o exemplo clássico de cesarismo reacionário - era mais representativo do tipo com maior probabilidade de surgir no decorrer de uma revolução passiva".

En nuestra opinión, Hugo Chávez, ha estado trabajando en una perspectiva cesarista progresista. Defendemos esta posición en virtud de que su gobierno no ha hecho concesiones a las tradicionales fuerzas políticas venezolanas. El tutelaje de movimientos sociales, por otra parte, no ocurrió de manera absoluta.

\footnotetext{
${ }^{18}$ Além do cesarismo, a segunda característica mais importante da revolução passiva da Itália e o que Gramsci chamou de transformismo, exemplificado na política italiana por Giovanni Giolitti, que procurou fazer uma coalizão de interesses mais ampla possível e que dominou a cena política nos anos que precederam o fascismo". (...) Cox, apud lbidem, pp. 108-109.
} 
El gobierno de Chávez alienta la inclusión de la población en el juego y en la vida política del país. En una infinidad de veces, la población fue invitada a participar de las decisiones políticas del país. Sobre la participación popular en el gobierno de Chávez y las medidas adoptadas por el Palacio de Miraflores en este sentido, el sociólogo Antonio Plesmann ${ }^{19}$ señaló que:

"A Constituição de 1999 tem como objetivo principal reduzir a brecha entre o representante e o representado. Isso começa já na elaboração do próprio texto da Carta, que teve intervenção de movimentos sociais, acadêmicos, ONGs... Um processo inédito na América Latina. Paralelamente, o governo acabou com a criminalização dos movimentos sociais. As rádios comunitárias, que sempre existiram, cresceram muito durante a década, e são atualmente as mais numerosas do continente. Outro exemplo: a Venezuela tem hoje 5.920 Comitês de Terras Urbanas (CTUs), que lutam pelo direito à moradia nas favelas, e representam cerca de 4,7 milhões de pessoas. Desde o começo, esse governo entendeu que dependia da força política das bases. Essa percepção aumentou ainda mais depois do golpe de estado contra Chávez, em abril de 2002, quando o povo exigiu sua volta ao poder. O governo multiplicou medidas que expandiam a participação política popular. É o caso das missões sociais, que procuram eliminar o entrave tradicional da burocracia. $O$ governo procurou também facilitar a participação eleitoral dos mais pobres. Foram cadastradas milhões de pessoas que nunca tiveram direito a carteira de identidade, e milhares de colombianos refugiados receberam nacionalidade venezuelana, alguns já da terceira geração. O Conselho Nacional Eleitoral colocou mesas de voto nas favelas. Antes, para os pobres, era complicado demais votar. Pagavam caro o transporte e perdiam o dia para chegar até os

\footnotetext{
19 "Participação popular aumentou na Venezuela, mas amigos do rei continuam se fartando, diz sociólogo". 19/12/2008. <http://operamundi.uol.com.br/conteudo/entrevistas/16430> Acessado em 02/01/2012.
} 
centros de votação. Acabavam não indo votar, já que a Venezuela é um dos únicos países da América Latina onde o voto não é obrigatório".

El libro de Carlos Martínez, Michael Fox, y Jojo Farrell, titulado Venezuela Speaks! Voices from the Grassroots, presenta una excelente evaluación del movimiento social y chavista con entrevistas con los principales líderes sociales ${ }^{20}$.

Otro aspecto que cabe señalar es que la idea planteada por los medios de comunicación latinoamericanos conservadores de que Chávez controla todos los movimientos sociales y/o políticos venezolanos no se condice con la realidad. Existen numerosos grupos "disidentes" dentro del movimiento chavista con gran actividad política.

Evaluando el desempeño de Chávez en el proceso de superación del neoliberalismo y de la construcción de una participación política más efectiva de la población, Greg Wilpert ${ }^{21}$ señala que:

"Since his election, Chávez has not only become an unapologetic spokesperson for the necessity to overcome capitalism as an economic system, the need to defeat U.S. dominance in the world, and the drive to replace or at least complement representative democracy with participatory democracy; he has actually delivered on many of these promises. Venezuela has probably gone further than any other country in reversing the neoliberal policies of the past through nationalizing key industries, reintroducing extensive social programs, promotional social ownership via cooperatives, and through re-regulating capital. Chávez has been one of main promoters of regional Latin American integrations by forming Bolivarian Alliance for our America (ALBA), supporting the development of Union of South America nations (UNASUR), and

\footnotetext{
${ }^{20}$ Oakland, PM Press, 2010.

${ }^{21}$ Op. cit., p. vii, 2010.
} 
promoting energy integration via PetroCaribe and PetroSur. In terms of going beyond representative democracy, Venezuela continues to actively give its citizens the opportunity to participate in all levels of politics, especially locally, via direct democratic councils".

Los cambios que se producen en Venezuela transcienden el aspecto meramente político y social superficialmente demostrado por los principales medios conservadores en América Latina o en los EE.UU., que en su mayoría representan a los intereses hegemónicos.

\section{2 - El Análisis de Sistemas-Mundo}

El trabajo desarrollado por Wallerstein en los últimos treinta años es de gran importancia para la comprensión del capitalismo de hoy, cuyo principal aporte es el Análisis de Sistemas-Mundo (MSA).

La construcción del ASM desarrollada por Immanuel Wallerstein tiene tres influencias importantes en su constitución: La Escuela de Annales, el Marxismo y La Teoría de la Dependencia ${ }^{22}$.

En su explicación del actual Sistema-Mundo, Wallerstein señala que fue originada por la crisis del sistema feudal y el ascenso a la supremacía de

\footnotetext{
${ }^{22}$ Da Escola dos Annalles, (...) "Wallerstein got from Braudel's his insistence on the long term (la longue durée). (...) The impact of the Annales is at the general methodological level". De Marx, "Wallerstein learned that (1) the fundamental reality if social conflict among materially based human groups, (2) the concern with a relevant totality, (3) the transitory nature of social forms and theories about them, (4) the centrality of the accumulation process and competitive class struggles that result from it, (5) a dialectical sense of motion through conflict and contradiction". (...) Wallerstein, "draws heavily form dependency theory, a neo-Marxist explanation of development processes, popular in the developing world (...) Dependency theory focuses on understanding the 'periphery' by looking at core-periphery relations (...)".Vela, Carlos A. Martinez. World Systems Theory. ESD. 83 Fall 2001, p.3.
} 
Europa Occidental entre 1450 y 1670 . Acerca del Sistema-Mundo contemporáneo, Wallerstein ${ }^{23}$ explica que,

\begin{abstract}
"Um sistema-mundo não é o sistema do mundo, mas um sistema que é um mundo e que pode ser, e frequentemente tem sido localizado numa área menor que o globo inteiro. Uma análise de sistemas mundiais argumenta que as unidades da realidade social dentro das quais nós operamos, cujas regras nos restringem, são na maioria tais sistemas mundos".
\end{abstract}

El teórico aun señalaba la existencia de dos tipos de sistemas-mundo: los imperios mundiales y las economías-mundos. La diferenciación entre los dos tipos de sistemas-mundo se produce en el hecho de que los imperios mundiales serían un gran mundo de estructura burocrática con centralización política y una división del trabajo central, una coexistencia de múltiples culturas.

La economía-mundo, por el contrario, caracterizase por una gran división central del trabajo, muchos centros políticos que mantienen la coexistencia de múltiples culturas. Wallerstein, haciendo un análisis de la expansión del capitalismo desde el siglo VI. XVI, señala que:

"O mundo no qual nós estamos inseridos agora, ou seja, o sistema mundial moderno teve suas origens no século XVI. Este sistema mundial foi então localizado em somente uma parte do globo, principalmente em regiões da Europa e das Américas. Ele se expandiu ao longo dos anos e atingiu todo o globo. É, e sempre foi, uma economia mundo. É, e sempre foi, uma economia mundo capitalista" ${ }^{24}$.

\footnotetext{
${ }^{23}$ Apud Márcio Roberto Voigt. "A Análise dos sistemas-Mundo e a Política Internacional: uma Abordagem Alternativa das Teorias das Relações Internacionais". Textos de Economia. Florianópolis, v. 10, no 2, 110, jul/dez, 2007.

${ }^{24}$ Op. cit, p.111.
} 
Por lo tanto, el capitalismo se entiende como sistema social moderno, una economía-mundo, que cuenta con numerosos centros políticos (Estados), que disputan la hegemonía del sistema. En el ASM, la definición de la hegemonía se sumaría a los ciclos sistémicos de acumulación que veremos más adelante.

En este punto, sería de gran importancia hacer una nota en el examen realizado por Antonio Negri y Michael Hardt, desde el año 2000, con el libro Imperio $^{25}$. Sin duda, los autores trataron de arrojar nueva luz sobre la configuración actual del poder dentro del sistema capitalista. Los autores crearon una interpretación única de la "novedad" del proceso de Globalización que se traduciría en una restructuración del poder global. Específicamente, Negri y Hardt sostienen que:

(...) "essa mudança torna perfeitamente claro e possível o atual projeto capitalista de unir o poder econômico ao político, para materializar, em outras palavras, uma ordem convenientemente capitalista. Em termos constitucionais, os processos de globalização já não são apenas um fato, mas também uma fonte de definições jurídicas que tende a projetar uma configuração única e supranacional de poder político"26.

No estamos de acuerdo con la idea de los teóricos que defienden la Globalización como algo relativamente nuevo ${ }^{27}$. El proceso de Globalización es intrínseco al desarrollo del capitalismo, una condición sine qua non para su reproducción. Sobre la necesidad de la burguesía conseguir nuevos mercados y las condiciones que facilitan la reproducción del capital, Marx ya señaló que en el siglo XIX:

\footnotetext{
${ }^{25}$ Império. Rio de Janeiro, Editora Record, 8ª ed., 2006.

${ }^{26}$ Op. cit., pp. 26-27.

${ }^{27}$ Ibidem, p. 26.
} 
(...) "Impelida pela necessidade de mercados sempre novos, a burguesia invade todo o globo. Necessita estabelecer-se em toda parte, explorar em toda parte, criar vínculos em toda parte.

Pela exploração do mercado mundial a burguesia imprime um caráter cosmopolita à produção e ao consumo em todos os países. Para desespero dos reacionários, ela retirou à indústria sua base nacional. As velhas indústrias nacionais foram destruídas e continuam a sê-lo diariamente. São suplantadas por novas indústrias, cuja introdução se torna uma questão vital para todas as nações civilizadas, indústrias que não empregam mais matérias-primas autóctones, mas sim matérias-primas vindas das regiões mais distantes, e cujos produtos se consomem não semente no próprio país mas em todas as partes do globo. Em lugar das antigas necessidades, satisfeitas pelos produtos nacionais, nascem novas necessidades, que reclamam para sua satisfação os produtos das regiões mais longínquas e dos climas mais diversos. Em lugar do antigo isolamento de regiões e nações que se bastavam a si próprias, desenvolvem-se um intercâmbio universal, uma universal interdependência das nações. $E$ isto se refere tanto à produção material como à produção intelectual. As criações intelectuais de uma nação tornam-se propriedade comum de todas. A estreiteza e o exclusivismo nacionais tomam-se cada vez mais impossíveis; das inúmeras literaturas nacionais e locais, nasce uma literatura universal”28.

Según Hardt y Negri, el “(...) novo paradigma é definido pelo declínio definitivo dos Estados-nação soberanos, pela desregulamentação dos mercados internacionais, pelo fim do conflito antagônico entre entidades independentes e, assim por diante" ${ }^{29}$.

\footnotetext{
${ }^{28}$ Manifesto Comunista. Karl Marx e Friedrich Engels. www.eBooksBrasil.com, pp.12-13, 1999. <http://www.ebooksbrasil.org/adobeebook/manifestocomunista.pdf> Acessado em 18/12/2011. ${ }^{29}$ Op. cit., p.31.
} 
Arrighi y Silver, en su libro Chaos and Governance and the Modern World System, ${ }^{30}$ indican que

"The thesis that globalization disempowers states has also been challenged by critics who focus on the longer-term aspects of the phenomenon and see much déjà vu in the alleged novelties of recent changes in the state-capital relations. Wallerstein has gone as far as to argue that the basic relationship between states and capital has remained the same throughout capitalist history, with "transnational corporations... maintaining today the same structural stance vis-à-vis states as did all their global predecessors, from the Fuggers to the Dutch East India Company to nineteenth-century Manchester manufacturers" (Wallerstein, 1995c, 24-25). More common is the contention that the transformations that go under the rubric of "globalization" originate in the nineteenth century. "If the theorists of globalization mean that we have an economy in which each part of the world is linked by markets sharing close to real-time information, "claim Paul Hirst and Grahame Thompson, "then that began not in the 1970s but in the 1870" (1996, 9-10)".

Desde la perspectiva que vamos a defender en nuestro trabajo, el análisis debe ser sistémico y no se basa en la existencia a priori del EstadoNación o en su declive, a posteriori. No compactamos, también, con la visión de que se sale de un período "post-imperial" y yendo hacia un período "Imperial", como sostienen los autores ${ }^{31}$.

El gran cambio de fase por el cual se pasa seria la transición hacia un nuevo ciclo sistémico de acumulación, como se discute a continuación.

\footnotetext{
${ }^{30}$ P. 8.

${ }^{31}$ (...) "uma noção de direito, ou melhor, um novo registro de autoridade e um projeto original de produção e de instrumentos legais de coerção que fazem valer contratos e resolvem conflitos". Império. Rio de Janeiro, Editora Record, $8^{\mathrm{a}}$ ed. p. 27, 2006.
} 


\section{3 - Los Ciclos Sistémicos de Acumulación}

En su libro $O$ Longo Século $X X^{32}$, Giovanni Arrighi ha proporcionado una importante cooperación al ASM. Su contribución se produjo en el análisis de la hegemonía bajo la inspiración gramsciana y en los ciclos de acumulación capitalista.

Arrighi era adepto, así como Wallerstein, de los ciclos de Kondratieff, la elaboración teórica del economista ruso Nikolai Kondratieff en la decada de 1920. El argumento del economista para el capitalismo era que su desarrollo se basó en ciclos ${ }^{33}$.

Bajo la inspiración de los Ciclos de Kondratieff, el sistema capitalista, para Arrighi, tendría pasado por cuatro ciclos sistémicos de acumulación y expansión: genoveses, holandeses, británicos y estadounidenses. Los ciclos sistémicos de acumulación de capital constituyen una cadena de etapas que se superponen parcialmente, mediante las cuales la economía capitalista europea ha transformado la economía mundial en un sistema de intercambio intenso.

\footnotetext{
${ }^{32}$ Los libros O Longo Século XX, Chaos and Governance in the Modern World System The (coautor con Beverly Silver) y Adam Smith en Pekín. Juntos forman una trilogía sobre el capitalismo en todo el mundo desde una perspectiva histórica y se encuentran entre las obras más importantes de las análisis de los sistemas-mundo.

${ }^{33}$ Un ciclo de Kondratieff tendría un período de duración limitada (40-60 años), que corresponde aproximadamente a la devolución del mismo fenómeno. Tiene dos fases distintas: una fase ascendente (fase A) y una fase descendente (fase B). Estas fluctuaciones serían a largo plazo, características de la economía capitalista.

La primera referencia del economista ruso Nikolai Kondratieff a los ciclos largos ocurrió en su libro A economia mundial e sua conjuntura durante e depois da guerra (1922). Para él, la naturaleza particularmente aguda de la crisis de posguerra esta bien explicado por el hecho que marcó un punto de inflexión en el ciclo prolongado y el comienzo de su mala racha. En 1926, Kondratieff presenta en su libro "As ondas longas da conjuntura", el hipótesis de la existencia de ciclos largos. Kondratieff hizo su base en el análisis de series temporales de precios al por mayor de 1790 a 1920, el período de potencias capitalistas: Estados Unidos, Francia y Reino Unido.

A partir de las curvas empíricas, Kondratieff ha desarrollado curvas teóricas que, a su juicio, mostraron tendencias seculares. Consideró haber encontrado dos ciclos de largo y medio entre 1780 y 1920, a partir de la fase descendiente del tercer ciclo. Según Kondratieff, la base de los ciclos largos es el desgaste, la sustitución y mejora de los bienes de capital de fondos básicos, cuya producción se requiere grandes inversiones. Sustitución y mejora de este fondo no sería un proceso continuo y dirigido por saltos. Los ciclos económicos se producen a partir de estos hechos.
} 
Figura 1 - KONDRATIEFF WAVES

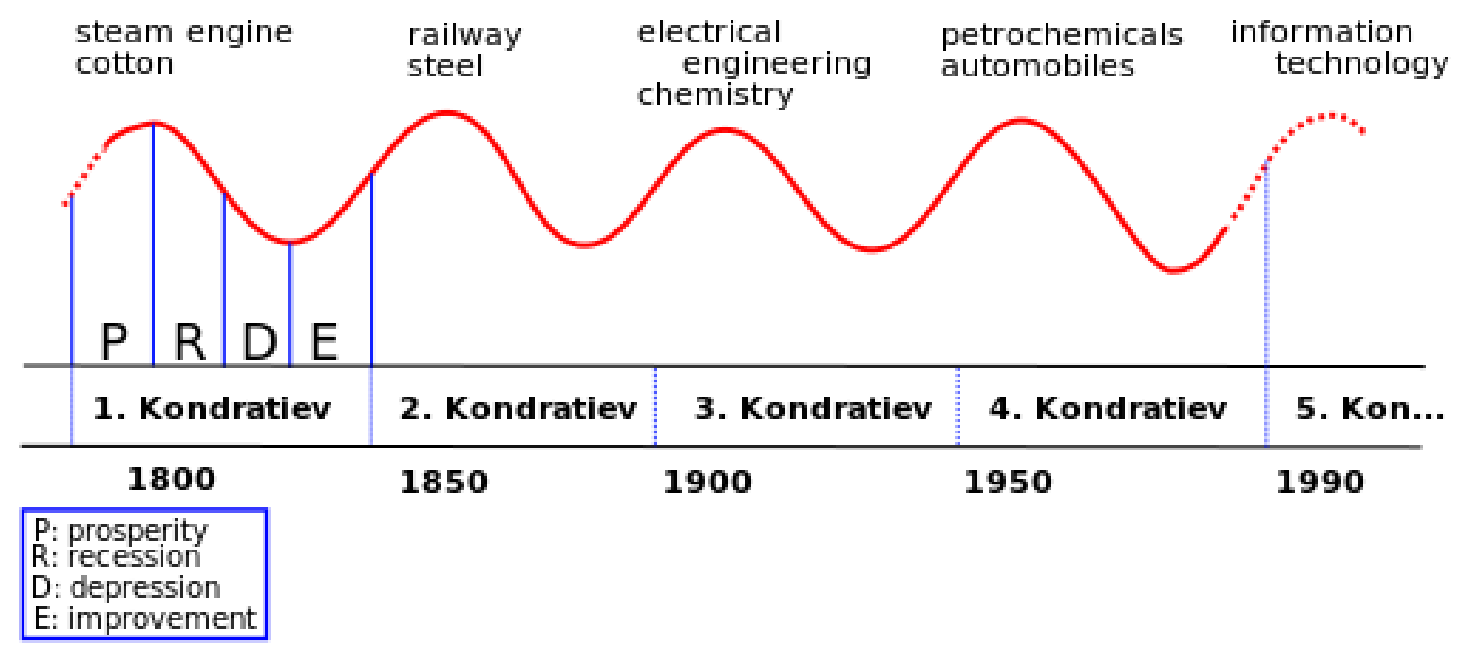

La superposición de estos ciclos se produce en el paso de una a la otra, es decir, mientras un ciclo está llegando a su fin, mientras que otro ciclo sistémico de acumulación empieza a formarse. Esta fase de superposición tiene lugar durante la turbulencia financiera del ciclo que está llegando a su fin. $^{34}$.

Así, las grandes expansiones materiales y financieras se producen cuando un bloque dominante se había acumulado suficiente para dominar el sistema mundial que, al llegar a su fin, resultaría en el cambio de poder hegemónico. Cuando esto ocurre, un nuevo ciclo sistémico de acumulación comienza.

\footnotetext{
34 "O aspecto principal do perfil temporal do capitalismo histórico aqui esquematizado é a estrutura semelhante de todos os séculos longos. Todos esses constructos consistem em três segmentos ou períodos distintos: (1) um primeiro período de expansão financeira (que se estende de Sn-1 a Tn-1), no correr do qual o novo regime de acumulação se desenvolve dentro do antigo, sendo seu desenvolvimento um aspecto integrante da plena expansão e das contradições deste último; (2) um período de consolidação e desenvolvimento adicional do novo regime de acumulação (que vai de Tn-1 a Sn), no decorrer do qual seus agentes principais promovem, monitoram e se beneficiam da expansão material de toda a economia mundial; e (3) um segundo período de expansão financeira (de Sn a Tn), no decorrer do qual as contradições do regime de acumulação plenamente desenvolvido criam espaço para 0 surgimento de regimes concorrentes e alternativos, um dos quais acaba por se tornar (no tempo Tn) o novo regime dominante". Arrighi, Op. cit., pp. 219-20.
} 


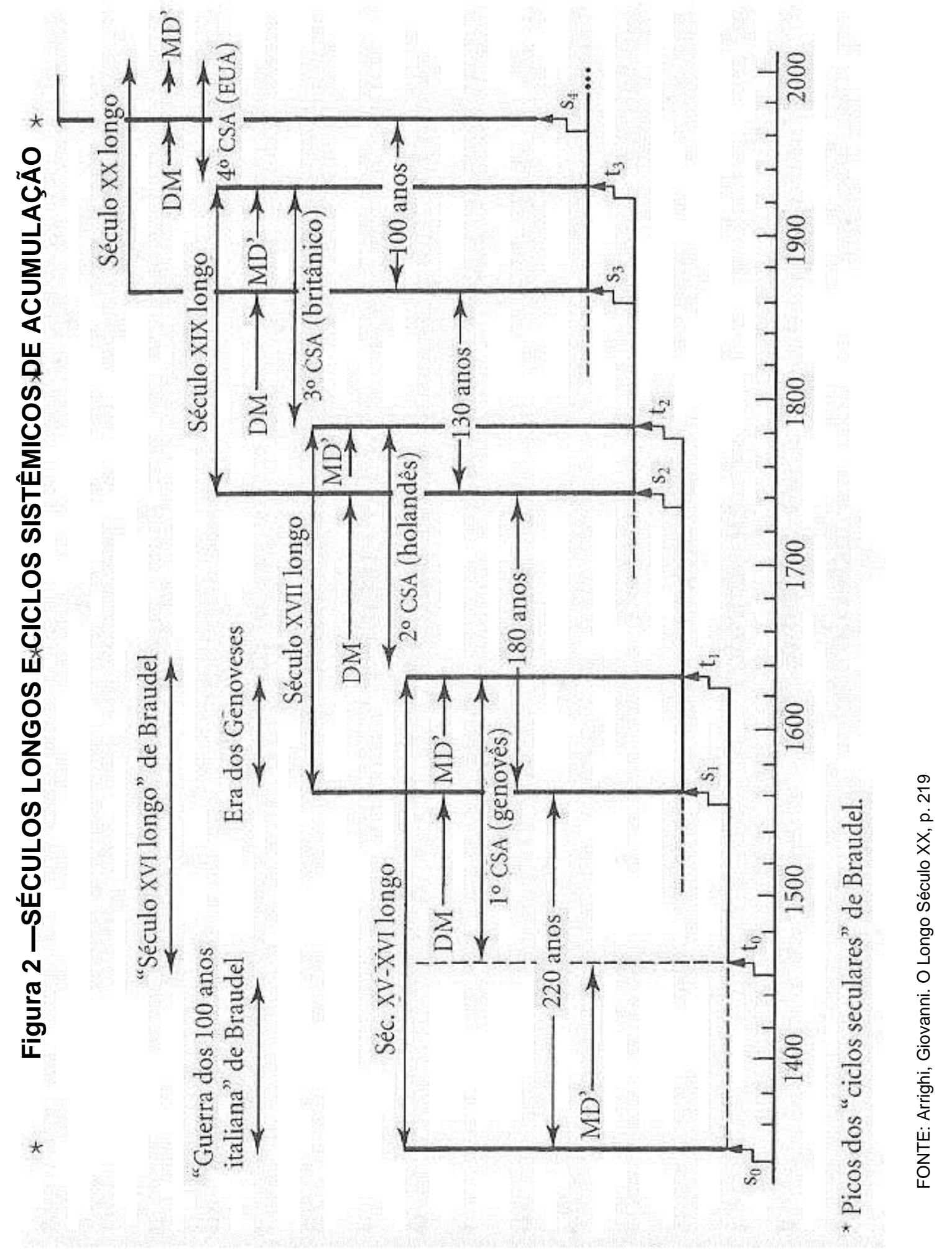


Arrighi confirma que la contribución más importante y perenne para el desarrollo del capitalismo como sistema mundial encontrase en el ámbito de las altas finanzas, durante el Renacimiento italiano de final del siglo XIV y principio del del siglo XV, que es el período de su aparición.

El primer ciclo sistémico, el genovés, según Arrighi, explicase a partir de Fernand Braudel. Durante este período (...) "a maturidade de todos os grandes desenvolvimentos da economia capitalista mundial é anunciada por uma guinada peculiar do comércio de mercadorias para o comércio de moedas”35.

El capitalismo financiero genovés se ha desarrollado en la segunda mitad del siglo. XVI. Según Arrighi ${ }^{36}$,

(...) "À medida que se intensificaram as pressões competitivas e que houve uma escalada na luta pelo poder, o capital excedente, que já não encontrava investimentos lucrativos no comércio, foi mantido em estado de liquidez e usado para financiar a crescente dívida pública das cidades-Estado, cujo patrimônio e receita futura foram assim, mais completamente alienados do que nunca a suas respectivas classes capitalistas". (...)

Siguiendo con el ciclo de acumulación genovés, Arrighi señaló que este período fue el punto máximo de la expansión capitalista:

(...) "uma grande expansão material da economia mundial europeia, através do estabelecimento de novas rotas de comércio e da incorporação de novas áreas de exploração comercial foi acompanhada por uma expansão financeira que acentuou 0 controle de capital sobre uma economia mundial ampliada. Além disso, uma classe capitalista claramente identificável (a genovesa) incentivou, supervisionou e se beneficiou das duas expansões,

\footnotetext{
${ }^{35}$ Ibidem, p. 111.

${ }^{36}$ Ibidem, p. 112.
} 
em virtude de uma estrutura de acumulação de capital que, em sua maior parte, já passara a existir quando a expansão material teve início" ${ }^{37}$.

Para Arrighi, este modelo sería el "ciclo sistémico de acumulación". Los capitalistas genoveses serían los precursores, en el siglo XVI, de este padrón, hecho que se produciría tres veces más ${ }^{38}$.

Después del ciclo genovés, vinieron los ciclos holandés, el ciclo británico y el ciclo de América del Norte, que es lo que nos interesa en la preparación de este trabajo, pues sería la expansión del sistema-mundo moderno que se produjo durante la mayor parte del siglo XX y sufriría una crisis en la década de 1970.

Por lo tanto, se vive una crisis del ciclo sistémico de acumulación, lo que favorece la aparición de nuevas perspectivas antisistémicas para superar la fase actual. Sobre las perspectivas de transformación del actual ciclo de acumulación, Wallerstein señala:

"Estamos passando por uma transição em nosso atual sistema mundial, a economia mundial capitalista, estará se transformando em outro sistema - ou em outros sistemas - mundiais. Não sabemos se essa mudança será para melhor ou para pior. E não saberemos até que cheguemos lá, um processo que pode demorar ainda uns cinquenta anos a partir do momento em que

\footnotetext{
${ }^{37}$ Ibidem, pp. 129-130.

${ }^{38}$ En el ciclo holandés, su supremacía comercial estaba basado en una lógica capitalista de poder (representada por la fórmula D-T-D'), mientras que la supremacía comercial posterior, la inglesa que empieza en el inicio del siglo XVIII, estuvo basado en una síntesis armónica entre la lógica territorialista de poder (T-D-T') y la capitalista (D-T-D'). Esta síntesis fue el factor fundamental para el régimen inglés haber logrado un ciclo sistémico de acumulación mucho más avanzado que el holandés. El ciclo británico se ha caracterizado por el proceso continuo de expansión, restructuración y reorganización financiera de la economía mundial capitalista. Los períodos de expansión financiera fueron momentos en que aumentan las presiones competitivas tanto sobre los gobiernos cuanto empresas y comercio. Estas presiones favorecieron a la expansión industrial inglesa, que se mantuvo en la supremacía económica mundial hasta el inicio del siglo XX. Ibidem, p. 204.
} 
estamos. Sabemos, no entanto, que o período de transição será um período difícil para todos os que vivenciarem"39.

Después de configurar el marco teórico que guiará nuestra investigación, la hipótesis que será elaborada por nosotros en este trabajo es la siguiente:

- El gobierno de Hugo Chávez tiene como objetivo poner a Venezuela como un player internacional y el retador de la hegemonía de EE.UU.?

Vamos a tener como variables los siguientes objetivos específicos:

- $\quad$ identificar el papel antisistémico de Venezuela en América Latina;

- Investigar el conjunto de las políticas oficiales del gobierno venezolano dirigidas a la inserción del país en el comercio y en la comunidad internacional;

- Identificar la política hegemónica de los Estados Unidos en el siglo XX en América Latina;

- $\quad$ Analizar la construcción de la "influencia política" para América Latina;

Como objetivos secundarios:

- Investigar la evolución del sistema político venezolano y analizar la dinámica que permitió al país convertirse en un modelo de estabilidad política durante gran parte del siglo XX;

- $\quad$ Analizar la política exterior de Venezuela y sus consecuencias para América Latina.

Con la importancia que asume el liderazgo de Hugo Chávez y la polarización causada por sus acciones tanto en América Latina (construyendo alianzas políticas con Bolivia y Ecuador, por ejemplo) y mediante la confrontación con los EE.UU., se convierte muy relevante el estudio sobre

\footnotetext{
${ }^{39}$ Wallerstein, Immanuel. Utopística ou as decisões históricas do século vinte e um. Petrópolis, Editora Vozes, p. 49, 2003.
} 
Venezuela. A partir de este, vamos a tratar de poner de relieve el papel de la Venezuela contemporánea en el actual sistema-mundo. 


\section{2 - EL DECLIVE DE AMÉRICA DEL NORTE}




\section{1 - La Economía-Mundo Capitalista}

La economia-mundo actual (sistema-mundo) capitalista se originó, según Wallerstein, en la crisis del sistema feudal y en la ascensión de Europa Occidental a la supremacía mundial, entre 1450 y 1670, como ya se ha comentado en el capítulo anterior.

Estas presiones favoreceran a la expansión industrial inglesa, que se mantuvo en la supremacía económica global hasta el inicio del siglo XX.

La hegemonía anterior a la actual, la británica, se caracterizó por una expansión continua, reestructuración y reorganización financiera de la economía mundial capitalista. Los períodos de expansión financiera fueron momentos en que se han incrementado las presiones competitivas tanto sobre los gobiernos como sobre los negocios y sobre el comercio. Estas presiones han favorecido la expansión industrial inglesa, que se mantuvo en la supremacía económica mundial hasta el siglo XX.

Después de la caída hegemónica de Gran Bretaña, los EE.UU. surgieron como una gran potencia económica y, después de la Segunda Guerra Mundial, llegaron a la supremacía tecnológica y militar durante la Guerra Fría y se convirtieran en una superpotencia después de la caída del bloque socialista, en 1989, y el fin de la Unión Soviética en, 1991.

La economía-mundo capitalista demuestra una relación desigual y jerárquica entre las naciones, lo que llevó a un colapso en el sistema. Para su comprension, creemos que la llamada Teoría de la Dependencia ${ }^{39}$ es la más informativa, teniendo como telón de fondo un análisis sistémico. Wallerstein ${ }^{40}$ señala que

39 La Teoría de la Dependencia es una formulación teórica que se originó en los años 1950/1960, en base a una lectura crítica marxista y no dogmática sobre los procesos de la reproducción del subdesarrollo en la periferia del capitalismo mundial.

${ }^{40}$ The Modern World-System I: Capitalist Agriculture and the Origins of the European WorldEconomy in the Sixteenth Century. California, University of California Press, p. 349, 2011(1974). 
"World-economies then are divided into core-states and peripheral areas. (...) There are also semiperipheral areas which are in between the core and periphery on a series of dimensions, such as the complexity of economic activities, strength of machinery, cultural integrity, etc. some of these areas had been core-areas of earlier versions of a given world-economy. Some had been peripheral areas that were later promoted, so to speak, as result of the changing geopolitics of an expanding world-economy.

The semiperiphery, however, is not an artifice of statistical cutting points, nor is it as residual category. The semiperiphery is a structural element in a world-economy. These areas play a role parallel to that played mutatis mutandis, by middle tranding groups in an empire". (...)

Según La Teoría de la Dependencia, el capitalismo se basaba en una estructura interdependiente: El Centro, la Semi-Periferia y la Periferia. La posición sistémica de cada nación estaría determinada en gran medida por la capacidad de desarrollar sus fuerzas sociales y económicas.

El centro del sistema está configurado con una alta concentración de la riqueza y alto desarrollo tecnológico en todos los sectores económicos. El comercio nacional e internacional son de gran envergadura y fuentes importantes de fondos para el mantenimiento del centro financiero. Esta área del sistema corresponde a las antiguas ciudades de Europa, EE.UU. y Japón.

La Periferia del sistema dispone de condiciones opuestas: el bajo desarrollo tecnológico y social. Su dinámica económica se basa en la producción agrícola y extracción de mineral, es decir, productos con bajo valor agregado. En general, esta área se compone de las antiguas colonias.

La Semi-Periferia tiene una característica intermedia, más precisamente con la producción de algunos bienes de valor relativo y el uso de la tecnología. En una etapa más alta de los países periféricos estarian Brasil, México, los Tigres Asiáticos, China e Indonesia, por ejemplo. 
Desde la década de 1970 la competencia entre los países centrales y semiperifericos se intensificó con ventajas comparativas para el segundo grupo de países. Tales ventajas son específicas de los países semiperifericos, sobre todo de China y de los Tigres Asiáticos.

Con esta configuración, la economía-mundo capitalista bajo la hegemonía de EE.UU. llegó al siglo XXI en más una crisis cíclica sistémica, que se inició en la década de 1970 y se ha extendido hasta los días de hoy.

\section{2 - La Crisis del Sistema Fordista de Producción}

Como se mencionó en el punto anterior, el actual Ciclo Sistémico de Acumulación, liderado por los EE.UU., atraviesa un período de crisis. Este proceso refleja la característica inherente al sistema capitalista, es decir, las crisis económicas son parte de la dinámica sistémica.

La crisis del sistema fordista de producción comenzó a finales de 1960. El poder adquisitivo de los trabajadores creció a un ritmo más rápido y, por lo tanto, se redujo la tasa de ganancia.

La competición internacional acirrava con la inclusión de América Latina y los países del sudeste de Asia, llevando a la caída del dólar, la moneda de reserva mundial y, en consecuencia, aumentando el problema fiscal de EE.UU. Una de las soluciones fue el despido de los trabajadores. Sin embargo, la rigidez del empleo crió una sobrecarga a la recaudación del Welfare State ${ }^{41}$.

La primera crisis del petróleo contribuyó aún más para la caída del fordismo. La extracción de los ingresos del petróleo se ha acelerado esta

\footnotetext{
${ }^{41}$ El estado de bienestar social (Welfare State) ganó impulso después de la Segunda Guerra Mundial, cuando las fuerzas políticas europeas aceptaron el papel del Estado como agente importante para proteger y promover el desarrollo social y económico.
} 
primera consecuencia: la crisis de la organización del trabajo - la crisis de inversión - la crisis del Welfare state ${ }^{42}$.

El Fordismo y la regulación económica keynesiana, en el período de ocho años (1965 a 1973), no lograron resolver estos problemas. Los problemas intrínsicos al capitalismo persisten. De hecho, era el problema,

"(...) [na] rigidez dos investimentos de capital fixo de longa escala em sistemas de produção em massa que impediam muita flexibilidade de planejamento e presumiam crescimento estável em mercados de consumo invariantes.

(...) A rigidez dos compromissos do estado foi se intensificando à medida que programas de assistência (seguridade social, direitos de pensão, etc.) aumentavam a pressão para manter a legitimidade num momento em que a rigidez na produção restringia expansões da base fiscal para gastos públicos. O único instrumento de resposta flexível estava na política monetária, na capacidade de imprimir moeda em qualquer montante que parecesse necessário para manter a economia estável" ${ }^{43}$.

Harvey va más allá y afirma que:

"A profunda recessão de 1973, exacerbada pelo choque do petróleo, evidentemente retirou o mundo capitalista do sufocante torpor da estagflação (estagnação da produção de bens e alta de inflação de preços) e pôs em movimento um conjunto de processos que solaparam 0 compromisso fordista. $\mathrm{Em}$ conseqüência, as décadas de 70 e 80 foram um conturbado período de reestruturação econômica e de reajustamento social e

\footnotetext{
${ }^{42}$ D. Leborgne \& A. Lipietz. Flexibilidade Defensiva ou Flexibilidade Ofensiva: Os Desafios das Novas Tecnologias e da Competição Mundial, In: Reestruturação Urbana-Tendências e Desafios (Orgs.), Rio de Janeiro, Nobel/IUPERJ, 1990, p. 22.

${ }^{43}$ D. Harvey, Condição Pós-Moderna, São Paulo, Edições Loyola, 1992, pp. 135-136.
} 
político. No espaço social criado por todas essas oscilações e incertezas, uma série de novas experiências nos domínios da organização industrial e da vida social e política começou a tomar forma. Essas experiências podem representar os primeiros ímpetos da paisagem para um regime de acumulação inteiramente novo, associado com um sistema de regulamentação política e social bem distinta".

Con estas contradicciones, se inició la transición del fordismo al postfordismo.

\section{3 - El Post-Fordismo}

El proceso de crisis del sistema fordista de producción provocó una serie de experimentos que pretendían dar un "nuevo impulso" al sistema capitalista. Lo que marca el postfordismo es la oposición al paradigma fordista, es decir, su rigidez y la consiguiente falta de credibilidad y la "flexibilidad".

El proceso de producción fordista se ha relajado, desmantelando todo lo que existía hasta entonces. De hecho, lo que se observó fue una revolución tecnológica que tiene como principal objetivo revertir a la crisis del fordismo: una disminución de la productividad y de la rentabilidad. Tavares ${ }^{44}$ aclara que:

"Contrariamente à rigidez que caracterizava o taylorismofordismo, as novas tecnologias buscam obter o máximo de flexibilidade no que respeita a processos de produção, desenhos e produtos, bem como a ocupação da força de trabalho".

${ }^{44}$ H. M. Tavares, Complexos de Altas Tecnologia e Reestruturação do Espaço, In: Caderno IPPUR/UFRJ, Rio de Janeiro, V, VII, 1, 1993, p.41. 
Sin embargo, Harvey ${ }^{45}$ afirma que:

"A acumulação flexível (...) é marcada por um confronto direto com a rigidez do fordismo. Ela se apóia na flexibilidade dos processos de trabalho, novos mercados de trabalho, dos produtos e padrões. Caracteriza-se pelo surgimento de setores de produção inteiramente novos, novas maneiras de fornecimento de serviços financeiros, novos mercados e, sobretudo, taxas altamente intensificadas de inovação comercial, tecnológica e organizacional. A acumulação flexível envolve rápidas mudanças dos padrões de desenvolvimento desigual, tanto entre setores como entre regiões geográficas, criando, por exemplo, um vasto movimento no emprego do chamado "setor de serviços", bem como conjuntos industriais completamente novos em regiões até então subdesenvolvidas (tais como, a Terceira Itália, Flandes, vários vales e gargantas de silício, para não falar da vasta profusão de atividades dos países recém-industrializados)".

Leborgne y Lipietz $^{46}$ muestran, sin embargo, algunos problemas en el uso de estas innovaciones tecnológicas. Las fallas en los sistemas, máquinas obsoletas y los costos de mantenimiento son problemas que deben ser tomados en consideración. Pero aún así, señalan que:

"A principal característica da revolução tecnológica atual é a invasão do microprocessador e das interfaces eletrônicas não apenas em novos produtos, mas também no próprio processo de trabalho: a microeletrônica redefine o próprio significado da automação".

\footnotetext{
${ }^{45}$ D. Harvey, Op. cit., p. 140.

${ }^{46}$ Op. cit., p. 25.
} 
En el núcleo de esta nueva dinámica capitalista, el postfordismo fue tomando forma, provocando una importante re-articulación en todos los niveles sociales y económicos. Las relaciones laborales y la estructura industrial acompañaron al nuevo ritmo.

La flexibilidad se caracteriza en la organización del trabajo, en la tecnología y en las nuevas estructuras institucionales surgidas. Los patrones de consumo fueron fragmentados y privatizados; la desintegración vertical despegó y los pequeños y medianos productores se especializaron.

La nueva base de la dinámica de la competencia capitalista ha cambiado, es decir, el eje de la competencia ha cambiado el precio para nuevos tipos de productos adaptados al mercado. Los mercados se han vuelto imprevisibles y volubles, llevando a una producción diferenciada y adecuada a la nueva realidad. La producción buscó ocupar estos nichos lucrativos ${ }^{47}$.

El postfordismo trató de vivir con la corriente de saturación debido a la economía basada en las prácticas fordistas y la selectividad; de ahí la gran variedad de tipos y tamaños que se ofrecen ${ }^{48}$. Por lo tanto, existe una creciente importancia de las pequeñas y medianas empresas, promoviendo el intercambio, la subcontratación y otras relaciones interdependientes.

Con la reducción de los márgenes de beneficios, los empresarios buscaron "flexibilizar" las relaciones laborales, con el objetivo de recuperar el óptimum de la rentabilidad. Como ya se ha señalado, la rigidez ha contribuido al declive del modelo fordista de acumulación y la salida encontrada, entre otras cosas, fue atacar el contracto de trabajo.

La relación rígida ha experimentado un cambio importante, en que se desmanteló el modo de regulación (el Welfare State) poco a poco. La estabilidad del empleo se vio socavada, aprovechando el debilitamiento del poder sindical y el excedente de mano de obra, debido a la crisis ${ }^{49}$.

\footnotetext{
47 M. Boddy. Reestruturação Industrial, Pós-Fordismo e Novos Espaços Industriais, In: Reestruturação-Tendências e Desafios, Rio de janeiro, Nobel/IUPERJ,1990, p. 46.

${ }^{48}$ Op. cit., p. 41.

${ }^{49}$ Ver D. Harvey, Op., cit., p.143.
} 
El trabajo de tipo regular fue sustituído por trabajo temporales parciales y por los subcontratistas. Si en el fordismo, el trabajador no participa en el proceso de fabricación, en el postfordismo ocurrió lo contrario: fue reagrupado lo que en el taylorismo fue dicotomizado, es decir, los aspectos manual e intelectual del trabajo. ${ }^{50}$

\subsection{1 - Asia como un adversario competitivo}

La crisis fordista causó, ccomo se ha mencionado anteriormente, la necesidad de buscar ventajas competitivas y de localización que superasen la caída de los beneficios. El alto costo de la mano de obra y la legislación ambiental estricta, por ejemplo, eran componentes importantes para la caída de la rentabilidad. La realidad encontrada por los empresarios para superar este problema era muy difícil de resolver dentro de las sociedades capitalistas centrales occidentales.

El alto nivel de politización y organización sindical había vuelto el movimiento obrero extremadamente fuerte y unido en defensa de las garantías keynesianas, principalmente en Europa. Si la salida de la caída de la rentabilidad era la disminución de los costos, era necesario encontrar una manera de poner en práctica esta medida. El postfordismo fue una de las salidas, pero, sin embargo, no llegó a todos los países europeos, haciéndose fuerte en Inglaterra de Margaret Thatcher y en el otro lado del Atlántico, los EE.UU. de Ronald Reagan.

Asia se ha convertido en una importante alternativa a la problemática del capitalismo occidental. Tomando el ejemplo de Japón ${ }^{51}$, el país se encontraba en el proceso de recuperación económica con la adopción de la tecnología en el proceso de producción y las condiciones sindicales más favorables al capital

\footnotetext{
${ }^{50}$ Ver D. Leborgne \& A. Lipietz, Op. cit., p.26.

${ }^{51}$ Al mismo tiempo, Japón entró en un rápido crecimiento económico desde 1960, alcanzó un máximo de economía capitalista segundo y tercero en el mundo después de la Unión Soviética en la década de 1980. Con énfasis en la alta tecnología y la producción manufacturera, los japoneses se convirtió principales competidores estadounidenses.
} 
que en el Occidente. Sin una unión sindical comparable a los europeos, fue posible lograr una mayor rentabilidad.

En el lado socialista, las transformaciones fueron verificadas a través del desarrollo de la Revolución Cultural ${ }^{52}$ en China, que causaria un impacto significativo en la economía capitalista mundial en las décadas siguientes. El fin de la Revolución Cultural se convirtió en una posibilidad de los países occidentales resolveren a su problema (caída de la rentabilidad) a partir de la década de 1980, debido a las transformaciones sociales y económicas que se han producido en China.

Después de la muerte de Mao Zedong en 1976, China entró en un proceso de transformación social y económica, consolidada desde 1978 bajo el liderazgo de Deng Xiaoping. La lejanía del país de la órbita soviética a partir de la década de 1960 llevó a la aproximación del gigante rojo con el Occidente todavía bajo el liderazgo de Mao Zedong ${ }^{53}$.

A finales de 1970, la nueva dirección del Partido Comunista lanzó el Programa de las Cuatro Modernizaciones (agricultura, industria, ciencia y tecnología y la defensa nacional), con el objetivo de promover el desarrollo económico y social del país, frente a una nueva realidad geopolítica: su posición autónoma dentro del bloque socialista y, a veces, haciendo oposición a la URSS.

\footnotetext{
${ }^{52}$ Diferencias entre las alas reformista y conservadora del Partido Comunista. Deng Xiaoping es uno de los principales exponentes reformistas. Para contrarrestar esta influencia, los conservadores provocaran un retroceso político y económico, el cierre del país al contacto con el exterior y perseguir a los reformadores. La llamada Revolución Cultural (1966-1976) llega a su fin con la muerte de Mao Zedong en 1976.

${ }^{53}$ El conflicto chino-soviético tiene como telón de fondo las diferencias ideológicas en torno al modelo comunista que se deben seguir y se expandió por el mundo. El "voluntarismo" chino fue criticado por el Kremlin y la ausencia de "las acciones para la construcción del comunismo a nivel mundial" por los soviéticos no fue aceptada por los líderes en Beijing. Así, en 1969, los dos países entraron en fricción militar por una isla en el río Ussuri, llamada por los soviéticos de Damansky y por los chinos de Zhenbao, una región de frontera. Con la afirmación de que había sido atacado inicialmentee, las dos naciones están en guerra, conflicto que causó la muerte (datos no oficiales) entre 100-600 chinos y 58 soviets.
}

En 21/02/1972 el entonces presidente de EE.UU. Richard Nixon fue recibido por el líder Mao Zedong de China, convirtiéndose en el primer líder de EE.UU. a visitar la República Popular de China. El hecho fue destacado en el contexto internacional de la Guerra Fría. Las relaciones entre los dos países, desde entonces, sufrió un gran desarrollo. 
Los líderes de la era post-Mao tuvieron como imperativo promover el desarrollo industrial del país y eran necesarias inversiones y tecnología. En el lado occidental, China se presenta como una importante área de oportunidad. Las inversiones occidentales serían importantes para la creación de un parque industrial y para la transferencia de tecnología que podría transformar a China en las décadas siguientes.

Con el acercamiento al Occidente desde 1978, China se ha convertido en un importante proveedor de mano de obra para el desarrollo de productos americanos y europeos, que buscan salidas para la mejora de los costos de producción generados por el fordismo y por la inflación de los años 1970. La creación de Zonas Económicas Especiales (ZEE) para acoger las industrias extranjeras y facilitar la producción para la exportación fue uno de los grandes logros de los lideres chinos en la era Deng Xiaoping.

Sin embargo, el crecimiento y el dinamismo de China superó las mejores expectativas de los analistas e investigadores de todo el mundo. Los chinos lograron en las últimas décadas crear su propio mercado, crear sus propios negocios y exportar sus propios productos, convirtiéndose en un país de gran importancia dentro del sistema-mundo capitalista (ver Cuadro 23, Anexos). Este dinamismo rivalizaba con los países capitalistas centrales.

Entre 1980 y 2004, el crecimiento real del PIB chino ha promediado $9,5 \%$, convirtiendo al país en el sexto lugar en la economía mundial ${ }^{54}$. Desde entonces, la fortaleza del crecimiento chino puede ser verificada a través de su participación en el comercio mundial. En 1980 su participación fue 1\% y en la actualidad se sitúa en el $6 \%{ }^{55}$. Un estudio más detallado sobre la ascensión de Asia está disponible en los libros Adam Smith em Pequim e llusões do Desenvolvimento (capítulo "A Ascensão do Leste Asiático: um Milagre ou Muitos?”) de Giovanni Arrighi.

\footnotetext{
54 "O Crescimento Econômico da China". Federal Reserve Bank of Atlanta. $<$ http://www.frbatlanta.org/pubs/econsouth/05q2portugues_o_crescimento_. cf> Acessado em 28/12/2011. Ver também Anexos.

${ }^{55}$ Ibidem.
} 
Incluso en la década de 1980, la economía japonesa, con su gran crecimiento favoreció la expansión económica en Asia a introducir los países en el proceso de industrialización. El "derrame" de su economía, es decir, la necesidad de mano de obra y espacio, hizo con que nuevos países fueran beneficiados por la lógica capitalista.

Los japoneses trasladaron parte de su producción a países como Corea del Sur, Hong Kong, Singapur y Taiwán, con el objetivo de obtener mano de obra más barata, terrenos con un bajo costo y legislación laboral y ambiental menos rígida. Al igual que con los chinos a finales de 1990, países como Corea del Sur se han convertido en competidores globales para producir y desarrollar sus propias marcas en el mercado mundial.

Como podemos ver, la potencia asiática es un ejemplo de los desafíos que enfrentan los Estados Unidos para mantener su hegemonía en el campo económico.

\section{4 - La Pérdida de la Hegemonía}

Desde el punto de vista histórico, la hegemonía de EE.UU. comenzó con la recesión mundial de 1873, cuando la economía creció fuertemente, mientras que la economía británica entró en una inflexión. Entre 1873 y 1914, por ejemplo, los EE.UU. y Alemania se convirtieron en los principales productores de acero y productos químicos, lo que demuestra la fortaleza industrial de la economía de los EE.UU. La búsqueda por la hegemonía económica y/o militar se convirtió en un proceso natural. Arrighi señala que:

"Um estado dominante exerce uma função hegemônica quando lidera o sistema de estados numa direção desejada e, com isso, é percebido como buscando um interesse geral. É esse tipo de liderança que torna hegemônico um estado dominante" ${ }^{\text {"56 }}$.

${ }^{56}$ Arrighi, O Longo Século XX, p.29. 
La política exterior de Washington en la segunda mitad del siglo XIX trató de establecer su dominio sobre su periferia inmediata, a saber, América Central y el Caribe y, posteriormente, aumentar su influencia en América del Sur. Además de evitar la influencia de los europeos a través de la Doctrina Monroe, los EE.UU. aseguró su influencia económica y política en las Américas.

La Segunda Guerra Mundial permitió a los EE.UU. influir decisivamente en el sistema internacional. El post-conflito confirió una posición privilegiada a los norteamericanos porque no habían sufrido directamente los efectos catastróficos de la guerra. Su territorio no habia sufrido ningún daño, a diferencia de Europa y Asia.

La economía de EE.UU. pudo mantener su ritmo de producción en gran parte intacto durante la guerra, mientras que se convirtió en un importante proveedor de los bienes industriales y de créditos a Europa.

Con la derrota del nazismo, el comunismo se convirtió en el principal obstáculo a la hegemonía de EE.UU. en el ámbito internacional. La conversión de China al comunismo en 1949, Corea del Norte en 1950 y Vietnam en 1975, fueron los grandes golpes a la economía-mundo capitalista en Asia. Por no hablar de Europa Oriental, bajo el régimen soviético desde 1945.

Sin embargo, su papel en la reconstrucción de Japón y Europa Occidental, por ejemplo, permitió a los estadounidenses encontrar lagunas importantes para mantener al comunismo lejos de sus principales aliados. La contención del comunismo en Asia era en su mayor éxito. Pero las consecuencias del éxito de este proceso serían perjudiciales con el tiempo, especialmente en el aspecto económico.

Según Wallerstein, el éxito de los EE.UU. en el período de postguerra como una potencia hegemónica está causando su propia caída:

"O sucesso dos EUA como potência hegemônica no período do após-guerra criou as condições para que a sua pópria hegemonia fosse minada. Este processo pode ser capturado em quatro 
símbolos: a guerra do Vietnã, as revoluções de 1968, a queda do Muro de Berlim em 1989 e os ataques terroristas de setembro de 2001. Cada símbolo acresce ao anterior, culminando na situação em que os EUA se encontram hoje: uma superpotência solitária à qual falta um verdadeiro poder, um líder mundial que ninguém segue e poucos respeitam, e uma nação perigosamente à deriva, imersa em um caos global que não pode controlar" ${ }^{57}$.

Wallerstein ofrece una visión de la hegemonía en el sistema mundial actual, basado en la perspectiva de ampliar el factor de competencia como creador de "rivalidades" que podrían causar los "Ciclos de la hegemonía." La expansión de la dinámica capitalista promovería tales ciclos, como se puede ver en la Figura 3.

Figura 3

\begin{tabular}{|c|c|c|c|c|}
\hline \multicolumn{5}{|c|}{ WALLERSTEIN'S HEGEMONIC CYCLE } \\
\hline RIVALRY & & HEGEMONY & & RIVALRY \\
\hline $\begin{array}{l}\text { Competitive } \\
\text { expansion }\end{array}$ & $\begin{array}{l}\text { Concentration of } \\
\text { productive, commercial } \\
\text { \& financial competitive } \\
\text { edge in particular state } \\
\text { (hegemony) }\end{array}$ & $\begin{array}{l}\text { Economic and political } \\
\text { consolidation of } \\
\text { hegemony } \\
\text { Global liberali } \\
\text { world war }\end{array}$ & $\begin{array}{l}\text { Spread of } \\
\text { technological } \\
\text { expertise outside } \\
\text { the state's } \\
\text { domains } \\
\text { Increase in the } \\
\text { incomes of the } \\
\text { hegemonic state's } \\
\text { workers and } \\
\text { cadres }\end{array}$ & $\begin{array}{r}\text { Competitive } \\
\text { expansion }\end{array}$ \\
\hline
\end{tabular}

${ }^{57}$ O Declínio do Poder Americano. Rio de Janeiro, Editora Contraponto, p. 25, 2004. 
Los cuatro eventos mencionados por Wallerstein representarían a cada momento lo que sería el declive del poder estadounidense, "el pozo del águila".

El fracaso de Washington en Indochina marcó un cambio en la dimensión militar del país. Como principal rival de la URSS y con capacidad nuclear considerable, el país no tuvo éxito en la lucha contra el movimiento de liberación nacional de los vietnamitas. En cambio, sucumbió a las tácticas de guerrilla de un ejército creado bajo bases de campesinos con capacidad militar de baja sofisticación y tácticas de guerra asimétricas, dirigido por el legendario General Giap. La derrota militar en Vietnam tuvo un alto costo en vidas, demostrando que la mayor potencia del mundo no era invencible.

Las rebeliones estudiantiles de 1968 condujeron a la aparición de los movimientos de contracultura en la sociedad capitalista, que repudió la lógica militarista y ideológica de la disputa Capitalismo X Socialismo, preconizada por Washington. A finales de 1960, los bloques ideológicos mostraron signos de saturación por no presentar propuestas concretas para superar la desigualdad económica, social y política

En el lado capitalista, muchos países de todo el mundo vivían o viven bajo regímenes dictatoriales de derecha apoyados por EE.UU. De este lado, el objetivo era impedir el avance comunista y/o las transformaciones sociales $y$ económicas en las estructuras arcaicas.

En el lado dirigido por la URSS, la promesa de la "liberación de la opresión capitalista", produjo régimenes de la fuerza que no difirieron mucho de regímenes de derecha capitalistas de todo el mundo. Las "democracias populares" basadas sobre el Trabajo y su enajenación, cuya plusvalía era apropiada para el Estado socialista, mantuvieron los trabajadores vinculados a la lógica irracional de la acumulación.

La represión de la Sublevación Húngara de $1956^{58}$ y la asfixia de su propia Primavera de Praga en $1968,{ }^{59}$ es un reflejo del fracaso del modelo

\footnotetext{
${ }^{58}$ Revuelta popular espontánea contra las políticas económicas impuestas por el gobierno de la República de Hungría y la Unión Soviética. El movimiento duro del 23/10 hasta 10/11 de 1956. La revuelta comenzó con una manifestación estudiantil que reunió a miles de personas ante el Parlamento húngaro, en el centro de Budapest. La noticia se propagó rápidamente y el desorden y la violencia estalló en la capital, provocando la caída del gobierno. Un nuevo
} 
soviético de organización social y económica. No es muy útil utilizar la dicotomía Capitalismo X Socialismo por los EE.UU. o la URSS para mantener y justificar su control sobre su bloque ideológico por todos los medios legales e ilegales.

Otra señal de la caída reportada por Wallerstein de la hegemonía de EE.UU. fue el fin del bloque socialista en 1989, y en 1991 de la propia URSS, que desmanteló la lógica de la Guerra Fría que había generado una "zona de confort" de la política exterior de Washington en el cual todos los medios eran permitidos para mantener su hegemonía. Sin la Guerra Fría, el control ideológico de los EE.UU. ha perdido sentido y los países fueron capaces de se "liberar" y trazar su política exterior sin depender del carácter ideológico del enemigo comunista.

El ejemplo más reciente de probar la decadencia hegemónica estadounidense serían los ataques del 2001, lo que demuestra que la nación más poderosa del mundo no estaba a salvo de los efectos de sus acciones beligerantes en relación a la geopolítica internacional, por ejemplo, el apoyo irrestricto a Israel contra los palestinos en el Medio Oriente.

Las acciones del gobierno de George W. Bush después de los ataques del 11 de septiembre representó la disminución de la aceptación internacional de los EE.UU. como una nación defensora de los "valores universales", tales como la democracia y los derechos humanos. Lo que contribuyó a esta situación fue el desarrollo de un discurso belicoso contra los "enemigos" de los EE.UU. a través del documento de La Estrategia de Seguridad Nacional de los Estados Unidos (2002), conocida como la Doctrina Bush, que "permite" a los

gobierno se formó, los presos políticos fueron puestos en libertad, mientras que las personas vinculadas al gobierno anterior fueron ejecutadas. El 04/11/1956 tropas soviéticas invadieron el país en estado de shock contra los rebeldes. Más de 3.000 húngaros y soviéticos fueron asesinados durante el levantamiento. Una oleada de represión política tras el fin del conflicto y cualquier tipo de oposición política fue suprimida en Hungría.

59 Bajo el mando del reformista Alexander Dubček, Checoslovaquia trató de hacer una liberalización política y económica en contra de los principios defendidos por la URSS, que controla todo el este de Europa. El intento para hacer el régimen más flexible duró deste 05/01/1968 hasta 21/08/1968, cuando las tropas de la URSS y del Pacto de Varsovia invadieron el país. 
EE.UU. no tener en cuenta el derecho internacional y hacer uso de las "guerras preventivas".

Así la era Bush ha erosionado completamente la geocultura ${ }^{60}$ estadounidense bajo el punto de vista ideológico. De antiguos "defensores del mundo libre", los EE.UU. se asoció con la opresión y la tortura, un "villano global".

Dos aspectos de la decadencia de los EE.UU. pueden resumirse en el binomio gasto militar (en línea de crecimiento, a pesar del fin de la Guerra Fría) y el debilitamiento ideológico del sistema capitalista como defensor de una "sociedad libre", que conjuga demostrar este marco.

El hecho es que sin la vieja confrontación de la Guerra Fría, los EE.UU. estaban solos en el escenario global y, para ejercer su poder, ahora muy cuestionado, tuvieron que utilizar el hard power de una manera más incisiva.

Lógicamente no podemos defender la idea de un "fin del capitalismo" como en las líneas defendidas por los marxistas ortodoxos en la primera mitad del siglo XX. El proceso es complejo y tiene numerosas variables. Pero sí está ocurriendo bajo las bases hasta ahora demostradas.

Una variable importante es el campo económico, donde la decadencia estadounidense ha aumentado aún más desde 2008. La crisis en el mismo año se inició con la desregulación total en el sector financiero del país, ha contaminado a la economía mundial y ha causado la quiebra de muchos bancos estadounidenses y arruinado la vida de millones de trabajadores, no sólo en los EE.UU. pero también en Europa.

El hecho es que a través de un análisis más detallado de los factores que causaron la crisis financiera global, su salida fue una consecuencia de los incumplimientos en el pago de hipotecas en Estados Unidos. Las bajas tasas

\footnotetext{
${ }^{60}$ Segundo Wallerstein, "Géoculture [...] ce terme, crée par analogie avec celui de géopolitique, désigne des normes et des pratiques discursives largement reconnues comme légitimes au sein d'un système-monde. Dans ce livre, nous expliquons qu'une géoculture n'apparaît pas automatiquement avec l'émergence d'un système-monde, mais qu'elle doit être créée". Comprendre le Monde. Paris, La Découvert, p. 150, 2006.
} 
de interés y el crédito en exceso en el mercado de los EE.UU. eran una invitación para una mayor consumo en el país.

El estímulo para buscar financiamiento para la compra de la casa propia creó un boom inmobiliario, especialmente entre la población de más baja renta. Para financiar estos nuevos compradores, los bancos recadaron fondos en el mercado a través de la disposición de instrumentos financieros ligados a hipotecas de bienes inmuebles.

Por otra parte, las tasas de interés subieron de nuevo para luchar contra el avance de la inflación (véase el gráfico 1). Las altas tasas de interés provocaron un aumento en el valor de los pagos de la propiedad de la vivienda, ya que los precios de las casas comenzaron a caer. La morosidad aumentó y títulos que estaban respaldados por hipotecas perdieron valor.

\section{Gráfico 1}

\section{UNITED STATES INTEREST RATE}

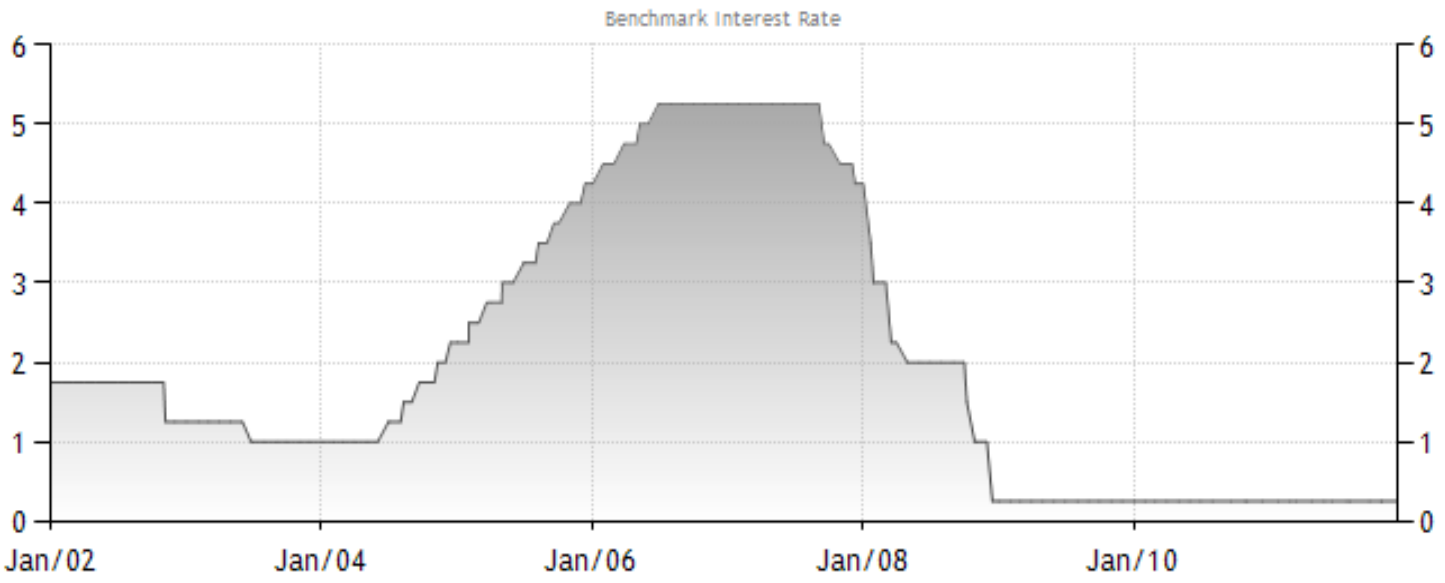

SOURCE: WWW.TRADINGECONOMICS.COM | FEDERAL RESERVE

En septiembre de 2008 se verificaron pérdidas billonarias para los bancos y instituciones financieras, como el banco estadounidense Lehman Brothers. El gobierno de EE.UU. inyecta dinero en el sistema financiero para evitar más quiebras bancarias o financieras. Al otro lado del Atlántico, los gobiernos de Alemania, Francia, España, Reino Unido y Portugal, entre otros países, también han anunciado ayuda billonaria a los bancos. 
Con este marco, la crisis de confianza en los mercados era inevitable y tuvo un impacto principalmente en la cantidad de dinero disponible en todo el mundo. Es decir, debido al temor de los impagos, los bancos no prestan más dinero. Así que para obtener préstamos, las empresas y los individuos también comenzaron a pagar un interés mucho más alto. El crédito más caro paralizó los planes de inversión de las empresas y también hizo que la población dejase de consumir.

Menos inversión significa también menor capacidad de expansión de las economías, porque las empresas ya no tienen como financiar su crecimiento. El resultado directo fue la reducción del empleo y, a su vez, la disminución de la capacidad de consumo de las personas. El escenario de crisis se mantuvo hasta 2011, con el aumento de los efectos de la crisis en países como Grecia, España, Portugal, Italia e incluso Francia.

El más emblemático es la simple disminución de investiment grade (grado de inversión) de la economía estadounidense por la agencia Stand \& Poor's (05/08/2011), de AAA a $A A+{ }^{61}$. Nada que significara un debacle económica, pero era la primera vez en la historia que los EE.UU. tuvieron su evaluación bajada (downgrade). Un indicador de que algo no está dentro de los estándares.

\footnotetext{
${ }^{61}$ AAA: Capacidad extremadamente fuerte para honrar compromisos financieros. Rating más alto; AA: Capacidad muy fuerte para honrar compromisos financieros; A: Fuerte capacidad para honrar compromisos financieros, pero es de alguna manera suscetíble a las condiciones económicas adversas y a los cambios circunstanciales; BBB: Capacidad adecuada para honrar compromisos financieros, pero más suscetíble a las condiciones económicas adversas; BBB-: Considerado el nível más bajo de la categoria de grado de inversión por los participantes del mercado; BB+: Considerado el nível más alto de categoria de grado especulativo por los participantes del mercado; BB: Menos vulneráble en el corto plazo, pero enfrenta actualmente grande suscetibilidad a las condiciones adversas de negócios, financieras y económicas; $\mathbf{B}$ : Más vulneráble a las condiciones adversas de los negócios, financieras y económicas, pero actualmente presenta capacidad para honrar compromisos financieros; CCC: Actualmente vulnerable y dependiente de condiciones favorábles de los negócios, financieras y económicas para honrar sus compromisos financieros; CC: Actualmente fuertemente vulnerable; C: Un pedido de quebra fue registrado o acción similar implementada, pero los pagos de las obrigaciones financieras siguen siendo realizados; D: Incumplimiento en sus compromisos financieros.
}

http://www.blogdoinvestidor.com.br/economia/o-que-significa-o-rebaixamento-dos-titulosamericanos/ Acessado em 13/011/2011. 
Wallerstein en un artículo titulado Vinte anos para mudar o mundo, declaró que ${ }^{62}$ :

(...) "A Standard \& Poor's reduziu o rating de crédito dos Estados Unidos de AAA para AA+, outro fato "inédito". Mas isso é uma ação relativamente leve. A agência equivalente na China, Dagong, já reduziu a credibilidade dos Estados Unidos para A+ em novembro, e agora para A-. O economista peruano Oscar Ugarteche declarou que os Estados Unidos tornaram-se uma "república de bananas". Ele diz que o país "escolheu a política da avestruz, como modo de não perder as esperanças [de melhora]". Em Lima, nessa última semana, o encontro dos ministros de Finanças dos países sul-americanos discutiu medidas urgentes para isolar a região dos efeitos do declínio econômico dos Estados Unidos".

Este escenario de debilitamiento económico y geopolítico está permitiendo los "huecos" necesarios para el surgimiento de desafíos a la hegemonía de EE.UU. El caso de Venezuela es un importante ejemplo de este fenómeno.

17/08/2011 <http://www.outraspalavras.net/2011/08/17/vinte-anos-para-mudar-o-mundo/> Acessado em 04/01/2012. 
3 - MOVIMIENTOS ANTISISTÉMICOS EN EL SISTEMAMUNDO 


\section{1 - Movimientos Antisistémicos como una alternativa en el Sistema-Mundo Moderno}

En la década de 1970, I. Wallerstein acuñó el término "movimiento antisistémico" para unir dos tipos de movimientos históricos y populares que se originaron en la segunda mitad del siglo XIX, pero al mismo tiempo, rivales: los "sociales" y los "nacionales"64.

Los "movimientos sociales" estarían vinculados a los partidos socialistas y sindicatos, cuyo objetivo era intensificar la lucha de clases dentro de cada Estado. Los "movimientos nacionales", por otro lado, se incluyeron inicialmente en la construcción de los Estados-nacionales, por ejemplo, el caso de Italia (siglo XIX) y, más tarde, en el proceso de descolonización de la posguerra, con el objetivo, de parte de las naciones africanas y asiáticas, de la búsqueda de la independencia en relación a las metrópolis europeas.

En Antysistemics Movements ${ }^{65}$, los movimientos antisistémicos se habían organizado en cinco aspectos hasta la década de 1960:

"First, opposition to oppression has been a constant of the modern world-system. Nevertheless, before the middle of the nineteenth century this opposition was short-term and "spontaneous, and as such largely ineffectual at the level of the system. This innovation had important repercussions on the dynamic of the world capitalist system $(\ldots)^{n, 66}$.

Según Arrighi, Hopkins y Wallerstein, el primer aspecto es la constatación de que la opresión como una forma de control efectivo de los movimientos antisistémicos estaba perdiendo su efectividad en el proceso

\footnotetext{
${ }^{64}$ O Declínio do Poder Americano. Rio de Janeiro, Contraponto, p. 266, 2004.

${ }^{65}$ Arrighi, Giovanni et alli. Antisystemics movements. New York, Verso, 1989.

${ }^{66}$ Ibidem, pp. 29-30.
} 
político del sistema-mundo capitalista a finales del siglo XIX y principios del siglo $X X$.

El aspecto central fue fundado en los siglos XIX y XX y en la perspectiva marxista del conflicto entre las clases sociales. Los movimientos sociales estarían dispuestos a "sustituir al capitalismo por el socialismo"67.

El tercer aspecto se basa en la idea de que los movimientos sociales iban a controlar el Estado. El cuarto aspecto constituyente de los movimientos contrahegemónicos se produce debido a la falta de políticas públicas en los Estados menos desarrollados, el antiguo "Tercer Mundo"68.

Y por último, el quinto pilar: la inclusión social de las clases desfavorecidas, situadas en el propio sistema, no garantizaba las condiciones mínimas para la supervivencia digna para estas personas. Todos los pilares serían un resultado de los factores siguientes:

"(a) a reduced capacity of First and Second World states to police the Third World;

(b) a reduced capacity of dominant status groups in core countries (older generations, males, "majorities") to exploit/ exclude subordinate status groups (younger generations, females, "minorities");

(c) a reduced capacity of managerial strata to enforce labor discipline in the workplace and associated global search for "safe heavens" of 3 such discipline;

(d) a reduced capacity of states to control their respective civil societies and associated crisis of "bourgeois" (...)"69.

\footnotetext{
${ }^{67}$ Ibidem.

${ }^{68}$ Ibidem, pp.103-106.

${ }^{69}$ Ibidem.
} 
Dentro de una perspectiva macrosistémica, los países centrales no tienen la capacidad de ayudar a los países periféricos hacia el crecimiento económico, mientras que las elites de los países menos desarrollados, por otro lado, no reducirían las tensiones internas que resultan de las desigualdades sociales ${ }^{70}$. Ambos movimientos, nacionales y sociales, entraron en crisis a finales de 1960.

La revolución mundial de 1968 fue un hito importante en la configuración de los nuevos movimentos antisistémicos como dice Wallerstein ${ }^{71}$. Los objetivos perseguidos por los movimientos en el período anterior (la revolución socialista, por ejemplo), no ocurrieron. Al contrario, se demostró un proceso de burocratización de los partidos socialistas y la eliminación de los ideales revolucionarios en casi todo el mundo.

Los movimientos antisistémicos "clásicos", por así decirlo, serían reemplazados por una nueva perspectiva a partir de 1968. Para Wallerstein, emergieron cuatro intentos de movimientos antisistémicos. Ellos fueron: el "maoísmo", entre 1960 y 1970, los "nuevos" movimientos sociales ${ }^{72}$, las organizaciones de derechos humanos y, a finales de 1990, los movimientos anti-globalización.

Analisando a este último movimiento, las protestas en Seattle en 1999 en la reunión de la OMC, se convirtieron en un hito en la construcción de un Frente antisistémico al reunir, bajo una misma bandera, los movimientos sociales de diversos matices $\mathrm{y}$, al mismo tiempo, los grupos de operaciones local y transnacional.

El factor unificador fue la oposición al neoliberalismo y sus efectos sociales adversos que afectaron a países de todo el mundo, desde Europa hasta América Latina. A pesar de ello, cada grupo mantiene sus especificidades inmediatas.

\footnotetext{
${ }^{70}$ lbidem.

${ }^{71}$ O Declínio do Poder Americano. Rio de Janeiro, Contraponto, p. 271, 2004.

${ }^{72}$ Verdes, ambientalistas, feministas, minorias raciales y étnicas. Ibidem, p. 272.
} 
La unificación de los movimientos bajo la bandera neoliberal provocó la creación del Foro Social Mundial, que contó con un gran número de participantes desde entonces. Sin embargo, el FSM todavía carece de puntos organizativos y estratégicos que hacen la lucha contra los efectos del neoliberalismo más eficaz ${ }^{73}$.

Para Wallerstein, estaríamos viviendo en un tiempo de manifestaciones antisistémicas como resultado de la expansión de las contradicciones y tensiones del capitalismo a escala mundial. ${ }^{74}$. Por lo tanto, estas manifestaciones serían los "movimientos de liberación nacional, las insurgencias proletarias, las resistencias y desafíos de civilización, contraculturas" $[\ldots]^{75}$.

El sistema-mundo actual se encuentra, por lo tanto, en un proceso de transición debido a la crisis estructural del capitalismo. Tal crisis se traduciría en un período de "bifurcación y caos"76. Los movimientos antisistémicos muestran hoy metas bien dirigidas y, en este aspecto, dijo Carvalho

Desta forma, é possível constatar, a priori, que os movimentos antissistêmicos englobam atualmente, uma série de manifestações anti-hegemônicas, numa luta incessante contra o capital e o modelo neoliberal, visando à busca de alternativas para a construção de uma nova estrutura social e uma redefinição na arena econômica e política ${ }^{77}$.

Los movimientos antissistémicos, de micro o macro escalas, están frente a un escenario de crisis sistémica y una realidad importante para superar el actual sistema-mundo contemporáneo.

\footnotetext{
${ }^{73}$ Charles Pennaforte. Fragmentação e Resistência. Rio de janeiro, E-Papers, pp. 69-70, 2003.

${ }^{74}$ Carvalho, Giane Alves de. Os movimentos antissistêmicos: conjuntura de lutas ou impasses políticos ideológicos? In: Mediações. UFSC, v. 13, p. 216, Jan/Jun e Jul/Dez, 2008.

${ }^{75}$ Apud, Op. Cit.

${ }^{76}$ O Declínio do Poder Americano. Op. cit., p. 276.

${ }^{77}$ Ibidem, p. 216.
} 
Si por un lado los grupos sociales se organizan en torno a un "enemigo común", por ejemplo el neoliberalismo o la discriminación contra las minorías, se pudo comprobar la existencia de una perspectiva macro de los países que tienen una posición también antisistémica en el ámbito internacional, enfrentando la potencia hegemónica.

\section{2 - Las condiciones históricas para el surgimiento de Hugo Chávez: el fracaso del neoliberalismo}

Con el objetivo de facilitar la comprensión de nuestro análisis sobre la posición antisistémica de Venezuela, vamos a recapitular sobre la realidad histórica y económica del país y del continente en la década de 1990.

Las condiciones económicas experimentadas por Venezuela en esta década incitó a las contradicciones sociales y políticas que posibilitaron el surgimiento de Hugo Chávez y, posteriormente, la creación de su "socialismo del siglo XXI" y el comienzo de sus operaciones antisistémicas.

\section{3 - La Década Neoliberal}

La década de 1990 estuvo marcada por la implementación del proyecto neoliberal en toda América Latina. La elección de varios gobiernos conservadores e incluso de "izquierda", después del proceso de redemocratización en el continente, provocó la "conversión" de las diversas fuerzas políticas al credo neoliberal. Con este proceso, fue fácilmente aceitada la implementación de programas de "ajuste estructural" (PAE), desarrollados por el Consenso de Washington a finales de $1980^{78}$.

\footnotetext{
${ }^{78}$ El Consenso de Washington es un conjunto de medidas económicas formuladas en 1989 por el FMI, el Banco Mundial y el Departamento del Tesoro de los Estados Unidos. La base para la aplicación de las medidas fue un texto del economista John Williamson, del International Institute for Economy. El texto se convirtió em la política oficial del Fondo Monetario Internacional en 1990. El "recetario neoliberal" tiene que ser administrado en los países en desarrollo con graves problemas económicos, con miras a promover el "ajuste
} 
A través de las políticas económicas establecidas por el Fondo Monetario Internacional (FMI), el Banco Mundial y el Tesoro de los EE.UU., los gobiernos del continente colocaron en práctica los postulados del neoliberalismo, que sólo variaban en intensidad para cada país ${ }^{79}$. Sin embargo, los efectos fueron desastrosos para las economías latinoamericanas, especialmente para Venezuela, como dijo Steve Ellner ${ }^{80}$ :

"Venezuela's experience with free market reforms in the 1990s was as much a demonstration as anywhere in Latin America of the acute social conflict and political crisis engendered by neoliberalism and its failure to attract popular support".

El objetivo neoliberal era alcanzar el desarrollo económico del continente a través de una "modernización rápida". Eso haría las economías dinámicas y promovería el crecimiento.

En Washington DC, el análisis de los economistas fue que las economías latinoamericanas estaban "vinculadas" al modelo keynesiano, que no había funcionado, y al proteccionismo. Las deudas externas, por ejemplo, representarían esta situación.

Otro aspecto que se utilizó como parámetro "favorable" a la adopción de los preceptos neoliberales en la década de 1990 fue un estudio de Sachs e Warner ${ }^{81}$, que señaló una relación entre el crecimiento económico y la apertura

macroeconómico": disciplina fiscal, reducción del gasto público, reforma tributaria, tasas de interés del mercado; mercado cambiario, la apertura del comercio, la inversión extranjera directa, con la eliminación de las restricciones, la privatización de las empresas estatales, la desregulación (flexibilización de las leyes económicas y laborales) y la ley de propiedad intelectual.

79 El canadiense Michel Chossudovsky hace un resumen detallado de las reformas estructurales en el mundo en su libro A Globalização da Pobreza - Impactos das reformas do FMI e do Banco Mundial.

${ }^{80}$ Rethinking Venezuelan politics. Boulder, Lynne Rienner Publishers, p. 89, 2008

${ }^{81}$ SACHS, Jeffrey \& WARNER, Andrew. (1995) Economic reform and the process of global integration. Brookings Papers on Economic Activity, 1: 1-118. Apud ARBIX, Glauco. Da liberalização cega dos anos 90 à construção estratégica do desenvolvimento. Tempo Social; Rev. Sociol. USP, S. Paulo, 14(1): 1-17, maio de 2002. <http://www.scielo.br/pdf/ts/v14n1/v14n01a01.pdf> 
de la economía. El resultado no podría ser más diferente: cuanto mayor sea la apertura, mayor será la probabilidad de crecimiento económico debido a que:

"Economias abertas são capazes de provocar uma convergência de renda mais rapidamente do que as economias fechadas, uma vez que a mobilidade internacional de capital e tecnologia pode acelerar a transição para uma condição mais estável e equilibrada da renda" ${ }^{2}$.

Sobre la base de estos estudios, se formularon políticas que "resolverían" los problemas económicos que actúan en dos puntos centrales: la desregulación y la apertura de la economía. Como se ha señalado Arbix, citando Sachs y Werner:

(...) "A mecânica dessas sugestões residia na busca da recuperação da eficiência econômica - perdida com o envelhecimento das políticas protecionistas - e, dessa forma, do crescimento sustentado, deixando para os mercados, mais do que para os governos, a definição da melhor alocação dos recursos. Sem os constrangimentos estatais do passado, a eficiência desse processo de investimento estaria garantida pela decisão autônoma dos agentes econômicos individuais, sendo que estaria reservado ao setor público a salvaguarda das regras do novo jogo, ou seja, a manutenção da estabilidade macroeconômica"³.

En términos prácticos, el objetivo era mucho más que "desarrollar" las economías de América Latina. El verdadero interés era el de facilitar la inversión en el continente a través de las condiciones favorables al capital internacional y una mayor rentabilidad para estos inversionistas.

\footnotetext{
${ }^{82}$ Ibidem.

${ }^{83}$ Ibidem, p.8.
} 
Sin embargo, la "receta para el éxito" resultó ser un grande engaño, como testificó el FMl y el Banco Mundial ${ }^{84}$ :

\begin{abstract}
"Embora tenham sido feitos vários estudos sobre o assunto na década passada, não se pode dizer com certeza se os programas 'funcionaram' ou não [...]. Tomando por base os estudos existentes, certamente não se pode afirmar que a adoção dos programas patrocinados pelo Fundo levou a uma melhora no desempenho da inflação e do crescimento. De fato, descobre-se com frequência que os programas estão associados a um aumento da inflação e a uma queda da taxa de crescimento".
\end{abstract}

La efectividad de los principios del Consenso de Washington no se ha demostrado en la práctica, ya que las economías de América Latina no han logrado resolver sus problemas estructurales, por lo contrario, solo servieron para aumentar drásticamente los males sociales. Una vez más, demuestra Chossudovsky ${ }^{85}$ :

"As implicações sociais dessas reformas (entre elas, seu impacto sobre a saúde, a educação, os direitos das mulheres e o ambiente) têm sido fartamente documentadas. Fecham-se escolas e demitem-se professores, devido à falta de verbas; no setor de saúde há um colapso geral, mas medicinas curativas e preventivas, em consequência da falta de equipamentos médicos e suprimentos, das péssimas condições de trabalho e dos baixos salários pagos aso seus profissionais". (...)

\footnotetext{
${ }^{84}$ Michel Chossudovsky. A Globalização da Pobreza - Impactos das reformas do FMI e do Banco Mundial. São Paulo, Editora Moderna, p. 60, 1999.

${ }^{85}$ Ibidem, p.61
} 
La pobreza en América Latina se mantiene sin cambios significativos entre 1980 y 1999, según la CEPAL. En términos porcentuales, la pobreza aumentó de 34,7\% a 35,3\%, lo que refleja las grandes desigualdades de renta en el continente: el $40 \%$ más pobres mantienen sus condiciones, mientras que el $10 \%$ más ricos duplicaron su riqueza.

Las siguientes tablas dan una idea de los resultados alcanzados por la era neoliberal en América Latina. Permiten la conclusión de que el crecimiento económico, como la única base para la superación de las desigualdades sociales, no ocurrió. En la práctica, por cada punto porcentual de crecimiento del PIB en la década de 1990, la pobreza se redujo en un 0,12\%. En la década anterior, el porcentaje fue del $0,88 \%{ }^{86}$.

El cuadro 1 muestra que no hubo una reducción significativa de la pobreza en la década de 1990 con los intentos de "dinamismo económico" propuesto por Washington. En el período indicado, el nivel de pobreza e indigencia se incrementaron principalmente entre 1980 y 1990.

\section{Cuadro 1}

Incidencia de la Pobreza y de la Indigencia en América Latina - 1980-2006

\begin{tabular}{|c|c|c|c|c|}
\hline \multirow{2}{*}{ ANOS } & \multicolumn{2}{|c|}{ POPULAÇAOPOBRE } & \multicolumn{2}{c|}{ POPULAÇÄOINDIGENTE } \\
& Percentual & Pessoas & Percentual & Pessoas \\
\hline \hline 1980 & 40,5 & 136,0 & 18,6 & 62,4 \\
\hline 1990 & 48,3 & 200,2 & 22,5 & 93,4 \\
\hline 1994 & 45,7 & 201,5 & 20,8 & 91,6 \\
\hline 1997 & 43,5 & 203,8 & 19,0 & 88,8 \\
\hline 1999 & 43,8 & 211,5 & 18,5 & 89,4 \\
\hline 2000 & 42,5 & 207,1 & 18,1 & 88,4 \\
\hline 2001 & 43,2 & 213,9 & 18,5 & 91,7 \\
\hline 2002 & 44,0 & 221,4 & 19,4 & 97,4 \\
\hline 2003 & 44,3 & 226,0 & 19,2 & 98,0 \\
\hline $2004(2)$ & 42,0 & 217,0 & 16,9 & 90,0 \\
\hline $2005(2)$ & 39,8 & 209,0 & 15,4 & 88,0 \\
\hline $2006(3)$ & 38,5 & 205,0 & 14,7 & 79,0 \\
\hline
\end{tabular}

FONTE: CEPAL (2006). Panorama Social de América Latina 2006.

(1) Pessoas em domicílios em situação de pobreza; inclui a população em situação de indigência.
(2) Estimativa correspondente a 19 países da região.

(3) Dados estimados

${ }^{86}$ Panorama Laboral 2002 apud Proposta de Constituição de um Fundo Interamericano de Promoção do Trabalho Decente.

<http://portal.mte.gov.br/data/files/FF8080812BA5F4B7012BABB9926D2506/PropostadeFundo .pdf> Acessado em 10/04/2011. 
En em cuadro 2, es posible tener una noción importante de la concentración de renta en el continente y en particular en los países seleccionados. La concentración de renta se mantuvo intacta entre los más pobres. Mientras ocurre lo contrario con el 10\% de la población más rica.

\section{Cuadro 2}

Participación de los estratos sociales en la distribución de ingreso total en América Latina 1990-2005

\begin{tabular}{|c|c|c|c|c|c|c|}
\hline \multirow[b]{2}{*}{ PaISES } & \multirow[b]{2}{*}{ Anos } & \multicolumn{4}{|c|}{ PARTICIP AÇZO NA READA T OTAL } & \multirow{2}{*}{$\begin{array}{r}\text { RELAÇZODE } \\
\text { RENDAMLDLA } \\
\text { PER CAPITA } \\
\text { AID }\end{array}$} \\
\hline & & 40\% Mais Pobres & $30 \%$ Seguintes $(\mathrm{B})$ & $\begin{array}{l}20 \% \text { Anterior aos } \\
10 \% \text { Mais Ricos (C) }\end{array}$ & $\begin{array}{r}10 \% \text { Mais } \\
\text { Ricos } \\
\text { (D) }\end{array}$ & \\
\hline \multirow{4}{*}{ Argentina (1) $^{1)}$} & 1990 & 14,9 & 23,6 & 26,7 & 34,8 & $13, \bar{x}$ \\
\hline & 1999 & 15,4 & 21,6 & 26,1 & 37,0 & 16,4 \\
\hline & 2002 & 13,4 & 19,3 & 25,3 & 42,1 & 20,0 \\
\hline & 2004 & 16,0 & 22,3 & 24,5 & 37,3 & 15,5 \\
\hline \multirow{4}{*}{ Brasil } & 1990 & 9,5 & 18,6 & 28,0 & 43,9 & 31,2 \\
\hline & 1999 & 10,1 & 17,3 & 25,5 & 47,1 & 32,0 \\
\hline & 2001 & 10,2 & 17,5 & 25,6 & 46,8 & 32,2 \\
\hline & 2004 & 11,7 & 18,7 & 25,6 & 44,1 & 26,6 \\
\hline \multirow{3}{*}{ Chile } & 1990 & 13,2 & 20,8 & 25,4 & 40,7 & 18,2 \\
\hline & 2000 & 13,8 & 20,8 & 25,1 & 40,3 & 18,7 \\
\hline & 2003 & 13,8 & 20,8 & 25,7 & 39,7 & 18,6 \\
\hline \multirow{4}{*}{ Colômbia(2) } & 1994 & 10,0 & 21,3 & 26,9 & 41,8 & 26,8 \\
\hline & 1999 & 12,3 & 21,6 & 26,0 & 40,1 & 22,3 \\
\hline & 2002 & 12,3 & 22,4 & 26,5 & 38,8 & 24,1 \\
\hline & 2004 & 12,1 & 22,0 & 26,0 & 39,9 & 25,1 \\
\hline \multirow{4}{*}{ Equador ${ }^{31}$} & 1990 & 17,1 & 25,4 & 27,0 & 30,5 & 11,4 \\
\hline & 1999 & 14,1 & 22,8 & 26,5 & 36,6 & 17,2 \\
\hline & 2002 & 15,4 & 24,3 & 26,0 & 34,3 & 15,7 \\
\hline & 2004 & 15,0 & 24,5 & 27,5 & 33,0 & 15,2 \\
\hline \multirow{3}{*}{ Guatemala } & 1989 & 11,8 & 20,9 & 26,8 & 40,6 & 23,5 \\
\hline & 1998 & 143 & 21,6 & 25,0 & 39,1 & 20,4 \\
\hline & 2002 & 14,2 & 22,2 & 26,8 & 36,8 & 18,4 \\
\hline \multirow{4}{*}{ México } & 1989 & 15,8 & 22,5 & 25,1 & 36,6 & 17,2 \\
\hline & 2000 & 14,6 & 22,5 & 26,5 & 36,4 & 17,9 \\
\hline & 2002 & 15,7 & 23,8 & 27,3 & 33,2 & 15,1 \\
\hline & 2004 & 15,8 & 23,3 & 26,3 & 34,6 & 15,9 \\
\hline \multirow{3}{*}{ Peru } & 1997 & 13,4 & 24,6 & 28,7 & 33,3 & 17,9 \\
\hline & 2001 & 13,4 & 24,6 & 28,5 & 33,5 & 17,4 \\
\hline & 2003 & 149 & 23,7 & 27,9 & 33,6 & 15,6 \\
\hline \multirow{4}{*}{ Venezuela(t) } & 1990 & 16,7 & 25,7 & 28,9 & 28,7 & 12,1 \\
\hline & 1999 & 14,6 & 25,1 & 29,0 & 31,4 & 15,0 \\
\hline & 2002 & 14,3 & 24,9 & 29,5 & 31,3 & 14,5 \\
\hline & 2004 & 16,1 & 26,5 & 289 & 28,5 & 12,0 \\
\hline
\end{tabular}

FONTE: CEPAL (2006), Panorama Social 2006.

(1) Oito cidades principais e El alto.

(2) Total das zonas urbanas.

(3) Republica Bolivariana de Venezuela. 
En el cuadro 3, se observa principalmente en el período 1990-1999 una renta per cápita baja en relación al PIB, e incluso la variación negativa de la remuneración percibida por los trabajadores urbanos. Definitivamente, los experimentos centrados en los ajustes macroeconómicos no han dado los resultados esperados.

\section{Cuadro 3 \\ Evolución de algunos indicadores económicos en América Latina 1990-99 e 2000-03}

\begin{tabular}{|c|c|c|c|c|c|}
\hline PaÍSES & AHOS & $\begin{array}{l}\text { DOPIB PERCAPITA: } \\
\text { (taxa média anual de } \\
\text { variação) }\end{array}$ & $\begin{array}{l}\text { DESEMPREYO URBANO } \\
\text { Média Simples do Período } \\
(\%)^{(2)}\end{array}$ & 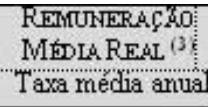 & 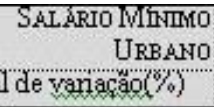 \\
\hline \multirow[t]{2}{*}{ Argentina } & $1990-99$ & 2,5 & 11,9 & 0,9 & 0,8 \\
\hline & $2000-05$ & 0,5 & 15,8 & 0,0 & 9,5 \\
\hline \multirow[t]{2}{*}{ Brasil } & $1990-99$ & 0,2 & 5,6 & $-1,0$ & $-0,4$ \\
\hline & $2000-05$ & 1,1 & 9,8 & $-2,8$ & 47 \\
\hline \multirow[t]{2}{*}{ Chile } & $1990-99$ & 4,6 & 7,6 & 3,5 & 5,9 \\
\hline & $2000-05$ & 3,2 & 8,8 & 1,6 & 3,3 \\
\hline \multirow[t]{2}{*}{ Colômbia } & $1990-99$ & 0,9 & 11,6 & 2,2 & $-0,4$ \\
\hline & $2000-05$ & 1,6 & 16,5 & 1,4 & 0,9 \\
\hline \multirow[t]{2}{*}{ Equador } & $1990-99$ & 0,3 & 9,4 & 5,3 & 0,9 \\
\hline & $2000-05$ & 3,1 & 10,8 & - & 3,3 \\
\hline \multirow[t]{2}{*}{ Guatemala } & $1990-99$ & 1,7 & 4,0 & 5,4 & $-9,8$ \\
\hline & $2000-05$ & 0,2 & 5,0 & $1,2^{7}$ & 3,2 \\
\hline \multirow[t]{2}{*}{ México } & $1990-99$ & 1,5 & 3,6 & 1,0 & $-4,7$ \\
\hline & $2000-05$ & 1,1 & $4,3^{3 s}$ & 2,6 & $-0,1$ \\
\hline \multirow[t]{2}{*}{ Peru } & $1990-99$ & 1,3 & 8,5 & $-0,8$ & 1,4 \\
\hline & $2000-05$ & 2,4 & 9,3 & 0,9 & 2,6 \\
\hline \multirow[t]{2}{*}{ Venezuela $(s)$} & $1990-99$ & 0,2 & 10,3 & $-4,0$ & $-3,0$ \\
\hline & $2000-05$ & 0,7 & 14,8 & -47 & 1,2 \\
\hline \multirow[t]{2}{*}{ América Latina "6 } & $1990-99$ & 1,1 & 7,7 & 1,0 & 2,3 \\
\hline & $2000-05$ & 1,1 & 10,3 & $-0,4$ & 3,1 \\
\hline
\end{tabular}

1) A partir do valor do PIB em dólares, a preços constantes de 1995; a cifra correspondente a 2003 é uma estimativa preliminar.

(2) No Chile, Guatemala, Nicarágua, República Dominicana e Venezuela se referem ao desemprego total nacional. Ademais, no espaço do período de 1990-1999 se considerou o espaço do tempo entre 1991 e 1999 para Cuba.

(3) Em geral, a cobertura desse índice é muito parcial; na maioria dos países, refere-se aos trabalhadores formais do setor industrial. A cifra correspondente de 2003 é uma estimativa preliminar, e o ano final para Bolívia e Guatemala é 2002.

(4) O ano inicial do período para a Nicarágua é 1992.

(5) República Bolivariana de Venezuela.

(6) Estimativas realizadas a partir de 20 países da região.

(7) Corresponde ao período de 1998-2004.

(8) A partir del año 2000 se utilizó una nueva metodología para medir la tasa de desempleo, no comparable con la de años anteriores.

En la década de 1990, el crecimiento en América Latina (incluyendo el Caribe) fue, en promedio, superior al crecimiento global: aumento de $3,3 \%$ por año, mientras que el planeta estaba en el $2,4 \%{ }^{87}$.

${ }^{87}$ Ibidem. 
En el cuadro 4, el crecimiento del PIB en la década de 1990 presentó un resultado razonable. Sin embargo, a pesar del "crecimiento" de la economía del continente haber sido más alto, esto no representa mejora de las condiciones de vida de millones de latinoamericanos.

\begin{tabular}{|c|c|c|c|c|c|c|c|c|c|}
\hline \multicolumn{10}{|c|}{ Cuadro 4 - AMÉRICA LATINA: INDICADORES ECONÓMICOS \% } \\
\hline & $1985 / 90$ & 1990 & 1991 & 1992 & 1993 & 1994 & 1995 & 1996 & 1997 \\
\hline PIB & 1,6 & $-0,2$ & 3,9 & 3,2 & 4,1 & 5,6 & 0,4 & 3,5 & 5,3 \\
\hline Exportación & 5,2 & 6,0 & 3,6 & 7,1 & 11,7 & 10,7 & 10,4 & 11,3 & 13,2 \\
\hline $\begin{array}{l}\text { Formación } \\
\text { de capital }\end{array}$ & 17,2 & 18,2 & n.a & 19,1 & 19,4 & 20,5 & 19,1 & 19,3 & 21,21 \\
\hline Inflación & 686,5 & 1188,8 & 199,3 & 426,7 & 890,2 & 337,6 & 25,8 & 18,5 & 10,6 \\
\hline
\end{tabular}

El empobrecimiento de la población en muchos países durante la década de 1990 se señaló como una de las causas para el cambio político hacia la "izquierda" en América Latina, en la primera década de los años 2000. La saturación del modelo neoliberal permitió la gestación de alternativas políticas y "no convencionales" que vendrian a disputar a las elecciónes entre finales del siglo XX y principios del siglo XXI. El compromiso con las prácticas anti-neoliberales fue un componente importante para el éxito de los partidos políticos en el proceso electoral.

Así que no hay sorpresa en lo que se ha llamado "ola roja" de la primera década de este siglo, con la victoria de los partidos de izquierda en América Latina. Fue un proceso "natural", bajo el punto de vista histórico y en vista del fracaso neoliberal de la década de 1990. 


\section{4 - La Llegada de Hugo Chávez al Poder}

Clasificada como una tradicional democracia estable ${ }^{88}$ en América Latina, Venezuela caminó hacia la inestabilidad política tras el fracaso neoliberal, puesto en práctica en el siglo XX.

La década de 1990 estuvo marcada por la "Apertura Petrolera" y por el "Gran Viraje" del presidente Carlos Andrés Pérez. Rafael Caldera y Teodoro Petkoff contribuyeron al proceso con la llamada "Agenda Venezuela"89.

88 En su excelente libro "Rethinng Venezuelan Politics", Steve Ellner demuestra que el "paradigma de la democracia venezolana" no fue muy bien. En realidad era un "mito", promovido por académicos venezolanos y estadounidenses. La estructura política era basada en la "partidocracia" a favor de la reducción de los conflictos entre las clases dominantes, mediante la creación de un entorno favorable de "respeto" por la democracia.

89 “'La Apertura Petrolera' fue, sin duda, la más importante de las fórmulas adoptadas durante la última década del siglo XX, para responder acríticamente a las exigencias y condiciones de la globalización neoliberal. Con ella se inició un proceso que transfirió del sector público al sector privado, fundamentalmente al capital transnacional, importantes actividades de la industria de los hidrocarburos en el país, que desde la nacionalización habían estado reservadas al Estado venezolano. Además, los pasos dados en esa dirección acarrearon muy elevados costos para el fisco nacional. Con la Apertura se avanzó hacia una profundización de la autonomía de PDVSA y sus filiales respecto al Estado, tratando de hacer de ella un Estado dentro del Estado. (...) Entre 1986 y 1987 se volvió al viejo régimen de concesiones, al iniciarse lo que se llamó la "Apertura Petrolera", esta vez bajo la modalidad de convenios operativos y asociaciones estratégicas para reactivar campos, producir crudo, explotar gas natural costa afuera, explorar áreas prospectivas, crear empresas mixtas, competir libremente en los mercados petroleros, y explotar y comercializar el carbón. En 1992, la vieja PDVSA inició un proceso masivo de "tercerización" que ocasionó una pérdida, nunca antes vista, de la efectividad nacional para manejar la industria petrolera y terminó dejándola prácticamente en manos de compañías extranjeras". "La Apertura petrolera: reprivatización del negocio".

<http://www.pdvsa.com/index.php?tpl=interface.sp/design/readmenuhist.tpl.html\&newsid_obj_id $=111 \&$ newsid_temas=13> Acessado em 27/11/2011.

Gran Viraje. (...) "es conocido el programa de ajustes elaborado por el gobierno de Carlos Andrés Pérez y anunciado oficialmente en febrero de 1989. Para muchos (...) este fue hecho a la medida de las recetas emanadas del Fondo Monetario Internacional y acordes con el así llamado Consenso de Washington". Alejandro Maldonado Fermín. "Instituciones clave, producción y circulación de ideas (neo)liberales y programas de ajuste estructural en Venezuela, 1989-1998".

<http://bibliotecavirtual.clacso.org.ar/ar/libros/grupos/grim_cult/Maldonado.pdf> Acessado em 24/11/2011.

Agenda Venezuela. (...) "es conocido el programa de ajustes elaborado por el gobierno de Carlos Andrés Pérez y anunciado oficialmente en febrero de 1989. Para muchos (...) este fue hecho a la medida de las recetas emanadas del Fondo Monetario Internacional y acordes con el así llamado Consenso de Washington". Alejandro Maldonado Fermín. "Instituciones clave, producción y circulación de ideas (neo)liberales y programas de ajuste estructural en Venezuela, 1989-1998".

<http://bibliotecavirtual.clacso.org.ar/ar/libros/grupos/grim_cult/Maldonado.pdf> Acessado em 24/11/2011. 
Carlos Andrés Pérez fue elegido en diciembre de 1988 con la propuesta de "revivir" la "época de oro" de 1960 y 1970 en Venezuela. La perspectiva de mejora económica y social es que proporcionó la elección de Pérez con más de $56 \%$ de los votos válidos.

La situación económica en Venezuela a finales de la década de 1980 era un caos. La fuga de capitales, el desempleo y la alta inflación de $40 \%$ anual, formaron la imagen desagradable del país.

Con el objetivo de obtener el préstamo de USD 4,5 millones del FMI y "salvar" al país, a principios de 1989, Carlos Andrés Pérez comenzó a utilizar de las medidas tradicionales impuestas por la institución, es decir "(...) desvalorização da moeda, redução do gasto público e do crédito, liberalização dos preços, congelamento dos salários e aumento dos preços dos gêneros de primeira necessidade" $(\ldots)^{90}$.

Sin embargo, como ya se ha señalado, el discurso electoral de Carlos Andrés Pérez fue muy diferente para la sociedad venezolana. Como ha señalado Severo, esto ocurre debido a que:

"Tudo se fez supostamente em nome da redução do déficit fiscal, do estímulo à entrada de capitais estrangeiros, à modernização da indústria nacional, maiores eficiência, produtividade $\mathrm{e}$ competitividade, redução da inflação e diminuição do desemprego. Puro verso semântico para dissimular o Consenso de Washington e apresentá-lo com a doçura de um canto de sereia"1.

Las medidas preconizadas por el FMI como una "solución" y puestas en práctica por el presidente venezolano proporcionó un "resultado rápido": en 1990, la población por debajo del umbral de la pobreza había aumentado a $15 \%$ (1988) al $45 \%$.

90 Gilberto Maringoni. A Revolução Venezuelana. São Paulo, EDUSP, p. 70, 2004.

${ }^{91}$ Ibidem. 
En el ámbito macroeconómico, la receta neoliberal fue seguida estrictamente: la reducción del papel del Estado, la privatización de las empresas y sectores estratégicos. A modo de ejemplo, podemos señalar la Compañía Nacional de Teléfonos (Cantv), la Siderúrgica del Orinoco (Sidor), la Venezolana Internacional de Aviación SA (Viasa), instituciones financieras, centrales azucareras, astilleros y empresas de la construcción en la industria. ${ }^{92}$.

Todo este cuadro de devastación económica era totalmente anacrónico con la riqueza petrolera de Venezuela. En la década de 1970, los países productores de petróleo enriquecieron con los altos precios del barril, la recuperación se produjo a partir de 1973 (primera crisis del petróleo).

El cuadro 5 muestra la ruta económica venezolana entre la crisis económica de la década de 1980 y la adopción del neoliberalismo en la década de 1990. Los resultados fueron terribles para la población venezolana, pero aseguraron la rentabilidad del capital internacional de los fondos invertidos en el país.

Cuadro 5: Algunos indicadores macroeconómicos (1979-1999)

\begin{tabular}{|c|c|c|c|c|c|}
\hline ANO & $\begin{array}{l}\text { PIB milhões } \\
\text { Bs. } 1984\end{array}$ & $\begin{array}{l}\text { Crescimento } \\
\text { (var. PIB) }\end{array}$ & $\begin{array}{l}\text { Inflação1 } \\
\text { (var. IPC) }\end{array}$ & $\begin{array}{l}\text { tipo de } \\
\text { câmbio2 } \\
\text { (Bs./\$) }\end{array}$ & $\begin{array}{l}\text { Reservas } \\
\text { internac. } \\
\text { milhões \$3 }\end{array}$ \\
\hline 1979 & 494.942 & 1,50 & 12,83 & 4,30 & 8.819 \\
\hline 1980 & 474.205 & $-4,19$ & 22,89 & 4,30 & 8.885 \\
\hline 1981 & 467.395 & $-1,44$ & 15,94 & 4,30 & 11.409 \\
\hline 1982 & 451.781 & $-3,34$ & 8,52 & 4,30 & 11.624 \\
\hline 1983 & 420.099 & $-7,01$ & 5,85 & 9,90 & 12.181 \\
\hline 1984 & 410.067 & $-2,39$ & 12,16 & 12,65 & 13.723 \\
\hline 1985 & 415.349 & 1,29 & 11,40 & 14,40 & 12.341 \\
\hline 1986 & 431.594 & 3,91 & 11,58 & 22,70 & 11.685 \\
\hline 1987 & 459.613 & 6,49 & 28,08 & 30,55 & 9.402 \\
\hline 1988 & 477.564 & 3,91 & 29,46 & 39,30 & 6.555 \\
\hline 1989 & 460.813 & $-3,51$ & 84,47 & 43,05 & 7.411 \\
\hline 1990 & 492.170 & 6,80 & 40,66 & 50,58 & 11.759 \\
\hline 1991 & 532.605 & 8,22 & 34,20 & 61,65 & 14.105 \\
\hline 1992 & 556.669 & 4,52 & 31,43 & 79,55 & 13.001 \\
\hline 1993 & 558.202 & 0,28 & 38,12 & 106,00 & 12.656 \\
\hline 1994 & 545.087 & $-2,35$ & 60,82 & 170,00 & 11.507 \\
\hline 1995 & 566.627 & 3,95 & 59,92 & 290,00 & 9.723 \\
\hline 1996 & 565.506 & $-0,20$ & 99,87 & 476,50 & 15.229 \\
\hline 1997 & 601.534 & 6,40 & 50,04 & 504,25 & 17.818 \\
\hline 1998 & 600.878 & $-0,10$ & 35,78 & 564,50 & 14.849 \\
\hline 1999 & 557.777 & $-7,20$ & 23,56 & 655,25 & 15.030 \\
\hline
\end{tabular}

${ }^{92}$ Ibidem. 
Una gran contradicción es que a pesar de haber recibido US \$ 270 mil millones en la venta de petróleo entre 1976 y 1995, la deuda externa venezolana aumentó de US \$16,4 mil millones a US \$33,5 mil millones entre los años 1978 y $1983^{93}$, hecho que se debió a los errores económicos de los gobiernos.

La dinámica neoliberal impuesta por Carlos Andrés Pérez sólo acentuó la crisis económica y social durante la década de 1990. Fueron emblemáticos el Caracazo o Sacudón de 1989 y la llamada insurrección cívico-militar de 1992.

\section{Cuadro 6: HOGARES EN SITUACIÓN DE POBREZA (1980-1997)}

\begin{tabular}{|lccc|}
\hline ANO & № de lares & $\begin{array}{c}\text { \% lares em } \\
\text { pobreza }\end{array}$ & $\begin{array}{c}\text { \% lares em } \\
\text { pobreza extrema }\end{array}$ \\
\hline $\mathbf{1 9 8 0}$ & 2.806 .679 & 17,65 & 9,06 \\
\hline $\mathbf{1 9 8 1}$ & 2.880 .084 & 22,82 & 10,71 \\
\hline $\mathbf{1 9 8 2}$ & 3.019 .932 & 25,65 & 12,14 \\
\hline $\mathbf{1 9 8 3}$ & 3.130 .682 & 32,65 & 14,95 \\
\hline $\mathbf{1 9 8 4}$ & 3.183 .339 & 37,58 & 18,90 \\
\hline $\mathbf{1 9 8 5}$ & 3.211 .477 & 34,77 & 16,60 \\
\hline $\mathbf{1 9 8 6}$ & 3.412 .139 & 38,88 & 17,67 \\
\hline $\mathbf{1 9 8 7}$ & 3.541 .504 & 38,84 & 16,61 \\
\hline $\mathbf{1 9 8 8}$ & 3.659 .369 & 39,96 & 16,77 \\
\hline $\mathbf{1 9 8 9}$ & 3.821 .954 & 44,44 & 20,07 \\
\hline $\mathbf{1 9 9 0}$ & 3.859 .923 & 41,48 & 18,62 \\
\hline $\mathbf{1 9 9 1}$ & 3.914 .165 & 35,37 & 16,01 \\
\hline $\mathbf{1 9 9 2}$ & 4.032 .402 & 37,75 & 15,52 \\
\hline $\mathbf{1 9 9 3}$ & 4.190 .519 & 41,37 & 16,81 \\
\hline $\mathbf{1 9 9 4}$ & 4.396 .784 & 53,65 & 27,52 \\
\hline $\mathbf{1 9 9 5}$ & 4.396 .354 & 48,20 & 22,95 \\
\hline $\mathbf{1 9 9 6}$ & 4.549 .363 & 61,37 & 35,39 \\
\hline $\mathbf{1 9 9 7}$ & 4.468 .445 & 48,33 & 27,66 \\
\hline
\end{tabular}

Fonte: IESA, 2000. Maragrita López Maya. Luta hegemônica na Venezuela: a crise do puntofijismo e a ascenção de Hugo Chávez.Traduzido do original castelhano Del Viernes Negro al Referendo Revocatorio. $2^{\mathrm{a}}$ ed. Caracas: Alfadil, 2005.

Rafael Caldera sucedió Pérez, pero no pudo escapar de los marcos económicos establecidos por su predecesor. ${ }^{94}$. La grave crisis económica continuó con más intensidad y llegó a los más pobres. Entre algunas de las

\footnotetext{
${ }^{93}$ Ibidem.

${ }^{94}$ En 1993, Carlos Andrés Pérez fue destituido debido a la pérdida de apoyo político generado por la crisis económica y las acusaciones de corrupción.
} 
soluciones puestas en marcha por Caldera para salvar al país, teníamos: una devaluación de la moneda y los controles de cambio y de precios.

Como era de esperar, la pobreza aumentó considerablemente por debajo de la dinámica neoliberal. El cuadro 6 muestra la evolución de la pobreza y la pobreza extrema en Venezuela entre 1980 y 1990 . El cuadro 8 muestra la situación del trabajo entre 1983 y la elección de Hugo Chávez en 1998. La situación en Venezuela entre 1980 y 1990 mostró los efectos del neoliberalismo en la población: el fuerte incremento de la pobreza.

El cuadro 7 muestra los datos del mercado laboral venezolano entre 1983 y 1998. Llama la atención el descenso del empleo del sector público y el aumento del sector informal en el período. La población no tenia outra opción que no el subempleo como una forma de mantener su medio de vida, aunque, en algunos años, el crecimiento del PIB mostró un fuerte incremento (ver cuadro 6).

En medio de una situación de empeoramiento de la debacle económica y social, el coronel Hugo Chávez aparece en la escena nacional, en el comando de algunos militares en el fallido golpe militar el 2 de febrero de 1992. Según Chávez, seis mil militares participaron en el ensayo con tanques y helicópteros. La lucha ocurrió en Miraflores, Maracaibo, Valencia y Maracay. La cifra oscilaba entre 17 y 100 muertos.

Cuatro meses después del intento de golpe de Estado las encuestas de opinión indicaban que cerca del 65\% de los venezolanos considera el a Hugo Chávez como una "persona de confianza". ${ }^{95}$

En 1995, la inflación alcanzó el $105 \%$ al año, por primera vez en la realidad venezolana ${ }^{96}$. El final del gobierno de Rafael Caldera tuvo la recesión del sector petrolero más alta en 40 años.

Venezuela estaba, así, en el horno. La economía y la clase política desacreditada favorecieran el escenario que hicieron posibles los cambios que se producirían a finales de 1990.

\footnotetext{
${ }^{95}$ Gilberto Maringoni. Op. cit., p. 96.

${ }^{96}$ Ibidem, p.105.
} 
Cuadro 7: FUERZA DE TRABAJO (1983-1998)

\begin{tabular}{cccccc}
\hline ANO & PEA & $\begin{array}{c}\text { Desocupados } \\
\text { \% PEA }\end{array}$ & $\begin{array}{c}\text { Setor } \\
\text { público } \\
\text { \% ocupados }\end{array}$ & $\begin{array}{c}\text { Formal } \\
\text { privado } \\
\text { \% ocupados }\end{array}$ & $\begin{array}{c}\text { Setor } \\
\text { informal } \\
\text { \% ocupados }\end{array}$ \\
\hline $\mathbf{1 9 8 3}$ & 5.407 .292 & 10,30 & 22,67 & 36,03 & 41,30 \\
$\mathbf{1 9 8 4}$ & 5.716 .207 & 13,4 & 21,78 & 36,42 & 41,80 \\
$\mathbf{1 9 8 5}$ & 5.915 .573 & 12,1 & 20,18 & 39,52 & 40,30 \\
$\mathbf{1 9 8 6}$ & 6.107 .115 & 10,30 & 19,38 & 39,12 & 41,50 \\
$\mathbf{1 9 8 7}$ & 6.321 .344 & 8,50 & 18,86 & 42,44 & 38,70 \\
$\mathbf{1 9 8 8}$ & 6.572 .049 & 6,90 & 18,71 & 43,19 & 38,10 \\
$\mathbf{1 9 8 9}$ & 6.900 .588 & 9,60 & 19,68 & 40,62 & 39,70 \\
$\mathbf{1 9 9 0}$ & 7.154 .622 & 9,90 & 19,85 & 38,65 & 41,50 \\
$\mathbf{1 9 9 1}$ & 7.417 .929 & 8,70 & 19,07 & 40,43 & 40,50 \\
$\mathbf{1 9 9 2}$ & 7.537 .817 & 7,10 & 18,05 & 42,35 & 39,60 \\
$\mathbf{1 9 9 3}$ & 7.546 .241 & 6,30 & 16,80 & 42,60 & 40,60 \\
$\mathbf{1 9 9 4}$ & 8.025 .928 & 8,46 & 16,40 & 34,29 & 49,31 \\
$\mathbf{1 9 9 5}$ & 8.608 .653 & 10,22 & 17,57 & 33,99 & 48,44 \\
$\mathbf{1 9 9 6}$ & 9.024 .627 & 12,43 & 17,13 & 34,24 & 48,63 \\
$\mathbf{1 9 9 7}$ & 9.507 .125 & 10,65 & 16,96 & 35,57 & 47,47 \\
$\mathbf{1 9 9 8}$ & 9.699 .330 & 11,28 & 16,33 & 35,47 & 48,20 \\
\hline
\end{tabular}

Fonte: IESA, 2000 e cálculos próprios para algumas porcentagens.

Maragrita López Maya. Luta hegemônica na Venezuela: a crise do puntofijismo e a ascenção de Hugo Chávez.Traduzido do original castelhano Del Viernes Negro al Referendo Revocatorio. $2^{\underline{a}}$ ed. Caracas: Alfadil, 2005.

La elección de Hugo Chávez como representante del descontento popular con la "vieja política" venezolana y su posterior postura de liderar el proceso de transformación social y económica a través de su figura emblemática fueron fundamentales para poner en práctica su proyecto bolivariano.

La creación de un proyecto político cuyo objetivo era introducir una gran parte de la población venezolana en la arena política, a través de la transformación de una democracia representativa en una democracia participativa, fue el grande optimum. Los avances sociales son otro aspecto importante que assegura al líder venezolano el apoyo popular necesario para atacar a las viejas élites políticas y la burocracia del país.

Bajo este punto de vista - una mayor participación popular, mejoras soocioeconômicas y la confianza en el líder - podemos poner el éxito del proyecto liderado por Hugo Chávez. Lógicamente, el proceso todavia está en marcha. 
El éxito, hasta ahora, del proyecto chavista debe ser analizado y entendido dentro de una perspectiva crítica y dialéctica de la sociedad venezolana durante la hegemonia neoliberal ${ }^{97}$. Como ha señalado Severo ${ }^{98}$, la crisis de la economía neoliberal venezolana llevó Hugo Chávez al poder a través de:

\begin{abstract}
“(...) em grande medida, Hugo Chávez ganhou as eleições de 1998 porque a Venezuela enfrentava sua mais catastrófica crise econômica, política, social, institucional e moral, depois de 40 anos de alternância no poder dos partidos Ação Democrática (social-democracia) e COPEI (democracia-cristã). O país e o povo agonizavam como efeito da corrupção, do desperdício e da perversidade da IV República (1958-98)".
\end{abstract}

La conquista de la hegemonía por Hugo Chávez se volvió incontestable a partir de 2000, y se explica por su grande capacidad de satisfacer las demandas de las clases populares. Esta supremacía se basa en la formación y consolidación de su bloque histórico con una "nueva classe social" dirigente antineoliberal y con un amplio apoyo popular a través del desarrollo de la revolución pasiva ${ }^{99}$.

\footnotetext{
97 "Na prática, o chavismo é uma combinação entre princípios do nacional-desenvolvimentismo com mecanismos de democracia direta. Desta síntese, resultariam práticas e ações governamentais, tais quais, ênfase em programas sociais e políticas focalizadas, centralização, projetos de desenvolvimento endógeno, mecanismos de participação popular e fomento à integração latino-americana. Esta última, remontando a um passado mítico através do resgate da figura de Simón Bolívar e sua luta pela independência e união dos povos da América Latina". Renata Peixoto de Oliveira. Velhos fundamentos, novas estratégias? Petróleo, Democracia e a Política Externa de Hugo Chávez (1999-2010). Universidade Federal de Minas Gerais, Programa de Pós-Graduação em Ciência Política, p. 24, 2010.

98 Venezuela: Petróleo semeando emancipação e crescimento econômico. Luciano Wexell Severo. <http://www.voltairenet.org/article141468.html>. Acessado em 23/05/2011.

${ }^{99}$ Enfoque teórico desarrollado en el capítulo Fundamentación Teórico-Metodológica, p. 20.
} 
Maciel habla sobre el apoyo que Presidente Chávez recibió para realizar reformas políticas en Venezuela, diciendo ${ }^{100}$ :

"Na presidência, Chávez empreendeu reformas políticas que iam de encontro ao antigo sistema, pautadas na representação política através de partidos. Estas mudanças ocorreram de forma pacífica, com apoio popular e militar através de instrumentos democráticos e constitucionais. As transformações, obviamente, não se deram na ausência de conflitos, parecendo em certos momentos que a democracia entraria em colapso. Entretanto, esta situação é compreendida dentro do quadro de polarização social e política do país".

Podríamos destacar como aspectos históricos importantes de su elección, entre otros factores, el fracaso del sistema político del País basado en el Pacto de Puntofijo ${ }^{101}$, la corrupción endémica y las élites económicas insensibles al marco social miserable.

En este contexto, el Presidente Hugo Chávez supo capitanear el descontento popular y asumir un proyecto dual — la "Revolución Bolivariana" - que tiene como una meta clara el antiamericanismo, al tiempo que propone una serie de acciones que aumenten su influencia continental e internacional, externamente. Internamente, trabaja para la satisfacción de las clases bajas a través de políticas sociales de largo alcance.

\footnotetext{
${ }^{100}$ Natalia Regina Maciel. Reforma Política e Política Externa na Venezuela: uma Ameaça à Segurança continental sob a Ótica Norte-Americana. In: Intellector. Rio de Janeiro, CENEGRI, Ano III, V. III, № 6, Janeiro/Junho de 2007, p. 5.

101 El Pacto de Punto Fijo, según Maringoni, (...) "tinha a pretensão de reduzir as diferenças ideológicas e programáticas entre seus signatários e lançar as bases para uma convergência de interesses que tinha como ponto de apoio o domínio do aparelho de Estado. Na prática, ele se converteria, mais tarde, num acerto entre AD (Ação Democrática) e Copei (Comitê de Organização Política Eleitoral Independente) e um terceiro partido (...). O pacto representou um jeito de acomodar na partilha do poder as diversas frações da classe dominante, incluindo aí o capital financeiro, as empresas de petróleo, a cúpula do movimento sindical, a lgreja e as Forças Armadas". (...) Op. cit., p. 62.
} 
El gran objetivo de Chávez fue políticamente superar el régimen político imperante desde 1961 y que dio lugar a la llamada "partidocracia", que condujo a la división de poderes entre el AD y COPEI. Para ello, debe existir la democracia participativa en Venezuela para superar el dominio de las estructuras partidarias en la participación popular efectiva.

A nivel nacional, Hugo Chávez representaba la contestación a la tradicional hegemonía de las élites venezolanas como declara el sociólogo Antonio Plesmann ${ }^{102}$ :

"A partir de 1999, uma nova elite assumiu o controle da maior parte das instituições do Estado venezuelano, com o objetivo claro de construir uma hegemonia alternativa àquela que existia há 40 anos. O discurso do governo Chávez mudou bastante nesta década, mas permaneceu uma constante: a necessidade de fazer da Venezuela um país igualitário. Trata-se não somente de ganhos no terreno material, ou seja, alcançar uma igualdade socioeconômica, mas também da possibilidade para todos de participar na definição dos assuntos públicos, que é a igualdade política, e da valorização dos diversos estatutos sociais, ou seja, a igualdade cultural".

\section{5 - Hugo Chávez en el Poder y el "Socialismo Bolivariano"}

La Revolución Bolivariana y la idea del "Socialismo del Siglo XXI" son las dos principales banderas defendidas por Hugo Chávez desde que asumió la dirección de Venezuela, a finales de $1990 .{ }^{103} \mathrm{El}$ mandatario venezolano llamó la atención del mundo y de la izquierda internacional por defender una

\footnotetext{
102 "Participação popular aumentou na Venezuela, mas amigos do rei continuam se fartando, diz sociólogo". 19/12/2008.

<http://operamundi.uol.com.br/conteudo/entrevistas/16430/www.derechos.org.ve> Acessado em 02/01/2012.

${ }^{103}$ Chávez salió victorioso en las urnas con el $58,25 \%$ de los votos. Los aliados del gobierno ganaron 21 de los 23 gobiernos de los estados en disputa.
} 
propuesta de socialismo diferente de la que existía en la URSS y Europa del Este y del llamado "socialismo real".

Para distinguir su propuesta, Chávez llamó a su proyecto de "Socialismo del Siglo XXI". Pero que sería, específicamente? Sería una propuesta (una más) del reformismo de la teoría marxista?

Los análisis del proyecto chavista son numerosas. Haremos, a partir de ahora, un "tour" sobre lo que dicen los expertos, tanto de la izquierda como de la derecha, en un intento de definir el "nuevo socialismo" que se está desarrollando en Venezuela.

Por ejemplo, en la crítica de incompatibilidad del "socialismo bolivariano" Oliveira dice: ${ }^{104}$ :

\begin{abstract}
"Essa aparente falta de consistência e precisão ideológica tem sido com freqüência, alvo de duras críticas. Grosso modo, o chavismo, como lembra Agullo (2005), não obedece claramente a uma cronologia ou hierarquia, podendo ser exemplificado, seja pelo seu caráter militarista, nacionalista, socialista, participativo e bolivarianista. Se, por um lado, os chavistas são tidos, muitas vezes, como - pobres, analfabetos, jovens e simpatizantes de regimes autoritários (RAMIREZ, 2005:80-82), por outro, vale a pena lembrar que a base de sustentação do regime tem sido ampla e heterogênea, incluindo setores de classe média, novos atores políticos, como os movimentos sociais e comunitários, abrindo espaço para uma nova cultura política participativa e solidária".
\end{abstract}

Según Carlos Cesar Almendra, Chávez habría sido influenciada por tres personajes principales de la historia de Venezuela, que constituyen la base teórica del momento presente "revolucionario" de Venezuela:

\footnotetext{
${ }^{104}$ Velhos fundamentos, novas estratégias? Petróleo, Democracia e a Política Externa de Hugo Chávez (1999-2010). Op. cit., p. 24.
} 
(...) “1) El Libertador, ou seja, o próprio Simón Bolívar, que atuou nas lutas pela libertação da Venezuela e Colômbia (1819), do Equador (1822) e da Bolívia (1825); 2) Simón Rodriguez, professor de Bolívar, que na década de 1820 defendia uma educação de caráter igualitária, incluindo aí os filhos de negros e índios, num momento no qual se mantinha a escravidão.

Defendia também que a América deveria desenhar sua própria identidade e não simplesmente imitar as grandes potências; 3) Ezequiel Zamorra, líder popular do século XIX, tinha um verdadeiro horror à oligarquia e defendia que os movimentos de camponeses e militares deveriam lutar pela reforma agrária e pela democracia direta" 105 .

Bajo tales influencias, Chávez creó una nueva perspectiva para el socialismo que no deberia repetir los mismos errores cometidos por el proceso revolucionario socialista originado a partir de 1917 en Rusia.

La Revolución Bolivariana, según Bueno ${ }^{106}$, se asienta sobre tres bases:

"La primera de ellas orientada a la implementación de nuevas formas de propiedad empresarial promovidas por el Estado, cooperativas y empresas de producción social; Seguida por una política denominada "núcleos endógenos básicos", en la que el Estado se dedica a la producción industrial y a la prestación de servicios, previa nacionalización de empresas del sector privado; La última relacionada con el establecimiento de programas de capacitación laboral".

\footnotetext{
${ }^{105}$ Hugo Chávez e a Revolução Bolivariana na Venezuela. In: IV Colóquio Marx e Engels do Centro de Estudos Marxistas. Unicamp, p.1, 8-11 de novembro de 2005.

<http://www.unicamp.br/cemarx/ANAIS\%20IV\%20COLOQUIO/comunica\%E7\%F5es/GT4/gt4m 3c4.PDF> Acessado em 28/12/2009.

${ }^{106}$ Juliana Gutiérrez Bueno.Venezuela en el camino hacia el socialismo del siglo XXI. La Plata, UNLP/IRI, p.1, 2008.
} 
El "Socialismo del Siglo XXI" se basa en una propuesta esencialmente democrática y que llevaría al desarrollo económico y humano. Por lo tanto, la base del nuevo socialismo bolivariano estaría sentado en el Consejo Comunitario de las zonas urbanas y rurales ${ }^{107}$.

En él, el proceso de decisión se realiza a través de una asamblea general, huyendo de la antigua democracia representativa. Es de notar que tales consejos son pequeños, para facilitar la participación por la vía directa de la población. El nuevo proyecto socialista tiene como locus de la actividad no más niveles municipales o provinciales, pero comunales. El consejo municipal es, por lo tanto, el fundamento del proyecto socialista del siglo século $\mathrm{XXI}^{108}$. Como señaló Lebowitz ${ }^{109}$ :

"Depois da reeleição de Chávez em dezembro de 2006, de uma campanha onde se colocou explicitamente o tema da construção de um novo socialismo, os conselhos comunais foram identificados como a célula fundamental do socialismo bolivariano e a base de um novo estado. 'Todo poder aos conselhos comunais".

En la misma línea de análisis de la importancia de los consejos comunales para construir una nueva sociedad, Seabra señala que: ${ }^{110}$

"Os Conselhos Comunais representam o maior esforço do governo bolivariano em organzar e incentivar a participação social. Eles seriam instâncias participativas, organizadas e articuladas dentro das próprias comunidades, para que estas

\footnotetext{
107 Michael A. Lebowitz. Venezuela: as lutas na Venezuela pelo socialismo bolivariano. http://alainet.org/active/22554\&lang=es Acessado em 10/06/2010.

${ }^{108}$ Idem, ibidem.

${ }^{109}$ Idem, ibidem.

110 Raphael Seabra. A revolução venezuelana: chavismo e bolivarianismo. In: Sociedade e Cultura. Goiania, v. 13, julho/dezembro 2010, p. 214.
} 
exercessem diretamente a gestão de políticas públicas e projetos pautados nas necessidades e prioridades locais. Sua lógica participativa atravessaria diretamente os níveis estaduais e municipais, estabelecendo não só uma relação direta entre a organização comunitária e o governo federal, mas também os mecanismos para sua constituição. Assim, os trâmites para a formulação de projetos e obtenção de recursos exigiriam poucas mediações burocráticas". (...)

En nuestra opinión, el proceso socialista bolivariano demanda, por lo tanto, poner en práctica la perspectiva de horizontalidad de los procesos de toma de decisiones, retomando el proyecto original bolchevique, los Soviets, en la fase inicial de la Revolución Rusa.

El objetivo principal es descentralizar el poder y las decisiones. ${ }^{111} \mathrm{E}$ socialismo bolivariano debe entenderse dentro de una perspectiva más amplia: estrutura y superestructura ${ }^{112}$. Es decir, sobre la base de las transformaciones económicas e ideológicas.

En estos aspectos, para el líder venezolano, la revolución tiene "cinco motores" que llevarán a la construcción del socialismo bolivariano. Ellos son: la Ley Habilitante ${ }^{113}$, la reforma socialista de la Constitución, la educación popular

\footnotetext{
${ }^{111}$ Según Carlos Romero Mendez, "Venezuela está tratando de definir un tipo de democracia participativa directa y plebiscitaria diferente a la tesis norteamericana de la democracia representativa sin la mediación de organizaciones intermedias". Las relaciones de seguridad entre Venezuela y Estados Unidos: la dimensión global. Caracas, Instituto Lationoamericano de Investigaciones Sociales, p. 13, 2007.

<http://library.fes.de/pdf-files/bueros/caracas/05549.pdf> Acessado em 10/04/2010.

112 "A metáfora do edifício - base (estrutura) e superestrutura - é usada por Marx e Engels para apresentar a ideia de que a estrutura econômica da sociedade (estrutura) condiciona a existência e as formas do Estado e da consciência social (superestrutura). Uma das primeiras formulações dessa ideia surge na Ideologia Alemã, onde há referênia à 'organização social que nasce diretamente da produção e do comércio, a qual, em todas as épocas, constitui a base do Estado, e do resto da superestrutura das ideias". (....) Tom Bottomore (Org.) Dicionário do Pensamento Marxista. Rio de Janeiro, Jorge Zahar Editor, p. 27, 1988.

${ }^{113}$ Foram 49 Leis aprovadas na Assembleia Nacional de grande envergadura regulando grande parte da vida econômica venezuelana. São as principais: a Lei de Terra, Lei de Pesca e Lei de Hidrocarburantes.
} 
("Moral y Luces"), la nueva geometría del poder y la explosión revolucionaria del poder comunal.

La construcción de una nueva sociedad debe abarcar toda la vida social, huyendo de la lógica socialista capitalista. Por lo tanto, la práctica socialista debe ocurrir en todas las esferas de la vida, y no limitarse sólo a los consejos comunales. Por lo tanto, habría un "triângulo elementar do socialismo: as unidades de propriedade social, a produção social e a satisfação das necessidades das comunidades"114. Después de siglos en los márgenes del proceso político y de las políticas sociales, la "Revolución Bolivariana" podría satisfacer, al menos en parte, a las necesidades concretas de los más pobres.

A su vez, en el campo económico, el comienzo del gobierno de Chávez se caracterizó por condiciones extremadamente adversas bajo el punto de vista económico. El petróleo, la principal riqueza venezolana, poseía el nivel más bajo en el mercado internacional desde la segunda crisis del petróleo.

\section{Gráfico 2 - Precios del Petróleo Crudo - Precios en Dólar 2010 CRUDE OIL PRICES \\ 2010 DOLLARS}

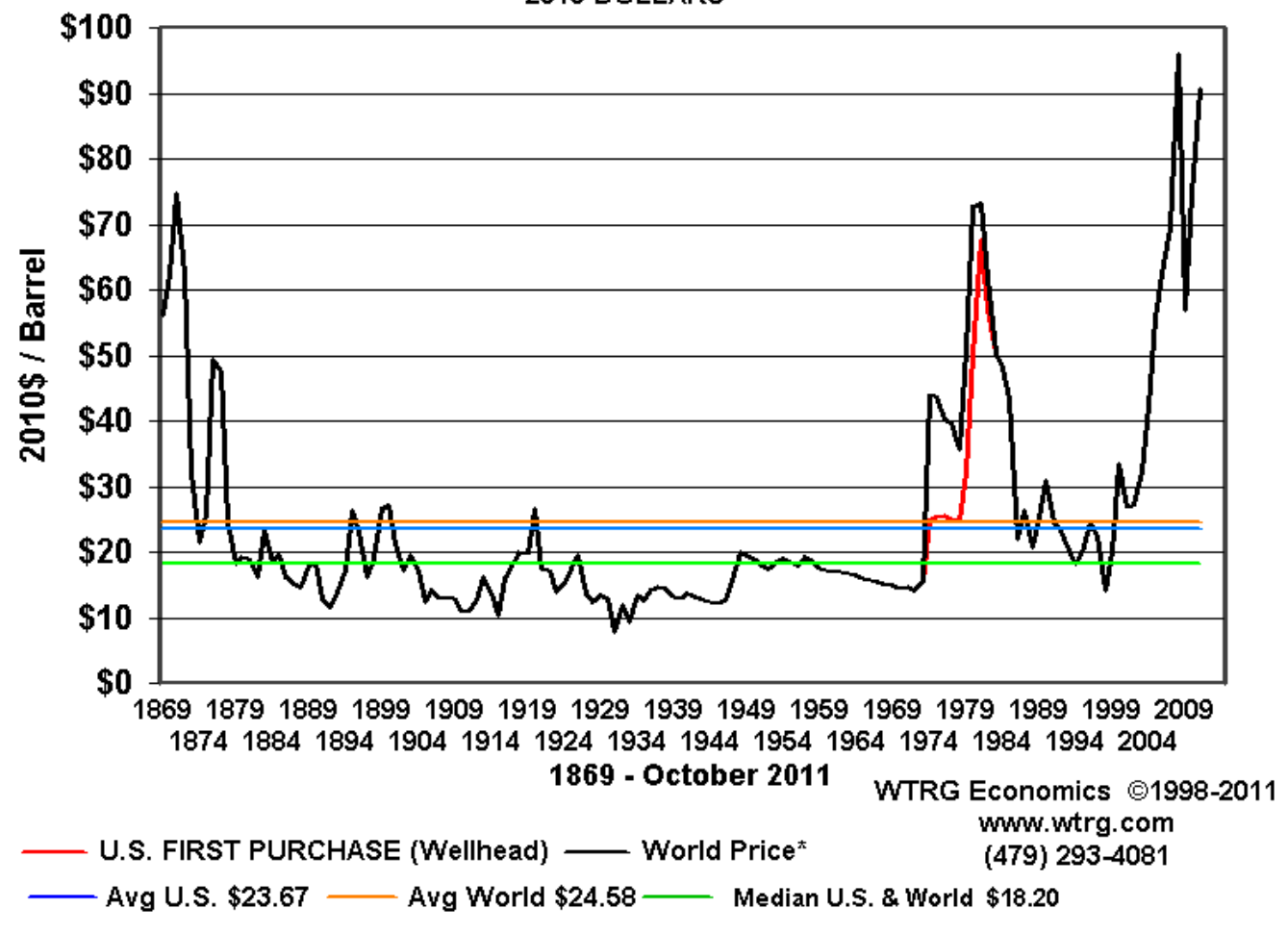

${ }^{114}$ Raphael Seabra. Op. cit. 
Con el fin de ilustrar la importancia del petróleo, son presentados dos cuadros. El gráfico 2 muestra la evolución del precio del barril de petróleo (crudo), haciendo una comparación que va desde el siglo XIX hasta 2009. Mediante el análisis de este cuadro, es evidente que Hugo Chávez asumió la presidencia, en 1999, con el precio del petróleo por debajo de USD 20,00 (promedio de los EE.UU. en todo el mundo / USD 18,20).

Entre 1999 y 2009, se produjo una recuperación que benefició al gobierno de Chávez. El precio del barril ha aumentado considerablemente, superando la barrera de los USD 90,00 entre 2004-2009. En promedio, el precio oscila entre USD 59/95, 00 en este periodo.

El gráfico 3 se refiere a la producción de petróleo venezolano entre 1979 y 2011. En 1998, Venezuela produjo 3,5 millones de barriles de petróleo y en el otro extremo, la producción cayó con la actuación de la oposición al gobierno de Chávez y la huelga del sector en 2002/2003.

\section{Gráfico 3 - Produción del Petróleo Crudo - Miles de Barris/día}

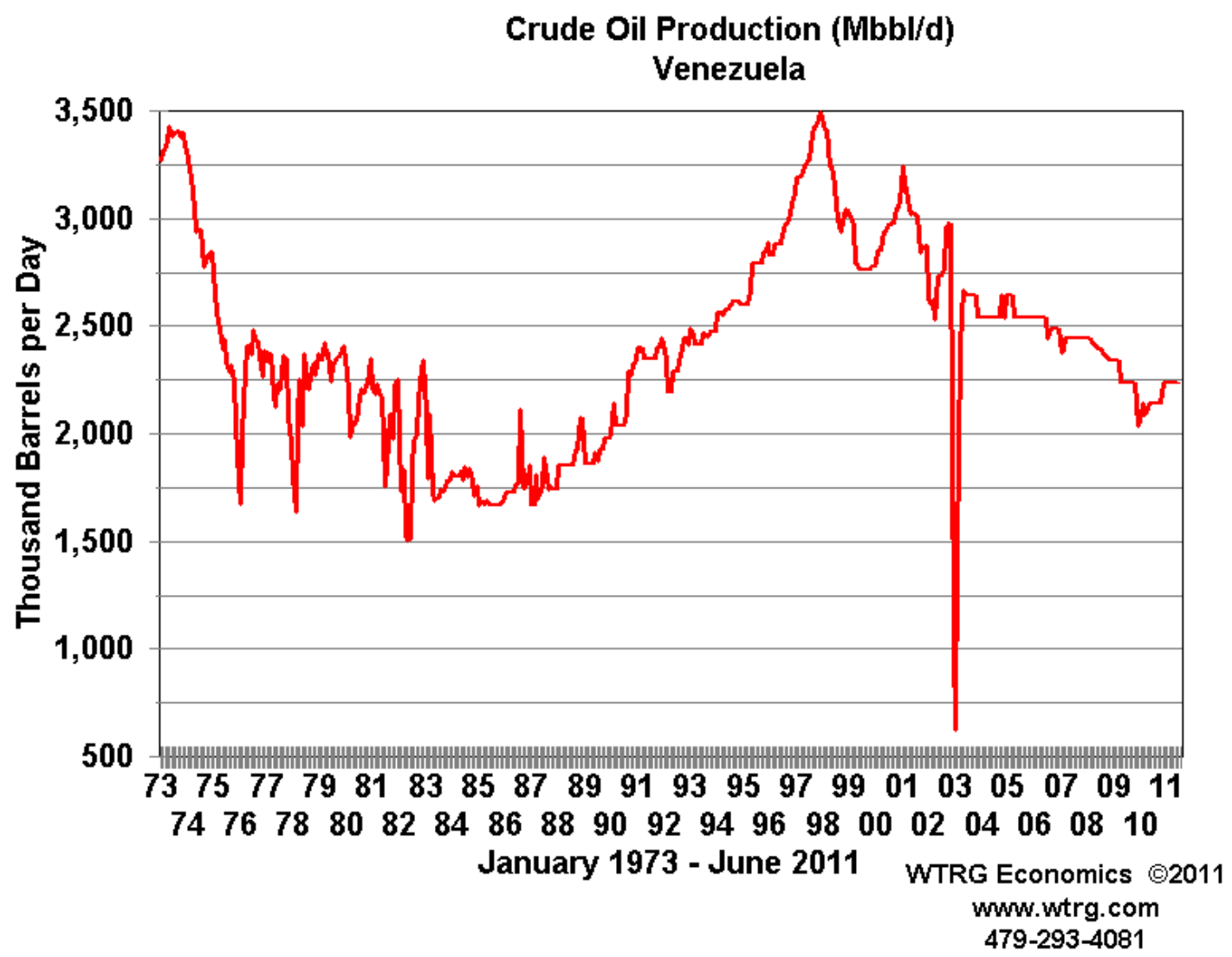


Para salir del letargio económico heredado del gobierno anterior, creó el Plan Bolívar 2000, con el objetivo de reactivar la economía, promover el aumento del suministro de alimentos, reducir las importaciones y aumentar el empleo en las zonas rurales, así como la integración de las fuerzas armadas en el proceso de lucha contra la pobreza ${ }^{115}$.

Aún durante los primeros años del gobierno de Chávez, se ha firmado una nueva Constitución con varios cambios legales de alto impacto en el área social, a saber: la inclusión y el reconocimiento de los pueblos indígenas, la expansión de los derechos humanos, la participación ciudadana en el aparato estatal, los cambios en la Ley de Tierras con la transferencia de tierras a cooperativas, etc. Entre otros cambios establecidos por la nueva Constitución, tuvimos:

La eliminación del Senado y la creación de una Asamblea unicameral;

Ampliar el período presidencial para seis años, con posibilidad de reelección;

> Posibilidad de expropiación de la propiedad privada para uso social;

D Fortalecimiento del control Ejecutivo sobre el Banco Central de Venezuela;

$>\quad$ La reducción de la semana laboral de 48 horas para 44 horas;

> Garantizar la salud, la educación y jubilación para toda la población;

Garantizar al Estado de las reservas de petróleo y otras actividades estratégicas, con la prohibición del gobierno de vender su participación en PDVSA ${ }^{116}$.

\footnotetext{
${ }^{115}$ SOUZA, Romina B. de Lucena \& SOUZA, Nalia de J. Análise de indicadores econômicos e sociais da Venezuela, 1999/2008. In: Revista de Desenvolvimento Econômico. Salvador, ano $X I$, no 20, p. 31, julho de 2009.

${ }^{116}$ lbidem.
} 
Entonces, al principio de su primer mandato se creó el Programa Económico de Transición 1999/2000. Los objetivos eran "promover o crescimento econômico sustentado e diversificado; reduzir a inflação; e aumentar o nível de emprego formal”117.

Con Chávez, el Estado venezolano se ha convertido en un agente importante en la promoción del desarrollo económico y social. Las Misiones son un ejemplo de este proceso. Las Misiones principales son: Barrio Adentro, Robinson, Mercal, Piar, entre otros ${ }^{118}$. Las Misiones

(...) "promovem estruturas de administração pública paralelas às tradicionais e alcançam amplos setores populares, além de um terço dos setores médios da sociedade venezuelana". ${ }^{119}$

Las Misiones tienen por objeto promover el desarrollo económico y social, además de la ampliación de la capacidad productiva de la población a través de superación de la pobreza ${ }^{120}$.

La expropiación de las fábricas también beneficiaron las clases bajas, pasándolas al control directo de los trabajadores o en régimen de co-gestión con el Estado. Otro aspecto que demuestra la prioridad de los programas sociales fue el uso de los ingresos petroleros en las políticas públicas, como señaló Seabra ${ }^{121}$ :

(...) "os recursos provenientes da exploração de petróleo são redistribuídos socialmente, com a intenção de melhorar as

\footnotetext{
117 Ibidem.

${ }^{118}$ Barrio Adentro: Acuerdo entre Venezuela y Cuba para la práctica de los médicos en barrios venezolanos; Robinson: misión educativa con el objetivo de erradicar el analfabetismo; Mercal: construcción de almacenes y supermercados con alimentos de primera necesidad subvencionado; Piar: creación de cooperativas y comités para la construcción de viviendas.

${ }^{119}$ Op. cit., p. 214

${ }^{120}$ Análise de indicadores econômicos e sociais da Venezuela. Op. cit., p. 31.

${ }^{121}$ Ibidem, p. 218.
} 
condições de vida da maioria da população pobre, nos âmbitos das Missões, na construção de moradias, de infraestrutura urbana e meios de transportes coletivos. De outro lado, são distribuídas subvenções às cooperativas e aos Conselhos". (...)

Con este tipo de políticas sociales, Chávez logró montar su bloque histórico, ahora basado en los sectores más pobres de la población, que reconoció el representante legítimo de su agente.

El éxito de las políticas públicas dió lugar a grandes avances sociales. En 1999, según el Instituto Nacional de Estadística de Venezuela, el 20,1\% de la población venezolana vivia en condiciones de pobreza extrema. En 2007, el porcentaje se había reducido al 9,5\%. También en 1999, la cantidad de pobres era de 11 millones de personas $(50,5 \%)$ y se redujo al $31,5 \%$.

Los cuadros 8,9 y 10 reflejan el desempeño del gobierno de Hugo Chávez en el área social. El aumento de las inversiones es visible y colaboran para el apoyo popular a su gobierno desde 1998.

En el cuadro 8 podemos observar el aumento del gasto público desde la llegada de Chávez al poder. El llamado "gasto social" ha pasado de $34,7 \%$ en 1998 al 44\% en 2006.

Con esta actuación sin precedentes hasta el momento para los estratos más pobres, Chávez sostuvo una transformación social importante. Los programas sociales bajo el control de la Presidencia comenzaron a ser financiados con los ingresos excedentes del petróleo, lo que garantiza una mayor eficiencia en sus resultados.

Los cuadros 8 y 9 demuestran que la inversion sociale produjo una mejora significativa en las vidas de la población venezolana. En el cuadro 9, por ejemplo, la situación de los hogares en pobreza y pobreza extrema habian sufrido reducciones significativas: la pobreza se redujo de $55,6 \%$ (1997) al $27,5 \%$ (2007). La pobreza extrema se redujo de $25,5 \%$ (1997) al 7,6\% (2007).

El número de personas en extrema pobreza disminuyó bruscamente: $29,5 \%$ (1997) al 9,4\% (2007). En el cuadro 10, vemos la caída del IDH entre 
1990 y 1998: 0,82 a 0,69. Desde el año 1999 el IDH alcanza 0,75 y alcanza 0,88 en 2007.

\section{Cuadro 8 - Gasto social del gobierno de Venezuela como percentual del}

PIB, 1998/2006

\begin{tabular}{l|r|r|r|r|r|r|r|r|r}
\hline \multicolumn{1}{c|}{ Item do gasto público } & $\mathbf{1 9 9 8}$ & $\mathbf{1 9 9 9}$ & $\mathbf{2 0 0 0}$ & $\mathbf{2 0 0 1}$ & $\mathbf{2 0 0 2}$ & $\mathbf{2 0 0 3}$ & $\mathbf{2 0 0 4}$ & $\mathbf{2 0 0 5}$ & $\mathbf{2 0 0 6}$ \\
\hline Gasto público total & 23,7 & $\mathbf{2 4 , 5}$ & $\mathbf{2 9 , 6}$ & 31,6 & $\mathbf{2 9 , 4}$ & 31,0 & $\mathbf{2 8 , 4}$ & $\mathbf{2 8 , 5}$ & 31,0 \\
Gasto social total & $\mathbf{8 , 2}$ & $\mathbf{9 , 4}$ & $\mathbf{1 1 , 0}$ & $\mathbf{1 2 , 1}$ & $\mathbf{1 1 , 2}$ & $\mathbf{1 2 , 1}$ & $\mathbf{1 1 , 8}$ & $\mathbf{1 1 , 6}$ & $\mathbf{1 3 , 6}$ \\
- Educação & 3,4 & 4,1 & $\mathbf{4 , 5}$ & $\mathbf{4 , 8}$ & $\mathbf{4 , 8}$ & $\mathbf{4 , 6}$ & $\mathbf{4 , 8}$ & $\mathbf{4 , 1}$ & 5,1 \\
- Saúde & 1,4 & 1,5 & 1,4 & 1,5 & 1,7 & 1,5 & 1,6 & 1,6 & 1,8 \\
- Moradia & 1,0 & 0,8 & 1,7 & 1,0 & 0,8 & 1,1 & 0,6 & 1,3 & 1,6 \\
- Seguridade Social & 1,4 & 2,0 & 2,2 & 3,4 & 2,8 & 3,4 & 3,1 & 3,0 & 3,6 \\
- Desenvolvimento e participação social & 0,8 & 0,9 & 0,8 & 0,9 & 0,8 & 1,1 & 1,2 & 0,9 & 1,0 \\
- Cultura e comunicação social & 0,2 & 0,1 & 0,2 & 0,2 & 0,1 & 0,3 & 0,3 & 0,3 & 0,3 \\
- Ciência e tecnologia & 0,1 & 0,1 & 0,2 & 0,3 & 0,1 & 0,1 & 0,3 & 0,3 & 0,2 \\
Gasto social (\% do Gasto público) & 34,7 & 38,5 & 37,3 & 38,4 & 38,2 & 39,0 & 41,4 & 40,6 & 44,0 \\
\hline
\end{tabular}

Fonte: CEPAL, Anuário estatístico de América Latina e Caribe, 2007.

Cuadro 9 - Índices de pobreza de Venezuela, 1997/2007 (\%) a

\begin{tabular}{c|c|c|c|c}
\hline \multirow{2}{*}{ Ano } & \multicolumn{2}{|c|}{ Domicílios em situação b } & \multicolumn{2}{c}{ Pessoas em situação b } \\
\cline { 2 - 5 } & Pobreza & Extrema pobreza & Pobreza & Extrema pobreza \\
\hline 1997 & 55,6 & 25,5 & 60,9 & 29,5 \\
1998 & 49,0 & 21,0 & 55,4 & 24,7 \\
1999 & 42,8 & 16,6 & 50,0 & 19,9 \\
2000 & 41,6 & 16,7 & 48,3 & 19,5 \\
2001 & 39,1 & 14,2 & 45,5 & 17,4 \\
2002 & 41,5 & 16,6 & 48,1 & 20,1 \\
2003 & 54,0 & 25,1 & 61,0 & 30,2 \\
2004 & 53,1 & 23,5 & 60,2 & 28,1 \\
2005 & 42,4 & 17,0 & 48,8 & 20,3 \\
2006 & 33,9 & 10,6 & 39,7 & 12,9 \\
2007 & 27,5 & 7,6 & 33,1 & 9,4 \\
\hline
\end{tabular}

Fonte: Instituto Nacional de Estatística. República Bolivariana de Venezuela apud Weisbrot \& Sandoval, 2008, p. 15 Obs.: a Período de referência: 1ํ semestre de cada ano; b Percentual do total declarado.

Fonte: Instituto Nacional de Estatística (INE), República Bolivariana de Venezuela 
Cuadro 10 - Evolución de indicadores sociales de Venezuela, 1950/2007

\begin{tabular}{c|c|c|c|c|c}
\hline Ano & $\begin{array}{c}\text { Renda per capita } \\
\text { (US\$ PPC) }\end{array}$ & $\begin{array}{c}\text { Expectativa } \\
\text { de vida }\end{array}$ & $\begin{array}{c}\text { Taxa de } \\
\text { alfabetização }\end{array}$ & $\begin{array}{c}\text { Taxa de } \\
\text { matrícula }\end{array}$ & IDH \\
\hline 1950 & 2.520 & 55,19 & 50,96 & 27,59 & 0,46 \\
1960 & 3.896 & 58,06 & 63,30 & 45,26 & 0,61 \\
1970 & 4.074 & 63,85 & 75,92 & 49,87 & 0,69 \\
1980 & 5.349 & 67,70 & 84,73 & 58,23 & 0,82 \\
1990 & 5.192 & 71,20 & 90,90 & 58,23 & 0,82 \\
1995 & 4.157 & 72,38 & 90,90 & 57,94 & 0,78 \\
1998 & 2.647 & 72,8 & 90,90 & 60,12 & 0,69 \\
1999 & 3.471 & 72,94 & 90,90 & 63,38 & 0,75 \\
2000 & 3.457 & 73,34 & 90,90 & 64,12 & 0,75 \\
2001 & 3.735 & 73,53 & 93,60 & 67,25 & 0,78 \\
2002 & 3.544 & 73,72 & 93,60 & 69,06 & 0,77 \\
2003 & 3.494 & 72,78 & 93,60 & 67,47 & 0,76 \\
2004 & 3.905 & 72,98 & 93,60 & 69,09 & 0,79 \\
2005 & 4.425 & 73,19 & 93,60 & 70,81 & 0,83 \\
2006 & 5.192 & 73,38 & 93,60 & 71,19 & 0,88 \\
2007 & 5.223 & 73,58 & 93,60 & 72,24 & 0,88 \\
\hline
\end{tabular}

Fonte: Instituto Nacional de Estatística (INE), República Bolivariana de Venezuela

Sin embargo, la hegemonía ganada por Hugo Chávez sufrió y sufre la resistencia, tanto en el orden interno del movimiento bolivariano como de sectores que perdieron los históricos privilégios económicos y políticos. A modo de ejemplo, el fallido golpe de Estado, en abril de 2002, llegó a remover a Chávez del poder por 48 horas.

También en 2002, el viejo sector privilegiado de Venezuela organizó un paro contra el gobierno bolivariano, liderado por empresarios de Fedecámara y por la dirección de PDVSA. El bloqueo duró 62 días y provocó la pérdida del $24 \%$ del PIB, causando escasez de alimentos y combustible. El objetivo de los sectores conservadores era provocar la renuncia de Hugo Chávez.

Con el fin de la huelga en PDVSA, el gobierno venezolano despidió a 18.000 empleados y asumió el control de la estatal, que funcionaba como un Estado dentro del Estado. 
La construcción del socialismo bolivariano se mantiene dentro de un proceso dialéctico en curso y dentro de la lógica, aun presente, del capitalismo. La creación de un modelo alternativo al imperativo sistémico actual implica una serie de dicotomías importantes. Aunque para algunos analistas, Chávez no hace nada más do que utilizar medios conocidos de intentar el desarrollo que a priori no es posible sin la participación de los países centrales. En este sentido, dice Méndez ${ }^{122}$,

"El gobierno del presidente Chávez revivió en el país la visión estructuralista y anticapitalista que genera la tesis del desarrollo endógeno, del fortalecimiento del Estado como instrumento central de desarrollo, del proteccionismo a la industria nacional y de la profundización del Estado socialista, formándose así un paquete ideológico "anti-occidental" configurado en una visión del mundo basada en las tesis de la rivalidad entre el centro y la periferia y en la lucha antiimperialista".

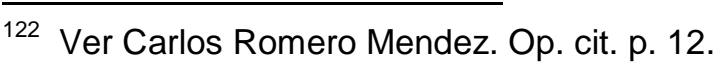


4 - LA ACTUACIÓN ANTISISTÉMICA DE VENEZUELA 


\section{1 - Los EE.UU. y la América Latina: la política exterior de Washington}

Para facilitar la comprensión del origen de una actuación que puede ser descrita como antissistémica de Venezuela, haceremos una retrospectiva histórica de la acción diplomática y militar de EE.UU. en el continente.

La política exterior de Washington para América Latina desde finales del siglo XIX, siempre se ha basado en el mantenimiento de gobiernos serviles a sus intereses ${ }^{123}$.

América Central y el Caribe han estado siempre bajo el control directo de Washington por estar ubicado en el punto de vista geo-económica en su "periferia-inmediata". América del Sur, por otro lado, se fija como " periferialejano".

A lo largo de la historia, Washington siempre ha trabajado para mantener el continente bajo su área de influencia, como Santos señala ${ }^{124}$ :

(...) "Pode dizer que os interesses norte-americanos na região sempre se moveram de acordo com suas preocupações em relação à segurança nacional, às políticas domésticas e aos interesses econômicos de suas empresas, configurando uma história de mudanças periódicas e cíclicas, com continuidades e modificações dependendo de variáveis como o volume de negócios, o grau de adesão das elites latino-americanas, a resistência de vários segmentos latino-americanos, a importância de um determinado país no sistema de segurança hemisférica,

\footnotetext{
123 "Las relaciones entre Estados Unidos y América Latina estuvieron determinadas por la Doctrina Monroe durante unos 150 años. La relación durante este largo periodo, que incluye la mayoría del siglo XIX hasta 1970, se basó en la asunción de que Estados Unidos era el primordial socio de América Latina, acaso el único relevante, y, por tanto, las negociaciones debían fundarse con base en los intereses norteamericanos". Torrijos, R. Vicente. Nuevas perspectivas en las relaciones internacionales entre Estados Unidos y América Latina. Revista de Relaciones Internacionales, Estrategia y Seguridad, Junio, 2009, p. 18.

${ }^{124}$ Marcelo Santos. O Poder Norte-Americano e a América Latina no Pós-Guerra Fria. São Paulo, AnnaBlume/FAPESP, pp.19-20, 2007.
} 
etc. Por essas razões que a diplomacia norte-americana nem sempre tratou as distintas regiões da América Latina de forma homogênea".

Si el siglo XIX fue la preocupación por "los de afuera" de Europa en el siglo XX fue la Guerra Fría. El principal enemigo fue el comunismo y sus "representantes" en el continente. Con el pretexto de la lucha contra la "amenaza comunista", Washington implementó, post-45, una nueva ofensiva de desestabilización política contra los gobiernos de América Latina presentando las medidas y las posiciones clasificadas como "antiestadounidense". Cabe señalar que las "medidas anti-estadounidenses" podría ser cualquier actitud defensiva de los intereses económicos, políticos etc, de la propia nación acusada. Como, por ejemplo, la protección de su industria.

Desde el punto de vista histórico, esta postura intervencionista se ha concretado en la administración de Theodore Roosevelt (1901-1909), que abandonó el "aislacionismo estratégico". El Corolario Roosevelt a la Doctrina Monroe en 1904, permitió a Washington el derecho de intervención y la injerencia en América Latina. Los países latinoamericanos deben "comportarse correctamente", de lo contrario sufrir la acción directa de EE.UU. (invasiones) o indirecta (presión política y / o económica). El país defensor de la democracia demostró al mundo que eran importante, sus "valores democráticos". En la práctica:

"O Corolário Roosevelt consagrou a diplomacia do Big Stick que envolve a utilização de intervenções militares estratégicas no sentido de garantir interesses econômicos, políticos e de segurança no continente. Trata-se de uma diplomacia agressiva, envolvendo métodos de força bruta e até mesmo a derrubada de governos"125.

${ }^{125}$ Op. cit., p.28. 
Sin embargo, la actuación estadounidense ya se había producido antes de que el Corolario Roosevelt, más precisamente en 1898. La Guerra Española-Americana dio la supremacía de Washington sobre Cuba, Filipinas y Puerto Rico. Haití, en 1902, había sido obligado por los EE.UU. para pagar su deuda con los acreedores del Viejo Mundo. En el mismo año aprobó la Enmienda Platt, que permitía la intervención directa de EE.UU. en Cuba si la situación política no se complace en Washington.

Al año siguiente, el tío Sam actuó en la separación de Panamá de Colombia. Esto abriría el camino para el control de EE.UU. sobre el Canal de Panamá. En 1903, los EE.UU. "ganó" el derecho a instalar una base militar en Guantánamo (Cuba).

Desde finales del siglo XIX hasta la década de 1930, el Caribe y América Central sentían literalmente la "porra" American encima de sus cabezas: Costa Rica, Cuba, Guatemala, Haití, Honduras, Nicaragua, Panamá y República Dominicana.

En la era de la posguerra, cuando la ideología socialista ganó fuerza en el Ilamado tercer mundo, los estadounidenses pusieron su política intervencionista en curso. Con el avance de los movimientos sociales y políticos en la región, exigiendo cambios en las estructuras socioeconómicas arcaicas de los países latinoamericanos, la política exterior de Washington se hizo más agresiva e incisiva.

La posibilidad de la subida de los grupos políticos fuera del espectro tradicional de derecha ocasionó intervenciones militares de Estados Unidos sobressalientes en América Latina Incluyendo la intervención en Guatemala en 1954, donde la CIA derrocó a Jacob Arbenz; diez años, y luego otra intervención, ahora en Panamá. En 1965 fue el turno de la República Dominicana que fue invadida y luego, tal vez lo más importante de todas las intervenciones, ahora "política": el derrocamiento de Salvador Allende en 1973 por el golpe militar de Augusto Pinochet, con la ayuda y actuación. directa de la CIA. 
También cabe mencionar la participación de EE.UU. en los golpes militares en Argentina (1962, 1966 y 1976), Guatemala, Ecuador y Honduras (1963), en Brasil (1964), Chile y Uruguay en 1973. Con la Revolución Cubana de 1959, la contrainsurgencia patrocinada por los EE.UU. obtuvo niveles altos, principalmente con el financiamiento de los aparatos represivos en América Latina.

No debemos olvidar el papel de Washington ${ }^{126}$ en colaboración con los Contras en Nicaragua, a partir de 1979, y en El Salvador (1980), cuando el FMLN contó con la oposición militares feroz patrocinada por los Estados Unidos, cuyas tropas se alojaron en la frontera con Honduras.

Con la redemocratización del continente, a partir de la década de 1980, y la disminución de el "movimiento comunista" mediante el asesinato y la represión masiva de los opositores, el control de EE.UU. comenzó a aflojarse. La llegada al poder de Mijail Gorbachov en la URSS, y la puesta en práctica de la Perestroika (Reestruração) y Glasnost (transparencia), fueron recibidos con entusiasmo por Washington.

Con la renuncia de Moscú en el apoyo a los nuevos gobiernos a ser comunista, o al menos apoyar a los movimientos que tuvieron éxito, los EE. UU. se habría dado cuenta de que tenían el control geopolítico de América Latina. En la época de la post-Guerra Fría, la región comenzó a perder su importancia (si es que alguna vez haya estado efectivamente), y los EE. UU. se dirigó para el Oriente Medio, región rica en petróleo, y de gran importancia estratégica

Con la transición a la democracia en todo el continente en la década de 1980, la izquierda latinoamericana comenzó a se reorganizar para la lucha institucional que comienzó a ocurrir en la próxima década. La elección de

\footnotetext{
${ }^{126}$ El gobierno de Ronald Reagan (1981-1989) actuó con decisión contra los gobiernos y movimientos de izquierda en América Central durante su mandato. En general se intensificó la carrera armamentista, con el objetivo de socavar el comunismo, dijo, el "Imperio del Mal".
} 
George W. Bush (2001-2009) y su preocupación con el Oriente Medio permitió el ascenso político de la izquierda en América Latina. ${ }^{127}$.

El triunfo de gobiernos progresistas también debe entenderse como un proceso natural de la bancarrota del neoliberalismo en el continente. Los efectos fueron analizados en el capítulo anterior.

Como resultado histórico, el legado dejado por los EE.UU. con su política exterior intervencionista ha marcado profundamente la vida social, política y económica de América Latina. Por lo tanto, es inevitable que los gobiernos que se han configurado como antissistémicos tener en cuenta que este histórico pasado intervencionista y tratar de disminuir o incluso romper con la influencia americana.

\section{2 - Venezuela Antisistémica}

El uso de la teoría gramsciana para explicar el papel actual de Venezuela se basa en el trabajo pionero de la renovación y el análisis del capitalismo. Entendemos por "renovación" un enfoque que agrega la "cuestión económica", los aspectos sociales y políticos para la comprensión de la sociedad capitalista entorno del materialismo-histórico.

La consolidación de su bloque histórico permitió Hugo Chávez recaudar nuevos vuelos en la escena internacional. Con la presentación de un papel proactivo en términos de su facilidad en el escenario internacional y América Latina, Venezuela ha jugado un papel antissistêmico.

El carácter antissistémico venezolano se refiere a su postura antiimperialista, anti-estadounidense y "piamontesa". El factor "piamontés" se deriva del proceso que se produjo en el estado de Piamonte durante la

\footnotetext{
127 "Algunos sugieren que estados Unidos se olvidó de América Latina, lo cual no tiene mucho asidero ni en tiempos pretéritos ni en lo que respecta a las administraciones desde Bill Clinton hasta Barack Obama. Lo que sucede, en consecuencia con el planteamiento del Consejo de Relaciones Internacionales Exteriores, es que los pilares de las relaciones entre Estados Unidos y América Latina no se han adaptado a las nuevas realidades, al punto de permitir el surgimiento de un sentimiento anti-americano que no tenía precedente en la región". Torrijos, R. Vicente, Op. cit., p. 18.
} 
unificación italiana en el siglo XIX, y fue analizado por Antonio Gramsci ${ }^{128}$. En la práctica, la función piamontesa corresponde a un estado que toma las riendas del proceso, dejando en un segundo plano las iniciativas originadas por grupos sociales.

Como Gramsci señaló: "El papel de Piemonte en el Resurgimiento italiano es una "clase dirigente"129. El pensador italiano, al considerar la realidad de la formación del nuevo Estado nacional italiano señaló la existencia de núcleos políticos que no eran, en realidad los dirigentes, ni quería tal función. Según Gramsci ${ }^{130}$,

(...) queriam que uma força nova, independente de qualquer compromisso e condição, se tornasse o árbitro da Nação: esta força foi o Piemonte (...).

El Piamonte fue comparado por Gramsci ${ }^{131}$ con un "partido" desempeñando un papel. Cuando nos fijamos en el actual proceso de actuación de Venezuela, sostenemos que el país tiene una perspectiva muy próxima en América Latina: una nación que actúa como un "líder", un Estado con esta función. Es decir, lo que podríamos llamar Venezuela Piamontésa.

Como ejemplo tenemos el liderazgo de Venezuela en América Latina dentro del ALBA-TCP, con los países miembros aceptando las orientaciones económicas e ideológicas del país, relegando la influencia tradicional procedente de Washington.

Otro concepto importante utilizado por el pensador italiano en su obra teórica también abarca el proceso de "revolución pasiva". Este concepto es de

\footnotetext{
${ }^{128}$ Cadernos do Cárcere - 5. Rio de Janeiro: Civilização Brasileira, 2002.

129 Ibidem, p. 328.

${ }^{130}$ Ibidem, pp. 328-329.

${ }^{131}$ Ibidem, p. 329. Según Gramsci, "(...) El Piamonte, así, tenía una función que, en cierto modo, se puede comparar a un partido, es decir, del personal dirigente de un grupo social ( $y$, de hecho, siempre se habló de un "partido piamontés"), con la particularidad de que era un Estado con un ejército, diplomacia, etc ".
} 
gran importancia para la comprensión de la Venezuela Piamontesa. Para Gramsci $^{132}$ :

"O conceito de 'revolução passiva' deve ser deduzido rigorosamente dos princípios fundamentais de ciência política: 1) nenhuma formação social desaparece enquanto as forças produtivas que nela se desenvolveram ainda encontrarem lugar para um novo movimento progressista; 2) a sociedade não se põe tarefas para cuja solução ainda não tenham germinado as condições necessárias, etc. Naturalmente, estes princípios devem ser, primeiro, desdobrados criticamente em toda a sua dimensão e depurados de todo resíduo de mecanicismo e fatalismo. Assim, devem ser referidos à descrição dos três momentos fundamentais em que se pode distinguir uma "situação" ou um equilíbrio de forças, com o máximo de valorização do segundo momento, ou equilíbrio das forças políticas e especialmente do terceiro momento, ou equilíbrio político militar". (...)

La revolución pasiva corresponde al desempeño de los líderes carismáticos que en función de la debilidad política de la sociedad para superar el status quo, se convirtió em "guías" del proceso de transformación sin la necesidad de revoluciones sociales clásicas. La participación de Hugo Chávez $^{133}$ luego sería, a nuestro juicio, incluida en el proceso de transformación de Venezuela como una revolución passiva.

A pesar de las luchas políticas que se producirán en Venezuela a lo largo de la historia, Chávez consiguió de forma personalista cambiar la correlación de fuerzas históricamente favorables a las élites venezolanas.

\footnotetext{
132 Ibidem, pp.321-322.

${ }^{133}$ (...) O impasse resultante com as classes sociais tradicionalmente dominantes criou as condições do que Gramsci chamou de "revolução passiva": a introdução de mudanças que não envolveram nenhuma sublevação de forças populares. Cox, Op. cit., p. 108.
} 
Gramsci también evalúa la "orientación política" de las revoluciones pasivas. Para el autor podría ser progresista o reaccionario. El tutelamento de los movimientos sociales por los líderes provocaría el aumento del cesarismo (líderes con una fuerza política significativa) o el transformismo (a través de la formación de alianzas de amplio espectro político) ${ }^{134}$.

El caso de Venezuela está más cerca del cesarismo progresivo al establecer una línea de acción política que tiene como objetivo satisfacer las aspiraciones de los más pobres del país y crear un nuevo paradigma político para Venezuela.

Su actuación en el escenario continental, así como su influencia en la política interna de varios países de la región, demuestra el interés de Chávez de crear un entorno favorable para su geopolítica, antissistémica y antiestadounidense.

Eso demuestra que el carácter de antissistémico de Venezuela es la formulación de una "contra-agenda" de carácter tanto regional como mundial, que se basa en cuatro puntos ${ }^{135}$, a saber:

> La búsqueda de un orden multipolar;

- La promoción de la democracia participativa como modelo;

El énfasis en la integración regional sin la influencia de EE.UU. y

El uso de la capacidad de energía del país como un instrumento de apoyo a la geopolítica.

\footnotetext{
134 De acordo com a análise gramsciana, um exemplo típico de revolução passiva é o cesarismo: um forte intervém para resolver o impasse entre forças sociais equivalentes e opostas. Gramsci admitia a existência tanto de forma progressistas quanto reacionárias de cesarismo: progressistas, quando o governo forte preside um processo mais ordenado de criação de um novo estado; reacionárias, quando estabiliza o poder existente. Napoleão I foi um caso de cesarismo progressista, mas Napoleão III - o exemplo clássico de cesarismo reacionário - era mais representativo do tipo com maior probabilidade de surgir no decorrer de uma revolução passiva.
}

Além do cesarismo, a segunda característica mais importante da revolução passiva da Itália é o que Gramsci chamou de transformismo, exemplificado na política italiana por Giovanni Giolitti, que procurou fazer uma coalizão de interesses mais ampla possível e que dominou a cena política nos anos que precederam o fascismo. (...) Ibidem, p. 109.

${ }^{135}$ Carlos Romero Méndez. Op. cit., p. 11. 
Añadimos a los cuatro puntos por encima de otro: la influencia ideológica. Usando el legado teórico y político de Simón Bolívar y la propuesta de "socialismo del siglo. XXI ", Venezuela ofrece una alternativa al status quo económico y político continental.

Venezuela pasó a dirigir varios países de América Latina aprovechando su gran capacidad económica derivada del petróleo. Su "diplomacia petrolera" permite una mayor facilidad para llevar a la práctica su proyecto geopolítico.

Aunque los países "liderados" tienen una escasa o nula influencia geopolítica en América Latina (por ejemplo, Cuba, Ecuador y Bolivia), este tipo de liderazgo ahora apunta a una "división de poderes" en el continente a partir de una retórica antiimperialista .

Lo que llamaríamos actitud proactiva para Venezuela encabezada por Hugo Chávez, debe entenderse dentro de una perspectiva más incisiva de acción en América Latina y afrontamiento a los EE.UU.

Lógicamente sabemos las dificultades y contradicciones de un proyecto de esta naturaleza ${ }^{136}$. Sin embargo, a pesar de estas dificultades, es posible establecer una línea de actuación dialéctica que permite Venezuela practicar su modelo.

\section{3 - La Política Exterior de Chávez: una Visión General}

La comprensión de la actuación antisssistémica de Venezuela está relacionada con el desarrollo de la política exterior llevada a cabo por el gobierno de Hugo Chávez. El papel de Venezuela en el escenario internacional está sometida a numerosas análisis favorables o contrarias de expertos ${ }^{137}$.

\footnotetext{
${ }^{136}$ Haremos un análisis detallado en el capítulo siguiente sobre el tema.

137 "En el siglo XXI, se asoma el fantasma del totalitarismo, presuntamente erradicado tras la derrota de la Alemania Nazi y la caída de la Rusia soviética, en la figura del líder populista que promete bienestar generalizado, justicia y equidad. El mundo de pos-guerra fría es un mundo en el que la democracia se encuentra amenazada". Torrijos, R. Vicente, Op. cit., p. 17.

Numerosos periódicos latinoamericanos ponen Hugo Chávez como un "dictador", "déspota", etc. La prensa estadounidense sigue la misma lógica, pero más "radical" ao describir el
} 
La política exterior de Caracas causa gran preocupación en Washington $y$ en las élites conservadoras en América Latina por la actitud proactiva y desafiante de la República Bolivariana al tradicional statu quo regional encabezado por los EE.UU. ${ }^{138}$.

Desde 1999, el país ha construido un arco de alianzas estratégicas que incrementan el desempeño del país en el ámbito internacional y su prestigio. Al mismo tiempo, ha ido ocupando el vacío político dejado por Washington en la última década. En la práctica,

[a] "Venezuela há empreendido una política exterior que tiene como uno de sus objetivos centrales construir uma política de alianzas, em particular uma política de alianzas antiestadounidense que se define com el instrumento central para disminuir la dependencia de estados Unidos, para impulsar um nuevo mapa geopolítico internacional y para impulsar um nuevo liderazgo mundial” ${ }^{139}$.

No debemos olvidar que la acción más "desafiante" de Venezuela (y otros gobiernos) en América Latina, refleja el debilitamiento de la posición ideológica y política de los Estados Unidos, especialmente durante el gobierno de George W. Bush.

Bajo el pacto Pontofijo, Venezuela mantuvo su proceso democrático sin la intervención directa de EE.UU., mientras que se mantuvo alineado con Washington, especialmente en la lucha contra el comunismo. Cómo marca Saraiva y Briceño Ruiz,

presidente venezolano como un "consumidor de drogas" y "traficante de drogas". El documental South of the Border (Al sur de la Frontera) de Oliver Stone hace un interesante resumen de las noticias difundidas por los "medios de comunicación" de Estados Unidos sobre Hugo Chávez. Otro análisis siempre desfarovável el líder venezolano Norman Gall es del director ejecutivo Fernand Braudel.

${ }^{138}$ La política exterior de la Venezuela Bolivariana. Working paper oㅜ 4, julio de 2010. www.plataformademocratica.org

${ }^{139}$ Carlos Romero Méndez. Las relaciones de seguridad entre Venezuela y Estados Unidos: la dimensión global. p. 19. 
(...) "A política externa venezuelana foi expressão do sistema de conciliação de elites que, no cenário internacional, propunha objetivos similares aos que o Pacto de Punto Fijo buscava a nível doméstico. Isto explica a permanência de metas como 0 compromisso com a consolidação da democracia, a constante busca da conciliação, do consenso e do compromisso, e a consciência de interdependência, especialmente em relação aos Estados Unidos" ${ }^{140}$. (...)

Retrocediendo un poco en el tempo, Vizentini señala que Venezuela, durante su desarrollo histórico enfrentó algunos problemas con una población pequeña y mal distribuida en su territorio, así como el predominio de la actividad agrícola. Tales aspectos habían dificultado la formación de una política exterior coherente y de proyección. Para Vizentini,

(...) "a Venezuela foi um ator bastante modesto nas relações internacionais, perdendo, inclusive, boa parte do território nacional para os Estados vizinhos e para a potência colonial inglesa, através da demarcação desfavorável das fronteiras contestadas" ${ }^{141}$.

La riqueza del petróleo es un activo que coloca a Venezuela en una posición privilegiada y, a partir de la década de 1960, el país ha creado las condiciones necesarias para mantener su autonomía.

El petróleo fue descubierto en 1878 en la provincia de Táchira. En el siglo XX, el consorcio Royal Dutch Shell comenzó la producción de petróleo en el Lago de Maracaibo, abriendo la explotación de petróleo venezolano a las

\footnotetext{
140 SARAIVA, Miriam Gomes; BRICENO RUIZ, José. Argentina, Brasil e Venezuela: as diferentes percepções sobre a construção do Mercosul. Rev. bras. polít. int., Brasília, v. 52, n. 1, Junho 2009.

${ }^{141}$ VIZENTINI, Paulo. A política externa da Venezuela. In: Venezuela - Visões brasileiras. Brasília, IPRI/FUNAG, 2003, p. 58.
} 
compañías extranjeras. A pesar de las facilidades fiscales y administrativas, el Estado venezolano ha mantenido como propietario de todas las riquezas. A finales de 1920, Venezuela produjo 137 millones de barriles de petróleo frente a 1,5 millones de barriles desde el comienzo de la década. El país se ha convertido en el segundo productor mundial después de los EE.UU..

Desde el punto de vista histórico, la diplomacia venezolana se vio influenciado por su posición colonial y periférico en la estructura españoles. Así el petróleo contribuyó a revertir ese marco, ya que la función:

(...) "ha sido el principal vehículo para la inserción de Venezuela en las relaciones internacionales contemporáneas. Este factor ha promovido a su vez una cultura política considerada como reguladora de la actividad privada, promotora de la dependencia de la sociedad del Estado y vulnerable ante las oscilaciones de los precios del barril del petróleo" ${ }^{\prime 142}$.

La abundante disponibilidad de petróleo transformó al país en exportador líder continental de la materia prima, y pre-Chávez gobiernos siempre han considerado la política exterior regional como "um instrumento básico na busca do desenvolvimento econômico, o que produziu atritos com os países hegemônicos, em particular os EUA"143. Gratius y Fürtig marcan la dimensión real de la Venezuela bolivariana. Según ellos:

"Venezuela is the only petro-state in Latin America and sixth largest oil producer in the world. Oil has been the main resource to finance Hugo Chávez' fourth 'Bolivarian Republic' of Venezuela based on a strong state ande centralisation of politics in the hands

\footnotetext{
142 Ibidem.

${ }^{143}$ (...) [a] "conversão da política externa em instrumento básico de busca do desenvolvimento econômico, o que produziu atrtos com países hegemônicos, em particular os EUA, e a formação de uma diplomacia mais autônoma (também uma forma de barganha)". Franklin, Cleber Batalha. Segurança e defesa nas relações entre o Brasil e a Venezuela. Caxambu: $30^{\circ}$ Encontro Anual ANPOCS, p. 22, 2006.
} 
of president. Under his presidency, Venezuela developed regional and even global power ambitions for the first time in its history, despite the country's limited size and power resources" ${ }^{\prime 14}$.

En el siglo XX, la política exterior venezolana pre-Chávez se caracteriza por su papel en el Movimiento de Países No-Alineados y por una autonomía diplomática considerable, mientras que el logro de buenas relaciones con los EE.UU. ${ }^{145}$. Como se ha dicho Carlos A. Romero,

"A raíz de la restauración de la democracia en el país en el año 1959, los gobiernos de Acción Democrática y de COPEI sostuvieron una diplomacia activa que llevó a muchos a pensar que se sobredimensionaba la presencia mundial venezolana, por la actuación en las Naciones Unidas, por la participación de Caracas en la creación y desarrollo de la Organización de Países Exportadores de Petróleo, OPEP, y por el impulso al mecanismo de integración económica y comercial conocido como el Acuerdo de la Junta de Cartagena, (hoy denominada como la Comunidad Andina de Naciones). A esto se le debe agregar el acercamiento de Venezuela al Movimiento de Países no Alineados y la procura de un nuevo orden internacional y de un diálogo Norte-Sur" ${ }^{146}$.

Según Carlos A. Romero no habría, necesariamente cualquier nueva postura sobre la actual política exterior bolivariana, como hemos visto anteriormente. Venezuela siempre ha tenido una considerable autonomía en el desarrollo de sus operaciones internacionales desde 1959. Sin embargo, el autor hace hincapié en que:

\footnotetext{
${ }^{144}$ Susanne Gratius e Henner Fürtig. Iran and Venezuela: bilateral alliance and global power projections, Fride. Comment, April 2009.

${ }^{145}$ Vizentini, Paulo. Op. cit., p. 57.

${ }^{146}$ La política exterior de la Venezuela Bolivariana. Working paper no 4, p. 4, julio de 2010. www.plataformademocratica.org
} 
"A nuestro entender, Venezuela atraviesa una "situación revolucionaria", lo que lleva a que la política exterior del gobierno del presidente Chávez no sea la misma de los que le precedieron. En efecto, el activismo de Venezuela se observa de manera tridimensional: en el manejo de las relaciones bilaterales, de las relaciones multilaterales y de las relaciones transnacionales" ${ }^{\text {"147. }}$.

En general, el "activismo" de la política exterior venezolana hoy en día es una característica desde 1960. Qué hubiera sido "cambiado", es como Venezuela busca su inserción internacional en los últimos años bajo el gobierno de Chávez. La política exterior puesta en practica desde Caracas se configura de acuerdo con Carlos A. Romero como $^{148}$ :

(...) un modelo político que se sustenta en la construcción de una visión del mundo en donde el enfoque 'amigo-enemigo' de la política, el uso indiscriminado de la tesis sobre la 'voluntad de la mayoría' y el afán de promocionar un 'paquete ideológico' radical, se han mezclado con tradiciones nacionales con el activismo internacional y el presidencialismo, en una oferta que ha contado con un poderosos verbo y una capacidad de gasto público que contempla importantes programas sociales".

Saraiva y Briceño Ruiz también observan que:

"A política externa dos governos venezuelanos entre 1958 e 1998 esteve delimitada pela condição de país ocidental, democrático e petroleiro, que começou a receber importantes recursos desde o primeiro boom do petróleo da década de 1970. Estes fatores determinaram as prioridades geográficas de sua política externa,

\footnotetext{
${ }^{147}$ Ibidem. p. 2.

${ }^{148}$ Ibidem.
} 
na qual os Estados Unidos apareciam como um parceiro natural na defesa da democracia e com o qual a Venezuela poderia partilhar uma estratégia assitencialista no Caribe com vistas a evitar a expansão do Comunismo" ${ }^{149}$. (...)

En nuestro análisis, la política exterior venezolana no debe ser entendida a través del enfoque utilizado por Carlos A. Romero, que contempla la idea de un binomio "amigo-enemigo" para que se mueva el país en el sistema internacional. Bajo este prisma, el "enemigo" en el ámbito internacional y latinoamericano de Venezuela Bolivariana en la actualidad se conoce muy claramente: los EE.UU..

Hay que destacar que el imperialismo de EE.UU. siempre ha trabajado en la construcción de una dimensión anti-democrática en América Latina, a pesar de la cacareada ideología dicen lo contrario.

El apoyo a los golpes militares y todo tipo de acción puestos en marcha por Washington desde la perspectiva de la prevención de la aparición de los movimientos sociales progresistas (si tenemos en cuenta sólo el siglo XX), por sí mismo, poner los EE.UU., sino como "enemigos" sino como obstáculo concreto a la democracia en América Latina ${ }^{150}$.

Sin embargo, a pesar de que tal afirmación suena como un discurso "izquierdista", como seguramente señalaría los "liberales y demócratas" la historia de América Latina muestra cuán dañino fueron los EE.UU trabajando contra la construcción de sociedades realmente más justas y democráticas.

Realmente nuevo en Venezuela, a nuestro juicio, sería un gobierno de izquierda, sin ninguna conexión con las tradicionales oligarquías venezolanas y sus intereses privados, allá de los lazos ideológicos y políticos con Washington. Otro aspecto importante es la conducta consistente de Venezuela en la creación de un bloque de países que se alojan en una organización, ALBA-

\footnotetext{
${ }^{149}$ SARAIVA, Miriam Gomes; BRICENO RUIZ, José. Op. cit.

150 Hemos mencionado los asesinatos, atentados, conspiraciones, desestabilización de los grupos de apoyo de los regímenes elegidos democráticamente, torturas etc.
} 
TCP, que sigue un proyecto político e ideológico coherente (el bolivarianismo y la construcción del socialismo siglo. XXI). Estamos de acuerdo con Carlos A. Romero cuando señala que:

"Pero hay otro proceso histórico que sí es novedoso: la llegada de un gobierno de izquierda al poder en Venezuela en 1999, que ha mantenido el activismo internacional de los gobiernos anteriores, profundizando su presencia mundial y apoyándose en las corrientes radicales de izquierda, marxistas y no marxistas que como un todo se han presentado como un pensamiento diferente a las ideas liberales. Por ello, la consolidación de la experiencia chavista ha originado una política exterior bifrontal, basada en su poder económico y en su compromiso revolucionario"151.

Venezuela, mientras actor interestatal, en nuestro análisis podría encajar en el modelo teórico de los movimientos antissistémicos propuesto por Arrighi (cuarto pilar) en que "uma reduzida capacidade dos Estados para controlar suas respectivas sociedades civis e associadas a crise (...)"152, permitiría el surgimiento de movimientos que no se podía ser controlado por las tradicionales estructuras políticas de poder. Siguiendo aún la proposición de movimientos antissistémicos, encontramos el quinto aspecto discutido en el Capítulo 3: la inclusión social de las clases desfavorecidas situadas en el propio sistema no garantizaba las condiciones mínimas para la supervivencia digna para estas personas.

Fueron las condiciones históricas que permitieron un ambiente familiar para apoyar Hugo Chávez, facilitando a practicar su política exterior. A comienzos del siglo XXI, Hugo Chávez, inició un cambio de la política exterior venezolana, que contempla en nuestro punto de vista los siguientes puntos:

\footnotetext{
${ }^{151}$ Op. cit., p. 4.

${ }^{152}$ Antisystemics movements. Op. cit., pp.103-106.
} 
Aumento de la influencia ideológica a través de la divulgación de una "visión latinoamericana" del mundo y difusión de los "valores bolivarianos" "153;

$>$ El liderazgo en posiciones antiamericanas en los foros internacionales;

La defensa de un mundo multipolar sin la supremacía de EE.UU.;

La Creación de un bloque económico (ALABA-TCP), que muestra fuertes componentes de las sinergias y la política social;

La Utilización natural de los recursos de petróleo para conseguir un papel destacado en la financiación del proceso de integración de los países que se unen al proceso.

Lógicamente se trata de una confrontación con la agenda hemisférica norteamericana que inevitablemente provoca enfrentamientos entre Washington y el Palacio de Miraflores.

El proyecto bolivariano es extremadamente consistente en la creación de nuevas formas de actuación en el sistema internacional con el declive de la influencia de EE.UU. en el continente y la nueva posición de Venezuela en el ámbito internacional ${ }^{154}$. Como señaló el Canciller del país Nicolás Maduro:

\footnotetext{
${ }^{153}$ Un ejemplo de la propuesta de disminuir la influencia ideológica de los tradicionales medios de comunicación internacionales con sede en los EE.UU., por ejemplo, y proporcionar información de los países del continente. Para ello, se estableció el 24 de julio de 2005, el canal de televisión TELESUR (La Nueva Televisora del Sur) a través de una idea inicial del presidente venezolano Hugo Chávez. Además de Venezuela, los países fundadores de la estación fueron Argentina, Cuba y Uruguay. Más tarde se unió a Bolivia (2006), Ecuador y Nicaragua (2007). Bajo el lema "Nuestro Norte y el Sur", se puede tener la idea de la estación propuesta en la lucha contra la ideología a los canales basados en los países centrales, en particular la de Estados Unidos.

154 "Desde un punto de vista mundial, el presidente Chávez se ha convertido en una especie de «enfant terrible» que ha venido tejiendo una diplomacia hiperactiva. Sus querellas con Estados Unidos, su acercamiento al régimen cubano y otros gobiernos vistos con reservas por Estados Unidos, la promoción de la OPEP, su clamor por un mundo multipolar, su creencia en la soberanía nacional absoluta y su apoyo a la revolución continental despiertan muchas simpatías en sectores sociales e intelectuales de América Latina". Ibidem, p. 12
} 
"Nosotros sabemos que la conquista del mundo pluripolar depende en buena medida de la articulación de nuevos liderazgos que hay en el Sur. Una articulación concreta, en base a esos proyectos, en base a construcción del Banco del Sur, la nueva arquitectura financiera del desarrollo de los países del Sur, en base a la construcción de un nuevo modelo de comercio justo entre las naciones, en base de un nuevo modelo de intercambio de tecnología y de reindustrialización de los países del Sur, en base a una nueva concepción de integración políticos. Sabemos que eses liderazgos están a prueba y sabemos que el gran reto es que tengan éxito en la construcción de los elementos que a nivel financiero, comercial, político, sustituían la hegemonía imperialista que ha sometido a nuestros países y que está profundamente agotada" 155 .

La demostración de este papel se puede ver con la modernización de las Fuerzas Armadas realizada por Hugo Chávez. Es importante hacer algunas consideraciones sobre la compra de armas por parte de Venezuela.

Sostenemos que la Doctrina Bush ha acelerado el "imperativo" de Venezuela para la modernización de sus fuerzas armadas ${ }^{156}$. La creación de la "guerra preventiva" contra los "enemigos" y "no empleados" en la guerra contra el terror consolidada en la perspectiva de defensa de los países que se incluyeron en la categoría de rogue states (Irán e Irak, por ejemplo) y la propia Venezuela Bolivariana. En el caso venezolano podría explicar el alto volumen de compras de equipo militar para mejorar sus defensas contra los Estados Unidos. Para Albernaz et al,

(...) "as motivações venezuelanas [dividem-se] entre evidentes e latentes. Os motivos evidentes ou as justificações do governo são:

\footnotetext{
${ }^{155}$ www.aporrea.org. Acesso em 26/09/2006.

${ }^{156}$ Cabe mencionar que la mayoría de los equipos militares venezolanos son obsoletos y no responde a las necesidades de defensa del país. Inevitablemente, tarde o temprano, debería haber una renovación de parte del equipo.
} 
preparação para uma guerra assimétrica com os EUA, relacionado à convicção de Chávez, e consequentmente, 0 fortalecimento das fronteiras com a Colômbia, aliada dos EUA e potencial inimiga, e a diversificação dos fornecedores militares; e a necessidade de reposição de equipamentos obsoletos. Os motivos latentes, os que mais influenciaram na decisão venezuelana são dois: manutenção da base de sustentação de Chávez (que garante sua liberdade política) composta por uma coalização do forte setor militar e do setor civil; e a ampliação do seu poder político na região, a busca por uma hegemonia regional" 157 .

Como un "efecto secundario", nunca está de más señalar que con tal volumen de compra las élites latinoamericanas y Washington desató la "bandera roja" para un posible "imperialismo venezolano" en la región. En Brasil, los medios conservadores trataron de enfatizar el peligro de Hugo Chávez con sus compras de armas.

El senador y ex presidente brasileño José Sarney (1985-1990), escribió un artículo en el periódico Folha de SP acerca del "peligro de la compra de armas" de Venezuela ${ }^{158}$ :

(...) "o plano de Chávez de gastar US\$ 60 bilhões em armas, transformando a Venezuela numa potência militar, é uma ameaça ao continente. Ele disse que ficará no governo até 2031 (não estarei mais por aqui) e se mostra "integracionista". Mas quem pode saber se um presidente da Venezuela não achará que deve ocupar a Amazônia para evitar sua internacionalização? Com os novos equipamentos - 14 caças Su-25, 600 mil bombas guiadas por GPS, estações de radar ultra-sofisticadas

\footnotetext{
${ }^{157}$ Albernaz, Bia et al. O aumento dos gastos militares da Venezuela. Realismo ofensivo e defensivo. In: Intellector. Rio de Janeiro, Centro de Estudos em Geopolítica e Relações Internacionais (CENEGRI), № 13, V. VII(1), julho/dezembro, p. 103, 2010.

158 "Luz Vermelha", Folha de S. Paulo, 14/07/2006.
} 
tridimensionais JYL da China e, em aquisição, 138 navios, dez a 15 submarinos e 150 supersônicos —, nossa soberania vira pó. Ninguém imaginou que isso pudesse ocorrer no continente sulamericano.

Para que tudo isso? Para enfrentar os Estados Unidos? Ora, para a superpotência isso não vale nada, mas para nós é uma força de fazer tremer. De duas uma: ou o Brasil entra na corrida armamentista para assegurar sua defesa, retirando o escasso dinheiro de seu Orçamento que está servindo para nossos programas sociais, ou então, para sobreviver, tem de acobertar-se no guarda-chuva da OTAN, tragicamente fazendo voltar a tese de Menen, como única forma de defender-se. Menen era contra o Brasil, agora seremos todos unidos para nos defendermos da "nova potência militar" que dominará a América do Sul". (...)

Declaraciones como esta, son incompatible con la realidad de los hechos, reflejan la opinión de los expertos y los políticos conservadores en los EE.UU.. Los medios de comunicación apuntaban a una posible "carrera armamentista" que comienza a prevalecer en el cual América del Sur estaría entrando. En Washington, el "análisis" en América del Sur.

El hecho es que, para actuar con aplomo, en su papel antissistémico Chávez tuvo que crear un enfrentamiento simbólico y geopolítico contra los EE.UU., como una forma de afirmar su posición en el actual sistema-mundo y ofrecer una alternativa en América Latina a la influencia de Washington.

Fuera del continente, además de Rusia, Hugo Chávez, realizó visitas a Libia, Corea del Norte y varios países africanos desde que asumió el cargo. Su objetivo era "hacer un soporte" y ganar proyección internacional, especialmente en relación a los EE.UU.. El hecho es que Chávez ha ocupado los titulares internacionales para esta posición.

La alianza con los rusos, por ejemplo, era inevitable, dado el hecho de ellos no aceptar la presión de EE.UU. para cualquier tipo de embargo sobre la venta de armas a Venezuela. La cooperación militar con los rusos incluió 
ejercicios militares navales conjuntos en 2008, cuando llegó al Caribe dos bombarderos estratégicos Tu-160 (conocido como Blackjack) y Tu-95MC, El crucero nuclear "Pedro el Grande" y la fragata Almirante Chabanenko, entre otros buques de escolta. Desde la crisis de los misiles de 1962, no había una gran presencia militar extranjera en el Caribe.

La influencia venezolana se produce no sólo en el sector político sino también en el sector económico a través de la provisión de ayuda generosa a todos los países que son aliados o amigos, o están cerca de la propuesta bolivariana. Este es el mismo mecanismo ejecutado por la Casa Blanca con el tiempo.

Argentina, otro ejemplo, a pesar de no tener una postura que se puede clasificar de alineación con la política venezolana desarrollada en la región, encontró un gran aliado cuando necesitó de ayuda económica.

Antes de dejar el gobierno en 2007, el presidente Néstor Kirchner contó con el apoyo financiero de Hugo Chávez. Argentina ha emitido 500 millones de dólares en títulos del Bono del Gobierno Nacional (Boden) con vencimiento en 2015. El país paga una tasa de interés del $10,43 \%$, consideradas dentro del margen cobrado por el mercado, los analistas dicen ${ }^{159}$.

La transacción fue de gran importancia para los argentinos, ya que el país no contaba (y no cuenta como hoy en día) con una buena evaluación de la comunidad financiera internacional después de declarar que no pagaría su deuda en diciembre de 2001, aún con la posterior renegociación. Entre 2005 y 2007, Venezuela ya había comprado 5,6 mil millones de dólares en bonos $\operatorname{argentinos}^{160}$.

En 2008 Argentina resolvió emitir títulos de deuda pública por 1.461,9 millones de dólares y con vencimiento en 2015 para venderlos de forma directa

\footnotetext{
159 "Venezuela volta a comprar títulos da Argentina". 23/11/2007.<http://www.estadao.com.br/noticias/internacional,venezuela-volta-a-comprartitulos-da-argentina,84646,0.htm > Acesso 22/11/2011.

160 lbidem.
} 
a Venezuela, Venezuela llevará adquiridos desde 2005 un total de 7.802 millones de dólares en bonos soberanos de Argentina. ${ }^{161}$.

La importancia de la ayuda de Venezuela a Argentina puede ser evaluada por los reconocimientos públicos realizados por la presidenta Cristina Kirchner, en enero de 2009, en una visita a Caracas. Según el presidente, "É importante dar esse reconhecimento, além das convicções, das visões comuns que nos unem em relação aos destinos de nosso continente" ${ }^{162}$.

En la oportunidad, el Presidente también agradeció la ayuda venezolana de 85 millones a la cooperativa láctea argentina Sancor que estaba en quiebra. Esta ayuda ha permitido a la empresa mantener el control en manos del capital nacional. A cambio, Sancor comenzó a suministrar leche en polvo y el sector de la tecnología para los venezolanos. ${ }^{163}$.

La presidenta Cristina Kirchner también dijo en esa oportunidade "a república irmã ajudou o país quando a Argentina precisava ter acesso ao mercado de capitais por causa de uma moratória que não foi declarada pelos governos que vieram depois de 2003"164.

La actuación venezolana trasciende los aspectos puramente políticos. Hay un proyecto que se ha puesto en práctica y que presenta innegables éxitos para crear un entorno favorable para la política exterior de Venezuela.

En nuestro análisis identificamos la existencia de dos acciones del proyecto chavista para poner en práctica su proyecto antissistémico: el primero está relacionado con el aumento de su influencia política e ideológica en América Latina, y el segundo, sus operaciones internacionales para obtener una mayor visibilidad y proyección.

A seguir vamos a analizar las dos formas de actuación de Venezuela, tratando de entender la viabilidad real del proyecto de Venezuela, los países que comenzaron a operar en la zona de influencia en el continente, y las

\footnotetext{
161 "Cristina Kirchner agradece a Venezuela por compra de títulos da dívida". 22/01/2009. <http://noticias.uol.com.br/ultnot/ansa/2009/01/22/ult6817u1400.htm> Acesso em 23/11/2011.

162 Ibidem.

163 Ibidem.

164 Ibidem.
} 
relaciones extra-continentales a partir de la política exterior desarrollada por el Palacio de Miraflores.

\section{4 - La Actuación de Venezuela en el ALBA-TCP}

La elaboración de la ALBA-TCP fue otro paso dado por Chávez con el fin de acelerar el proceso antissistémico en América Latina bajo su liderazgo.

En 1999 Hugo Chávez hizo su primera mención en lo que configuraría la Alternativa Bolivariana para las Américas (ALBA). La idea inicial fue llamada Confederación de Estados de América Latina. Chávez tenía en mente para contrarrestar el peso de la propuesta norteamericana de la Área de Libre Comercio de las Américas (ALCA), que ofrecen pocas perspectivas de un comercio más equilibrado entre los países de América Latina y Estados Unidos. Como símbolo de esta nueva propuesta para bloquear Chávez, Cuba sería parte de la nueva organización, yendo en contra de la postura de EE.UU. de aislar a la isla caribeña desde 1960.

En varias ocasiones el presidente venezolano mostró la necesidad de acelerar el proceso de integración del continente. Señaló el letargo del MERCOSUR hacia esta integración. Esta posición fue defendida, por ejemplo, en el programa de televisión brasileño "Roda Viva" en 2005. Durante casi dos horas se acercó a sus ideas para la integración latinoamericana.

La perspectiva antissistémica es notoria del proyecto chavista del ALBATCP al acelerar y conducir una perspectiva económica y ideológica que propone el anti-imperialismo como la acción constante de los países miembros, la actuación del Estado en la organización y regulación de la economía, la valorización de los valores humanos y filosóficos basados en una gran amalgama de corrientes de izquierda, indígenas, panamericanismo, tercermundismo etc, e intentar una entrada diferente en el moderno sistemamundo. 
El ALBA-TCP está integrado por países que no tienen gran base económica diversificada (ver Cuadro 11). La gran mayoría de los Estados miembros no tienen niveles de industrialización que se clasifican como mínima. Por el contrario, Venezuela se convierte en el país más importante debido a las reservas de petróleo. Tampoco existe una base industrial consistente, facto que hace que el país dependa de las importaciones de productos agrícolas y de las exportaciones de petróleo para su mayor enemigo ideológico y geopolítico, los EE.UU..

\section{Cuadro 11}

Datos económicos de los países miembros del ALBA-TCP

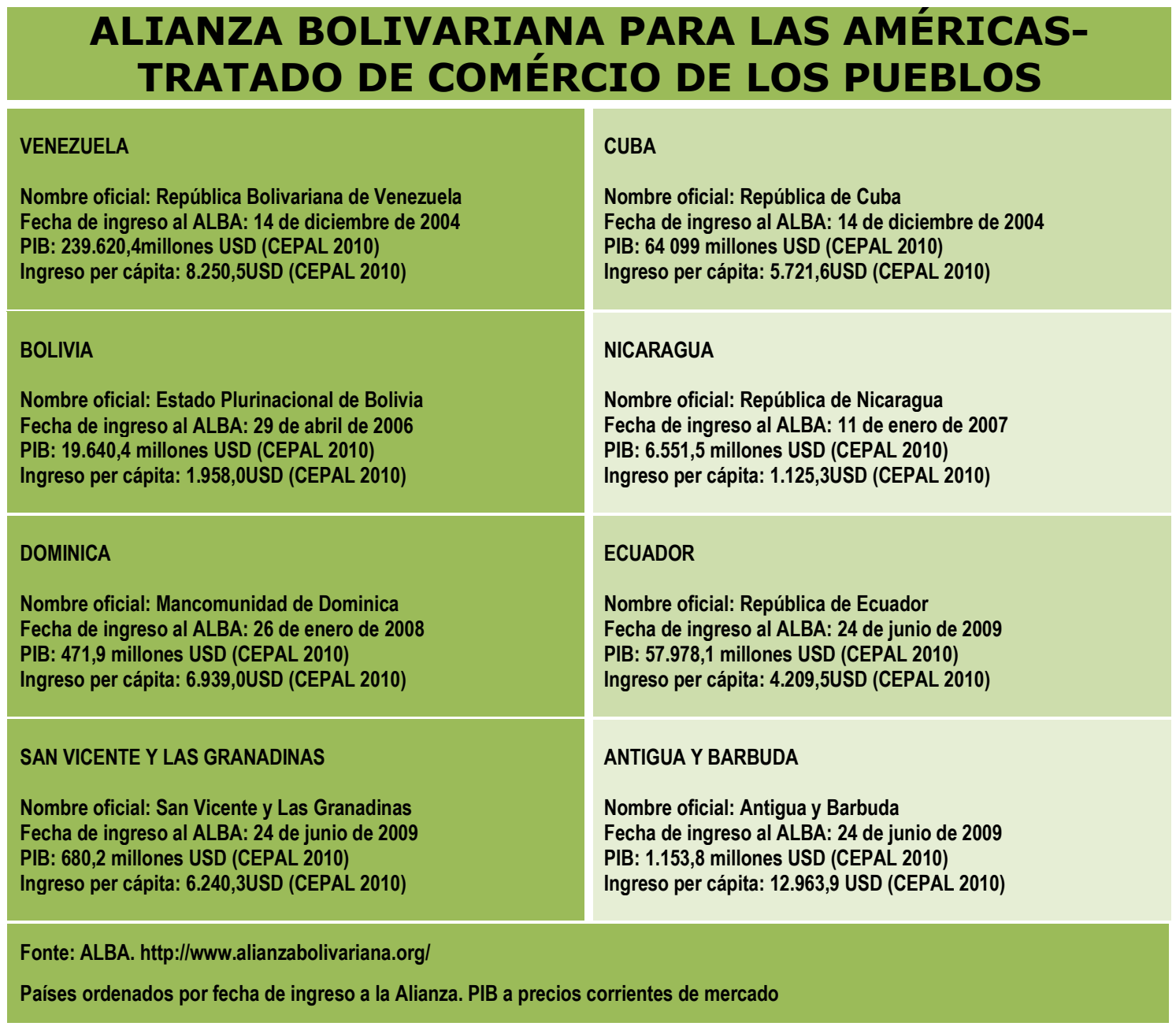


Fundador del ALBA-TCP de la primera hora con Venezuela, Cuba sigue teniendo un papel mitológico en América Latina. La Revolución Cubana fue durante el período de la Guerra Fría un ejemplo de la "victoria" del socialismo sobre el capitalismo. Una pequeña isla del Caribe, a $140 \mathrm{~km}$ de distancia de la Florida, había arreglado "derrotar" el "imperialismo yanqui". Generaciones enteras de izquierdistas del continente cultivan el fervor "revolucionario" demostrado por Fidel Castro y Che Guevara en la construcción de una sociedad socialista.

Sin embargo, la crisis económica que siguió al fin de la URSS en 1991, puso al país en un estado de "coma económico" permanente desde 1994. Pero el país ha encontrado un respiro financiero grande después de la elección de Hugo Chávez en 1998.

El Palacio de Miraflores, para demostrar su posición "revolucionaria" y antissistémica, eligió a Cuba como un aliado importante en América Latina. Chávez ha establecido vínculos privilegiados con La Habana asociando el nuevo período venezolano de un "proceso revolucionario", como ocurrió con Cuba post-59.

El aumento de las relaciones cubano-venezolanas comenzó en octubre de 2000, cuando Fidel Castro y Hugo Chávez, firmaron un Convenio Integral de Cooperación en que se estableció la venta de petróleo venezolano (53.000 barriles / día) a Cuba a cambio de apoyo técnico en las áreas de la educación, salud, deporte, ciencia y tecnología ${ }^{165}$. A cambio de esta condición beneficiosa de compra de petróleo de Venezuela, Cuba comenzó a ofrecer sus servicios médicos en el país.

Así que la presencia cubana en territorio venezolano es considerable, sobre todo en el sector social. En 2000, los dos gobiernos crearon el Programa

\footnotetext{
${ }^{165}$ Dan Erikson, Inter-American Dialogue. "Castro's Chávez Strategy" (PDF). Center for Latin American and Caribbean Studies, University of Connecticut. December 2005. <http://dspace.cigilibrary.org/jspui/bitstream/123456789/18826/1/Cuba\%20Venezuela\%20and\% 20the\%20Americas\%20A\%20Changing\%20Landscape.pdf?1> Acessado em 05/01/2012.
} 
Convenio de Atención a Pacientes, a través del cual Venezuela enviará sus enfermos a Cuba ${ }^{166}$.

Cinco años más tarde, un nuevo acuerdo se ha incrementado el número de cubanos en el sector de salud de Venezuela: 30000 trabajadores cubanos estaban en suelo venezolano. Con la ayuda de Cuba, Venezuela inició la creación de 1.000 centros de atención gratuita y de formación a 50.000 personas en el campo de la medicina bajo la supervisión de Habana. También en $2005,100.000$ venezolanos recibieron tratamiento quirúrgico en la isla caribeña $^{167}$.

En 2004, Hugo Chávez y Fidel Castro firmaron una declaración conjunta contra el ALCA, diciendo que sería "un mecanismo para aumentar la dependencia y la dominación extranjera"168. Los países han demostrado una gran afinidad en los discursos.

En febrero de 2005, Caracas aumentó el envío a Cuba de 53.000 barriles/día a 90.000 barriles/día, un 3,5\% de la producción petrolera venezolana $^{169}$. Una pequeña cantidad para Venezuela, pero muy importante para la isla caribeña. En la práctica, una buena parte del petróleo enviado a Cuba está subvencionado, casi en la línea de lo que sucedió en la época soviética.

El hecho es que la ayuda venezolana es sumamente generoso. Algunas estimaciones indican que en 2005, aproximadamente entre 20 mil y 25 mil barriles eran prácticamente "donado" por los venezolanos, lo que representa una economía que llegará a 6,8 millones de dólares en 2020. Como el consumo de Cuba es de 120 mil barriles /día y su producción nacional es de 80

\footnotetext{
166 Javier Corrales, Amherst College. "The Logic of Extremism: How Chávez Gains by Giving Cuba So Much" (PDF). Center for Latin American and Caribbean Studies, University of Connecticut.<http://news.caribseek.com/set-up/uploads-caribbean-documents/2005-cubavenezuela-and-the-americas.pdf> Acessado em 15/11/2011.

${ }^{167}$ Ibidem.

${ }^{168}$ Richard Peet. Geography of Power: Making Global Economic Policy. Zed Books. p. 173, 2007.

169 Cuba and Venezuela: oil and politics. BBC News. 22/10/2007. <http://news.bbc.co.uk/2/hi/americas/7157113.stm> Acessado em 15/11/2011.
} 
mil barriles/día, Habana consegue reexportar entre 40-50 mil barriles/día, aumentando sus reservas internacionales en divisas ${ }^{170}$.

En 2006, los dos países establecieron una join venture para construir una refinería de petróleo en la ciudad de Cienfuegos. Las dos naciones han invertido entre 800 millones de dólares y mil millones en un proyecto. El acuerdo preveía que el $51 \%$ de la planta estaría bajo el control de Cuba y el $49 \%$ estaría com Venezuela por PDVSA ${ }^{171}$.

En enero de 2007, Chávez y el vicepresidente cubano Carlos Lage suscribieron un acuerdo para desevolver proyectos involucrando níquel, electricidad y arroz. El acuerdo también contempla la construcción de cables de fibra óptica submarinos, resolviendo un problema de la calidad en las comunicaciones de Cuba. El problema existe debido a que más de la mitad de una década de embargo económico de EE.UU. ${ }^{172}$.

En junio de 2010, los dos países firmaron cinco acuerdos de inversiones conjuntas por valor de 1,3 mil millones de dólares durante el XI Comisión Intergubernamental ${ }^{173}$.

En junio de 2011, los países firmaron más cinco acuerdos de inversiones conjuntas por valor de más de 900 millones de euros en la XI Comisión Intergubernamental que tuvo lugar en la isla caribeña. A lo largo de este año se ha establecido aún la firma de 100 acuerdos para el desarrollo de 116 proyectos para el desarrollo de ambos países, incluida la energía, la construcción, el transporte, las comunicaciones, la cultura, los deportes y la información ${ }^{174}$.

\footnotetext{
170 Javier Corrales. Op. cit.

171 "Cuba and Venezuela: oil and politics". 22/12/2007. <http://news.bbc.co.uk/2/hi/americas/7157113.stm> Acessado em 05/11/2012.

172 "Cuba, Venezuela extend ties despite Castro's illness". 25/01/2007. $<$ http://www.dnaindia.com/world/report_cuba-venezuela-extend-ties-despite-castro-sillness_1076277> Acessado em 15/11/2011.

173 "Cuba/Venezuela: Cinco acordos assinados para investimento conjunto de 1.300 milhões de dólares". 12/06/2011. Visão. <http://aeiou.visao.pt/cubavenezuela-cinco-acordos-assinadospara-investimento-conjunto-de-1300-milhoes-de-dolares=f607447\#ixzz1e9emTf7Y > Acessado em 15/11/2011.

174 Ibidem.
} 
En términos militares, los cubanos también prestan asistencia a las Fuerzas Armadas Venezolanas desde el año 2004, cuyo objetivo es "eliminar" la influencia militar de EE.UU.. La acción cubana tiene lugar en la formación por el uso de equipo militar comprado a Rusia y la táctica de guerrillas y contrainsurgencia, área que el país cuenta con una gran experiencia desde $1960^{175}$.

La consecuencia para los cubanos en el corto plazo, es la capacidad para mitigar la débil estructura económica que no tiene la diversificación, y la obtención de divisas. Sin embargo, lo que podríamos llamar "daños colaterales" para Habana es el mantenimiento de la misma dependencia del país, como sucedió en la época soviética. Esta dependencia hace a Cuba vulnerable a los cambios de política que pueden ocurrir en Venezuela en un post-Chávez.

Bolivia es otro país a sufrir una fuerte dependencia de Venezuela, incluyendo militar. Para los bolivianos, Venezuela se ha convertido en una forma de estimular la economía mediante un socio económico con mayor capacidad económica y que actúa en el mismo campo ideológico.

La influencia de Hugo Chávez sobre Bolivia se puede sentir después de la histórica victoria electoral de Evo Morales en 2005. Poco después de las elecciones, Morales visitó Caracas para mantener contactos directos con Hugo Chávez. La visita fue una demostración de cómo la influencia de la Revolución Bolivariana y de Chávez se hizo importante en el país andino.

Un importante ejemplo de esta influencia se produjo el 1 de mayo de 2006, cuando el gobierno boliviano nacionalizó el sector de gas y petróleo de Bolivia, hasta ahora en gran parte controlada por la brasileña Petrobras.

Evo Morales al nacionalizar la industria petrolera, cumplió una de sus promesas de campaña. La nacionalización del sector habría sido una "influencia" de Chávez, que le había dado apoyo político y ofreció la logística de la estatal venezolana PDVSA para mantener la operación de los pozos de gas, si la ruptura del contrato llevasse a Petrobras a salir de Bolivia.

\footnotetext{
${ }^{175}$ Javier Corrales. Op. cit.
} 
La alianza entre Caracas y La Paz llevó a la firma de numerosos acuerdos bilaterales ${ }^{176}$ que aumentó la proximidad entre los dos países, aumentando la influencia de Venezuela sobre el vecino andino.

En 2006, los presidentes Hugo Chávez y Evo Morales, firmó más de 20 acuerdos en los sectores de hidrocarburos y petroquímica. Los dos gobiernos también acordaron proyectos de cooperación adicionales en las áreas de salud, educación y agricultura ${ }^{177}$.

El principal acuerdo firmado entre los dos países se refirió a un proyecto binacional en el sector petrolero. El acuerdo ha entrado en el Tratado de Comercio de los Pueblos (TCP) que los dos países promueven, junto con Cuba, para contrarrestar a los tratados de libre comercio (TLCs) propugnados por los Estados Unidos.

Además de los veinte acuerdos en los sectores de hidrocarburos y petroquímica, se establecieron aproximadamente 200 cartas de crédito para el desarrollo de proyectos comunitarios en las áreas de salud y educación.

Venezuela planea invertir cerca de 1,5 mil millones de dólares en la industria petrolera boliviana, y otros 100 millones de dólares en la agroganadera local, inversiones con las que Chávez y Morales pretenden promover una sociedad tri-nacional, en asociación con Cuba.

La petrolera estatal YPFB (Bolivia) y PDVSA (Venezuela) está de acuerdo en los detalles de cinco grandes proyectos en el sector energético. Una de las claves fue la creación de Petroandina, que debe proporcionar a las estaciones de combustible instaladas en ocho de los nueve departamentos de Bolivia. Otro proyecto consiste en la construcción de un complejo petroquímico en Bolivia. Sin embargo, los acuerdos entre los dos países no se limitan al sector de la energía.

La influencia venezolana se produce no sólo en el campo económico. En el ámbito social, Venezuela y Cuba están prestando apoyo a los programas

\footnotetext{
${ }^{176}$ Acuerdos de cooperación en las áreas: energía, agricultura y desarrollo rural, educación superior, desarrollo social, salud y el deporte.

177 Información obtenida del Ministerio del Poder Popular para Relaciones Exteriores. http://www.mre.gov.ve/
} 
sociales, tales como la cirugía ocular "Operación Milagro", que ha atendido a más de 800 personas en Bolivia. Los programas sociales también incluyen planes de alfabetización.

Con el apoyo de estos dos países, Bolivia que desea declararse zona libre de analfabetismo en 2007 (hecho que todavía tiene que materializarse), mientras que la Operación Milagro pretende servir cerca de 100 mil personas. Médicos cubanos trabajan en el país, así como en Venezuela. Cuando ellos fueren, centros médicos especiales funcionarán con médicos bolivianos. También está prevista el anuncio de la llegada de dos bancos venezolanos en el país y el envío de equipo técnico de Chávez que ayudará en la reforma agraria boliviana ${ }^{178}$.

En 2007, se firmaron más acuerdos. Uno de ellos contó con la participación de Venezuela en el desarrollo de grandes reservas de mineral de hierro boliviano El Mutún. Los pronósticos sugieren la existencia de cerca de 40 mil millones de toneladas de mineral.

Entre otros contratos, Bolivia y Venezuela también firmaron un acuerdo para construir una industria petroquímica en la región boliviana de Cochabamba. La fábrica procesará gas natural.

En el plano interno, los líderes de la oposición en Bolivia han acusado a Morales de "recibir órdenes" del Gobierno de Venezuela que, por su parte, se convirtió en un financiador importante para el país andino.

En 2008, se firmaron más acuerdos, ahora en el sector textil. Ellos predijon que Venezuela podría comprar textiles bolivianos, que han sido boicoteados por los Estados Unidos por su acercamiento a Hugo Chávez. ${ }^{179}$.

El acuerdo, firmado entre la estatal venezolana Suvinca y la boliviana Promueve, tiene la intención de incrementar el comercio entre los países. "Vamos exportar produtos têxteis para a Venezuela e a empresa Suvinca receberá nossa mercadoria"180, dijo la ministra boliviana de Producción y

\footnotetext{
${ }^{178}$ Ibidem.

179 Ibidem.

${ }^{180}$ Portal Latino-Americano da Agência Ansa. Data da publicação: 29/10/2008.
} 
Microempresa, Susana Rivero. Los dos presidentes también firmaron un acuerdo para fortalecer las relaciones comerciales bilaterales entre los sectores industriales de Venezuela y Bolivia.

Durante la firma, el presidente boliviano agradeció a Chávez por la apertura del mercado venezolano para productos textiles de Bolivia que, según él, fueron boicoteados por los Estados Unidos a causa de su política contra la intervención norteamericana en su país. "Quando a gente se opôs às políticas dos EUA, o governo norte-americano decidiu cortar as importações de produtos têxteis", dijo ${ }^{181}$.

La presencia de Venezuela en Bolivia continuó en 2010, cuando los dos países continuaron su enfoque económico. Este año se han firmado más de 15 acuerdos bilaterales, especialmente en materia de energía. Sin embargo, los acuerdos no limitarse únicamente a este sector. Se firmaron acuerdos para la creación de empresas binacionales y programas de cooperación en los ámbitos económico, social, científico y tecnológico.

Morales y Chávez firmaron un acuerdo marco para la creación de la Comisión Mixta de Integración Económica, que estará encabezada por ambos y que servirá para dibujar el mapa de cooperación y desarrollo conjunto, fomentando las relaciones que sustituyen el concepto de "desarrollo neoliberal". Es decir, que las acciones se toman con base en aspectos relacionados con los intereses sociales, y no en los supuestos de mercado: el beneficio como el fundamento básico.

Entre las empresas binacionales cuya constitución fue creada por los dos gobiernos, es una entidad mezclada destinada a desarrollar proyectos en el área de la industrialización del gas y de los hidrocarburos, y otra para impulsar el uso del gas como combustible para vehículos y como energía doméstica.

Entre otros convenios y actas de compromiso, contenía una "alianza estratégica, científica, tecnológica, financiera y de trabajo para el procesamiento del gas y la petroquímica", y la creación de una empresa que

181 Ibidem. 
"explore, transporte y almacene petróleo y gas". Los proyectos también incluyen el "refino, armazenamento, distribuição, transporte e comercialização de hidrocarbonetos para abastecer o mercado boliviano e a exportação de excedentes aos países do ALBA" ${ }^{182}$.

En el ámbito militar, el acuerdo entre los dos países data en mayo de 2008, con la firma del Memorando de Entendimiento en Materia de Seguridad y Defensa por los ministros de defensa: el boliviano Walter Sanmiguel y el venezolano Gustavo Rangel Briceño. Algunos puntos del acuerdo fueron dados a conocer por el gobierno venezolano y por la prensa boliviana en los sectores de la cooperación, capacitación del personal y en la zona marítima en la época ${ }^{183}$, es decir:

(...) "La cooperación en el área de aviación militar comprende el intercambio de pilotos a partir del primer semestre de 2009, la ejecución de misiones administrativas (transporte de personal y misiones de apoyo) y asesoramiento técnico al Sistema Aéreo Boliviano.

En capacitación, intercambiarán oficiales para participar en los cursos de Estado Mayor y como participantes y observadores en las maniobras militares. Además de brindar asesoramiento técnico para preparar, planificar y elaborar programas de juegos de guerra computarizados, crear y organizar liceos militares, y una escuela de idiomas en Bolivia.

En asuntos marítimos, intercambiarán pasantes en las campañas hidrográficas y de cartografía. La Fuerza Armada de Venezuela coordinará pasantías de hasta tres participantes de la Fuerza Naval Boliviana en Administración Portuaria y Astilleros. Intercambiarán personal militar en Astilleros Navales. (...)

\footnotetext{
182 Ibidem.

183 Jornal El Mercúrio, "Venezuela y Bolivia firmaron un acuerdo de "cooperación militar", 22/05/2008.
} 
Ecuador también se alió con el proyecto bolivariano con la victoria de Rafael Correa en 2007. La victoria del candidato de la izquierda siguió la misma lógica presente en las reivindicaciones de la población de Bolivia con Evo Morales. Así como en Bolivia, las camadas populares ecuatorianas siempre se ha desplazado del proceso político y económico del país. Rafael Correa se convirtió en un rápido aliado de Hugo Chávez de la misma manera de Bolivia. Recibido apoyo político y económico de Venezuela y pasó a formar parte de un "eje", "Caracas-La Paz-Quito".

En octubre de 2009, sin dejar de aumentar su influencia, Venezuela y Ecuador firmaron una serie de acuerdos relacionados con sectores de la energía, militar y financiero. Se estableció la creación de empresas binacionales, como la minería Mariscal Sucre y la Siderúrgica del Pacífico Eloy Alfaro, además de una empresa alimentaria.

También se acordó la creación de un fondo Ecuador-Venezuela para financiar proyectos binacionales en los sectores de transporte, turismo, alimentación, salud, medio ambiente, energía, infraestructura y telecomunicaciones, esta última tiene como objetivo construir un "Observatorio Latinoamericano de Medios de Comunicación Socia" y la incorporación del Ecuador en el proyecto de Radio Sur. Venezuela aún hizo una donación de 20 millones de dólares en sillas de ruedas, muletas y equipos médicos.

Se firmó un acuerdo técnico-militar que, según Chávez, tiene como objetivo "reforzar la capacidad militar de nuestros países, nuestras revoluciones" ${ }^{184}$. Según Correa, "Demos um passo à frente para alcançar esta união, integração, entre povos irmãos", ressaltou Correa, demonstrando a importância de acelerar este processo de integração, já que, segundo ele, "há muitos urubus que buscam fracassar as vias alternativas do socialismo" ${ }^{185}$.

En América Central Nicaragua se ha convertido en más un país a estar en el área de influencia venezolana. La presencia nicaragüense en el escenario geopolítico latinoamericano surgió con la Revolución Sandinista en 1979. El

\footnotetext{
${ }^{184}$ Ver Agência Ansa Latina em 08/10/2009.

<http://www.ansa.it/ansalatinabr/notizie/notiziari/equador/20091008083234959435.html> 185 Ibidem.
} 
país tiene una gran importancia para la creación de un nuevo frenesí anticomunista en América Latina en la década de $1980^{186}$. Desde la Revolución Cubana de 1959, el continente no presenció un proceso revolucionario que implicó una guerra civil. Como era natural, Washington estaba preocupado con desarrollo del proceso en Centroamérica.

Como ya hemos comentado anteriormente en este capítulo la respuesta dada por la Casa Blanca en la administración Reagan fue el apoyo (militar, financiero y logísitico) a los "Contras" que utilizan todo tipo de sabotaje contra el gobierno sandinista en los años 1980. Con tal desestruturacion económica, los sandinistas perdieron las elecciones celebradas en 1990 para la candidata de la derecha y apoyada por los EE.UU. Violeta Chamorro.

Los sandinistas sólo regresaron al poder en un contexto totalmente diferente de los años de la Guerra Fría. Con el marco político y ideológico de América del Sur favorable y con la hegemonía de EE.UU. en declinación, el antiguo líder sandinista Daniel Ortega una vez más se convirtió en presidente en 2006.

El acercamiento con Venezuela era inevitable y aseguró un gran aliento económico para el país y su reelección en $2011^{187}$. Elección garantiza el éxito de los programas sociales para los pobres.

Las relaciones económicas entre los dos países empezaron casi inmediatamente a la elección de Ortega en 2006. La Venezuela desde 2007 ha proporcionado una ayuda económica de 1,6 mil millones de dólares para Nicaragua. De acuerdo con los analistas y los propios Sandinistas, una ayuda de importancia fundamental. Esto ayuda en condiciones privilegiadas permitió al país centroamericano un crecimiento económico del 4,5\% en 2010, abajo

\footnotetext{
${ }^{186}$ En los años 1960 y 1970, el Frente Sandinista de Liberación Nacional (FSLN) hizo la oposición armada a la dictadura de Anastasio Somoza. En 1979, la FSLN logró la victoria y la implementación de un gobierno de orientación socialista.

187 “Nicarágua elege novo presidente e Parlamento". BBC, 06/11/2011.

<http://www.bbc.co.uk/portuguese/noticias/2011/11/111106_nicaragua_eleicao_fn.shtml> Acessado em 22/11/2011.
} 
solamente de Panamá ${ }^{188}$. La estimación para el año 2011 se registró un aumento del $4 \%{ }^{189}$.

Inevitablemente, la oposición nicaragüense empezó a detectar "lagunas" en la ayuda venezolana al país. Ella dice que gran parte de los recursos enviados por Hugo Chávez allá de se invierten en el desarrollo social, están siendo controlados por un pequeño grupo alrededor de Daniel Ortega, que serían los grandes beneficiados ${ }^{190}$.

La presencia de Venezuela en Nicaragua, además de preocupar los EE.UU., también preocupa el FMI. De acuerdo con la institución, existe el peligro de dependencia severa de la economía nicaragüense del capital de Caracas.

Como ocurre en cualquier relación de dependencia económica, Nicaragua puede sentir los efectos del corte abrupto en la relación económica entre los dos países. Esto puede ocurrir tanto por el cambio en la política en el Palacio de Miraflores como en Managua. El hecho es que sin la ayuda de Venezuela en el corto y largo plazo, la economía nicaragüense va a sufrir serios problemas ${ }^{191}$.

Desde el punto de vista analítico de las relaciones económicas dentro del ALBA-TCP encontramos importantes asimetrías entre los países participantes. Como se ha señalado, el "factor petróleo" es crucial para la hegemonía de Venezuela en el bloque económico. La riqueza del petróleo

\footnotetext{
188 "Venezuela's Chávez bankrolled Nicaragua with $\$ 1.6$ billion since 2007". Christian Science Monitor. April 7, 2011.

<http://www.csmonitor.com/World/Americas/2011/0407/Venezuela-s-Chavez-bankrolledNicaragua-with-1.6-billion-since-2007> Acessado em 22/11/2011.

189 Informação verificada em 21/04/2012. Fonte de consulta: World Fact Book https://www.cia.gov/library/publications/the-world-factbook/geos/nu.html

190 "Popular support for Daniel Ortega has grown thanks to patronist programs that are financed by [Venezuelan President Hugo] Chávez, who provides $\$ 500$ million per year, equivalent to $7 \%$ of the country's GDP," Chamorro adds that a portion of those funds are not accounted for in the national budget. He accuses the Ortega family of using the Chávez cash to finance private businesses, political campaigns and "numerous acts of corruption."

"Flush with Chávez petro-dollars, Nicaragua's Ortega eyes controversial third term". 04/11/2011. <http://worldcrunch.com/flush-ch-vez-petro-dollars-nicaragua-s-ortega-eyes-controversial-thirdterm/4043> Acessado em 22/11/2011.

${ }^{191}$ Ibídem
} 
permite a Hugo Chávez influir y organizar el bloque dentro de su "dimensión bolivariana".

\section{5 - La Actuación de Venezuela en el Escenario Internacional}

Después de consolidar su bloque histórico doméstico, Venezuela inició sus operaciones internacionales, promoviendo amplios contactos internacionales con países que tenían algún tipo de confrontación internacional con los EE.UU. y/o que no aceptan la perspectiva unipolar de los EE.UU..

Como ejemplo de este intento de crear un "entorno favorable" internacional, podemos citar como ejemplo la visita realizada por el presidente de Venezuela en 2006: Irán, Bielorrusia, Rusia y Vietnam (julio); Malí, China, Malasia, Qatar, Siria y Angola (agosto). Estos viajes han demostrado la voluntad de Chávez en en actuar de manera más incisiva en el ámbito internacional.

Después del golpe de Estado contra su gobierno en el año 2002 por los opositores que tenían el apoyo de los EE.UU., Chávez ha aumentado su retórica anti-imperialista a través de los ataques a Washington cada vez más intensos.

Al mismo tiempo, el Palacio de Miraflores apalancada, como se señaló en el punto anterior, una política exterior regional para aumentar su influencia entre las naciones de América Latina que estaban en la dirección o fueron cooptadas para el mismo espectro ideológico.

La alianza de primera hora fue con Cuba y se convirtió en un modelo. La relación con la isla caribeña, en términos económicos, representa una "marcación de la posición." No es que ha sido un evento nuevo en la política exterior venezolana (ver capítulo2). Pero la firma de varios acuerdos, principalmente con el intercambio de personas y de asesoramiento cubano, demostraron una relación más "profunda" entre los dos países. 
Además de Cuba, las victorias de Daniel Ortega en Nicaragua, Evo Morales en Bolivia y Rafael Correa en Ecuador han creado un entorno favorable para Venezuela liderar un espectro político-ideológico más a la izquierda en América Latina.

Irán cae como el ejemplo de un país que recibe sucesiva represalias de EE.UU. por su postura anti-occidental y su programa nuclear, que es considerado por Occidente como "militar".

Sin embargo, Irán ha sido un tradicional aliado de EE.UU. en el Oriente Medio hasta la revolución chiíta de 1979. Después de la instalación del "Régimen de los Ayatolás", la ruptura entre Washington y Teherán fue total. Especialmente con el secuestro de la embajada de EE.UU. por estudiantes chiitas en el mismo año. El apoyo de Washington a Saddam Hussein durante la guerra Irán-Irak aumentó la rivalidad entre los dos países.

La influencia de Irán se siente en todo el Oriente Medio, principalmente a través del apoyo a los movimientos palestinos contra la ocupación de Israel en Cisjordania. La "guerra contra el terror", auspiciada por George W. Bush y sedimentado a través de la Doctrina Bush, aumentó la escalada de beligerancia entre ambos países. Siendo Irán nombrado un "enemigo" declarado de EE.UU. y con la invasión a Irak en 2003, Teherán ha aumentado el ritmo de la ejecución de su programa nuclear.

Por lo tanto, por representar un país que "desafía" los EE.UU., Venezuela ha comenzado a establecer contactos cada vez mayor con el régimen de aitaolás. Por supuesto, Washington no está teniendo buenos ojos el acercamiento entre los dos países. El hecho es que ${ }^{192}$ :

"Caracas y Teherán han construido una relación política y comercial sustentada tanto en el apoyo en las áreas energética, productiva, de vivienda, alimentos y educativa; como en la

\footnotetext{
192 Venezuela e Irán afianzaron nexos más allá del petróleo. <http://www.eluniversal.com/2011/05/29/venezuela-e-iran-afianzaron-nexos-mas-alla-delpetroleo.shtml > Acessado em 15/07/2011.
} 
sintonía en el discurso antinorteamericano, que también sirve para desafiar a la comunidad internacional".

Desde 2005 se había firmado un compromiso de construir 10.000 viviendas para las familias que viven en extrema pobreza en Irán En total, los dos países han firmado más de 270 acuerdos ${ }^{193}$.

El comercio bilateral entre ambas naciones creció al mismo ritmo del discurso antinorteamericano y el acercamiento político. En 2004 la balanza comercial fue de 1,1 millon de dólares y fue a 89,3 millones de dólares, siendo 88,8 millones de dólares de importaciones venezolanas ${ }^{194}$.

En el ámbito educativo, en 2008, se firmó una alianza entre los dos países, a través del Ministerio de Educación, por la creación de la Universidad de las Civilizaciones, y la distribución de diez becas para maestrías y doctorados por los dos gobiernos ${ }^{195}$.

Como ejemplo del aumento de la aproximación entre los dos países ${ }^{196}$, podemos mencionar los doce acuerdos firmados en noviembre de 2010 para el sector de energía, electricidad, infraestructura y la cooperación científica y tecnológica.

En el sector energético, ha creado una joint venture para el campo en Dobokubi en el estado de Anzoátegui entre la Corporación Venezoelana del Petróleo y la símil Petropars. La iraní Petropars ya había participado en la operación de certificación de reservas en la Faja del Orinoco, y firmó un acuerdo con PDVSA para crear una exploración petrolera transnacional de explotación y producción para actuar en otros países ${ }^{197}$.

\footnotetext{
${ }^{193}$ Ibidem.

${ }^{194}$ Ibidem.

${ }^{195}$ Ibidem.

${ }^{196}<$ <ttp://www.gobiernoenlinea.ve/noticias-view/ver_detalles.pag?idNoticia=96156\#> Acessado em 10/09/2011.

${ }^{197}$ Ibidem.
} 
A finales de 2010 Irán y Venezuela anunciaron la construcción de una refinería en Siria, cuya capacidad de refinación fue de 140 mil barriles por día. La previsión es que estuvo en funcionamiento hasta $2012^{198}$.

Se estableció un proyecto para implementar la segunda etapa del acueducto Luisa Cáceres de Arismendi y la creación de un vuelo directo entre Caracas y Teherán, a través de una línea aérea iranania. Los dos países tienen también un fondo binacional para financiar proyectos sociales y económicos, con aproximadamente 200 millones de dólares.

Otro país que ganó importancia para Venezuela fue Rusia. El país obtuvo importancia por convertirse en proveedor de material bélico para la renovación de su sistema de defensa. Al mismo tiempo, los rusos defender una serie de posiciones que podríamos llamar el "anti-estadounidense", sobre todo en el este de Europa contra la expansión de la OTAN en la región.

La Venezuela bolivariana reintrodujo la influencia rusa en América Latina, después del colapso de la Unión Soviética y la posterior decadencia económica cubana a principios de 1990. Rusia surgió a los planes venezolanos como un importante proveedor de armas y como un ejemplo más de la autonomía del país hacia la política exterior de Washington

Otro aspecto que favoreció la aproximación de Caracas y Moscú es la visión compartida acerca de la función de cada país en el ámbito internacional: a los rusos cabe la búsqueda de una reinserción geopolítica mundial perdida con el fin de la URSS, y a los venezolanos, el aumento de su influencia en el ámbito internacional.

Para establecer estos contactos, Chávez visitó Rusia en ocho ocasiones desde 1999 y firmó sesenta protocolos de cooperación. La alianza rusovenezolana se desarrolla en las fuerzas armadas el y en el sector energético.

El hecho es que, bajo el liderazgo de Chávez, Venezuela ha aumentado considerablemente en la posición de la importación de armas: desde el lugar 39 en 1999 al octavo lugar en 2008. Segundo informe del Centro de Análisis del

\footnotetext{
${ }^{198}$ Ciertamente, la construcción de la refinería de Siria sufren retrasos debido a la turbulenta situación política del país, debido a la llamada "primavera árabe" y las medidas de represalia por parte de la comunidad internacional a partir de noviembre de 2011.
} 
Comercio Mundial de Armas (CACMA), con sede en Moscú, Venezuela se convertirá en el segundo mayor importador de armas de Rusia entre 2011 y 2014. ${ }^{199}$ En 2007, los venezolanos eran el tercer mayor comprador de armas rusas, detrás del chino y los indios.

Con el objetivo de reorientación y modernización de sus fuerzas armadas desde 2005 se han firmado doce contratos que superaron los 5 mil millones de dólares. En esa operación se pactó con Moscú pago en efectivo y a través de otras formas de compensación de 3,2 mil millones de dólares. El resto sería a través de crédito directo ruso: 1 mil millones de dólares y otros de 1,2 mil millones de dólares más tarde.

El armamento comprado a Rusia y que procovou preocupación grande en la Casa Blanca y las elites de América del Sur fueron los siguientes:

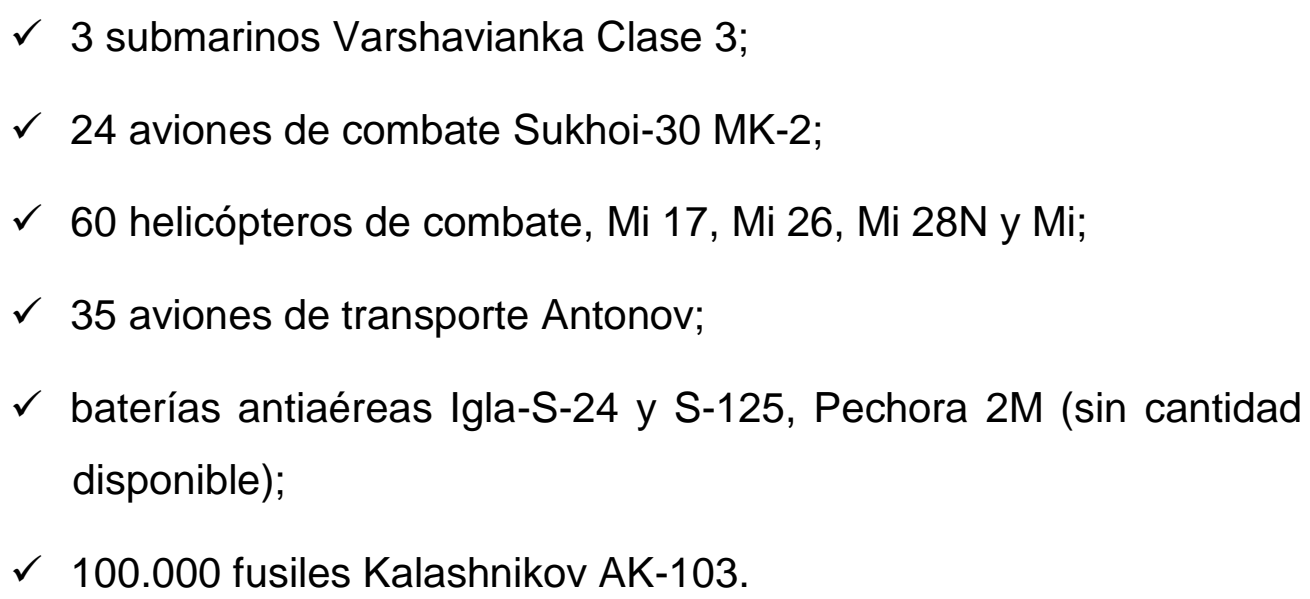

Fue establecido la construcción en Venezuela de una fábrica de fusiles AK-47, un centro de formación de pilotos de aviones militares y un centro de mantenimiento de helicópteros. Existe la posibilidad de comprar un segundo lote de armas más sofisticadas en el futuro próximo ${ }^{200}$ :

\footnotetext{
199 "Venezuela: $2^{\circ}$ importador de armas Rusas". <http://www.taringa.net/posts/imagenes/12936607/Venezuela_-2_-importador-de-armasRusas.html> Acessado em 17/11/2011.

${ }^{200}$ Carlos A. Romero. Op. cit., p. 53.
} 
$\checkmark$ Aviones Sukhoi Su-35;

$\checkmark$ Aviónes de patrulla II-114;

$\checkmark$ Sistemas de defensa antiaérea Strela-S-300PMU-2 y Tor-M2E;

$\checkmark$ Lanzadores de misiles Smerch;

$\checkmark$ Lanza-cohetes Buk-M1 y M2;

$\checkmark$ Radares Antey;

$\checkmark 2.500$ vehículos de combate blindados BMP-3 y eventualmente BMP-3S;

$\checkmark 90$ tanques T-72 y T-90;

$\checkmark$ Vehículos lanzadores de misiles 5P85SE;

$\checkmark$ Lanzadores de misiles 48N6E2;

$\checkmark$ Tres submarinos Proyecto-636;

$\checkmark$ Un proyecto submarinos-877;

$\checkmark 12$ transporte pesados militares Iliushin-76.

La concentración de tal compra demontra el interés real de Venezuela en modernizar efectivamente una parte de su armamento. Para aumentar aún más la preocupación de Washington en octubre de 2010, Hugo Chávez visitó Moscú otra vez a firmar un acuerdo para construir una planta nuclear para la generación de energía. En 2008, los dos países ya habían firmado un acuerdo de colaboración para el desarrollo de la energía nuclear con fines pacíficos.

En diciembre de 2011, tuvo lugar en Caracas la VIII Comisión Mixta Venezuela-Rusia, con la reunión entre el vicepresidente Elías Jaua y el primer ministro Vladimir Putin. Hemos firmado varios acuerdos ${ }^{201}$, entre ellos:

\footnotetext{
201 "Vicepresidente Elías Jaua y Primer Ministro Ruso firman nuevos acuerdos de cooperación". $<$ http://celac.gob.ve/index.php?option=com_content\&view=article\&id=18285:mppre\&catid=321: 1211-viii-comision-mixta-venezuela-rusia-\&Itemid=480> Acessado em 09/12/2011.
} 
$\checkmark$ Préstamo de Rusia para el país;

$\checkmark$ Acuerdo para la creación del banco binacional ruso-venezolano;

$\checkmark$ Ata de compromiso con la construcción de 30000 viviendas;

$\checkmark$ Memorandum de entendimiento sobre cooperación en el sector del gas.

El primer ministro ruso, Vladimir Putin, dijo en relación a los numerosos proyectos desarrollados entre los dos países: : "É imperante seguir trabalhando juntos para otimizar os resultados. Sim, podemos e devemos seguir trabalhando por eles"202.

La aproximación de Venezuela con la República Popular de China está insertada en la lógica de la diversificación de sus socios comerciales y de la demostración de que el país busca naciones que comparten la misma visión venezolana del sistema internacional, es decir, sobre la base de un mundo multipolar. En 2006, el embajador de Venezula en China, Rocio Maniero dijo acerca de las relaciones entre los dos países ${ }^{203}$ :

(...) "están en su momento óptimo. Venezuela y China tienen la misma posición en el concierto de naciones, el mismo enfoque basado en la búsqueda de la paz, en que todos los Estados son iguales jurídicamente, que todos tenemos un mismo peso específico en el marco del derecho internacional, en el principio de la no intervención, de la autodeterminación. China es un aliado natural de Venezuela, porque tenemos los mismos objetivos en el ámbito internacional".

\footnotetext{
202 "Putin: Grandes proyectos de desarrollo ejecutan Venezuela y Rusia".

<http://celac.gob.ve/index.php?option=com_content\&view=article\&id=18299:putin-grandesproyectos-de-desarrollo-ejecutan-venezuela-y-rusia-\&catid=321:1211-viii-comision-mixtavenezuela-rusia-\&ltemid=480> Acessado em 09/12/2011.

203 "China es un aliado natural de Venezuela". 21 de agosto de 2006.

<http://www.minci.gob.ve/noticiasprensapresidencial/28/10016/\%E2\%80\%9Cchina_es_un.htm> Acessado em 01/12/2011.
} 
Los chinos defienden la perspectiva multipolar enfáticamente, poniendo siempre que sea posible en el polo opuesto defendido por Washington en las organizaciones internacionales. La Casa Blanca, mientras que su economía depende de la gran estructura económica china, procura "cercar" Pekín en la escena internacional con acusaciones dirigidas a violaciónes de derechos humanos.

Como socio comercial China es de vital importancia para el cambio de dirección de la dependencia económica venezolana en relación a los Estados Unidos. A pesar de la retórica anti-imperialista de Hugo Chávez, ella no permitió un "corte total" en las relaciones económicas con Washington. Venezuela exporta $60 \%$ del petróleo crudo a los EE.UU.. ${ }^{204}$.

Desde 2000, Venezuela y China firmaron varios acuerdos de intercambio en los sectores de energía, alta tecnología, agricultura y en la construcción de infraestructura (Convenio de Cooperación Económica y Técnica). Como resultado de esta mayor aproximación, hubo un aumento considerable en el comercio bilateral entre chinos y venezolanos.

Venezuela exporta petróleo y sus derivados, y importa de China tractores, automóviles, tratatores, maquinaria, electrodomésticos y electrónica. Es decir, la mayor parte de su necesidad de bienes de consumo duraderos y no duraderos que cumplan con su mercado provienen del gigante asiático.

La importancia del comercio bilateral se puede medir por el salto de 276 millones de dólares generados en 1999 a 1333 mil millones de dólares en 2004. Cuatro años después el comercio entre los países habían llegado a 9850 mil millones de dólares.

Actualmente, China es el principal socio estratégico y el segundo en orden comercial Venezuela. El comercio bilateral entre los dos países alcanzó los 10 mil millones de dólares en 2010. La FCCV financia 69 proyectos en las

\footnotetext{
${ }^{204}$ Ben Schiller. The axis of oil: China and Venezuela. 02/03/2006.

<http://www.opendemocracy.net/democracy-corporations/china_venezuela_3319.jsp> Acessado em 30/11/2011.
} 
industrias básicas, vivienda, transporte, comunicaciones, educación, agricultura, medio ambiente, ciencia y tecnología, y electricidad, entre otros. ${ }^{205}$.

En abril de 2010, Hugo Chávez, anunció la concordancia de China para préstamo de 20 millones de dólares. Este préstamo servirá como una "ayuda" al país para "enfrentar" los momentos difíciles generados por el empeoramiento de la crisis mundial de 2008 y que a finales de 2011 aún persistía:

"If the loans materialize, they could give Mr. Chávez a muchneeded cash infusion. Some financial analysts, including the American investment bank Morgan Stanley, have said that Venezuela could soon face a cash crunch as it grapples with low oil revenues and a dearth of foreign investment" ${ }^{\text {206. }}$.

Beijing ya tienen inversiones en el país, que constituyen una importante fuente de impulso de la economía venezolana. Los dos países mantienen un fondo bilateral de 12 mil millones de dólares que ayuda a las relaciones entre las naciones. Cada año China aumenta su influencia económica en el país a través de mayores ventas de produtps que van desde maquinaria pesada a bienes de consumo, pasando por armamento militar.

La cooperación técnica es otro factor importante para los venezolanos. En el sector de la alta tecnología, Venezuela ha comprado satélites. y equipo militar. Fue gracias a los chinos que los venezolanos pusieron en marcha en octubre de 2008, su primer satélite artificial, el VENESAT/Simon Bolívar.

Se proyecta para el 2013 lanzar otro satélite con tecnología china. Lo que se refiere a lo equipamiento militar, Venezuela compró de los chinos radares 3-D JYL, más tres luchadores K-8W para formación.

205 "China e Venezuela renovam fundo de crédito com ampliação de US\$ 4 bilhões" 19/06/2011.<http://operamundi.uol.com.br/conteudo/noticias/12848/china+e+venezuela+renova m+fundo+de+credito+com+ampliacao+de+us+4+bilhoes.shtml> Acessado em 30/11/2011.

206 "Chávez Says China to Lend Venezuela \$20 Billion". April 18, 2010 <http://www.nytimes.com/2010/04/19/world/americas/19venez.html> Acessado em 29/11/2011. 
El avance de las relaciones chino-venezolano ha dado un paso importante en junio de 2010. La FCCV sufrió un aumento de 4 mil millones de dólares, que asciende a un total de créditos para proyectos en el país de 32 mil millones de dólares.

En noviembre de 2011, los chinos hicieron un nuevo préstamo a Venezuela por valor de 4 mil millones de dólares. Ahora, el objetivo era la modernización de las plantas de generación de energía en Venezuela y al mismo tiempo, aumentar la producción de petróleo. Con más potencia, Venezuela podría aumentar la producción de aluminio y hierro, materias primas indispensables para el crecimiento chino ${ }^{207}$.

Con respecto a la exportacion de petróleo de las empresas sinovenezolanas, aumentará de $100 \mathrm{mil}$ barriles/día a $330 \mathrm{mil}$ barriles/día. El objetivo del gobierno venezolano es llegar a 3 millones de barriles/día en $2015^{208}$. Cabe recordar que los préstamos son pagados con petróleo a los chinos. Las exportaciones de petróleo de Venezuela a China ascendieron a 410 mil barriles/día. Desde 2005, las exportaciones aumentaron casi diez veces.

La importancia de las inversiones chinas se caracteriza principalmente por el volumen de las inversiones y por los sectores involucrados. Además de los sectores mencionados, tenemos aún la construcción civil y los ferrocarriles que incluyen la participación de Beijing.

Venezuela y China tienen planes para aumentar la producción de mineral de hierro proyectos para expandir un puerto, el dragado del río Orinoco y ampliar la capacidad del ferrocarril para drenar la producción de mineral de hierro y aluminio.

Con el objetivo de aumentar la exportación de petróleo pesado de Venezuela, los dos países están avanzando en sus planes conjuntos de construir una refinería en China con capacidad para procesar 400.000 barriles/

\footnotetext{
207 "China concorda em conceder mais US\$ 4 bi em empréstimo à Venezuela”. 23/11/2011. Radio Nacional de Venezuela <http://www.rnv.gov.ve>Acessado em 29/11/2011.

${ }^{208}$ Ibidem.
} 
día. Gran parte de esto saldría de las reservas de petróleo pesado en la cuenca del Orinoco en Venezuela.

Además de los sectores tradicionales de la economía, los chinos también están presentes en el sector de la vivienda. El gobierno venezolano, en asociación con China, anunció la construcción de complejo habitacional Palma Sola de 335 edificios que totalizará 5.360 apartamentos. El proyecto se ubica en el estado de Barinas ${ }^{209}$.

Sin duda, la sinergia entre las dos economías ha crecido considerablemente en los últimos diez años. Si para Venezuela a China se configura con un socio de gran importancia para Beijing su influencia en América Latina está creciendo. Con este marco, Venezuela diversifica sus operaciones internacionales, optimiza sus negocios y busca reducir su dependencia de los EE.UU..

209 "Convenio China-Venezuela avanza con la construcción de 5 mil 360 apartamentos en Barinas". 16/04/2011.

<http://www.noticias24.com/actualidad/noticia/220588/convenio-china-venezuela-avanza-conla-construccion-de-5-mil-360-apartamentos-en-barinas/> Acessado 09/11/2011. 
5 - DILEMAS Y CONTRADICCIONES DE LA ACTUACIÓN ANTISISTÉMICA DE VENEZUELA 
El proyecto chavista de Inserción de Venezuela en el sistema-mundo contemporáneo enfrenta muchos obstáculos de orden, tanto interna como externa. Debemos reconocer la gran habilidad política de Hugo Chávez en la consolidación de su poder desde finales de 1990. Por otra parte, cabe señalar que la vieja elite política venezolana carecía de la capacidad necesaria para hacer frente al "fenómeno Chávez", optando por desacreditar el proceso que estaba teniendo lugar en el país, y facilitar, en cierto sentido, la consolidación del poder.

El golpe de Estado dirigido por los sectores conservadores contra un gobierno democráticamente elegido en 1992, y la negativa a participar en las elecciones parlamentarias de 2005 por "falta de garantías democráticas", favorecieran la supremacía política del PSUV ${ }^{210}$, el partido de Chávez. Con la supremacía política, Chávez puede actuar con calma en el desarrollo del proyecto bolivariano.

En el plano interno el éxito del proyecto bolivariano está estrechamente ligado al mantenimiento del poder en su figura personal en el Palacio de Miraflores. La falta de otros líderes de proyección nacional crea un problema en el corto y mediano plazo.

Otro aspecto importante es que a pesar de Caracas actuar completamente contra las directrices de la política de Washington y su discurso anti-imperialista, las exportaciones de petróleo para el país se mantuvo intactas. Esto apunta a la realidad adversa encontrada por Venezuela en la dependencia económica de su principal enemigo ideológico y político.

\footnotetext{
210 Fundado en 2007, el PSUV es la fusión de los partidos políticos y los grupos y organizaciones sociales: el Movimiento Quinta República (MVR), la Unidad Popular Venezolana (UPV), Movimiento Electoral del Pueblo (MEP), Une Movimiento Socialista por la Democracia Directa, Frente Bolivariana Civil-Militar, la Comunidad Nacional Independiente (IPCN) Unión Movimiento Tupamaro Venezuela, Movimiento Independiente Ganamos Todos (MIGATO), la Corriente Marxista Revolucionaria (CMR), así y partidos regionales como Abrebrechal, FIORP, LAGO, Minha Gente e Unidos Por Portuguesa Independiente. Ana Luiza Meirelles Paruolo et ali. In: As transformações na Democracia Venezuelana de 1999 a 2010 e as eleições legislativas de setembro de 2010. Cadernos do Tempo Presente. Rio de Janeiro, $\mathrm{n}$ 3, ISSN 2179-2143. <http://www.getempo.org/revistaget.asp?id_edicao=19\&id_materia=72> Acesso em 02/06/2012.
} 
Los EE.UU. son los principales compradores de petróleo crudo pesado venezolano ${ }^{211}$, que sólo el país tiene la capacidad para refinarlo. Otro gran problema para el proyecto bolivariano y antissistémico es la baja industrialización del país. ¿Cómo actuar de manera independiente dentro del sistema-mundo cuando usted no tiene los mecanismos que permiten esto?

Como resultado de estos aspectos, Venezuela trató de aumentar su influencia continental e internacional de manera más enfática, combinando, como vimos en el capítulo 2, la ideología y la construcción de las alianzas políticas y económicas con los países de América Latina y con otras partes del mundo. La diversificación de las relaciones económicas es un componente importante para el desarrollo de la actuación antissistémica.

Durante gran parte de su mandato, Hugo Chávez trató de establecer relaciones diplomáticas y económicas con los países que estaban en el polo opuesto a las directrices de la Casa Blanca. Para ganar proyección internacional compatible con el proceso político-ideológico que se estaba desarrollando en Venezuela, Chávez trató de extender su actuación antissistémica.

\section{1 - Venezuela y la Integración Regional}

Venezuela es entusiasta e incentivadora de todas las formas de reducir la dependencia económica externa en América Latina y el avance del proceso de integración regional. El país está presente en todos los organismos

\footnotetext{
${ }^{211}$ Hay diferentes tipos de petróleo que se clasifican según su densidad. Esta clasificación está relacionada con la relación entre el peso específico y el flujo de petróleo crudo en agua. Estos factores se miden en grados API (American Petroleum Institute), la clasificación universal da una indicación de la viscosidad o fluidez de cada óleo. De acuerdo con esta clasificación, el óleo puede ser ligero o extra ligero, mediano y pesado o extra pesado. El óleo extra-pesado

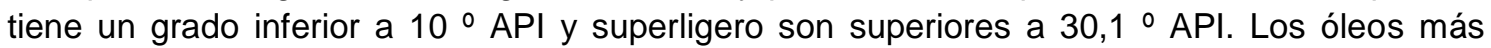
pesados son crudo, mayor es la necesidad de refinado, que se añade a su coste. En Venezuela existen diferentes tipos de petróleo extraídos de las diferentes áreas del país: Furrial (Monagas), Zuata Sweet (Anzoátegui), Merey 16 (este), Boscán (Monagas) y Tia Juana Bachaquero pesado (Zulia). Hay una franja del Orinoco con la presencia de petróleo pesado y extra pesado.
} 
regionales que apuntan en esa dirección y, en lo posible, con un papel de liderazgo.

Esta participación en diversos organismos no causa un conflicto de intereses para los venezolanos. Más bien, sirve como una forma complementaria del proceso de integración en América Latina. La existencia de esta variedad de organizaciones refleja las asimetrías existentes en el subcontinente americano.

Las iniciativas promovidas por Caracas con la creación del ALBA-TCP, del Banco del ALBA y Petrocaribe ${ }^{212}$, por ejemplo, demuestran el firme objetivo de reducir la influencia de EE.UU. en América Latina. Un nuevo reposicionamiento de América Latina en el sistema-mundo moderno es un objetivo fundamental de la Venezuela bolivariana.

Vamos a hacer un análisis de la participación de Venezuela en las organizaciones regionales.

\subsection{1 - ALBA-TCP}

El ALBA-TCP fue creado en oposición a la propuesta presentada por los EE.UU. de implementación del $\mathrm{ALCA}^{213}$, y se convirtió en un importante contrapunto ideológico, económico y político en América Latina a Washington.]

La propuesta de elaboración del ALBA fue nombrada por primera vez por Hugo Chávez en la III Cumbre de Jefes de Estado y de Gobierno, en la Isla

\footnotetext{
${ }^{212}$ Fundada en 2005, tiene como objetivo vender barriles de petróleo venezolano a los países del Caribe. Cada nación participante del acuerdo puede comprar hasta 185.000 barriles/día en condiciones ventajosas. Chávez también ha creado otros acuerdos similares: Petrosur (alianza estratégica entre las empresas de petróleo de la Región), Petroamérica (integración energética regional) y Petroandina.

${ }^{213}$ El Área de Libre Comercio de las Américas (ALCA) fue una propuesta presentada por los Estados Unidos, durante la Cumbre de las Américas (Miami) el 12.09.1994, con el objetivo de eliminar las barreras al comercio entre los 34 países de las Américas, excepto Cuba, formando así un área de libre comercio continental a finales de 2005. Sin embargo, ha habido numerosas críticas a los "intereses reales" de los EE.UU. con el proyecto de integración, ya que las concesiones económicas que deben ser hechas por Washington para facilitar el comercio en la región sin dejar nunca el papel.
} 
Margarita, en diciembre de $2001^{214}$. En el evento, Chávez destacó la necesidad de superar el neoliberalismo con otro basado en la integración latinoamericana:

"Ese modelo neoliberal no puede ser la base ni el marco para nuestros modelos de integración. No puede ser, es imposible que nosotros pongamos por delante para integrarnos, a la economía. No es la economía la que nos va a integrar y menos nuestras economías llenas de debilidades, de vulnerabilidades. No. Creo que se impone de nuevo lo que pudiéramos llamar la revancha de la política, que la política vuelva a la carga y que tome la vanguardia de los procesos de integración. $Y$ es la idea de Bolívar. (...) Un pacto político es lo que se impone hoy como era lo que se imponía entonces, y una integración integral, a lo bolivariano. El ALCA, por ejemplo, ¿es ese el camino? No.

Queremos un modelo que nos integre de verdad. No un modelo que nos desintegre, que integre a unos a expensas de la desintegración de otros, ese no puede ser el camino, por tanto con mucha modestia y humildad proponemos desde Venezuela, a los caribeños y a los latinoamericanos que vayamos pensando de una buena vez en otra alternativa porque esa creemos que no es posible. $Y$ es cuando se nos ha ocurrido lanzar una propuesta, que pudiera llamarse el ALBA, Alternativa Bolivariana para las Américas. Un nuevo concepto de integración que no es nada nuevo, se trata de retraer o de traer nuevamente un sueño que creemos posible, se trata de otro camino, se trata de una búsqueda, porque ciertamente la integración para nosotros es

\footnotetext{
${ }^{214}$ (...)[a] "tiene sus orígenes en el proyecto político del Socialismo del Siglo XXI de Hugo Chávez, presidente de Venezuela desde febrero de 1999. Fue ese mismo año cuando Chávez presentó por primera vez el embrión de lo que más tarde sería el ALBA bajo el nombre de Confederación de Estados de América Latina. Nombre que pone de manifestó la voluntad de su promoción inicial de someter desde el principio la dimensión económica a lo político". Rosa, Francisco Javier U. "La Alianza Bolivariana para las Américas-Tratado de Comercio de los Pueblos (ALBA-TCP): a análisis de un proyecto de integración regional latinoamericana con una fuerte dimensión altermundialistas", p. 1.
} 
vital: O nos unimos o nos hundimos. Escojamos pues las alternativas" $^{215}$.

En diciembre de 2004 se celebró en La Habana el I Cumbre del ALBATCP. Hugo Chávez y Fidel Castro firmaron una declaración conjunta de la creación del ALBA-TCP en los principios que deben guiar la organización:

\begin{abstract}
"Afirmamos que el principio cardinal que debe guiar el ALBA es la solidaridad más amplia entre los pueblos de América Latina y el Caribe, que se sustenta con el pensamiento de Bolívar, Martí, Sucre, O’Higgins, San Martín, Hidalgo, Petión, Morazán, Sandino, y tantos otros próceres, sin nacionalismos egoístas que nieguen el objetivo de construir una Patria Grande en la América Latina, según lo soñaron los héroes de nuestras luchas emancipadoras"216.
\end{abstract}

Otras cumbres se celebraron en 2005, 2006, 2007, 2008, 2009. ${ }^{217}$. El ALBA-TCP está integrado actualmente por Venezuela, Cuba, Bolivia, Nicaragua, Dominica, Honduras ${ }^{218}$, Ecuador, Antigua y Barbuda y San Vicente y las Granadinas.

\footnotetext{
${ }^{215}$ www.alianzabolivariana.org.

$<$ <ttp://www.alianzabolivariana.org/modules.php?name=Content\&pa=showpage\&pid=2080>

Acessado em 18/11/2011.

${ }^{216}$ Ibidem.

${ }^{217}$ En 2006, bajo la presidencia de Evo Morales, Bolivia se une a ALBA desde la firma del Tratado de Todos los Pueblos (TCP). Nicaragua firma su inclusión. Dominica y Honduras firman su inclusión. Banco del ALBA comienza a funcionar. El 24 de junio de 2009, el bloque se cambia el nombre de Alianza Bolivariana para los Pueblos de Nuestra América para Tratado de Comercio de los Pueblos (ALBA-TCP). Forman parte del bloque Ecuador, San Vicente, las Granadinas, Antigua y Barbuda.

218 Después del golpe de Estado en 28/06/2008 contra el presidente Zelaya, el candidato victorioso Porfirio Lobo respaldado por Washington retiró Honduras de la ALBA en enero de 2010.
} 
El Tratado de Comercio de los Pueblos tiene la intención de dar prioridad a los objetivos sociales, particularmente en las áreas de educación y salud, respetando la soberanía de cada Estado. ${ }^{219}$.

Otro paso importante hacia una mayor autonomía económica con respecto a la necesidad de la financiación internacional fue la creación del Banco del ALBA. La iniciativa del banco surgió en el VI Cumbre del ALBA en Caracas en enero de 2008. Con el banco, los países miembros del ALBA-TCP $\mathrm{u}$ otros que van a participar en el proyecto, pueden tener condiciones de financiación de sus proyectos sobre una base económica más ventajosa.

Continuando con la idea de la independencia económica frente a centros financieros en el sistema-mundo, especialmente los EE.UU., ha creado una "moneda" para el comercio regional entre los países del ALBA-TCP. En la VII Cumbre, celebrada en 2009, aprobó la creación de una moneda, el Sistema Unitario de Compensación Regional de Pago (SUCRE). El objetivo es reducir cada vez más la dependencia del dólar en las transacciones comerciales.

Inicialmente el SUCRE no existe físicamente sólo de manera virtual. Él servirá para la normalización del comercio y los pagos entre los bancos centrales de los países que se han adherido al sistema. Se puede ver claramente la influencia del Euro como un estándar a seguir por los países involucrados. El valor del SUCRE se deriva de un promedio de los valores de las monedas de los países que firmaron el Tratado Constitutivo del SUCRE. La fase final del SUCRE se producirá con la emisión de moneda física, sin hay fecha establecida de suceder.

\footnotetext{
219 "Son tratados de intercambio de bienes y servicios para satisfacer las necesidades de los pueblos. Se sustentan en los principios de solidaridad, reciprocidad, transferencia tecnológica, aprovechamiento de las ventajas de cada país, ahorro de recursos e incluyen convenios crediticios para facilitar los pagos y cobros.

Los TCP nacen, para enfrentar a los TLC, Tratados de Libre Comercio, impuestos por Estados Unidos, que conducen al desempleo y la marginación de nuestros pueblos, por la destrucción de las economías nacionales, a favor de la penetración del gran capital imperialista". "¿Qué son los TCP Tratados de Comercio de los Pueblos?" Portal ALBA. $<$ http://www.alianzabolivariana.org/modules.php?name=Content\&pa=showpage\&pid=2080> Acessado em 15/11/2011.
} 
El 27 de enero de 2010 se emitió 152.000 .000 "sucres" para su distribución entre los países miembros y el 03 de febrero se realizó la primera transacción comercial con participación de Cuba y Venezuela con el SUCRE.

Comparando con el MERCOSUR ${ }^{220}$, que ya tiene más de dos décadas de existencia, el avance del ALBA-TCP en el tema de la implementación de una moneda única demuestra la voluntad política de Venezuela para acelerar el proceso de integración monetaria. Sabemos que las economías del ALBA-TCP tienen un desarrollo pequeño, un hecho que, en comparación con las economías de Brasil y Argentina, por ejemplo, facilita la integración monetaria en el mediano y largo plazo. Por no hablar de los aspectos políticos que influyen en las políticas macroeconómicas internas que dificultan la creación de la moneda única en el MERCOSUR.

Sin embargo, el aspecto más importante es el político y simbólico. Más específicamente al poner la cuestión de la unificación monetaria como un objetivo importante de la integración económica dentro de la ALBA-TCP, e implementarlo en un corto tiempo.

\subsection{2 - MERCOSUR}

Con la perspectiva de permanecer insertado y participar en la vida económica de América Latina con los socios más importantes, como Brasil y Argentina, Venezuela ratificó el protocolo de entrada al MERCOSUR el 04/07/2006.

La asociación con Brasil, por ejemplo, es de gran importancia para los venezolanos. El punto alcanzado por Brasilia a la última década ha reforzado la percepción de liderazgo de Brasil en el escenario internacional como un interlocutor reconocido por la comunidad. Su interés en participar en el

\footnotetext{
${ }^{220}$ El 24 de julio de 1998 fue firmada en Ushuaia, en Argentina un documento que establece la creación de una moneda única para el MERCOSUR, lo que representa el último paso para la integración. El plazo para la ejecución de la moneda sería de 14 años. Sin embargo, las asimetrías que existen entre los miembros del bloque no permitía medidas concretas a la realización de la moneda única.
} 
MERCOSUR es perfectamente natural para el proyecto antissistémico y bolivariana del presidente Hugo Chávez.

En diciembre de 2009, el Senado brasileño aprobó el ingreso de Venezuela al MERCOSUR. Venezuela es un estado asociado en el proceso de adhesión. La última fase de la configuración del país, como pleno es el voto del Congreso paraguayo, que no tuvo lugar hasta $2012^{221}$.

La adhesión al MERCOSUR se produjo después de la salida del país de la Comunidad Andina de Naciones en 2006. Lo que precipitó esta decisión fue la firma de Acuerdos de Libre Comercio (TLCs) con los EE.UU. por parte de Colombia y Perú. Según los venezolanos,

(...) "os TLCs promoviam os princípios do liberalismo norteamericano, cujo objetivo era unificar os mercados do mundo para obter mais expansão. Tais objetivos fugiam totalmente da política de integração latino-americana que promove o governo venezuelano baseada em quatro princípios: cooperação, solidariedade, complementação econômica e respeito à soberania das nações"222.

El gobierno venezolano fue vehemente en sus críticas a la aproximación de los peruanos y colombianos de la órbita de influencia de EE.UU.. Esos tratados, pues, huyen por completo de la perspectiva antissistémica defendida por Venezuela. Si el objetivo es reducir e incluso eliminar la influencia de Washington, no habría sentido en permanecer en una organización que mantiene la característica opuesta.

\footnotetext{
${ }^{221}$ El Senado paraguayo, dominado por el Partido Colorado, en la oposición, sostiene que no hay garantías de la plena democracia en Venezuela, una condición previa para unirse al bloque, de acuerdo con el Protocolo de Ushuaia. Eso explicaría el retraso en la aprobación de Venezuela como miembro pleno del MERCOSUR. Sin embargo, el golpe político contra el presidente Fernando Lugo en junio de 2012, hiriendo al proceso democrático interno llevó a la suspensión de Paraguay del MERCOSUR el año 2013. Sin la oposición de Paraguay, Venezuela se constituyó oficialmente el 31 de julio de 2012.

${ }^{222}$ Carlos Romero Méndez. Op. cit., pp. 27-28.
} 


\subsection{3 - CELAC}

En julio de 2008, el ex presidente Luiz Inácio Lula da Silva convocó la I Cumbre de Líderes de América Latina y el Caribe con el fin de discutir y establecer las metas para el desarrollo regional y la integración. Más tarde, en febrero de 2010, en Playa del Carmen (México), en conjunto con la XXI Cumbre del Grupo de Río y la II Cumbre de América Latina y el Caribe sobre Integración y Desarrollo $(\mathrm{CALC})^{223}$, se llevó a cabo con la creación de la Comunidad de Estados América Latina y el Caribe (CELAC). En la declaración de Cancún ${ }^{224}$ se decidió:

1. Intensificar el diálogo político entre nuestros Estados y traducir, a través de la concertación política, nuestros principios y valores en consensos. La región requiere de una instancia de concertación política fortalecida que afiance su posición internacional y se traduzca en acciones rápidas y eficaces que promuevan los intereses latinoamericanos y caribeños frente a los nuevos temas de la agenda internacional.

2. Intensificar para ello, la concertación de posiciones regionales de cara a reuniones y conferencias de alcance global y adoptar un perfil más dinámico a favor de la concertación política y del trabajo de interlocución con otras regiones y países en la convicción de que ese diálogo contribuye a proyectar a la región y aumentar su influencia en el escenario internacional globalizado e interdependiente.

3. Reafirmar que la preservación de la democracia y de los valores democráticos, la vigencia de las instituciones y el Estado de Derecho, el compromiso con el respeto y la plena vigencia de

\footnotetext{
${ }^{223}$ EUA e Canadá não foram convidados a participar.

${ }^{224}<\mathrm{http}: / /$ www.celac.gob.ve/index.php?option=com_content\&view=article\&id=27\&ltemid=3\&lan $\mathrm{g}=\mathrm{es}>$ Acesso 02/06/2012.
} 
todos los derechos humanos para todos, son objetivos esenciales de nuestros países.

4. Impulsar una agenda integrada, con base en el patrimonio del Grupo de Río y los acuerdos de la CALC, así como de los mecanismos y agrupaciones de integración, cooperación y concertación ya existentes, que constituyen todos, de conjunto, un valioso activo regional que se sustenta en los principios y valores compartidos, con el propósito de dar continuidad a nuestros mandatos mediante un programa de trabajo que promueva vínculos efectivos, la cooperación, el crecimiento económico con equidad, justicia social, y en armonía con la naturaleza para un desarrollo sostenible y la integración de América Latina y el Caribe en su conjunto.

Dentro de esta perspectiva, la CELAC ofrece una nueva experiencia para aumentar la independencia política y económica de los países latinoamericanos frente a Washington, en especial los países que forman parte del ALBA-TCP 225 .

Cabe señalar que la participación enfática venezolana en los foros latinoamericanos desarrolla la perspectiva de crear una propuesta antagónica a la idea de la integración liderado por Washington con el ALCA desde 1994.

\footnotetext{
225 Los objetivos de la CALC son: "Profundizar la integración regional y establecer compromisos efectivos de acción conjunta para la promoción del desarrollo sostenible de sus pueblos; Fortalecer la cooperación en áreas de interés común; Construir un espacio común con el propósito de profundizar la integración política, económica, social y cultural de nuestra región y establecer compromisos efectivos de acción conjunta para la promoción del desarrollo sostenible de América Latina y el Caribe; Convencidos de que la región de América Latina y el Caribe debe seguir reafirmando su presencia en los foros de los que forma parte y pronunciarse sobre los grandes temas y acontecimientos de la agenda global; Intensificar el diálogo, la interacción y la sinergia entre los mecanismos regionales y subregionales de integración en América Latina y el Caribe para profundizar la integración y acelerar el desarrollo mediante la articulación de proyectos comunes y complementarios; Identificar e implementar estrategias de cooperación Sur-Sur y triangular que potencien los esfuerzos en el ámbito de la cooperación técnica entre los países de la región; Profundizar la coordinación de posiciones para proyectar una visión común de América Latina y el Caribe en diálogos externos".

$<$ http://www.celac.gob.ve/index.php?option=com_content\&view=article\&id=15\&ltemid=10\&lang $=p t>$ Acesso em 02/06/2012.
} 


\section{Cuadro 12: EVOLUCIÓN DE LA INTEGRACIÓN SUDAMERICANA}

\begin{tabular}{lllll}
\hline Firmante & 1969 & 1991 & 2004 & 2008 \\
En vigor & 1969 & 1991 & 2004 & 2011 \\
Documento & $\begin{array}{ll}\text { Acuerdo de } \\
\text { Cartagena }\end{array}$ & Tratado de & Declaración de & Tratado Constitutivo \\
& Asunción & Cuzco &
\end{tabular}

Unión de Naciones Suramericanas (UNASUR)

Pacto Andino (Comunidad Andina de Naciones)

Mercosur (Mercado Común del Sur)

Elaborado por el autor.

En la tabla 12 podemos ver cómo el proceso de interacción que ocurre en el continente. Desde la década de 1990, el MERCOSUR y el nuevo contexto político de América Latina aceleró la perspectiva "integradora", a pesar de las asimetrías existentes.

El proceso de integración, al menos políticamente, se acentúa cada vez más, sin la presencia de Washington, y refuerza la idea bolivariana defendida por el presidente venezolano: una unificación política y económica de la región. En este sentido tenemos la firma del Tratado Constitutivo de la UNASUR en mayo de 2008.

\section{1 .4 - UNASUR}

La Unión de Naciones Suramericanas (UNASUR), inicialmente llamada Comunidad Sudamericana de Naciones (CSN), creada a partir de la integración de dos uniones aduaneras: el Mercosur y la CAN. La idea es mantener el proceso de integración del continente en proceso dinámico permanente. Sin embargo, la propuesta fue recibida con escepticismo debido a las disparidades económicas y políticas existentes. Desde el punto de vista de consolidación del proyecto en el mediano y largo plazo, creemos que tendrá éxito en demostrar la importancia de la integración de las naciones del continente en la búsqueda de objetivos comunes en comparación con un sistema mundial en crisis. 
La UNASUR tiene siete consejos que involucran las siguientes áreas: Desarrollo Social, Lucha contra el Tráfico de Drogas, Educación, Cultura, Ciencia, Tecnología e Innovación, Energía, Infraestructuras y Planificación, Economía y Finanzas. Son tales consejos tienen la función de poner en práctica medidas que promuevan el desarrollo del subcontinente en estas áreas.

\section{Mapa 1 - UNASUR}

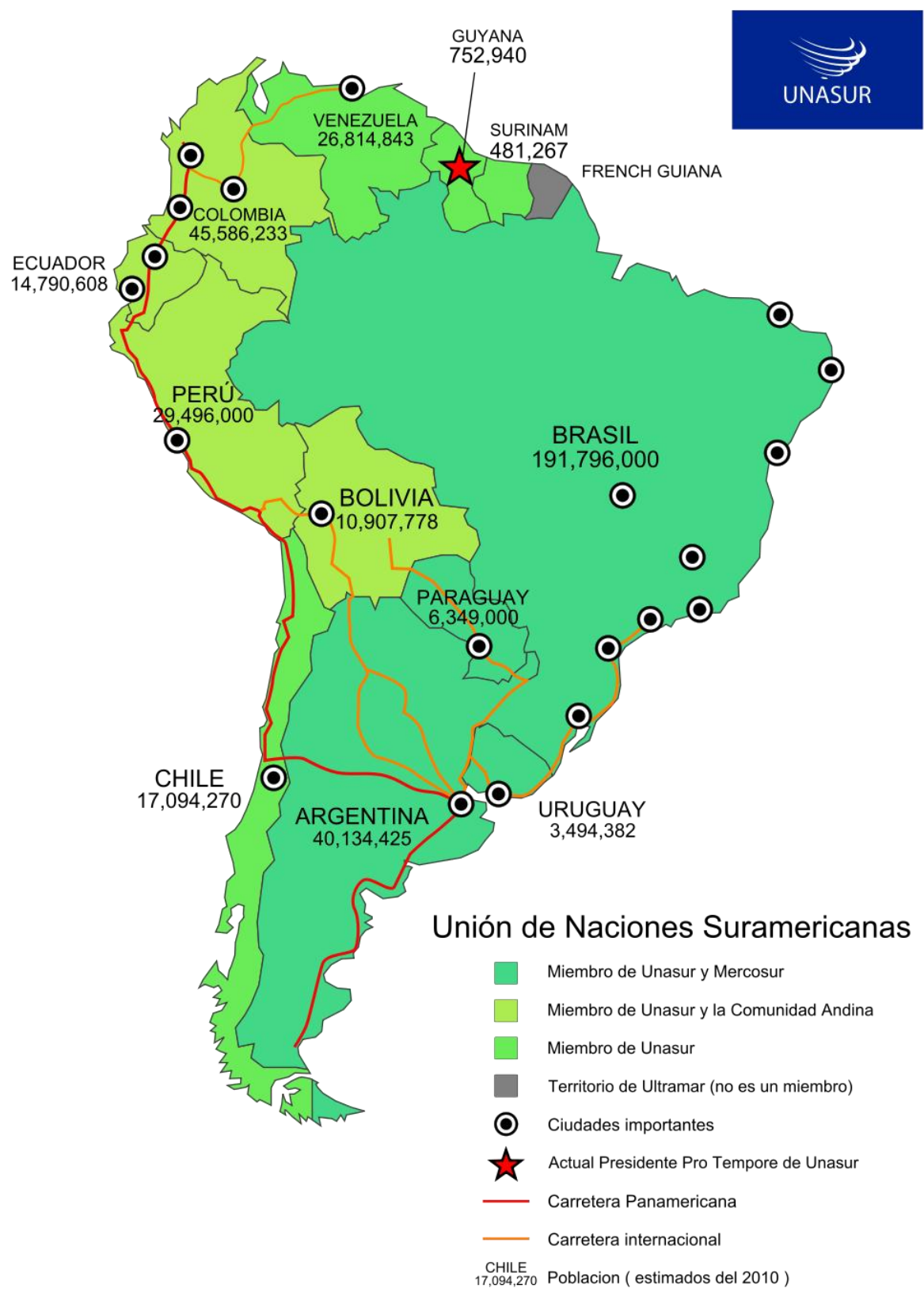

Fonte:elaborado por Camilo Sanchez. 
Un aspecto importante en la propuesta de la UNASUR es que ella facilita la discusión de la integración física del continente más allá del aspecto económico. "Reducir las distancias" es un factor clave en la integración sudamericana. Con la integración política, económica y de infraestructura, la región tiene ahora más fuerza para afrontar los desafíos planteados por la globalización, mientras que disminuye su dependencia de los mercados internacionales. El Mapa 1 proporciona una visión general de la importancia de los países en la UNASUR.

En este aspecto, la Integración de la Infraestructura Regional Suramericana (IIRSA), creada en 2000 por una propuesta del gobierno brasileño, y que contó con el apoyo de 12 países de la región, se ha creado un ambiente favorable para la discusión sobre la importancia de la integración de la infraestructura regional en América Latina.

Con países con distintos niveles de desarrollo económico es esencial que la infraestructura sea una prioridad para la integración real de la región, facilitando el comercio entres las naciones, así como su desarrollo social. El proyecto cuenta con el apoyo técnico y financiero del Banco Interamericano de Desarrollo (BID), la Corporación Andina de Fomento (CAF), y el Fondo Financiero para el Desarrollo de la Cuenca del Plata (FONPLATA) y del Banco gubernamental brasileño Banco Nacional de Desenvolvimento Econômico e Social (BNDES).

Para los países que tienen economías más pequeñas, La IIRSA surge como una gran oportunidad para mejorar su infraestructura, un hecho que apenas se producen debido a la falta de recursos en estos países. Este es un gran avance para la región.

\section{2 - Desafíos ante la Actuación Antisistémica}

Después del colapso del socialismo real en la década de 1990, la economía-mundo capitalista se ha convertido en hegemónica y ha incorporado casi todo el planeta. La propia China (que se hace llamar "comunista") entró en 
la economía-mundo capitalista en la década de 1980 y asumió patrones civilizacionales dentro de la lógica del consumo. No discutimos aquí la cuestión del sistema político del país, sobre la base de un solo partido y que va en contra de preceptos liberales propugnados en Occidente.

La actuación fuera de esta lógica económica y social es muy complicada en función del capitalismo ser un sistema social histórico y un proceso civilizatorio $^{226}$. Más que el consumo sobre la base económica, el sistemamundo capitalista organiza también el nivel cultural a través de la ideología. Esta es una etapa de desarrollo en que las economías están cada vez más unidas, y el patrón cultural es dictado desde los países centrales hegemónicos a través del control del capital, de los medios de comunicaciones tradicionales y digitales.

El intento de Venezuela de actuar de forma antissistémica implica una serie de problemas. Para el país la baja industrialización y la dependencia del petróleo representan los principales obstáculos para una actuación antissistémica consistente. La industrialización venezolana en los niveles actuales pone al país en condiciones económicas vulnerable, ya que se crea la necesidad de importaciones de bienes de producción y de consumo, impidiendo una real independencia en el sistema-mundo actual.

Hasta el momento, Hugo Chávez no logró alcanzar el éxito en la creación de condiciones económicas que van más allá del paradigma del atraso industrial de Venezuela. La dependencia del petróleo es el problema paradigmático en el país.

\footnotetext{
${ }^{226}$ Wallerstein en su libro Capitalismo Histórico e Civilização Capitalista examina en detalle la configuración del capitalismo como un fenómeno que transciende la economía. Él: "O Capitalismo é, em primeiro lugar e principalmente, um sistema social histórico". (...) "Algo distingue o sistema social que estamos chamando de capitalismo histórico: nele, o capital passou a ser usado (investido) de maneira especial, tendo como objetivo, ou intenção primordial, a auto-expansão. Nesse sistema, o que acumulou no passado só é 'capital' na medida em que seja usado para acumular mais da mesma coisa. Trata-se de um processo complexo, até sinuoso (...). Usamos a expressão 'capitalistas' para nomear essa meta persistente e autocentrada do detentor do capital (a acumulação de mais capital) e as relações que ele tem de estabelecer com outras pessoas para alcançá-lo". (...) pp. 13-14.
} 
Más preocupante para el desempeño de Venezuela como un actor antissistémico en el sistema-mundo capitalista es tener un vínculo económico muy importante con su enemigo declarado: los EE.UU. Las exportaciones de petróleo a los EE.UU. tienen una gran importancia para la economía de Venezuela. También sabemos que la ruptura con ese modelo no se puede hacer en poco tiempo, requiere décadas para dividir con este proceso histórico. Sin embargo, es imperativo cambiar este paradigma económico cuando se piensa en una actuación antisistémica.

Son reales les esfuerzos de Chávez en la diversificación de sus socios económicos. La revitalización de la ALBA-TCP, UNASUR y los "petros" en el subcontinente se encuentran dentro de este proyecto. La integración regional en América Latina va al encuentro de este punto de vista, ya que reduce la dependencia económica de los EE.UU.. Sin embargo, el petróleo sigue como el principal producto de exportación del país para los EE.UU., como se puede ver en la Tabla 13.

El sistema-mundo capitalista impide que los países obtengan una independencia comercial y tecnológica contra otras naciones. Esto es utópico del punto de vista práctico. La mayor nación del sistema-mundo no dispone de esta autonomía. La relación con China, el déficit comercial con los japoneses, y la dependencia del petróleo de Oriente Medio, y mismo Venezuela, demuestran la imposibilidad de una autonomía total de los EE.UU..

La diversificación de los socios comerciales es una buena salida para la economía venezolana, pero puede crear otras dependencias en el largo plazo. La dependencia estructural es el principal problema para cualquier país. A modo de ejemplo, el aumento de la influencia china en el continente.

Como se discutió en el Capítulo 3, la participación de China en América Latina y Venezuela aumentó considerablemente ${ }^{227}$. A La duplicación de la

\footnotetext{
227 "A presença de Beijing é cada vez maior no comércio. Um exemplo disso é o fato de a China ter mais que dobrado sua participação nas importações realizadas pelos países sulamericanos desde 2003. A parcela aumentou de 5,38\% para $12,07 \%$ em 2008, segundo a Federação das Câmaras de Comércio e Indústria da América do Sul. O total importado subiu mais de $700 \%$, de US $\$ 6,5$ bilhões para US $\$ 54,6$ bilhões". (...) Rafael Gonçalves de Lima. "O expansionismo chinês na América do Sul. Quais as consequências para o Brasil?"
} 
FCCV en 2009, fue importante para el país al garantizar más recursos en caja para eventuales problemas derivados de la crisis sistémica de 2008. ${ }^{228}$. Sin embargo, esto apunta a la posibilidad de desplazamiento de la dependencia para el chino

\section{Gráfico 4}

\section{Venezuelan Crude Oil Exports by Destination, 2010}

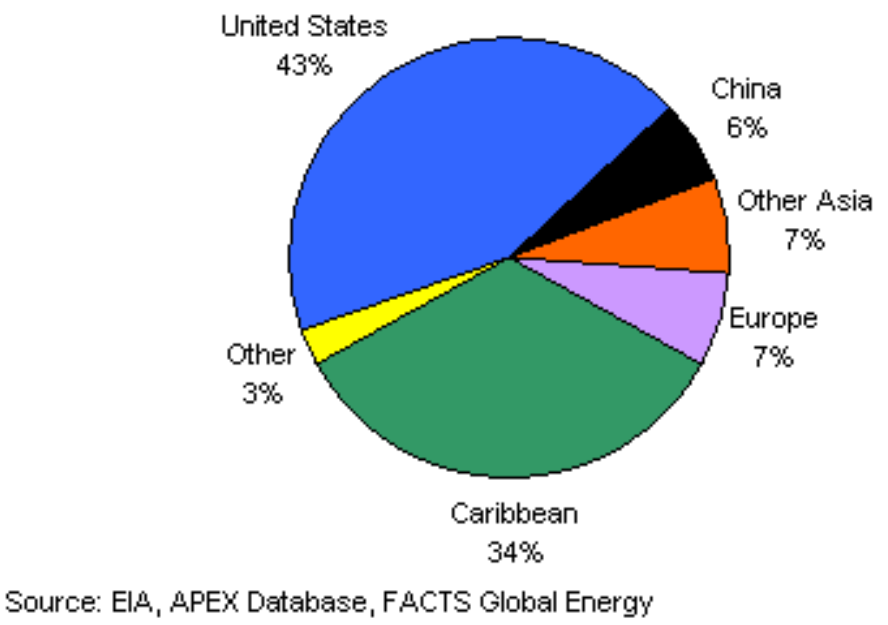

Por otro lado, en el ámbito político-ideológico, Venezuela consiguió triunfar, en nuestra concepción. Desde que Chávez inició su proyecto de una inserción antisistémica en el sistema-mundo actual, el país cuenta con gran relevancia. El número de países que han llegado a aceptar su liderazgo en el proceso político-económico regional se ha incrementado considerablemente. El éxito de la ALBA-TCP, pese a las críticas hechas al bloque, es un ejemplo de la actuación antissistémica venezolana.

La Venezuela participa en todos los foros regionales con propuestas siempre centradas en la integración, reducción de la dependencia financiera internacional, y de la denuncia del imperialismo de EE.UU. en el continente. Como ya se ha señalado, América Latina fue perdiendo importancia en las

<http://www.watershed.com.br/files/artigos/94435_o_expansionismo_chin\%C3\%AAs_na_am\% C3\%A9rica_do_sul.pdf> Acesso em 08/06/2012.

${ }^{228}$ Ibidem. 
últimas décadas, y parece que un retorno a la hegemonía de Washington es cada vez más distante.

¿Venezuela sería realmente un jugador internacional? En nuestra concepción, Venezuela, dentro de sus posibilidades económicas, políticas y militares, consiguió un gran destaque como jugador internacional limitado bajo el proyecto antissistémico de Hugo Chávez. Lógicamente situamos este desempeño dentro de los parámetros compatibles con Venezuela.

El uso del llamado poder blando a través del uso de "petróleo con fines humanitarios" es otra manera de Venezuela lograr una "buena imagen" en América Latina. La venta de petróleo subsidiado a Cuba y a precios más bajos para los demás países del ALBA-TCP colabora para una buena imagen de Venezuela. Por otro lado, las élites conservadoras promueven a través de los medios de comunicación justamente lo contrario: entre las clases medias en América Latina, denuncian Venezuela como tener un gobierno dictatorial, a pesar de que las elecciones supervisadas por organismos internacionales.

Su política exterior pro-activa e independiente de la presión de Washington podría ser visto por los contactos con países que figuran 0 figuraran como "enemigos" de Washington. Un caso destacado fueron los contactos con Teherán. Cuando toda la comunidad internacional hizo una fuerte presión contra Irán, Venezuela, en ningún momento pensó en seguir las directrices emitidas por Washington y mantuvo numerosos contactos de alto nivel entre los dos países, como se indica en el capítulo 4.

La posición de Venezuela en la construcción de un mundo multipolar se caracteriza de una manera más enfática que la observada en países como Brasil, Rusia o China. Lo que denominamos como "enfático" es que el Palacio de Miraflores designa al "enemigo", claramente como siendo los EE.UU. y denuncia sus "actos" sin tener en cuenta los aspectos diplomáticos de sus afirmaciones.

A pesar de las contradicciones, Venezuela ha sido capaz de desarrollar su papel antissistémico dentro de un proceso dialéctico, es decir, con la 
participación de numerosos avances y retrocesos. Los resultados sólo se pueden evaluar con la superación de estas dicotomías 


\section{6- CONCLUSIÓN}


Las contradicciones inherentes al sistema-mundo contemporáneo muestran que el surgimiento de los movimientos antissistémicos es una consecuencia "natural" de las relaciones desiguales que existen en el actual modelo de acumulación. En busca de una mejor posición dentro de la economía-mundo capitalista, los actores sociales y estatales buscan defenderse de la dinámica irracional y predatoria sistémica, cuyo símbolo es la formación de bloques económicos que reduzcan las disparidades, por ejemplo.

Venezuela es, como hemos tratado de demostrar a lo largo de la tesis, un ejemplo importante de actuación antissistémica. Nuestra preocupación era ofrecer una nueva comprensión del país bajo el gobierno de Hugo Chávez, dejando de lado el sentido común de asociar el líder venezolano a otro "líder populista", sin proyecto político del poder coherente mediante la introducción de Venezuela en el escenario internacional, de manera "torpe" además asociar única y exclusivamente la diplomacia venezolana actual a la "diplomacia del petróleo". Esta visión tiene como objetivo desacreditar la realidad de la transformación por el cual la nación de Simón Bolívar y lo que sucede en América Latina.

El líder venezolano reinsertó en el escenario político e ideológico la idea del socialismo como una solución a los problemas causados por el capitalismo neoliberal y sus consecuencias sociales, ambientales etc. Para superar el neoliberalismo, Chávez utiliza algunas categorías marxistas adaptándolas a la realidad venezolana contemporánea y fusionándolas con la elaboración teórica de Simón Bolívar. Surgió, así, el Socialismo del Siglo XXI.

Desde el fin del bloque socialista, en 1989, la propuesta socialista entró en el reflujo como una herramienta teórica para superar el capitalismo. Chávez reintrodujo esta discusión, utilizando a Venezuela como el locus para poner en práctica el "nuevo" socialismo que él defiende.

Algunas críticas al socialismo del siglo XXI son relevantes cuando se refieren a lo que sería el "personalismo" de Chávez en la realización del proyecto. El hecho es que los críticos buscan sólo hacer críticas que no se centran estrictamente en el marco teórico de la propuesta, es decir, tratan de enmarcar la propuesta del socialismo del siglo XXI como una "variación" del 
populismo latinoamericano del siglo $\mathrm{XX}$, basada en la falta de organización popular y en la ausencia permanente de una cultura política de la población.

Así buscamos ir en la dirección opuesta del sentido común del acercamiento conservador para ofrecer un análisis sobre la base que explican el proyecto de Hugo Chávez. Por lo tanto, creemos que el socialismo del siglo. XXI se encuentra en un proceso dialéctico de construcción que implica avances $y$ retrocesos.

Es importante mencionar que el contexto internacional derivado del fin del bloque socialista y de la adopción del neoliberalismo en términos continentales en la década de 1990, creó las condiciones necesarias para el florecimiento de las salidas "la izquierda" en América Latina. La propia política exterior de EE.UU. para el continente basada en el intervencionismo, como hemos visto, es una de las causas por las que las antissistêmicas alternativas surgieron.

Sin el temor del comunismo en América Latina para guiar el Departamento de Estado en Washington en América Latina y al mismo tiempo en que las preocupaciones se han convertido con gran énfasis para el Oriente Medio, fue posible para las fuerzas políticas de izquierda ponen sus proyectos políticos y económicos dirigidos para los intereses de las clases bajas.

Con este escenario surgió la Venezuela Bolivariana de finales de 1990, Hugo Chávez y su socialismo del siglo XXI, entrando definitivamente para el escenario y el discurso político alrededor del mundo.

El punto culminante alcanzado por Venezuela en el ámbito internacional fue otro aspecto importante. Con el objetivo de consolidar una imagen de independencia de los EE.UU., sobre todo después del golpe de 2002, Chávez mantuvo contactos con varios países, especialmente aquellos que trabajaban en el polo opuesto a los intereses de Washington.

Fue hecho, a lo largo de la tesis, un análisis detallado de estas relaciones y sus contradicciones para el país. La diversificación económica sin una transformación de la base industrial del país ciertamente mantendrá la 
dependencia, con nuevos países involucrados, manteniendo el ciclo de atraso industrial.

También se puede verificar el trabajo incansable de Caracas en el proceso de integración económica regional. La creación del ALBA-TCP en un tiempo corto y la puesta en práctica de los intercambios económicos basados en principios distintos de la mera acumulación entre las naciones participantes es, en nuestra opinión, sorprendente.

Sobre la base de lo que se presenta en esta tesis, Venezuela ha desempeñado un papel de gran importancia antissistémica y se configuró como una alternativa al modelo neoliberal de integración basado en el ALCA. Por otra parte, ofreció una respuesta a la integración política y económica con la formación del ALBA-TCP, conquistó países para su proyecto bolivariano, aumentó el comercio entre los países miembros, etc.

Sabemos que todo este proceso de actuación antissistémica se asocia con su capacidad financiera originada por el petróleo. Otro país no tiene tal capacidad de actuar de tal forma en los actuales modelos económicos y geopolíticos sin recursos financieros del mismo tamaño.

Sin lugar a dudas, a finales del siglo $X X$ y los primeros decenios del siglo. XXI son de gran importancia para la evolución de América Latina hacia la construcción de una comunidad de naciones unidas por los intereses de sus poblaciones y hacia un proceso de integración regional que no se guía por intereses externos. 
BIBLIOGRAFÍA 
ALBERNAZ, Bia et al. O aumento dos gastos militares da Venezuela. Realismo ofensivo e defensivo. In: Intellector. Rio de Janeiro, Centro de Estudos em Geopolítica e Relações Internacionais (CENEGRI), № 13, V. VII(1), julio/deciembre, p. 100-131, 2010.

ALMADA, Izaías. Venezuela: o povo e as Forças Armadas. São Paulo, Caros Amigos Editora, 2007.

ALMENDRA, Carlos Cesar. Hugo Chávez e a Revolução Bolivarina na Venezuela.

<http://www.unicamp.br/cemarx/ANAIS\%20IV\%20COLOQUIO/comunica\%E7\% F5es/GT4/gt4m3c4.PDF> Aceso en 20/05/2009.

AMIN, Samir. Imperialismo e Desenvolvimento Desigual. São Paulo, Vértice, 1987.

ARRIGHI, Giovanni. Hegemonia e Movimentos Anti-Sistêmicos. In: Os Impasses da Globalização: Hegemonia e Contra-Hegemonia (Vol.1). São Paulo, Ed. Loyola, p. 107-121, 2003.

et al. Antisystemic movements. New York, Verso, 1997.

. Hegemony and antisystemic movements. Rio de Janeiro, Seminar International REGGEN 2003.

. O Longo século XXI. Rio de Janeiro, Editora UNESP,1996.

. A llusão do desenvolvimento. Petrópolis, Editora Vozes, 1998.

. Adam Smith em Pequim - origens e fundamentos do século XXI. São Paulo, Boitempo Editorial, 2008.

. Chaos and governance in the modern world system. Minneapolis, University of Minnesota Press, 1999.

ARBIX, Glauco. Da liberalização cega dos anos 90 à construção estratégica do desenvolvimento. In: Tempo Social/Rev. Sociol. USP. São Paulo, 14 (1), pp. 1-17, mayo de 2002.

BATALHA Franklin, Cleber. Segurança e defesa nas relações entre o Brasil e a Venezuela. Caxambu, 30ํㅡㄹ Encontro Anual ANPOCS 2006. 
BOTTA, Paulo. Irán em América Latina: desde Venezuela hacia Brasil. In: Ágora Internacional, V. 4, № 9, pp. 43-47. Aceso en 17/06/2011. $<$ http://www.noticiasdeiran.com/>

BRAGA Nonnenberg, Marcelo José. China: estabilidade e crescimento econômico. Rev. Econ. Polit., São Paulo, v. 30, n. 2, Junio 2010 . Disponible en

<http://www.scielo.br/scielo.php?script=sci_arttext\&pid=S010131572010000200 002\&lng=en\&nrm=iso> Aceso en 28/12/2011.

BRAUDEL, Fernand. La dynamique du capitalisme. Éditions Flammarion, 2008.

. Civilization matérielle, économie et capitalisme - 1. Le strucutures du quotidien. Paris, Armand Colin, 1979.

Civilization matérielle, économie et capitalisme - 2 . Les jeux de l'echange. Paris, Armand Colin, 1979.

Civilization matérielle, économie et capitalisme - 3. Le temps du monde. Paris, Armand Colin, 1979.

BRICEÑO Monzón, Claudio Alberto. La política exterior de Venezuela em los tempos del Socialismo del Siglo XXI: entre la autonomia y la subordinación al capitalismo global. In: Cuadernos sobre Relaciones Internacionales, Regionalismo y Desarollo. Mérida, Vol. 6, № 12, JulioDeciembre 2011.

BRUCE, lan. The real Venezuela - Making socialism in the $21^{\text {st }}$ century. London, Pluto Press, 2008.

BRZEZINSKI, Zbigniew. Strategic Vision: America and the Crisis of Global Power. New York, Basic Books, 2012

BUCI-GLUCKSMANN, Christinne. Gramsci e o Estado. São Paulo, Paz e Terra, $2^{\mathrm{a}}$ ed., 1990.

ALVES de Carvalho, Giane. Os movimentos antissistêmicos: conjuntura de lutas ou impasses políticos ideológicos? In: Mediações. UFSC, v. 13, p. 216, Ene/Jun y Jul/Dec, 2008. 
CHOSSUDOVSKY, Michel. A Globalização da Pobreza - Imapctos das reformas do FMI e do Banco Mundial. São Paulo, Editora Moderna, 1999.

CLAIRMONT, Frederic. F. Venezuela: the nemeses of imperialism. Malaysia, Citizens International, 2007.

ELLNER, Steve. Las estrategias "desde arriba" y "desde abajo" del movimiento de Hugo Chávez. In: Cuaderno del Cendes. Caracas, № 62, V. 23, mayo de 2006.

Rethinking Venezuelan politics. Boulder, Lynne Rienner Publishers, 2008.

ENERGY INFORMATION ADMINISTRATION. Country Analysis Brief: Venezuela. http://www.eia.gov/cabs/venezuela/pdf.pdf. Aceso en 07/06/2012.

FERGUSSON, Niall. Colosso - Ascensão e queda do império ameircano. São Paulo, Editora Planeta, 2011.

GILL, Stephen (Org.). Gramsci, materialismo histórico e relações internacionais. Rio de Janeiro, Editora UFRJ, 2007.

GOLINGER, Eva. Él código de Chávez: descifrando la intervención de Estados Unidos em Venezuela. Caracas, Monte Ávila Editores latinoamericanos, 2005.

GOMES Saraiva, Miriam \& BRICEÑO Ruiz, José. O caso Venezuela: o giro hacia el sur e as percepções dos atores políticos. In: Argentina, Brasil e Venezuela: as diferentes percepções sobre a construção do Mercosul. Brasilia, Revista. Brasileira de Politica Internacional, Vol. 52, № 1, Junio 2009.

GOTT, Richard. À sombra do libertador. São Paulo, Expressão Popular, 2004.

GRAMSCI, Antonio. Concepção Dialética de História. Rio de Janeiro, Civilização Brasileira, 1989.

Cadernos do Cárcere - 5. Rio de Janeiro, Civilização Brasileira, 2002. 
. Escritos políticos - 1910/1920. Rio de Janeiro, Civilização Brasileira, v. 1, 2004.

. Escritos políticos - 1921/1926. Rio de Janeiro, Civilização

Brasileira, v. 2, 2004.

. Cartas do cárcere - 1926/1930. Rio de Janeiro, Civilização

Brasileira, v. 1, 2005.

Cartas do cárcere - 1931/1937. Rio de Janeiro, Civilização

Brasileira, v. 2, 2005.

GUTIÉRREZ Bueno, Juliana. Venezuela en el camino hacia el socialismo del siglo XXI. In: Centro de Estudios Sudamericanos/Departamento de América Latina y el Caribe. La Plata, Universidad Nacional de La Plata/Instituto de Relaciones Internacionales, 2008.

HARDT, Michel \& NEGRI, Antonio. Império. Rio de Janeiro, Editora Record, 2005.

HARRIS, Jerry. Bolivia and Venezuela: the democratic dialectic in new revolutionary movements. Institute of Race Relations, Race \& Class, Vol. 49(1).

HARVEY, David. O neoliberalismo: história e implicações. São Paulo, Edições Loyola,2008.

. O novo imperialismo. São Paulo, Edições Loyola, 4ª ed., 2010.

HAWKINS, Kirk A. Venezuela's chavismo and populismo in comparative perspective. New York, Cambridge University Press, 2010.

HOBSBAWM, Eric. Era dos extremos. São Paulo, Companhia das Letras, 1995.

. Tempos interessantes. São Paulo, Companhia das Letras, 2002.

. A era das revoluções. São Paulo, Paz e Terra, 22ª ed., 2007.

. A era do capital. São Paulo, Paz e Terra, 15ª ed., 2011.

A era dos impérios. São Paulo, Paz e Terra, 11aㅡ ed., 2007. 
Como mudar o mundo - Marx e o marxismo. São Paulo, Companhia das Letras, 2011.

JONES, Bart. Hugo Chávez. São Paulo, Geração Editorial, 2004.

KATZ, Hagai. Gramsci, hegemonia, e as redes da sociedade civil global. Revista hispana para el análisis de redes sociales (REDES).Vol.12, № 2, Junio 2007.<http://revista-redes.rediris.es/pdf-vol12/Vol12_2.pdf> Aceso en 17/12/2011.

LEAL Arienti, Wagner \& AMIN Filomeno, Felipe. Economia politica do moderno sistema mundial: as contribuições de Wallerstein, Braudel e Arrighi. In: Ensaios FEE. Porto Alegre, № 1, V. 28, pp. 99-126, julio de 2007.

LEBOWITZ, Michel A. As lutas na Venezuela pelo socialismo bolivariano. <http://alainet.org/active/22554(=es> Aceso en 15/06/2011.

LENINE, Vladimir I. O Imperialismo, fase superior do capitalismo. In: V.I. Lenine, Obras Escolhidas (Vol. 1). São Paulo, Editora Alfa-Ômega, 1986.

LIGUORI, Guido. Roteiros para Gramsci. Rio de Janeiro, Editora UFRJ, 2007. LOWENTHAL, Abraham. De la hegemonia regional a las relaciones bilaterales complejas: Estados Unidos y América Latina a princípios del siglo XXI. Buenos Aires, Revista Nueva Sociedad, № 206, noviembredeciembre 2006.

MCBETH, B.S. Juan Vicente Gomez andthe oil companies in Venezuela 1908-1935. Cambridge, Cambridge University Press, 1983.

MACIEL, Natalia Regina. Reforma política e política externa na Venezuela: uma ameaça à segurança continental sob a ótica norte-americana. In: Intellector. Rio de Janeiro, Centro de Estudos em Geopolítica e Relações Internacionais (CENEGRI), № 6, V. III (2), enero/junio, pp. 53-69, 2007.

MAYA, Margarita \& LANDER, Luis E. Venezuela: las elecciones presidenciales de 2006 ¿Hacia el Socialismo del Siglo XXI? Caracas, Cuaderno del CENDES, enero-abril, Vol. 24, ํo 64, 2007.

MALDONADO FERMÍN, Alejandro. Instituciones clave, producción circulación de ideas (neo)liberales programas de ajuste estructural en 
Venezuela, 1989-1998. En publicacion: Cultura y Neoliberalismo. Grimson, Alejandro. CLACSO, Consejo Latinoamericano de Ciencias Sociales, Buenos Aires. Julio 2007. ISBN: 978-987-1183-69-2 Disponible en: <http://bibliotecavirtual.clacso.org.ar/ar/libros/grupos/grim_cult/Maldonado.pdf> MAUS, Ingeborg. Do Estado Nacional para o Estado Global: o declínio da democracia. Impulso, Piracicaba, 14(33): 113-134, 2003.

http://www.unimep.br/phpg/editora/revistaspdf/imp33art07.pdf Aceso en 21/12/2011.

OLIVEIRA Lopes, Mariana de. Avanços e limites do processo bolivariano. <http://www.uel.br/grupo-pesquisa/gepal/terceirosimposio/marianaoliveira.pdf> Aceso en 15/09/2009.

MARINGONI, Gilberto. A Venezuela que se inventa. São Paulo, Editora Fundação Preseu Abramo, 2004.

A revolução venezuelana. São Paulo, Editora UNESP, 2009.

MARTINEZ, Carlos et alli. Venezuela Speaks! Oakland, PM Press, 2010.

MARTINS Senhoras, Elói \& BORGES Gama Neto, Ricardo. Petróleo como arma de poder: Uma contextualização da petrodiplomacia venezuelana nas relações internacionais. Boletim Meridiano 47, vol. 10, oo 105 (2009). $<$ http://seer.bce.unb.br/index.php/MED/article/view/722/439> Acessado em 30/11/2011.

MONIZ Bandeira, Luiz A. Formação do império americano. Rio de Janeiro, Civilização Brasileira, 2009.

NEGRI, Antonio \& COCCO, Giuseppe. Global: biopoder e luta em uma América Latina globalizada. Rio de Janeiro, Editora Record, 2005.

. Cinco lições sobre o império. Rio de Janeiro, DP\&A Editora, 2003.

NELSON, Brian A. The silence and the scorpion. New York, Nation Books, 2009.

http://dx.doi.org/10.1590/S0101-31572010000200002. 
MEIRELLES Paruolo, Ana Luiza et alli. As transformações na Democracia Venezuelana de 1999 a 2010 e as eleições legislativas de setembro de 2010. Rio de Janeiro, Boletim Tempo Presente, UFRJ.

$<$ http://www.getempo.org/revistaget.asp?id_edicao=19\&id_materia=72> Aceso en 02/06/2012.

PENNA FILHO, Pio. Hugo Chávez e a diplomacia venezuelana. Revista Meridiano 47. <http://www.red.unb.br/index.php/MED/article/view/1108/777> Acesado en 29/11/2011.

PENNAFORTE, Charles. América Latina e o Neoliberalismo: Argentina, Chile e México. Rio de Janeiro, E-Papers, 2001.

. Fragmentação e resistência: o Brasil e o mundo no século XXI. Rio de Janeiro, E-Papers, 2003.

- Depois do muro: o mundo pós-Guerra Fria. Rio de Janeiro, Ao Livro Técnico, 1998.

. Globalização, a nova dinâmica mundial. Rio de Janeiro, Ao Livro Técnico, 1998.

Análise dos Sistemas-Mundo: uma introdução ao pensamento de I. Wallerstein. Rio de Janeiro, Cenegri Edições, 2011.

PINHEIRO Guimarães, Samuel. \& H. CARDIM, Carlos. Venezuela - Visões brasileiras. Brasília, IPRI/FUNAG, 2003.

RATLIFF, William. China's Role in the World: Is China a Responsible Stakeholder? Hoover Institution, Stanford University.

<http://www.uscc.gov/hearings/2006hearings/written_testimonies/06_08_3_4wrt s/06_08_3_4_ratliff_william_statement.pdf> Aceso en 29/11/2011.

REIS, Carlos Nelson dos, OLIVEIRA, Mara de \& PINHEIRO, Lessi. A Pobreza na América Latina no pós-reformas estruturais: a pemanêmcia da iniquidade. In: Observatorio de la Economía Latinoamericana. <http://www.eumed.net/cursecon/ecolat/br/07/POBREZA\%20NA\%20AMERICA \%20LATINA\%20NO\%20POS\%20REFORMAS\%20ESTRUTURAIS.htm> aceso en 22/04/2012. 
ROMERO Mendez, Carlos. Las relaciones de seguridad entre Venezuela y estados Unidos: la dimensión global. In: Venezuela en el contexto de la seguridad regional. Caracas, Instituto Latinoamericano de Investigaciones Sociales-ILDIS, 2007. Aceso en 07/05/2009.

< http://library.fes.de/pdf-files/bueros/caracas/05549.pdf >

ROSA, la Francisco J. Ullán. La Alianza Bolivariana para las AméricasTratado de Comercio de los Pueblos (ALABA-TCP): análisis de um proyecto de integración regional latino-americana com uma fuerte dimensión altermundista. Paper, Alicante, España.

SCHILLER, Bem. The Axis of oil: China and Venezuela. Open Democracy, 02/03/2006. www.opendemocracy.net

SILVA Barros, Pedro. Chávez e Petróleo: Uma Análise da Nova Política Econômica Venezuelana. <http://www.usp.br/prolam/downloads/2006_2_7.pdf> Aceso en 30/11/2011.

SOUZA, Romina B. de Lucena \& SOUZA, Nalia de J. Análise de indicadores econômicos e sociais da Venezuela, 1999/2008. In: Revista de Desenvolvimento Econômico. Salvador, ano XI, № 20, julho de 2009.

TORRIJOS R., Vicente. Nuevas perspectivas en las relaciones entre Estados Unidos y América Latina. In: Revista de Relaciones Internacionales, Estrategia y Seguridad. Colombia, Universidad Militar Nueva Granada, N o 1, V. 4, pp. 15-30, enero/ junio, 2009,

UCHOA, Pablo. Venezuela: a encruzilhada de Hugo Chávez. São Paulo, Editora Globo, 2003.VIZENTINI, Paulo. A política externa da Venezuela. In: Venezuela - Visões brasileiras. Brasília, IPRI/FUNAG, 2003.

VOIGT, Márcio Roberto. A Análise dos sistemas-Mundo e a Política Internacional: uma Abordagem Alternativa das Teorias das Relações Internacionais. In: Textos de Economia. Florianópolis, v. 10, no 2, 110, jul/dec, 2007.

WALLENSTEIN, Immanuel. Geopolitics, class politics, and the current world disorder. Rio de Janeiro, Seminar International REGGEN 2003. 
. The Modern World-System I: Capitalist Agriculture and the Origins of the European World-Economy in the Sixteenth Century. California, University of California Press, 2011(1974).

- The Modern World-System II: Mercantilism and the Consolidation of the European World-Economy, 1600-1750. California, University of California Press, 2011(1974).

. The Modern World-System III: The Second Era of Great Expansion of the Capitalist World-Economy, 1730s-1840s. California, University of California Press, 2011(1974).

. The Modern World-System IV: Centrist Liberalism Triumphant, 1789-1914. California, University of California Press, 201.

. Universalismo europeu. São Paulo, Boitempo Editorial, 2007.

. O declínio do poder Americano. Rio de Janeiro, Contraponto, 2004.

. Utopística ou as decisões históricas de século vinte e um. Petrópolis, Editora Vozes, 2003.

- Capitalismo histórico e civilização capitalista. Rio de Janeiro, Contraponto, 2001.

. O fim do mundo como concebemos. Rio de Janeiro, Editora Revan, 2002.

. Capialisme et économie-monde (1450-1640). Paris, Flammarion, 1980.

. Comprendre le monde. Paris, La Découverte, 2006.

. Le capitalisme historique. Paris, Repères, 2002.

U.S. Weakness and the Struggle for Hegemony. Monthly Review, Juky-August 2000 . <http://www.iwallerstein.com/wpcontent/uploads/docs/MR3.PDF> Acesado en 03/12/2011. 
of the Trajectory of the World System. International Sociology F June $2000 \mathrm{~F}$ Vol 15(2): 251-267 SAGE (London, Thousand Oaks, CA and New Delhi).

<http://www.iwallerstein.com/wp-content/uploads/docs/TRAJWS1.PDF> Acesado en 03/12/2011

.The Curve of American Power.

<http://www.iwallerstein.com/wp-content/uploads/docs/NLRCURVE.PDF> Acesado en 03/12/2011.

WEBER, M. Os três tipos puros de dominação legítima. In: COHN, G. (org.). Weber : Sociologia. 7ª ed. São Paulo, Ática, 1999.

\section{Sites}

http://www.alianzabolivariana.org/

http://www.minci.gob.ve/lineas-de-chavez/82

http://www.pptunasur.com/inicio.php?idiom=1

http://www.immanuelwallerstein.com

http://www.faculty.rsu.edu/ felwell/Theorists/Wallerstein/index.htm

http://www.gpepsm.ufsc.br/html/index.php

http://wsarch.ucr.edu/

http://fbc.binghamton.edu/

http://irows.ucr.edu/

http://www.mre.gov.ve/

http://www.minci.gob.ve

http://www.alba-tcp.org/

http://venezuelanalysis.com

http://www.tradingeconomics.com/ 
http://www.wtrg.com/

http://www.eia.gov/

\section{Entrevistas disponibles en Internet}

Immanuel Wallerstein (Programa Milênio da GloboNews)

<http://www.youtube.com/watch?v=8XeJICHkNW4>

Questions sur les États-Unis et le Monde : Les États-Unis face à leur decline (2006)

<http://www.youtube.com/watch?v=nBuusuj7c3s>

Breakfast with Immanuel Wallerstein - On Latin America (2010)

<http://www.youtube.com/watch?v=G30fv0ZUWEo>

Breakfast with Wallerstein - On Central Asia (2010)

<http://www.youtube.com/watch?v=biDhDJ3vj0Y>

Immanuel Wallerstein on the end of Capitalism (2009)

<http://www.youtube.com/watch?v=nLvszWBf6BQ>

Wallerstein on the Structures of Knowledge

<http://www.youtube.com/watch?v=THR_Yks7YkU>

\section{Películas/DVDs}

Hugo Chávez. Programa Roda Viva, 2005.

Al Sur de la Frontera. Oliver Stone, 2010.

\section{Notícias}


“Nicaragua and Venezuela's Well-Oiled Relationship". 30/06/2011.

$<$ http://blog.american.com/2011/06/ortegas-nicaragua-to-chavez-please-dontdie-please/> Acessado em 22/11/2011.

"Forças armadas de Nicarágua e Venezuela fortalecem vínculos". 11/07/2011

<http://www.outroladodanoticia.com.br/inicial/17684-forcas-armadas-denicaragua-e-venezuela-fortalecem-vinculos.html> Acessado em 23/11/2011.

"Venezuela's Chávez bankrolled Nicaragua with \$1.6 billion since 2007". 07/04/2011.

<http://www.csmonitor.com/World/Americas/2011/0407/Venezuela-s-Chavezbankrolled-Nicaragua-with-1.6-billion-since-2007> Acessado em 22/11/2011. "Flush with Chávez petro-dollars, Nicaragua's Ortega eyes controvesial third term". 04/11/2011.

$<$ http://worldcrunch.com/flush-ch-vez-petro-dollars-nicaragua-s-ortega-eyescontroversial-third-term/4043> Acessado em 22/11/2011.

"Venezuela volta a comprar títulos da Argentina". 23/11/2007.

$<$ http://www.estadao.com.br/noticias/internacional,venezuela-volta-a-comprartitulos-da-argentina,84646,0.htm> Acesso 23/11/2011.

"China e Venezuela renovam fundo de crédito com ampliação de US\$ 4 bilhões". 19/06/2011.

<http://operamundi.uol.com.br/conteudo/noticias/12848/china+e+venezuela+ren ovam+fundo+de+credito+com+ampliacao+de+us+4+bilhoes.shtml> Acessado em 30/11/2011.

“Chávez Says China to Lend Venezuela \$20 Billion". April 18, 2010

<http://www.nytimes.com/2010/04/19/world/americas/19venez.html> Acessado em 29/11/2011.

"China es un aliado natural de Venezuela". 21 de agosto de 2006.

<http://www.minci.gob.ve/noticiasprensapresidencial/28/10016/\%E2\%80\%9Cch ina_es_un.html>Acessado em 01/12/2011. 
"China refuerza su presencia económica en Venezuela". 19/09/2010.

<http://www.eluniversal.com/2010/09/19/eco_ava_china-refuerza-supr_19A4488651.shtml> Acessado em 30/11/2011.

"Convenio China-Venezuela avanza con la construcción de 5 mil 360 apartamentos en Barinas". <http://www.noticias24.com/actualidad/noticia/220588/convenio-chinavenezuela-avanza-con-la-construccion-de-5-mil-360-apartamentos-enbarinas/> Acessado 29/11/2011.

"Participação popular aumentou na Venezuela, mas amigos do rei continuam se fartando, diz sociólogo". 19/12/2008.

$<$ http://operamundi.uol.com.br/conteudo/entrevistas/16430/www.derechos.org.v e> Acessado em 02/01/2012. 
ANEXOS 
RESUMEN HISTÓRICO: 1908-2012

\section{En 1908}

$\checkmark$ General Juan Vicente Gómez toma el control del país tras un golpe de Estado. Con el apoyo de EE.UU, abre la economía venezolana al capital extranjero. Pemanece en el poder durante casi tres décadas.

\section{En 1920}

$\checkmark$ En la cuenca del Lago de Maracaibo, el pozo perforado por Shell comienza a producir 100 mil barriles / día.

\section{En 1928}

$\checkmark$ Protestas estudiantiles organizadas en Caracas (Universidad Central) son duramente reprimidas.

\section{En 1931}

$\checkmark$ Fundación del Partido Comunista de Venezuela.

\section{En 1935}

$\checkmark$ Muere Juan Vicente Gómez.

\section{En 1936}

$\checkmark$ El Ministro de la Guerra, el general Eleazar López Contreras, asume la presidencia.

\section{En 1941}

$\checkmark$ Asume la Presidencia General Isaías Medina Angarita (abril).

$\checkmark$ Creación de la Acción Democrática (AD), socialdemócrata, por Rómulo Gallegos y Rómulo Betancourt (septiembre).

\section{En 1943}

$\checkmark$ Ley de Petróleo. Limita actuación de las empresas extranjeras. Creación de una concesión.

\section{En 1945}

$\checkmark$ Medina Angarita es derrocado por una rebelión militar (octubre). 
$\checkmark$ Rómuto Betancourt preside junta compuesta de cinco civiles y dos militares.

\section{En 1947}

$\checkmark$ Se creó el partido COPEI, de orientación social-cristiana.

\section{En 1948}

$\checkmark$ Presidente Rómulo Gallegos es derrocado por un golpe militar.

$\checkmark$ Los partidos políticos están prohibidos.

\section{En 1952}

$\checkmark$ Elecciones ocurren y los golpistas son derrotados. Sin embargo, Pérez Jiménez (golpista) es declarado ganador.

\section{En 1958}

$\checkmark$ Crisis económica favorece el fin de la dictadura.

$\checkmark$ El Pacto de Punto Fijo se ha fijado en 31 outrubro por los partidos que se oponían a la dictadura (AD, COPEI y URD). EI PCV no se adhiere al acuerdo. En el convenio se establece la gobernanza y la alternancia en el poder, especialmente entre AD y COPEI.

$\checkmark$ En diciembre, Rómulo Betancourt (AD), es elegido presidente.

\section{9-1962}

$\checkmark$ En Puerto Cabello y Carúpano empiezan rebeliones militares que pronto son derrotadas.

$\checkmark$ La oposición de izquierda, principalmnete el PCV, únese a la lucha armada.

\section{En 1961}

$\checkmark$ Nueva Constitución aprobada en enero.

\section{En 1965}

$\checkmark$ La guerrilla del PCV no produce los efectos deseados y es revista por la agremiación política. 


\section{En 1973}

$\checkmark$ Primera crisis del petróleo, cuando el precio por barril es cuadruplicado.

$\checkmark$ Carlos Andrés Pérez hace cargo de la Presidencia, dando inicio a los "años dorados" de Venezuela.

\section{En 1976}

$\checkmark$ Se creó PDVSA y el petróleo fue nacionalizado.

\section{En 1982}

$\checkmark$ Hugo Chávez y otros compañeros del ejército crearon el Movimiento Bolivariano. Su actuación es ilegal.

\section{En 1983}

$\checkmark$ En febrero ocurre el Viernes Negro, poniendo fin a la "edad de oro" del país. El precio del petróleo cae en picado, mientras que hay devaluación de la moneda.

\section{En 1989}

$\checkmark$ Carlos Andrés Pérez llegó a la presidencia por segunda vez con propuestas para "revivir" los "años dorados".

\section{En 1992}

$\checkmark$ El entonces teniente coronel Hugo Chávez lideró un intento de los militares para derrocar el gobierno, en febrero, y no tuvo éxito. Fue encarcelado.

$\checkmark$ En noviembre, la Armada y la Fuerza Aérea también organizan revueltas, pero los intentos fallan.

\section{En 1993}

$\checkmark$ Sin apoyo político, Carlos Andrés Pérez es sacado de la presidencia bajo acusaciones de corrupción, en mayo.

$\checkmark$ En diciembre, Rafael Caldera vuelve a la presidencia por medio de elecciones.

\section{En 1994}


$\checkmark$ El gobierno de Rafael Caldera enfrenta las primeras crisis económicas.

$\checkmark$ Hugo Chávez y sus seguidores son amnistiados.

\section{En 1996}

$\checkmark$ Para hacer frente a la crisis económica, Caldera tiene un plan de privatización denominado Agenda Venezuela. PDVSA es una de las empresas que serán privatizadas.

\section{En 1997}

$\checkmark$ El partido Movimiento $V$ República (MVR), dirigido por Chávez está inscrito en el sistema electoral.

\section{En 1998}

$\checkmark$ Hugo Chávez fue elegido presidente con $56 \%$ de los votos.

\section{En 1999}

$\checkmark$ Chávez llama a una Asamblea Nacional Constituyente para crear una nueva constitución. En diciembre, la Constitución Bolivariana fue aprobada con más del $70 \%$ de los votos.

\section{En 2000}

$\checkmark$ El petróleo presenta substacial aumento del precio.

$\checkmark$ En julio, un nuevo Congreso y gobernadores son elegidos.

\section{En 2001}

$\checkmark$ El gobierno decretó un paquete de 49 leyes en diciembre.

$\checkmark$ La Fedecámaras y la Central de Trabajadores de Venezuela (CTV) promueven una huelga nacional de "protesta".

\section{En 2002}

$\checkmark$ En abril, otro paro nacional convocada por Fedecámaras, CTV y los directores de PDVSA.

$\checkmark$ Golpe de Estado para derrocar a Hugo Chávez, patrocinado por la derecha y con el apoyo de EE.UU. 
$\checkmark$ El golpe es derrotado y, en diciembre, la oposición llama a un "paro nacional" que resulta en una crisis económica grave, con pérdidas de US \$ 7 millones, según el gobierno.

\section{En 2003}

$\checkmark$ En febrero, la huelga termina y el PIB se redujo en $10 \%$.

$\checkmark$ En noviembre, la oposición intenta recoger firmas para un referendo para revocar su mandato, en conformidad con las normas de la Constitución

\section{En 2004}

$\checkmark$ En junio, el Consejo Nacional Electoral (CNE) anunció que la oposición pudo reunir más de 2,4 millones de firmas para validar el referendo revocatorio del mandato de Chávez.

$\checkmark$ Chávez gana el referendo con $59 \%$ de los votos y se ratifica en el cargo en agosto.

\section{En 2005}

$\checkmark$ Los principales partidos de oposición anuncian, en noviembre, la retirada de sus candidatos de las elecciones parlamentarias del 4 de diciembre, alegando desconfianza en el sistema de votación y en el CNE.

$\checkmark$ Ocurren las elecciones, sin la participación de la oposición. Los partidários de Chávez ocupan 167 asientos en la Asamblea Nacional, en un proceso que registró una abstención superior al 70\%.

\section{En 2006}

$\checkmark$ En agosto, Chávez formaliza su inscripción ante las autoridades electorales como candidato a la relección del 3 de diciembre.

$\checkmark$ El Gobernador del estado de Zulia, Manuel Rosales, fue candidato a la presidencia con el apoyo de 41 partidos de la oposición.

$\checkmark$ En 3 de diciembre Chávez gana las elecciones para el período 20072013 con más de $62 \%$ de los votos, en proceso marcado por la tranquilidad y una participación electoral superior al $75 \%$, según la CNE.

$\checkmark$ En 15 de diciembre Chávez anuncia la creación de un título único llamado el Partido Socialista Unido de Venezuela (PSUV), a través del 
cual pretende reunir a las 24 organizaciones políticas que apoyaron su relección.

\section{En 2007}

$\checkmark$ Chávez anuncia ajuste ministerial, en enero, con el nombramiento de Jorge Rodríguez como nuevo vicepresidente para sustituir a José Vicente Rangel, su hombre de confianza en los primeros ocho años de gobierno.

$\checkmark$ Chávez acompaña juramento de los nuevos miembros del Gobierno. El presidente sigue invirtiendo en la profundización de la "revolución" y en el establecimiento del socialismo del siglo XXI en Venezuela. Anuncia que en este nuevo mandato va a nacionalizar "todo lo que fue privatizado".

$\checkmark$ En el 21 de febrero, Chávez, acompañado por el entonces presidente de Argentina, Néstor Kirchner, anuncia la creación de Banco del Sur

$\checkmark$ En 1 de mayo, el Estado venezolano, a través de PDVSA, asumió el control operativo de las actividades primarias relacionadas con hidrocarburos en la región del Orinoco, en el centro del país.

$\checkmark$ En 27 de mayo, el Canal "RCTV" deja de transmitir por señal aberta, después de la decisión del gobierno de Chávez de no renovar su contrato de concesión, en medio a fuertes protestas.

$\checkmark$ En agosto, Chávez presenta la propuesta de reforma constitucional, que incluye la modificación de 33 de los 350 artículos de la Constitución de 1999.

$\checkmark$ La Asamblea Nacional, en noviembre, aprueba el proyecto de ley de reforma de los 33 artículos, más tarde ampliado a 69 por los diputados. Ese mismo día, la CNE pide un referendo sobre los cambios constitucionales para el 2 de diciembre.

$\checkmark$ En diciembre, los votantes rechazan la reforma constitucional promovida por Chávez, que incluía la posibilidad de relección indefinida. 


\section{En 2008}

$\checkmark$ El 2 de marzo, Venezuela ordenó el retiro de su personal diplomático en Bogotá en medio de una crisis con las Fuerzas Armadas Revolucionarias de Colombia (FARC) y anuncia la movilización de tropas en la frontera.

$\checkmark$ El entonces presidente colombiano, Álvaro Uribe y Chávez abren camino para la reconciliación y en julio confirman el cese de las hostilidades por el caso de las FARC.

$\checkmark$ En 19 de junio, Venezuela nacionaliza el sector del cemento.

$\checkmark$ En septiembre, Venezuela expulsó al embajador de EE.UU. en Caracas, en solidaridad con Bolivia.

$\checkmark$ Las elecciones regionales se celebraron en 23 de noviembre, en las que el PSUV ganó 17 de los 22 gobiernos en disputa y $80 \%$ de los municipios. La oposición tiene los estados clave.

\section{En 2009}

$\checkmark$ En enero, Venezuela rompe relaciones diplomáticas con Israel, en protesta por la situación en Gaza.

$\checkmark$ Está previsto para el 15 de febrero de 2010 un referendo sobre la relección ilimitada, un proyecto de ley que permitiría a Chávez postularse para un tercer mandato en 2012.

\section{En 2010}

$\checkmark$ El referendo, realizado en el 15 de febrero, aprobó la relección ilimitada, abriendo el camino para que Chávez sea candidato de nuevo en 2012.

$\checkmark$ En 26 de septiembre, ocurren las elecciones parlamentarias en que el gobierno y la oposición compiten por los 165 asientos de la Asamblea Nacional.

$\checkmark$ El gobierno del presidente Hugo Chávez ganó la mayoría de asientos en las elecciones para el Parlamento. El partido governante, el PSUV, ganó 90 de los 165 asientos en juego. 
$\checkmark$ La oposición, por su parte, ganó 59 asientos, más de un tercio de la composición de la Cámara. La participación electoral fue 66,45\%, entre los más altos en la historia de las elecciones.

\section{1}

$\checkmark$ En 31 de julio, Chávez anunció que tenía cáncer.

$\checkmark$ Los opositores dicen que el ciclo de Hugo Chávez está llegando a su fin.

\section{2}

$\checkmark$ A pesar de la recaída de más de una centena de días en tratamiento en Cuba, desde el pasado mes de junio, el presidente es el favorito para las elecciones presidenciales de octubre, con márgenes de 5 a 33 puntos de ventaja, según las encuestas. El rival es el único candidato de la oposición, Henrique Capriles.

$\checkmark$ Chávez anuncia sus logros, como la inyección de fondos en el programa de viviendas populares, la versión venezolana de "Minha Casa, Minha Vida" (programa habitacional implementado en Brasil por el gobierno de Lula y Dilma). También creó la misión "Amor Mayor", para las personas mayores, y los "Hijos de Venezuela", para los niños - ambos programas de transferencia de ingresos.

$\checkmark$ En mayo, en su presentación pública más reciente y breve, aprobó una nueva ley laboral, que se extiende de 4 meses para 6,5 meses el permiso de maternidad, haciendo más difícil despedir a los trabajadores, entre otras medidas populares. 


\section{MAPA 2 - VENEZUELA FÍSICO}

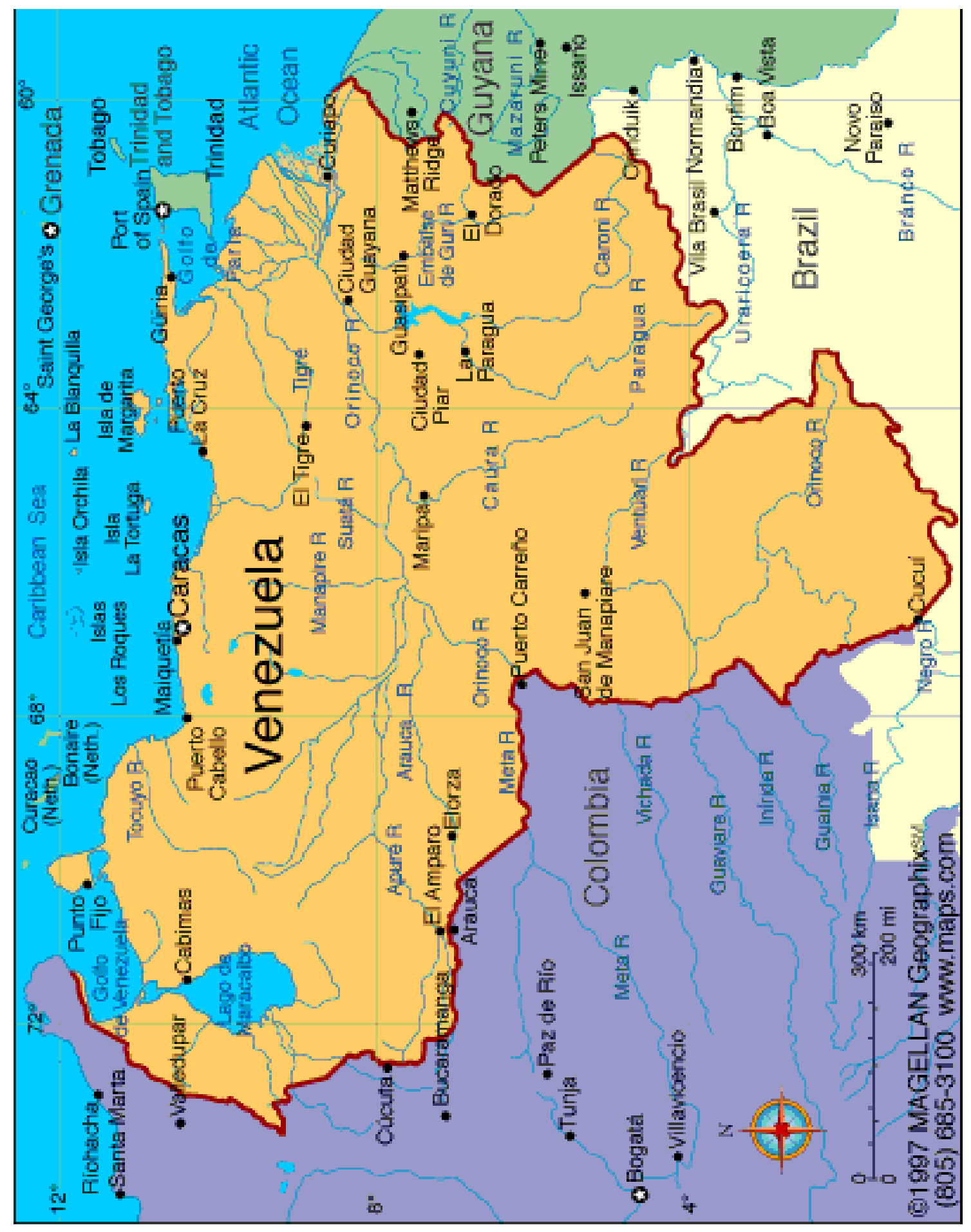




\section{MAPA 3 - VENEZUELA POLÍTICO}

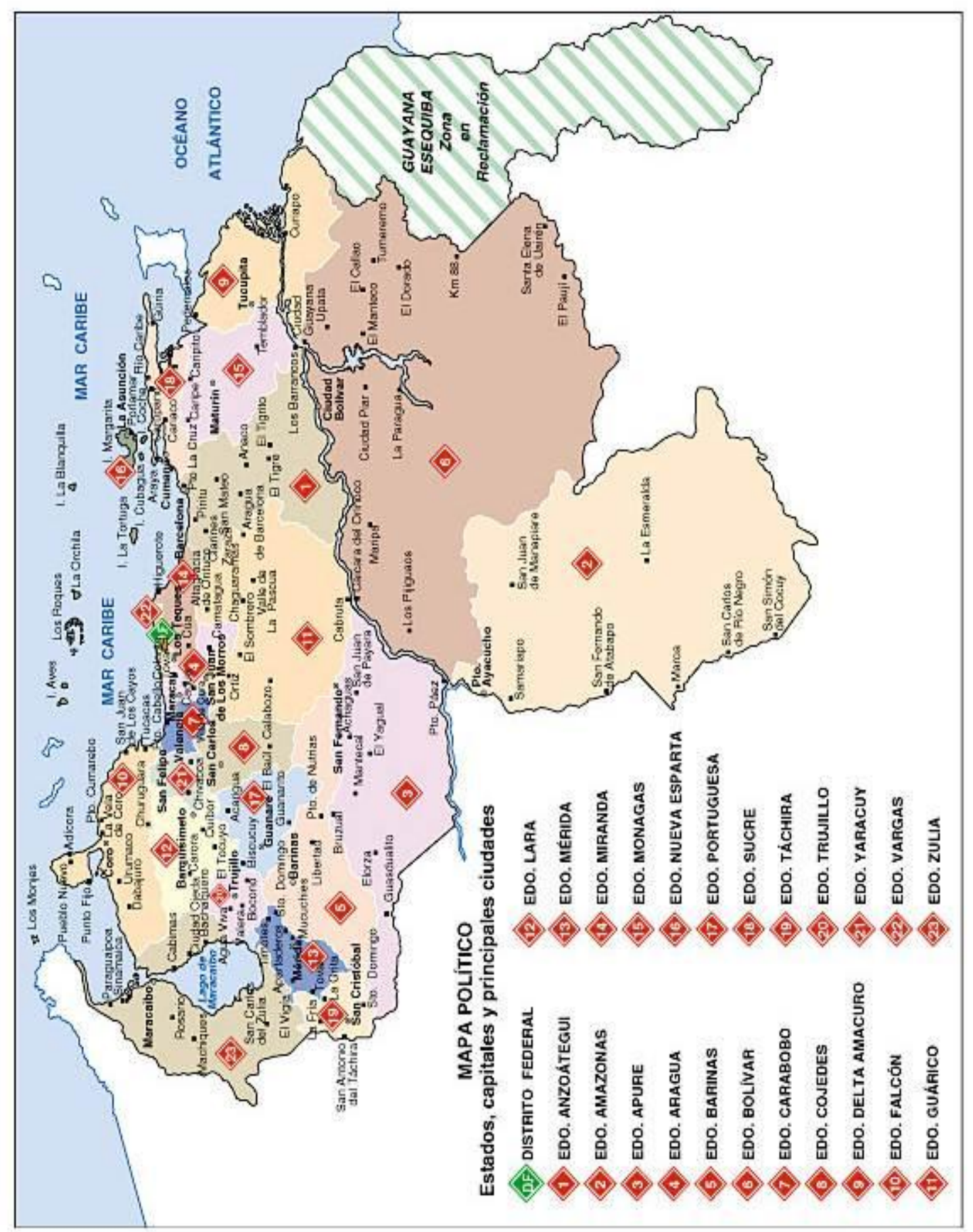




\section{CUADRO 13 - VENEZUELA INDICADORES ECONÓMICOS 2010}

\begin{tabular}{|c|c|}
\hline \multicolumn{2}{|c|}{ INDICADORES ECONóMICOS } \\
\hline Venezuela 2010 & Valores \\
\hline PNB Crescimento (Constant Prices, Moeda Nacional) & $-1.905 \%$ \\
\hline PNB (Preços correntes, Moeda Nacional) & $\begin{array}{l}\text { Bolívar Venezuelano } \\
\text { 1,002.84 Billion. }\end{array}$ \\
\hline PNB (Preços correntes, US Dollars) & US\$290.678 Billion \\
\hline PNB Per Capita (Constant Prices, Moeda Nacional) & $\begin{array}{c}\text { Bolívar Venezuelano } \\
1,883.11\end{array}$ \\
\hline PNB Per Capita (Preços correntes, Moeda Nacional) & $\begin{array}{l}\text { Bolívar Venezuelano } \\
\quad 34,363.55\end{array}$ \\
\hline PNB Per Capita (Preços correntes, US Dollars) & US\$ 9,960.45 \\
\hline PNB (PPC), US Dollars & US\$ 345.21 Billion \\
\hline PNB Per Capita (PPC), US Dollars & US\$11,829.06 \\
\hline Investimento (\% do PNB) & $20.683 \%$ \\
\hline $\begin{array}{l}\text { Inflação, média de preços ao consumidor (Indexado para } \\
\text { 2000) }\end{array}$ & $\begin{array}{c}\text { 143,119. } 22(\text { Index, ano- } \\
\text { base } 2000=100)\end{array}$ \\
\hline Inflação (Média de preços ao consumidor, variação \%) & $28.187 \%$ \\
\hline Inflação (variação anual \%) & $27.184 \%$ \\
\hline $\begin{array}{l}\text { Volume de importação de todos os itens, incluindo bens e } \\
\text { serviços (variação percentual) }\end{array}$ & $0.796 \%$ \\
\hline $\begin{array}{l}\text { Volume de importação somente de bens (variação } \\
\text { percentual) }\end{array}$ & $-1.082 \%$ \\
\hline $\begin{array}{l}\text { Volume de exportação de todos os itens, incluindo bens e } \\
\text { serviços (variação percentual) }\end{array}$ & $11.612 \%$ \\
\hline $\begin{array}{l}\text { Volume de exportação somente de bens (variação } \\
\text { percentual) }\end{array}$ & $14.172 \%$ \\
\hline Valor da importação de petróleo & US\$1.508 Billions \\
\hline Valor da exportação de petróleo & US\$ 62.317 Billions \\
\hline Taxa de desemprego (\% da força de trabalho) & $8.6 \%$ \\
\hline População & 29.183 Million \\
\hline Dívida pública total (\% of PNB) & $38.7 \%$ \\
\hline Ano Fiscal PNB, Preços correntes & $\begin{array}{c}\text { Bolívar Venezuelano } \\
1,002.84 \text { Billions. }\end{array}$ \\
\hline Saldo em Conta Corrente (US Dollars) & US\$14.378 Billion \\
\hline Saldo em Conta Corrente (\% PNB) & $4.946 \%$ \\
\hline
\end{tabular}

PPC: Poder de Paridade de Compra

Fonte: Economic Watch. Adaptado e traduzido pelo Autor. Acesso em 09/06/2012.

<http://www.economywatch.com/economic-statistics/country/Venezuela/\#yearListing> 
CUADRO 14 - PIBpm, la balanza comercial y reservas internacionales de Venezuela, 1998/2008

\begin{tabular}{|c|c|}
\hline 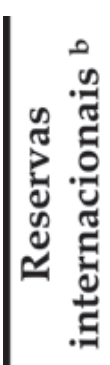 & 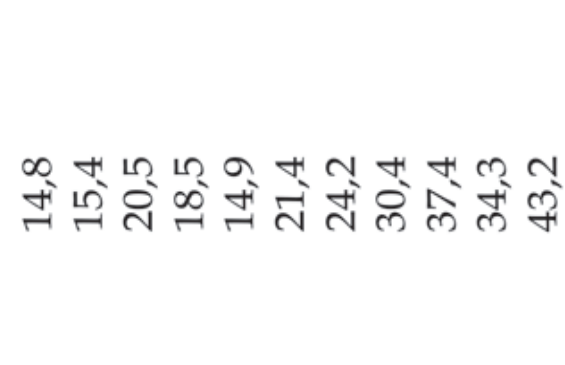 \\
\hline 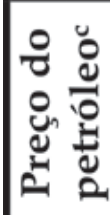 & 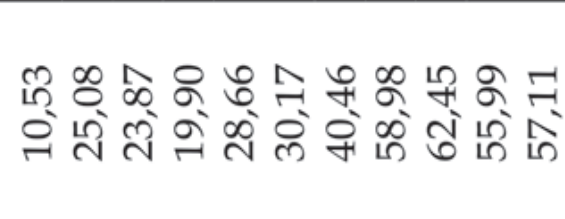 \\
\hline 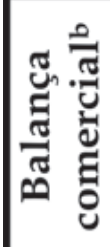 & 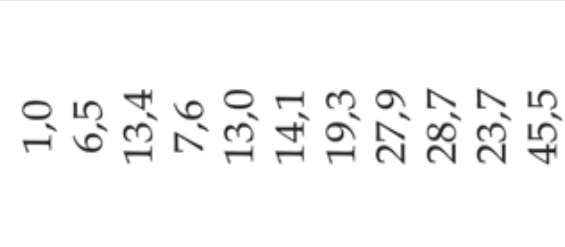 \\
\hline 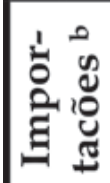 & 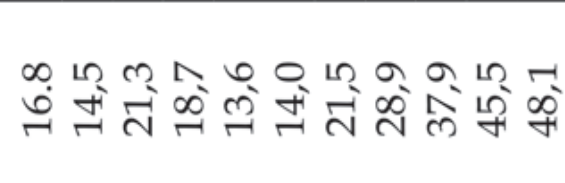 \\
\hline 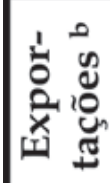 & 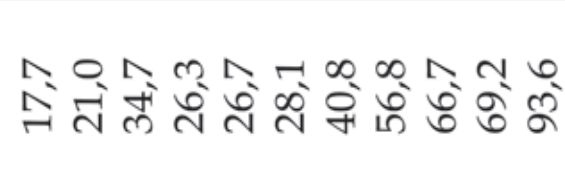 \\
\hline 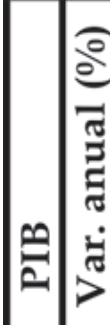 & 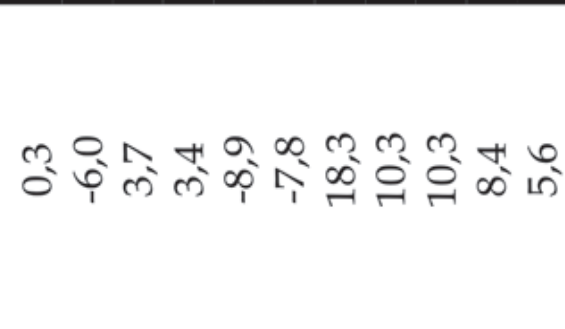 \\
\hline 苞 & 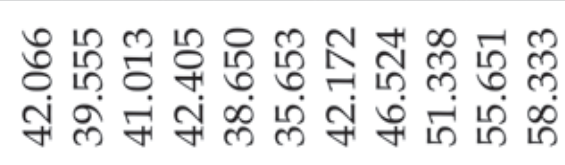 \\
\hline$\stackrel{8}{4}$ & 只 \\
\hline
\end{tabular}

Fuente: Banco Central de Venezuela; CEPAL, Anuário estatístico de América Latina e Caribe, 2007 ANÁLISE DE INDICADORES ECONÔMICOS E SOCIAIS DA VENEZUELA, 1999/2008.

Romina Batista de Lucena de Souza e Nali de Jesus de Souza. 
CUADRO 15- Evolución de la pobreza de la población venezolana, 1998/2007 (2을 semestre)

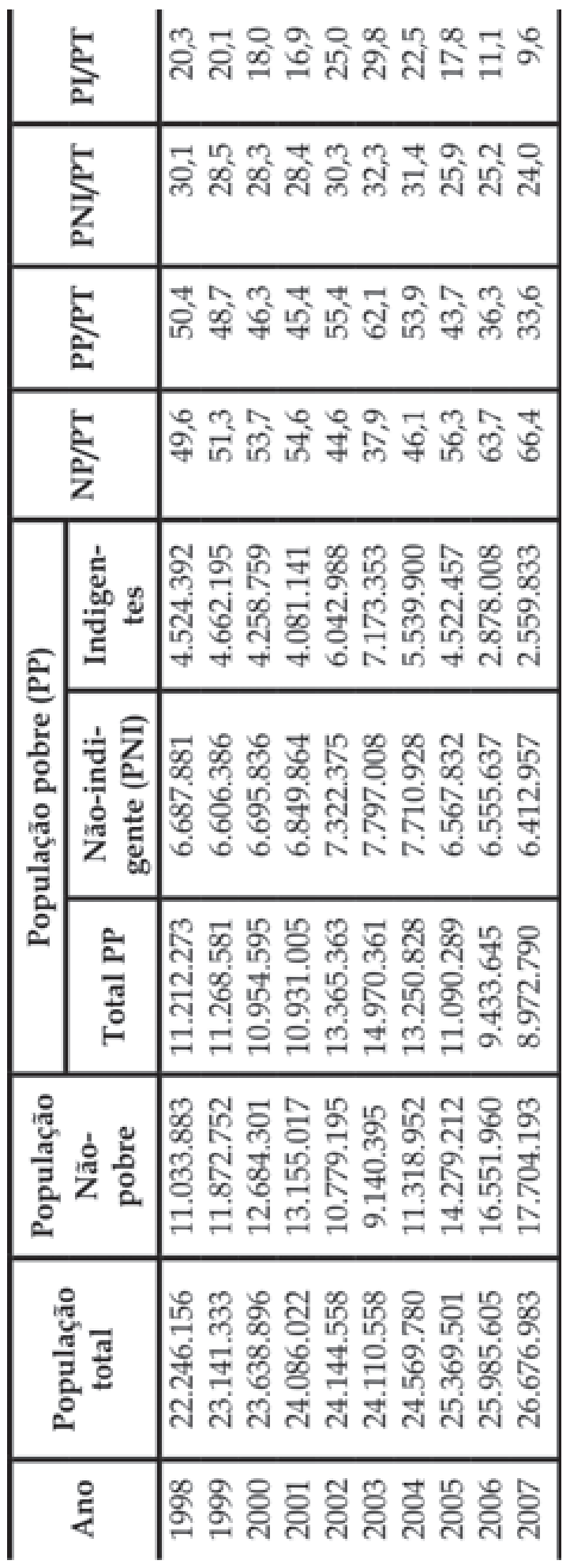


CUADRO 16 - Distribución de la renta entre las clases sociales y el coeficiente de Gini de Venezuela 1998/2007 (\%)

\begin{tabular}{|c|c|}
\hline 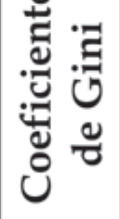 & 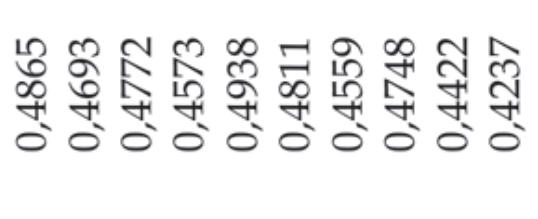 \\
\hline 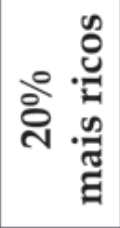 & 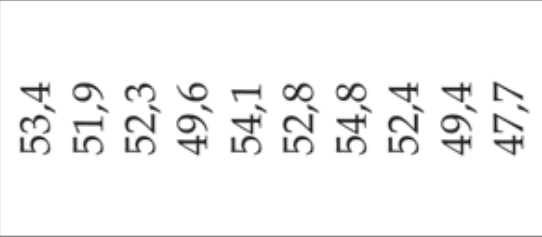 \\
\hline 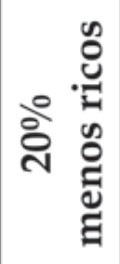 & 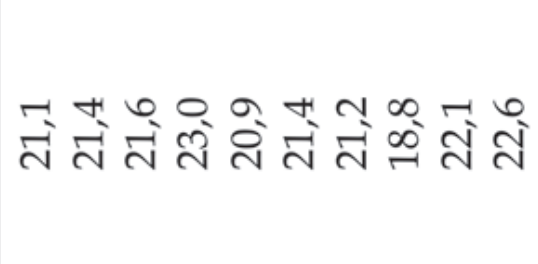 \\
\hline 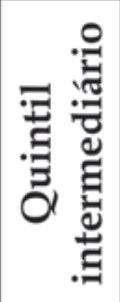 & 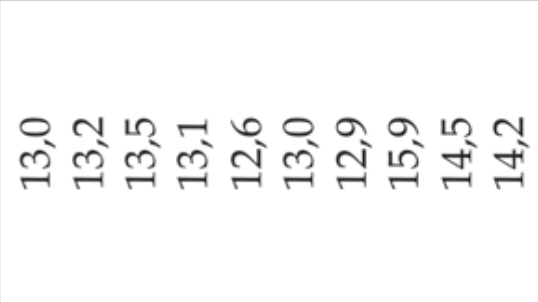 \\
\hline 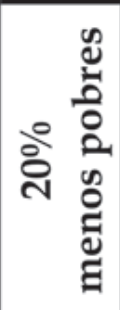 & 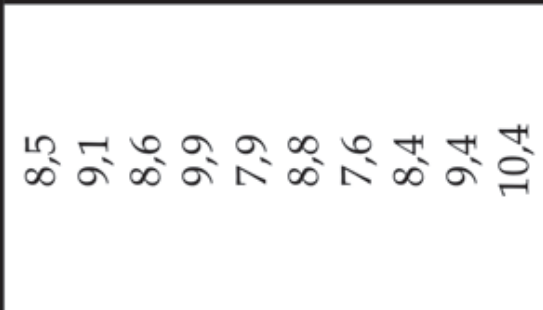 \\
\hline 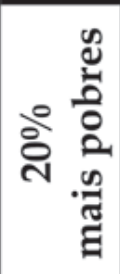 & 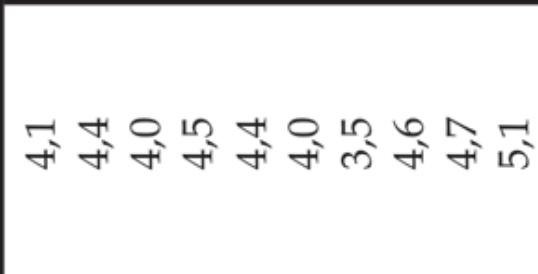 \\
\hline 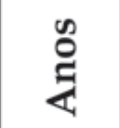 & 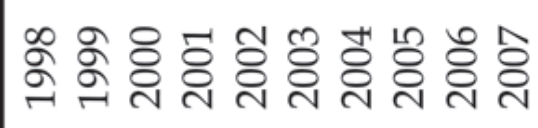 \\
\hline
\end{tabular}


CUADRO 17 - Tasa de desocupación, marzo 1999-2010

Instituto Nacional de Estadística - República Bolivariana da Venezuela

Mayo de 2010

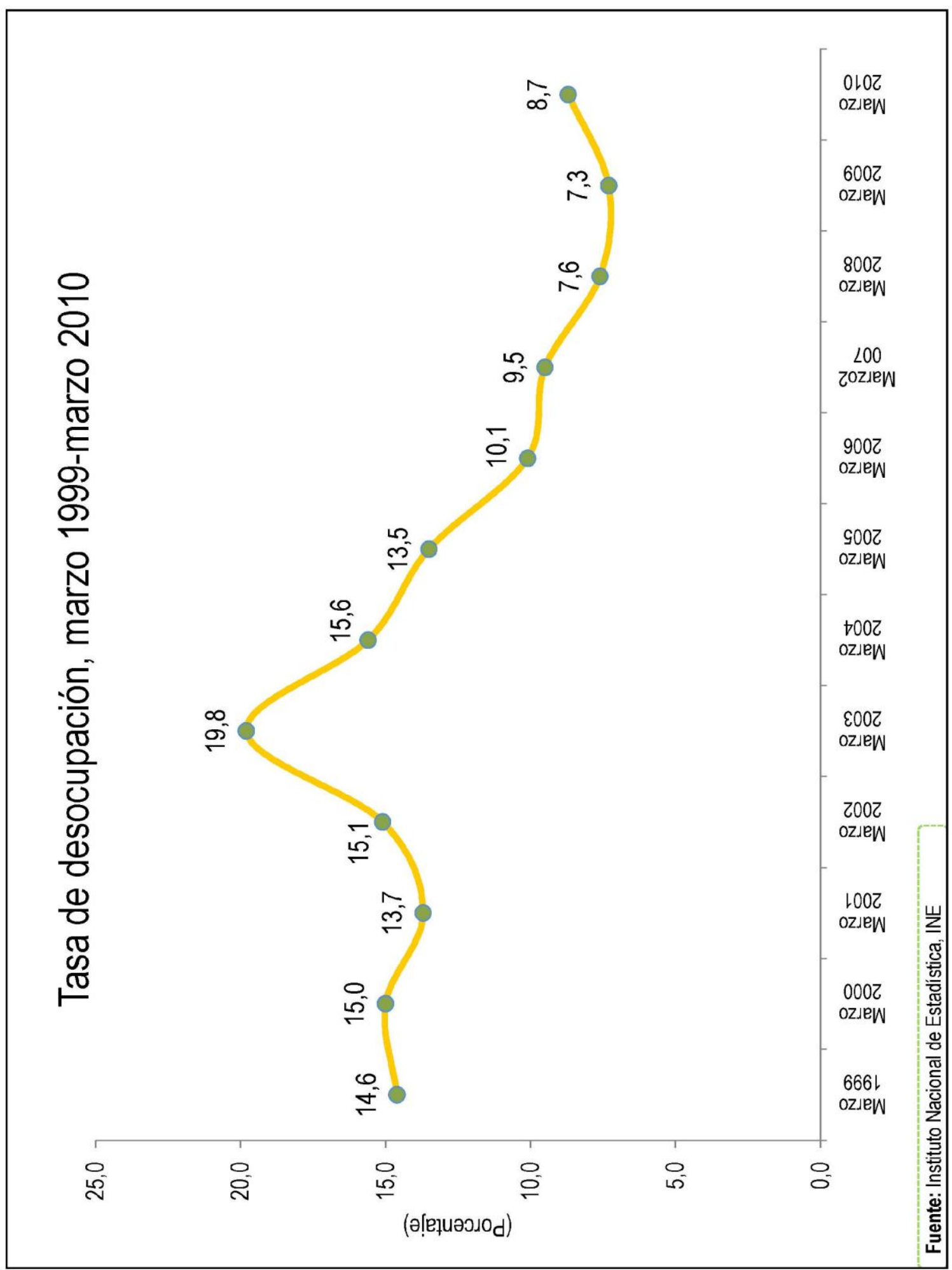


CUADRO 18 - Venezuela. Tendencia de largo plazo del índice de Desarrollo Humano, 1980-2007

Instituto Nacional de Estadística - República Bolivariana da Venezuela Mayo de 2010

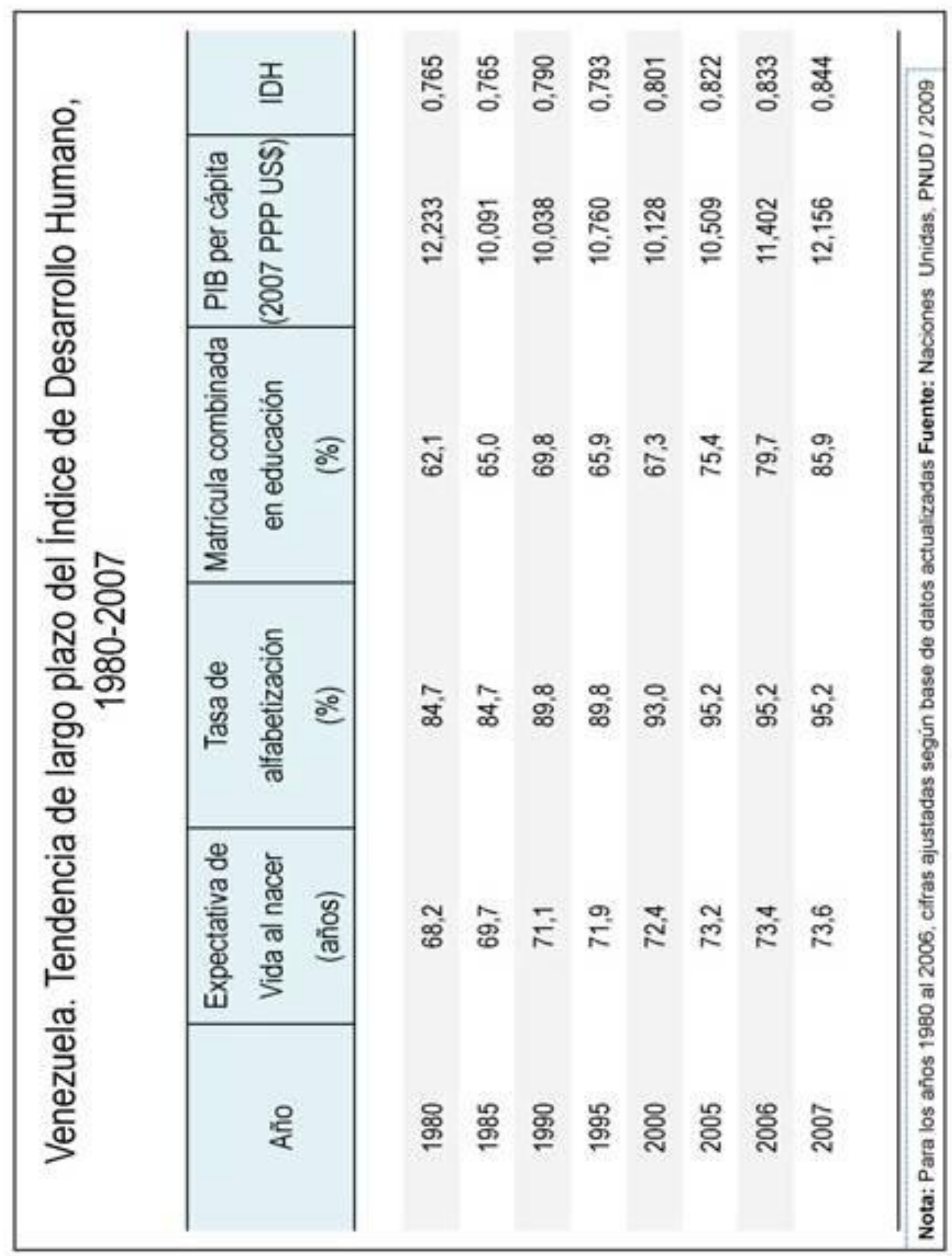


CUADRO 19 - Venezuela. Evolución del índice de Desarrollo Humano, 1980-2007

Instituto Nacional de Estadística - República Bolivariana da Venezuela

Mayo de 2010

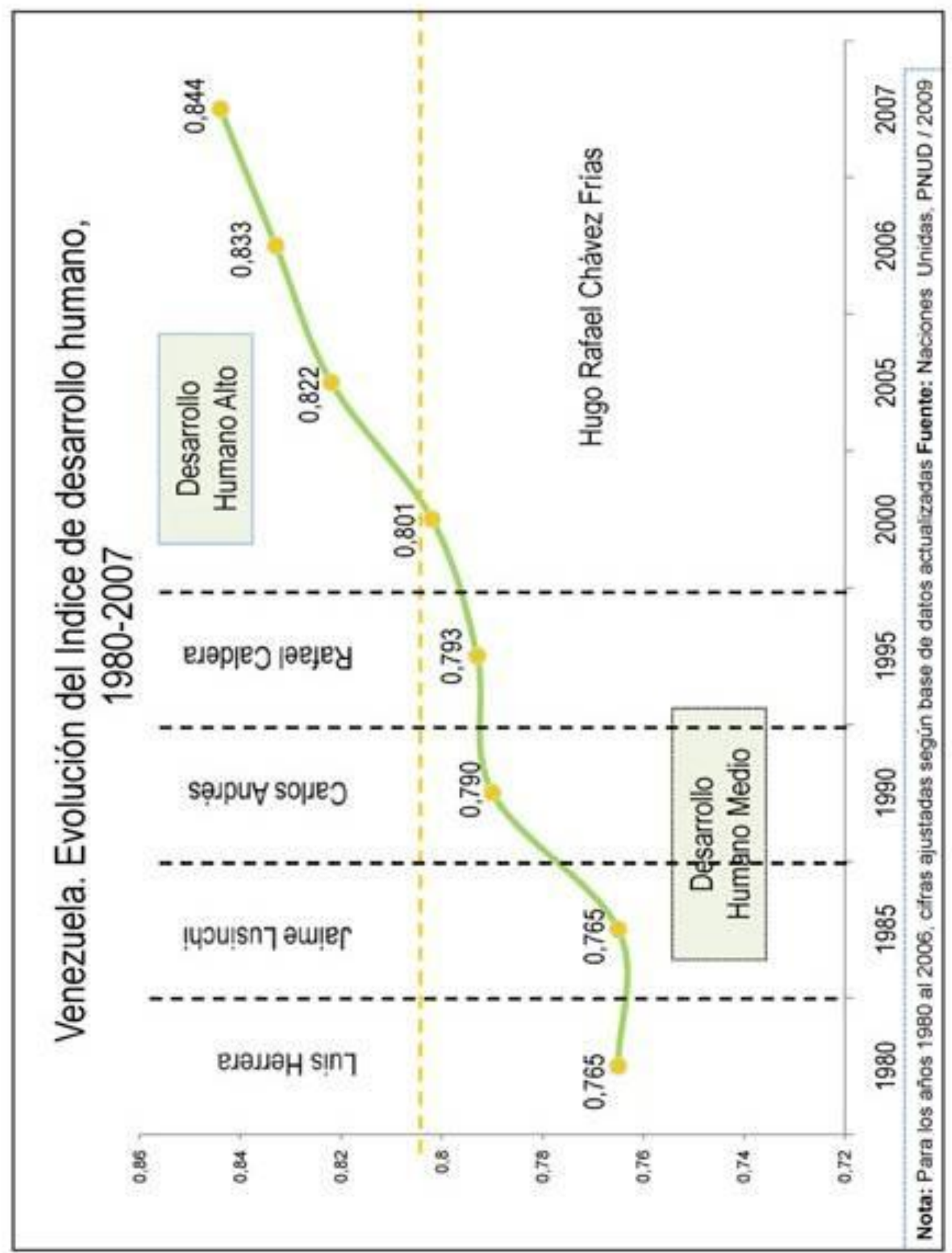


CUADRO 20 - Tasa de mortalidad general, 1998-2007

Instituto Nacional de Estadística - República Bolivariana da Venezuela Mayo de 2010

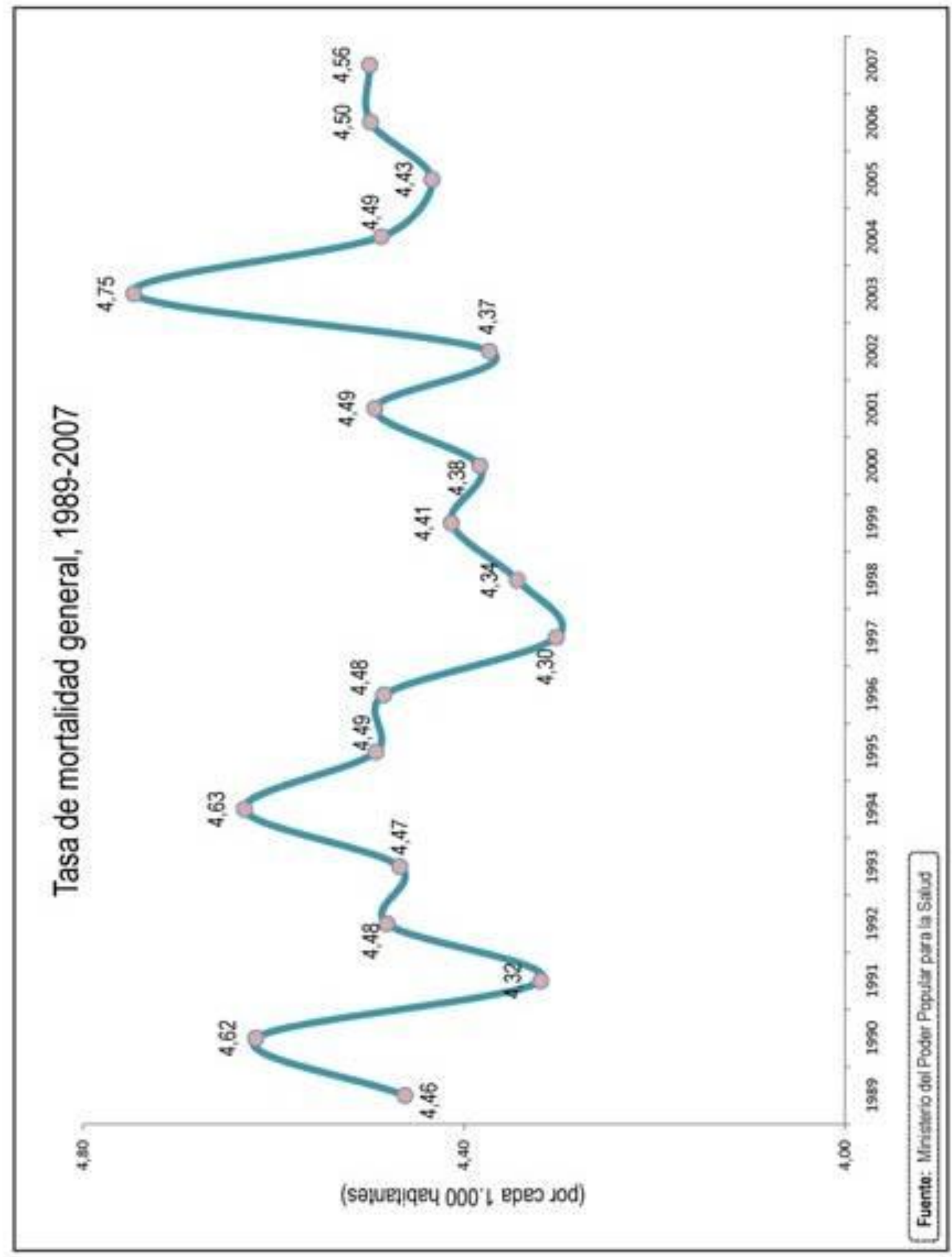


CUADRO 21 - Tasa de mortalidad general, 1990-2008

Instituto Nacional de Estadística - República Bolivariana da Venezuela Mayo de 2010

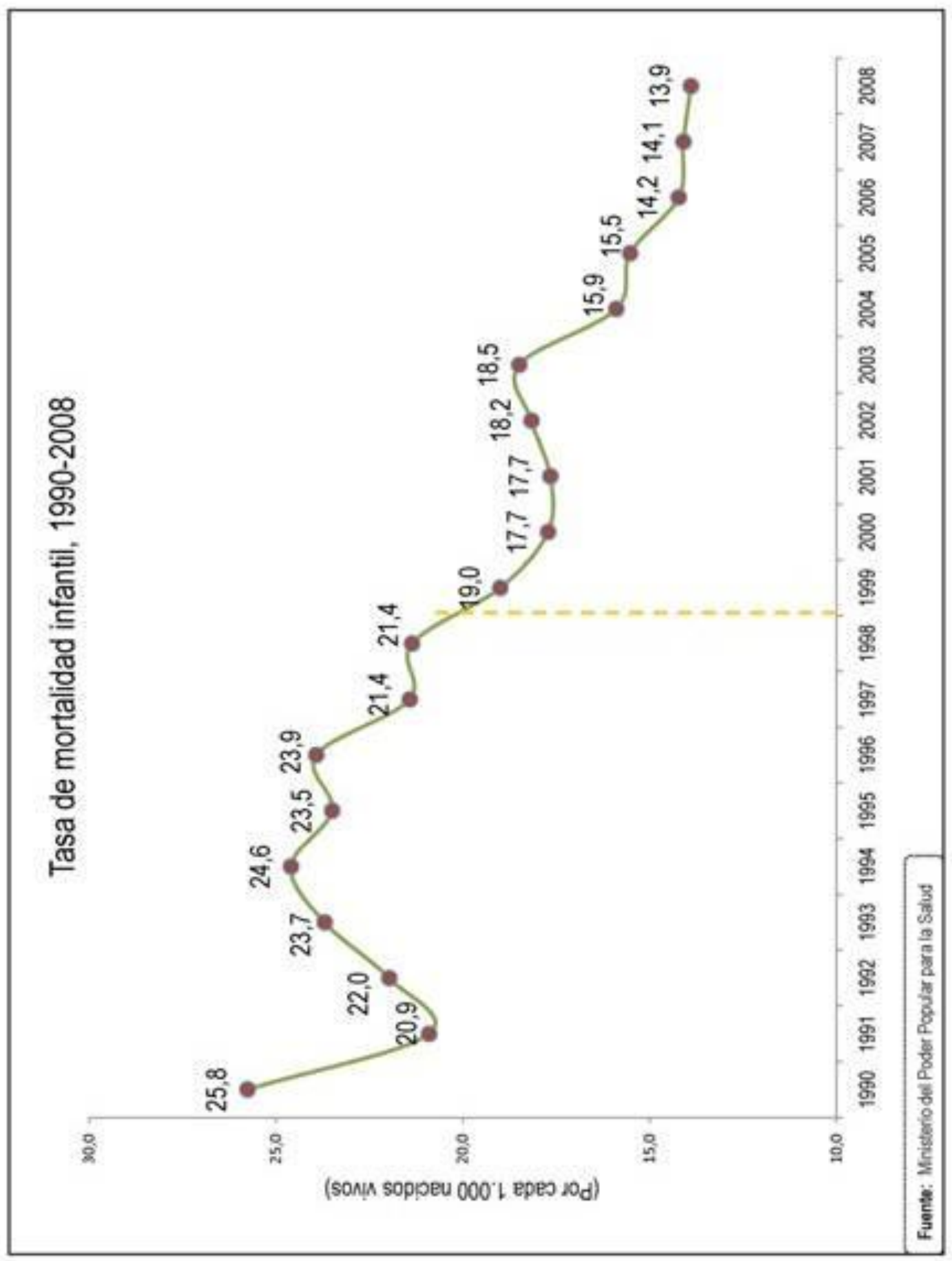


CUADRO 22 - Esperanza de vida al nacer, 1989-2009

Instituto Nacional de Estadística - República Bolivariana da Venezuela Mayo de $\mathbf{2 0 1 0}$

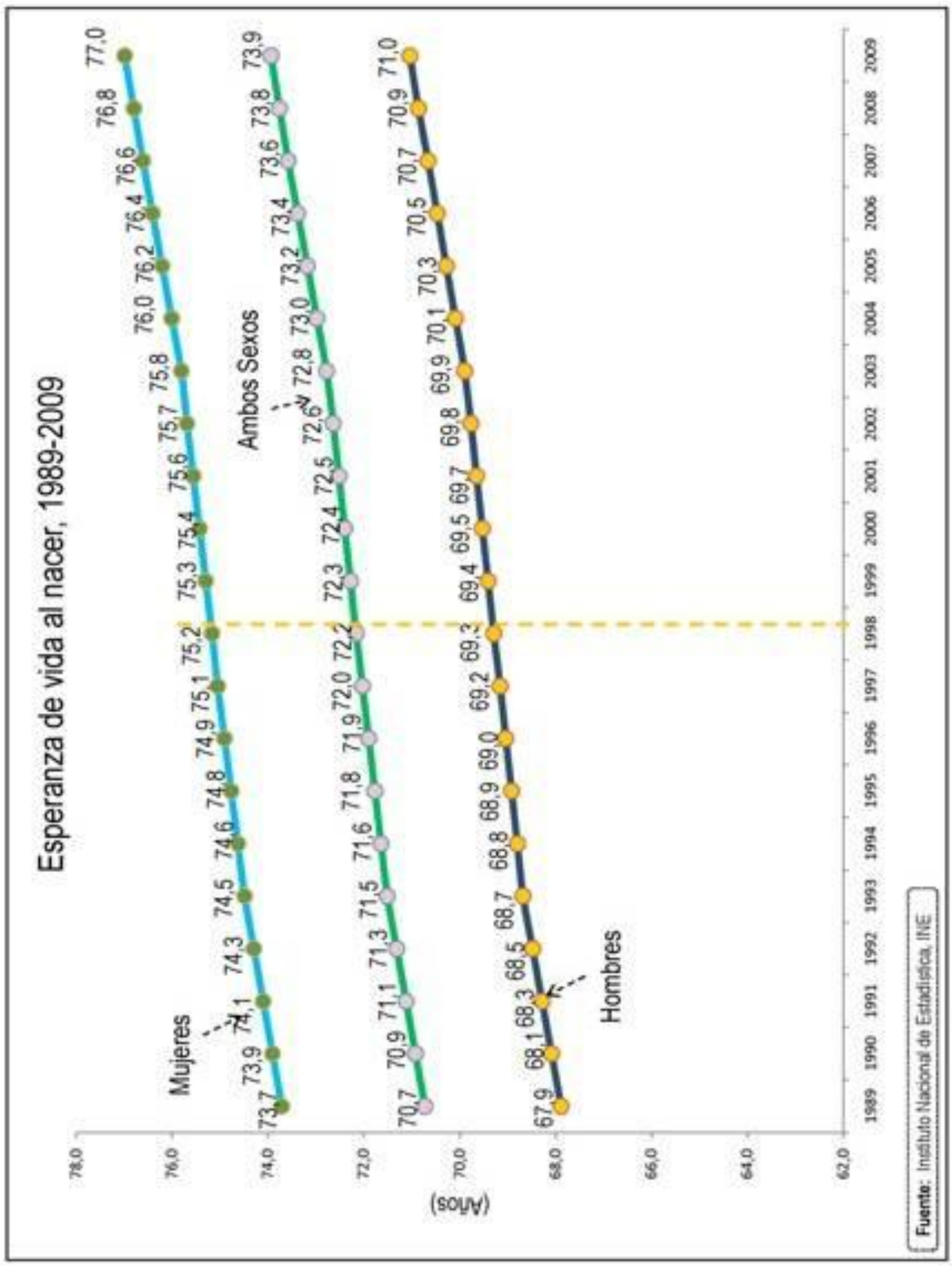




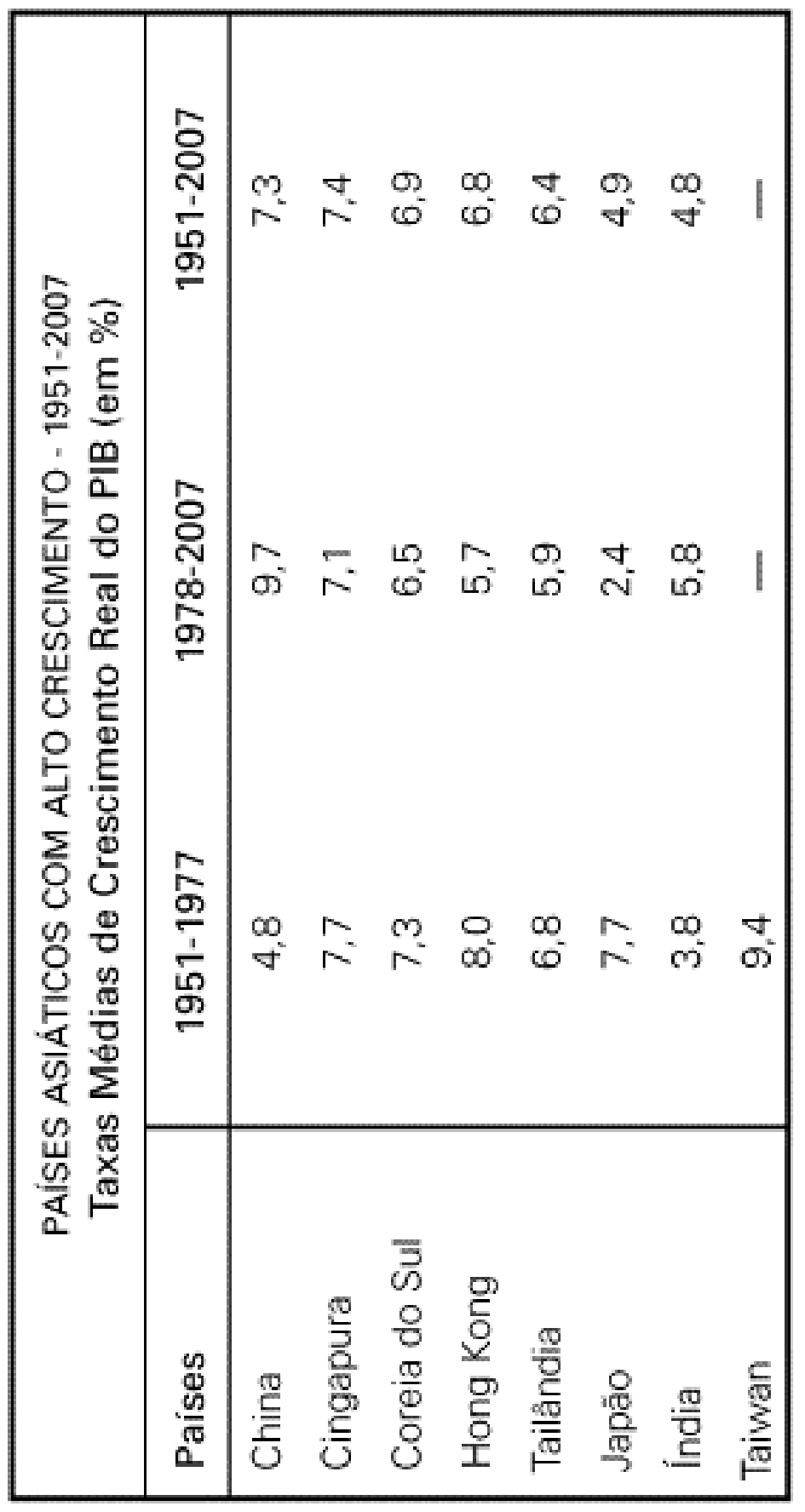

Fuente: NONNENBERG, Marcelo José Braga. China: estabilidade e crescimento econômico. Rev. Econ. Polit., São Paulo, v. 30, n. 2, June 2010 . Available from <http://www.scielo.br/scielo.php?script=sci_arttext\&pid=S010131572010000200002\&lng=en\&nr $\mathrm{m}=$ iso>. access on 28 Dec. 2011. http:///dx.doi.org/10.1590/S0101-31572010000200002. 